\title{
Groundwater-Surface Water Interactions and Agricultural Nutrient Transport in a Great Lakes Clay Plain System
}

\author{
by \\ Ceilidh Mhari Mackie
}

\begin{abstract}
A Thesis
presented to
\end{abstract}

The University of Guelph

In partial fulfilment of requirements

for the degree of

Master of Applied Science

in

Engineering

Guelph, Ontario, Canada

(C) Ceilidh Mackie, August, 2019 


\section{ABSTRACT}

\section{GROUNDWATER-SURFACE WATER INTERACTIONS AND AGRICULTURAL NUTRIENT TRANSPORT IN A GREAT LAKES CLAY PLAIN SYSTEM}

Ceilidh Mhari Mackie

University of Guelph, 2019
Advisor:

Dr. Jana Levison

Agricultural nutrient contamination is a serious concern for surface and groundwater quality within the Great Lakes Basin (GLB). A year-long field-based watershed-scale study was executed to investigate the spatiotemporal evolution of phosphorus and nitrate in surface and subsurface pathways in an agriculturally-dominated clay plain system within the GLB. Samples from were analyzed for total, total dissolved, soluble reactive, and particulate phosphorus, and nitrate- $\mathrm{N}$ to examine the dynamics of key hydrological pathways for transport of agriculturally-derived nutrients in this system. Surface runoff and tile drains were the dominant transport pathways in the watershed, while groundwater was not considered to be a significant contributor of nutrients to the stream. No distinct relationship was observed between nutrient concentrations in the hyporheic zone and the hydrologic connection between groundwater and surface water. The results of this research are imperative for refining and executing nutrient management strategies and agricultural best management practices in the basin. 


\section{ACKNOWLEDGEMENTS}

I would like to express my deepest appreciation to both Dr. Jana Levison and Dr. Andrew Binns. Without your ceaseless guidance, motivation, and enthusiasm, this research would not have been possible. Thank you for your unwavering support. I would also like to extend my thanks to Dr. Ivan O'Halloran for the helpful feedback and input on the project.

I would like to acknowledge project funding for this research from the Ontario Ministry of Agriculture and Rural Affairs (OMAFRA) and the Ontario Agri-Food Innovation Alliance.

I would like to thank Carolin Barnscheidt, Linus Gummert, Michelle Robinson, and Daniel Noble for helping in the field and in the lab, and for sharing your extremely valuable ideas and perspectives. I am forever grateful for Sarah Rixon and Elisha Persaud; words cannot express how thankful I am for your endless knowledge, assistance, and friendship over the past two years. Thank you to Joanne Ryks for all your generous time assisting me with laboratory analysis.

I wish to give a warm thank you to all my friends; I am indebted for the encouragement and positive influence you've bestowed on me throughout the completion of this research (especially during those times of frustration!). I am forever grateful for my family, especially my parents, who believed that I could do anything I set my mind to and pushed me to do just that. I'd also like to sincerely thank you, Brendan, for always encouraging me to continue my education and for agreeing to read my thesis drafts before you knew what you were getting in to. You and Nessie have succeeded in keeping me sane. 


\section{TABLE OF CONTENTS}

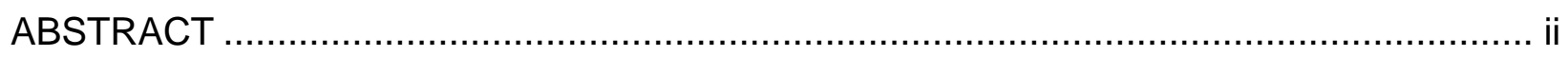

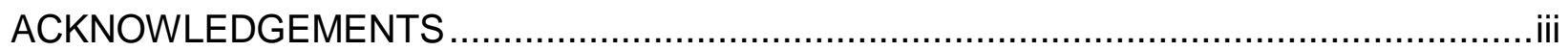

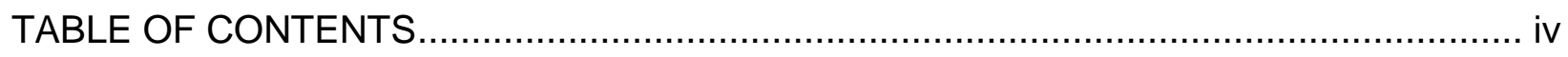

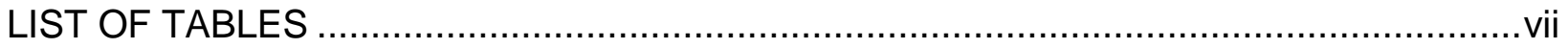

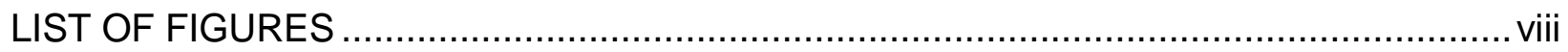

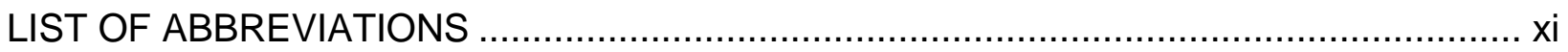

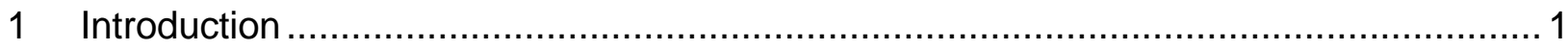

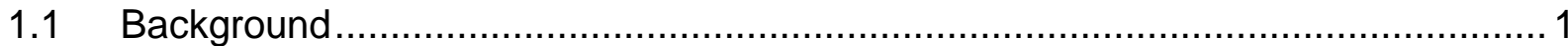

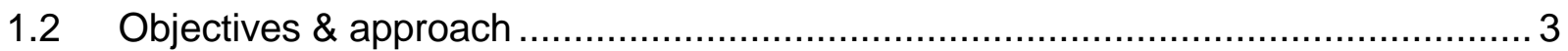

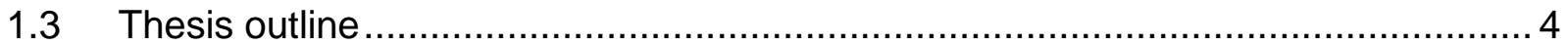

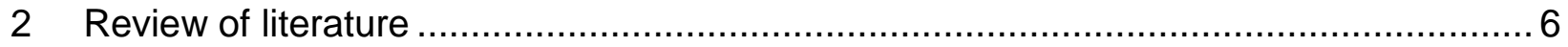

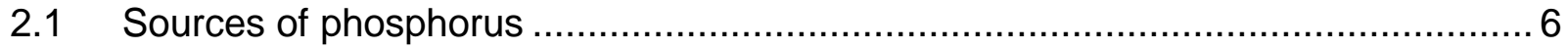

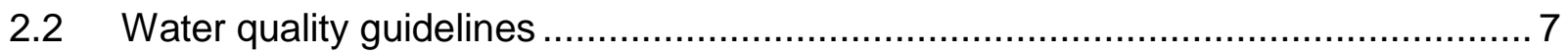

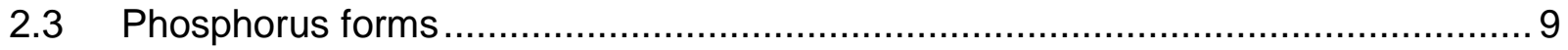

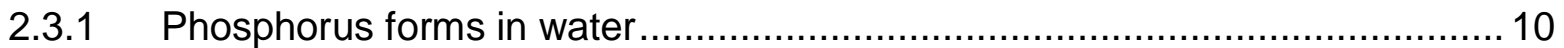

2.4 Phosphorus fate in terrestrial systems …………......................................... 11

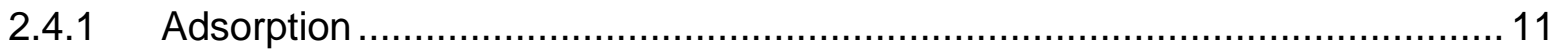

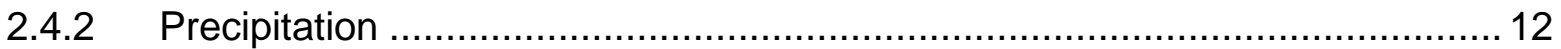

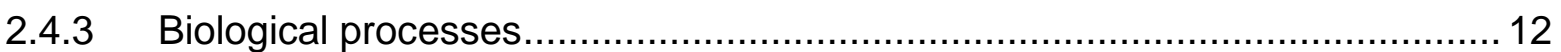

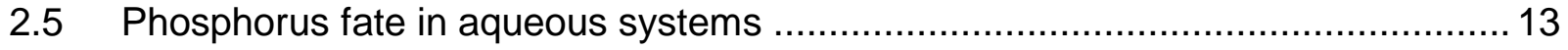

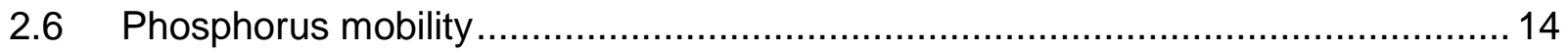

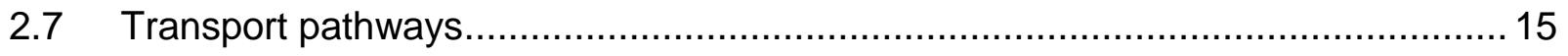

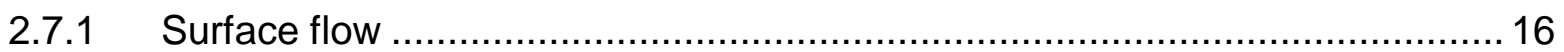

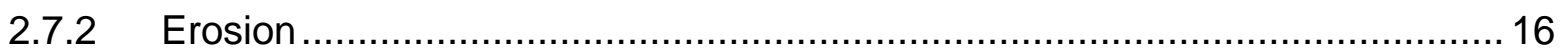

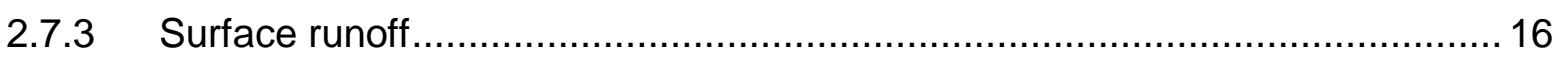

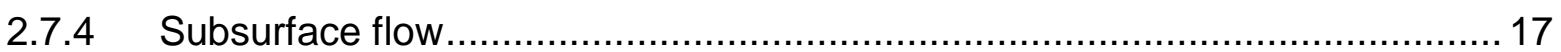

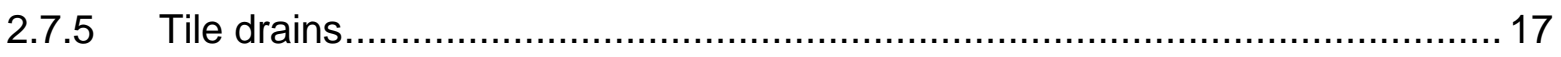

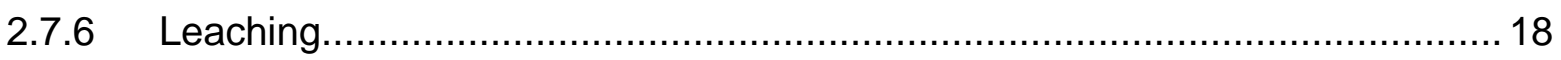

2.8 Groundwater-surface water interactions................................................... 19

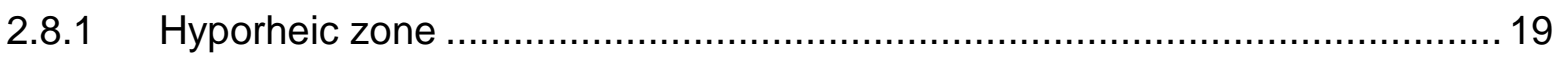

3 Groundwater - Surface Water Interactions and Agricultural Nutrient Transport in a Great

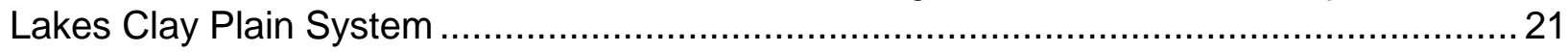

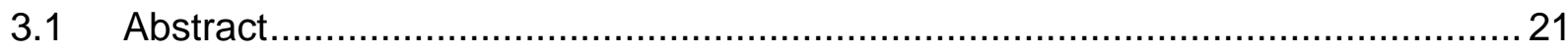




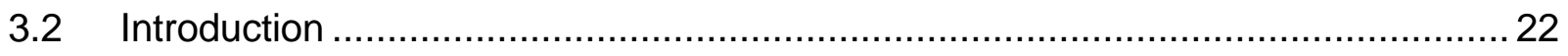

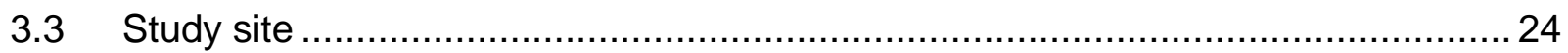

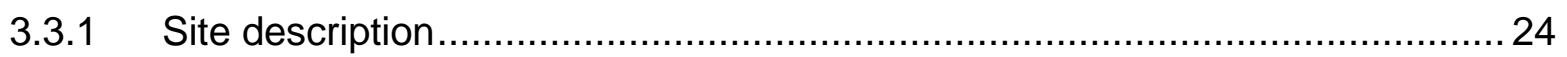

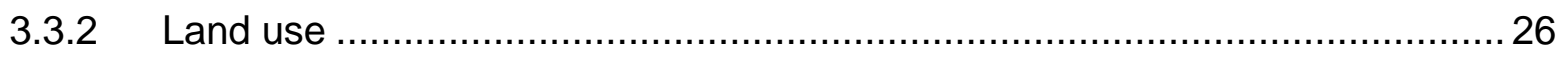

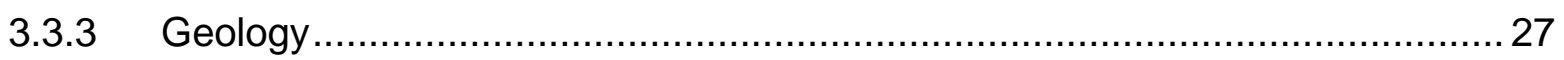

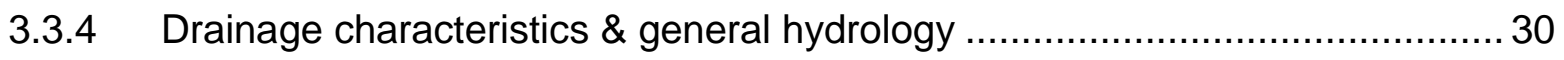

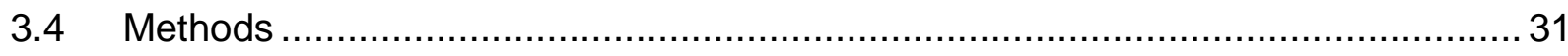

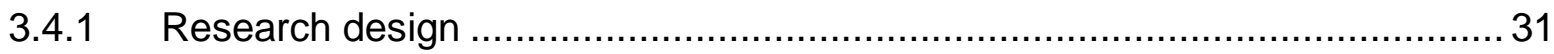

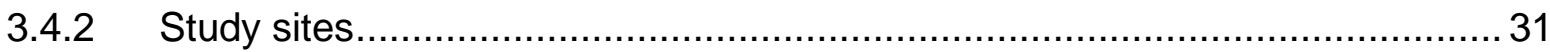

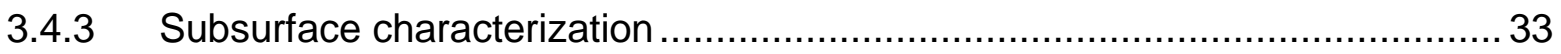

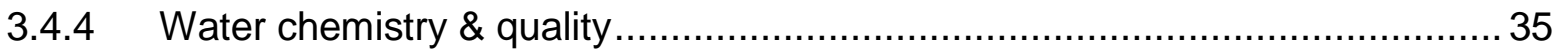

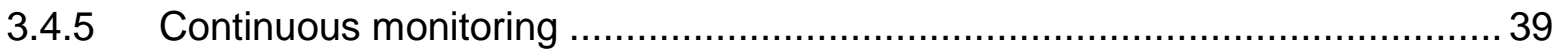

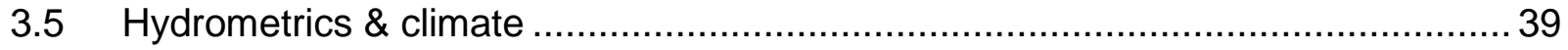

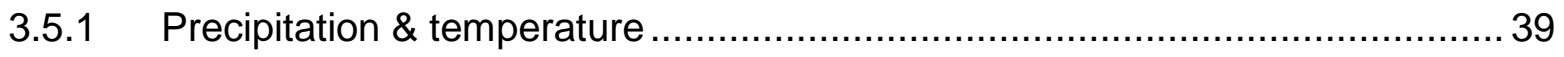

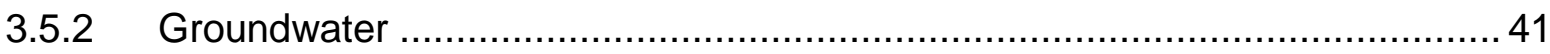

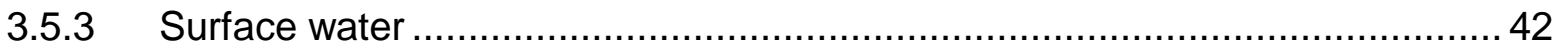

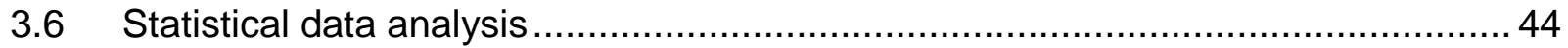

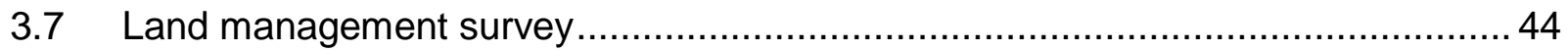

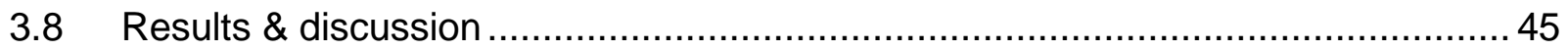

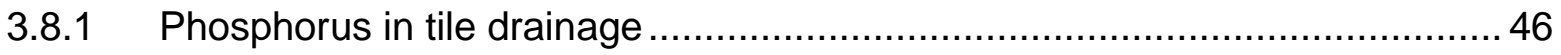

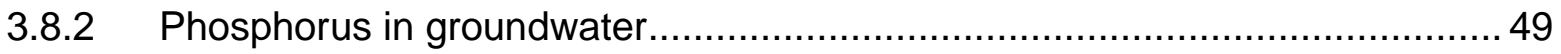

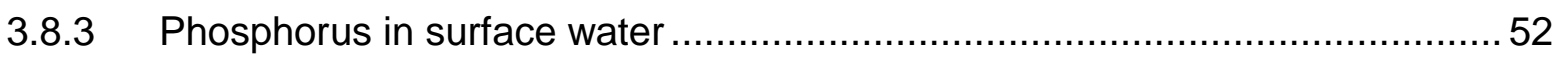

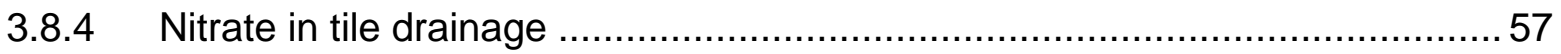

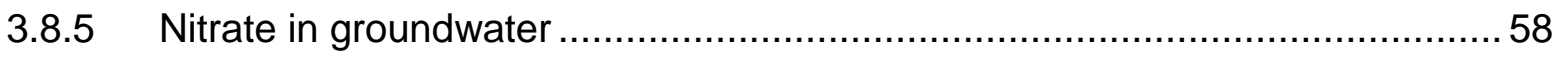

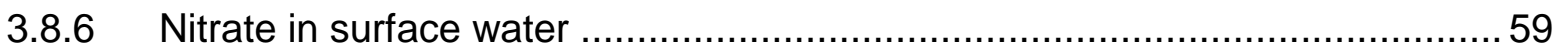

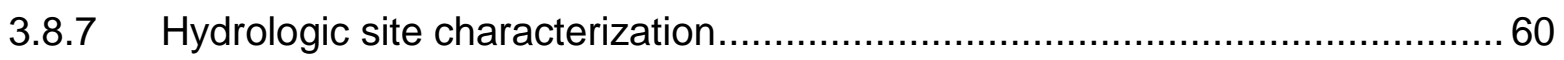

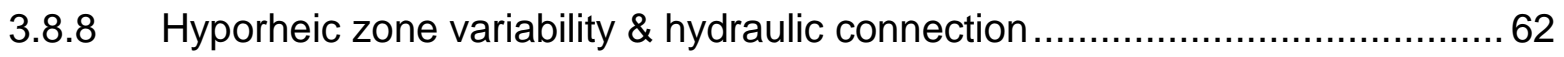

3.8.9 Land management practices \& water quality observations ............................ 65

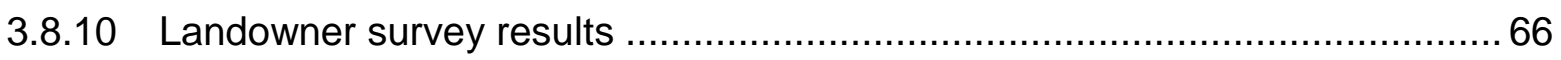

3.8.11 Phosphorus and land management practices ......................................... 68

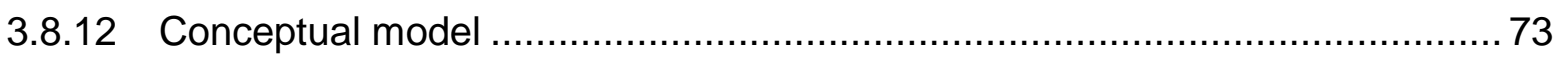

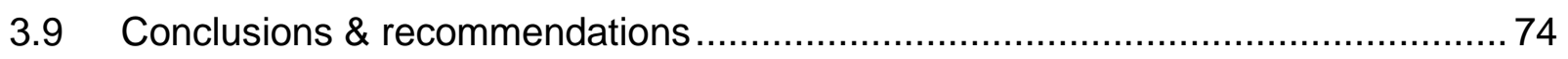

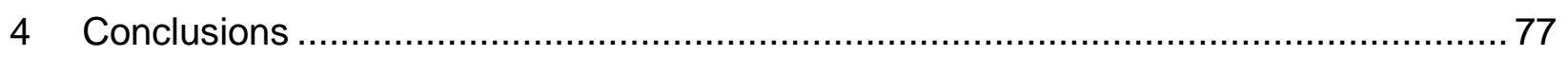

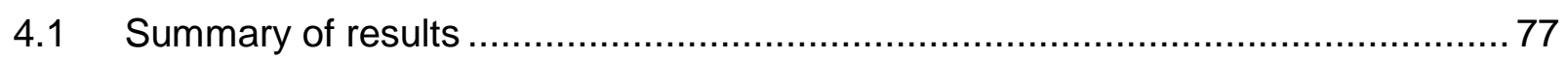




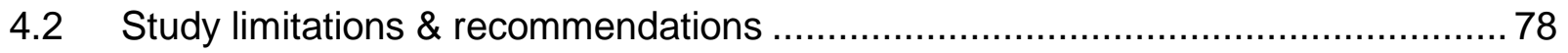

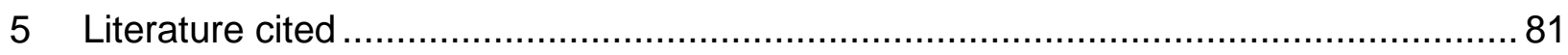

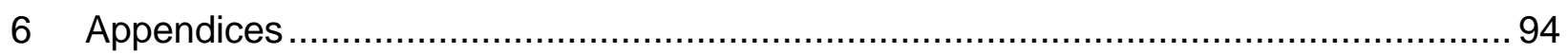

Appendix A - Historical water quality data ……….................................................. 94

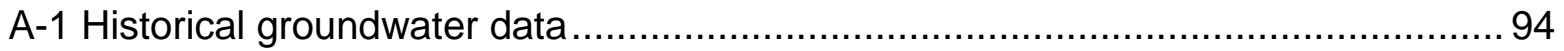

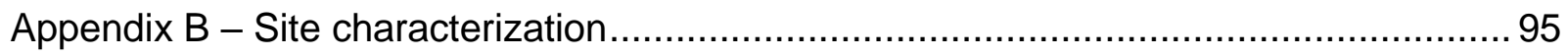

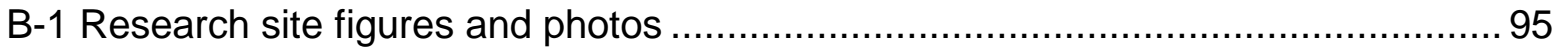

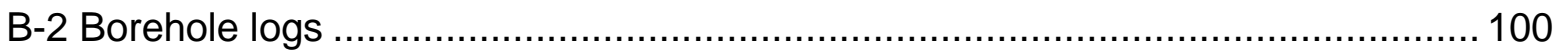

Appendix C - Additional sampling and analysis data .............................................. 107

C-1 Phosphorus analytical results for all surface water and groundwater locations. .. 107

C-2 Tile drain and drive-point piezometer analytical results .................................... 109

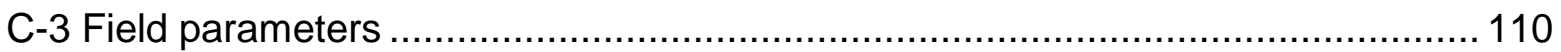

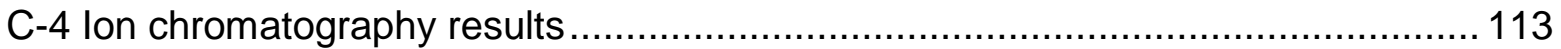

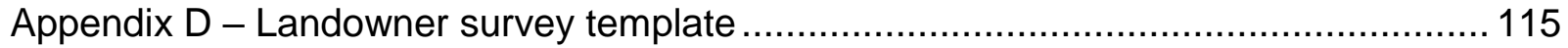

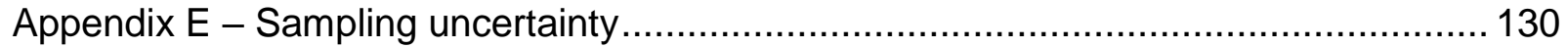




\section{LIST OF TABLES}

Table 2-1: Total phosphorus trigger ranges based on CCME (2004) ............................... 8 Table 3-1: Methods of analysis for various phosphorus species and anions in water samples.

Table 3-2: A summary of typical planting and harvesting periods for corn, soybean, and winter wheat crops (Anonymous land owners, personal communication, 2018, 2019). 66 Table 3-3: A summary of typical fertilizer type, application period, and application type for corn, soybean, and winter wheat crops in the watershed (Anonymous land owners, personal communication, 2018, 2019) 67

Table 6-1: Historical groundwater data for total phosphorus and nitrate-N from discrete sampling dates between 2003 and 2015 (Government of Ontario, 2019). 94 Table 6-2: Phosphorus species (TP, TDP, SRP, and PP) concentrations for all surface water and groundwater sampling locations. 108 Table 6-3: Tile drain, streambed piezometer (at Mooresville location), and average floodplain drive-point phosphorus concentrations. 109

Table 6-4: Temperature, electrical conductivity, dissolved oxygen, $\mathrm{pH}$, and oxidation reduction potential at each sampling location (groundwater and surface water) for every sampling date. 112 Table 6-5: IC results for surface water, groundwater, and tile water for nitrate-N, sulphate, and chloride. 


\section{LIST OF FIGURES}

Figure 2-1: The terrestrial phosphorus cycle showing inputs, losses, and transformations (Mullen, 2005). 10

Figure 2-2: In-stream cycling of phosphorus near the sediment-water interface (adapted from Mainstone \& Parr, 2002; Environment Agency, 2015). 14

Figure 3-1: A) Upper Parkhill Watershed in relation to the Canadian and American boundaries of the Great Lakes Basin. B) Upper Parkhill Watershed with sampling locations (red) and natural areas (green). C) Conceptual model of site instrumentation at the Mooresville location, including groundwater wells and drive-point piezometers. 25

Figure 3-2: A) Land use distribution in the Upper Parkhill Watershed in 2017 and B) 2018 (Agriculture and Agri-Food Canada, 2019). .27

Figure 3-3: A) Surficial geology in the Upper Parkhill Watershed (Canadian Soil Information Service, 2013). B) Soil distribution in the Upper Parkhill Watershed (Canadian Soil Information Service, 2013). 29

Figure 3-4: Tile drained areas and main surface water feature, Parkhill Creek, in the watershed (Land Information Ontario, 2015). 31

Figure 3-5: Total daily precipitation in the watershed with corresponding sampling dates for the tile outlet water. 37

Figure 3-6: Total daily precipitation, total daily snow accumulation, and average daily temperature from June 1, 2018 to May 31, 2019 (Ontario Ministry of Natural Resources and Forestry, 2019; Environment and Climate Change Canada, 2019).

Figure 3-7: Daily average water levels of the two monitoring wells (shallow and deep) and surface water at the McGuffin (MCGF) research site.

Figure 3-8: Total daily precipitation, daily average flow, and daily average air temperature from June 1, 2018 to May 31, 2019 (Ontario Ministry of Natural Resources and Forestry, 2019). 43

Figure 3-9: Eckhardt baseflow analysis of daily average streamflow data at the Integrated Water and Climate Monitoring Station (Canadian Rivers Institute, 2019; Ontario Ministry of Natural Resources and Forestry, 2019).

Figure 3-10: Phosphorus concentrations in the tile outlet water for each discrete sampling event. 47 
Figure 3-11: Total phosphorus concentrations in the tile outlet water and closest sampled stream reach.

Figure 3-12: Dissolved phosphorus (TDP and SRP) concentrations for the shallow (MCGF$\mathrm{S}, 6.7 \mathrm{mbgs}$ ) and deep (MCGF-D, $15.8 \mathrm{mbgs}$ ) monitoring wells at the McGuffin research site for each discrete sampling event.

Figure 3-13: Temporal variability in TP concentrations for each surface water sampling location. .54

Figure 3-14: Boxplot representation of TP, TDP, PP and SRP concentrations for each surface water sampling location from north to south in the watershed. The median (center line), the average (the $\mathrm{x}$ ), the first quartile (bottom of box), and third quartile. Minimum and maximums are represented by bars extending from the boxes. 56

Figure 3-15: Nitrate concentrations in the tile outlet water and closest sampled stream reach. 58

Figure 3-16: Monthly surface water nitrate concentrations and precipitation to date of sampling event. 59

Figure 3-17: Schematic diagram of unsaturated zone travel times $\left(t_{u}\right)$ and saturated zone travel times $\left(\mathrm{t}_{\mathrm{s}}\right)$ for a conservative contaminant or water particle. 61

Figure 3-18: TP and TDP concentrations for the hyporheic zone water (HW) and surface water body (stream -Mooresville sampling location). 63

Figure 3-19: Relationship between the vertical hydraulic gradient (VHG) and TDP concentrations in the streambed piezometers at the Mooresville research location. 64 Figure 3-20: Total phosphorus concentrations from discrete sampling events at PWQMN station 0302 from 2003-2016 (Government of Ontario, 2019). 70 Figure 3-21: Soluble reactive phosphorus from discrete sampling events at PWQMN station 0302 from 2003-2016 (Government of Ontario, 2019). 71 Figure 3-22: Conceptual model of phosphorus transport pathways in the Upper Parkhill watershed. Transport pathways are scaled to illuminate principal nutrient paths in the system.

Figure 6-1: Location of PGMN well from which historical groundwater data was obtained. 94 Figure 6-2: Layout of site instrumentation at the McGuffin study location (Integrated Water and Climate Monitoring Station). Adapted from ABCA and E. Persaud (2019). .95 
Figure 6-3: Photos of McGuffin research site. A) Site instrumentation. B) Upstream perspective of stream reach. C) Downstream perspective of stream reach....................... 96

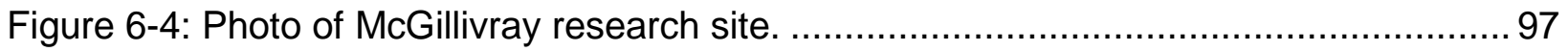

Figure 6-5: Photo of Mount Carmel research site. .................................................. 97

Figure 6-6: Photos of Mooresville research site. A) Stream reach. B) Monitoring well in floodplain adjacent to the stream. C) Close-up of core from drilling of wells at this location. D)

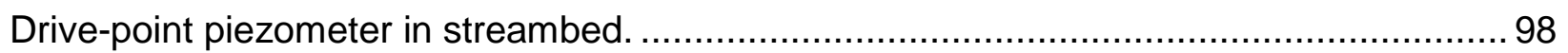

Figure 6-7: Photos of Goshen research site. A) Stream reach. B) Monitoring well locations in floodplain. C) Close-up of core during drilling of wells at this location................................ 99

Figure 6-8: Borehole log for shallow McGuffin well (adapted from Huron Geosciences, 2011).

Figure 6-9: Borehole log for deep McGuffin well (adapted from Huron Geosciences, 2011).

Figure 6-10: Borehole log for shallow Mooresville well. 102

Figure 6-11: Borehole log for deep Mooresville well. 103

Figure 6-12: Borehole log for shallow Goshen well 104

Figure 6-13: Borehole log for deep Goshen well..... 105 106 


\section{LIST OF ABBREVIATIONS}

$\begin{array}{ll}\text { ABCA } & \text { Ausable Bayfield Conservation Authority } \\ \text { BFI } & \text { Baseflow Index } \\ \text { BMP } & \text { Best Management Practice } \\ \text { CGPAL } & \text { Canadian Guideline for the Protection of Aquatic Life } \\ \text { DO } & \text { Dissolved Oxygen } \\ \text { EC } & \text { Electrical Conductivity } \\ \text { GLB } & \text { Great Lakes Basin } \\ \text { GOS } & \text { Goshen } \\ \text { HDPE } & \text { High Density Polyethylene } \\ \text { HW } & \text { Hyporheic Water } \\ \text { K } & \text { Hydraulic conductivity } \\ \text { MAP } & \text { Monoammonium phosphate } \\ \text { MASL } & \text { Metres Above Sea Level } \\ \text { MBGS } & \text { Metres Below Ground Surface } \\ \text { MCGF } & \text { McGuffin } \\ \text { MCGL } & \text { McGillivray } \\ \text { MECP } & \text { Ministry of the Environment, Conservation and Parks } \\ \text { MOO } & \text { Mooresville } \\ \text { MTC } & \text { Mount Carmel } \\ \text { N } & \text { Nitrogen } \\ \text { ORP } & \text { Oxygen Reduction Potential } \\ \text { P } & \text { Phosphorus } \\ \text { PGMN } & \text { Provincial Groundwater Monitoring Network } \\ \text { PP } & \text { Particulate Phosphorus } \\ \text { PWQMN } & \text { Provincial (Stream) Water Quality Monitoring Network } \\ \text { PWQO } & \text { Provincial Water Quality Objectives } \\ \text { RPD } & \text { Relative Percent Difference } \\ \text { SRP } & \text { Soluble Reactive Phosphorus } \\ \text { SUNA } & \text { Submersible Ultraviolet Nitrate Analyzer } \\ \text { SUP } & \text { Soluble Unreactive Phosphorus } \\ \text { TDP } & \text { Total Dissolved Phosphorus } \\ \text { TP } & \text { Total Phosphorus } \\ \text { UAN } & \text { Urea Ammonium Nitrate } \\ \text { VHG } & \text { Vertical Hydraulic Gradient } \\ & \end{array}$




\section{INTRODUCTION}

\subsection{Background}

Twenty per cent of the world's surface fresh water and nearly all of the agricultural industry in Ontario is located within the Great Lakes Basin (GLB) (OMAFRA, 2016). Agricultural activities, therefore, represent a significant source of nutrients to surface and subsurface waters with approximately one third of the land within the entire basin currently farmed (Robinson, 2015; Grannemann \& Van Stempvoort, 2016). While phosphorus (P) and nitrogen (N) are natural components of aquatic ecosystems, excessive loadings of these nutrients to water bodies can have critical environmental and ecological impacts by stimulating inordinate macrophyte and algal growth (Grannemann \& Van Stempvoort, 2016).

Phosphorus is recognized as the principal growth-limiting nutrient in temperate freshwater systems, specifically within the Great Lakes, and thereby governs the trophic state of these water bodies (Heathwaite et al., 2005). Extensive algal growth resulting from excessive inputs of $P$ within the basin has been a recurring water quality issue since the 1960s (Environment Canada, 2017). Nutrient imbalances resulting in eutrophication continue to threaten the health of the Great Lakes ecosystems to this day (Environment Canada, 2017). Canada and the United States, through the 2012 Great Lakes Water Quality Agreement, have therefore pledged to "...manage phosphorus concentrations and loadings, and other nutrients if warranted, in the Waters of the Great Lakes." (Government of Canada and Government of the United States of America, 2012). Phosphorus loadings as it relates to water quality of the Great Lakes is also a research priority for the Ontario Ministry of Agriculture, Food and Rural Affairs (OMAFRA) (OMAFRA, 2018). Regulating point sources and establishing agricultural management practices have been the focus of managing nutrient loading to the Great Lakes (Government of Canada and Government of the United States of America, 2012; Grannemann \& Van Stempvoort, 2016); however, the role of various hydrological pathways in nutrient transport to water bodies remains poorly understood.

Inordinate $\mathrm{P}$ loadings combined with warmer temperatures in the summer prompts the excessive growth of algae. As bacteria consume the continuously decomposing algae, their increased metabolism and respiration reduces oxygen levels, potentially inducing oxygen depletion in the water body (Government of Canada and Government of the United States of 
America, 2012). Resultant geochemical changes can cause fish kills, reduced diversity of aquatic species, and invasion of new species (Sharpley et al., 1994; Carpenter et al., 1998; Government of Canada and Government of the United States of America, 2012). Furthermore, toxins from harmful algal blooms can contaminate drinking water treatment facilities, thus negatively affecting drinking water supplies (Government of Canada and Government of the United States of America, 2012; Environment Canada, 2017). With more than $80 \%$ of Ontario residents receiving their drinking water from one of the Great Lakes (Government of Ontario, 2016), eutrophication thus represents not only an ecological concern, but a human health one as well.

Phosphorus is subject to cycling in the environment thereby influencing the form and mobility of the nutrient (Grannemann \& Van Stempvoort, 2016). Phosphorus readily sorbs and reacts with soil particles and geological media thus reducing its mobility in the subsurface (Holman et al., 2008). Consequently, surface runoff and erosion are the predominant pathways through which $P$ is transported from agricultural land to surface water bodies (Hansen et al., 2002). Phosphorus loss in surface flow is typically dependent on the rate, time, and method of $P$ application; the type of fertilizer or manure applied; the quantity and the timing of precipitation events after the application; antecedent conditions; and the land cover (Shigaki et al., 2006). However, under certain conditions subsurface losses of $P$ via tile drainage and leaching can act as a source of this nutrient to surface water receiving groundwater or tile discharge. Recent studies suggest that tile drains beneath agricultural land can be a substantial pathway for $P$ transport to the receiving water bodies (Macrae et al., 2007; King et al., 2015). Both dissolved and particulate forms of $\mathrm{P}$ have been observed in tile drains and in groundwater in settings with considerable networks of preferential flow pathways or in soils with low Psorption capacities (low in clay, Fe and Al oxides, and carbonates), thus indicating that tile and groundwater systems can intensify P loss from agricultural land (Beauchemin et al., 1998; Stamm et al., 1998; Carlyle \& Hill, 2001; Hansen et al., 2002; Domagalski \& Johnson, 2011; Robinson, 2015). Groundwater contributions of $P$ to surface water bodies are exceedingly important in areas receiving groundwater discharge or that have favourable geochemical and/or hydrogeological settings (Tesoriero et al., 2009). Groundwater, therefore, can make consequential contributions to the biologically available $P$ in surface water bodies and may have the ability to elicit or sustain eutrophication (Holman et al., 2008). Groundwater-surface 
water interactions play a critical role in the exchange of nutrients between the two systems via complex biogeochemical reactions and hydrological processes in transition zones (Grannemann \& Van Stempvoort, 2016), yet are not well understood and often overlooked when evaluating the overall water quality of a system (Robinson, 2015).

Understanding and evaluating the ways in which $\mathrm{P}$ is transported to surface water bodies via various hydrological pathways in an agriculturally intensive area remains complex but is essential to control the water quality of receiving waters. Through comprehensive spatial and temporal water quality monitoring of distinct hydrological pathways in an agriculturaldominant watershed within the Great Lakes Basin this research aims to enhance the understanding of nutrient transport dynamics and the importance of groundwater-surface water interactions. The outcomes, therefore, will be significant for refining nutrient management strategies and agricultural best management practices in the basin and in similar hydrological and agricultural settings.

\subsection{Objectives \& approach}

Non-point source agricultural contamination is a serious concern for surface and groundwater quality within the Great Lakes Basin. The dynamics and transport of nutrients through the groundwater-surface water interface are not presently well-understood. This research aims to investigate the spatial and temporal evolution of $\mathrm{P}$ and nitrate in the groundwater, hyporheic zone, stream water, and tile drainage water in an agriculturally-dominated clay plain system within the Great Lakes Basin. A field-based study was conducted in the $127 \mathrm{~km}^{2}$ Upper Parkhill watershed, an environmentally-sensitive, agriculturally intensive watershed located in southwestern Ontario. Parkhill Creek, the main surface water feature in the watershed, is an eventual tributary to Lake Huron.

Five study sites across the watershed were selected to monitor the quality of surface and subsurface water. The main research site (MCGF) is host to an Integrated Water and Climate Monitoring Station established in collaboration with the Ontario Ministry of the Environment, Conservation and Parks (MECP) and the Ausable Bayfield Conservation Authority (ABCA) in 2012. This station serves to provide long-term continuous monitoring of water and climate data via 28 climate, soil, and water quality instruments, in addition to two monitoring wells and three drive-points. Four additional field sites provide surface water and/or groundwater 
sampling locations and were selected to represent the variability in riparian zones and land use along Parkhill Creek, the main surface water feature in the watershed (see Chapter 3).

Continuous and discrete data and samples were collected over one year from June 2018 to May 2019 to investigate spatial and temporal variations of $P$ and nitrate and groundwatersurface water interactions within the agricultural-dominated clay plain system. Five surface water locations, six groundwater wells, six drive-points (two in the streambed), and one tile drain outlet in the watershed were sampled once a month over these 12 months. Samples were analyzed for a suite of common nutrient species, including total P (TP), total dissolved $P(T D P)$, soluble reactive $P(S R P)$, particulate $P(P P)$, and nitrate-N. Field parameters (electrical conductivity, $\mathrm{pH}$, temperature, oxidation-reduction potential, and dissolved oxygen) were also measured monthly at each sampling location. At the main research site, continuous monitoring of the surface water and groundwater nitrate concentrations and field parameters was achieved using a Submersible Ultraviolet Nitrate Analyzer (SUNA ${ }^{\text {TM}}$ ) and a YSI EXO'TM sonde located in one monitoring well and in the main surface water body. A landowner survey was executed in winter 2018 and winter 2019 in the watershed to determine specific land management and fertilization practices.

This research aims to use field-based data collection to help to fill the knowledge gaps that exist concerning nutrient transport through surface water, hyporheic, and groundwater interfaces, and the hydrogeological processes influencing this transport in clay dominated settings, typical of the GLB. The subsequent research objectives are to:

1. Evaluate the spatial and temporal variability of nutrient concentrations in surface and subsurface pathways.

2. Examine the temporal variability in nutrient dynamics and hydrologic connection related to the hyporheic zone.

3. Investigate relationships between water quality observations and land management practices within the watershed.

\subsection{Thesis outline}

This thesis is written using a manuscript format. Chapter 2 provides a review of the literature, directed at highlighting $\mathrm{P}$ dynamics and transport within an agricultural system, as well as 
current research gaps. A description of the research sites and outlines of field investigations completed is presented in Chapter 3. Chapter 3 is intended for manuscript submission and discusses the results of the research in relation to significant groundwater-surface water interactions and $P$ transport dynamics through various hydrological systems. Chapter 4 , the final chapter, summarizes the conclusions of the study and imparts recommendations for future work with respect to the proposed research objectives. 


\section{REVIEW OF LITERATURE}

\subsection{Sources of phosphorus}

Phosphorus in the environment originates from both natural and anthropogenic sources via different pathways and at varying times throughout the year. The largest natural resource of $P$ is minerals present in rocks, sediment, and soil (Mueller \& Helsel, 1996). The principal natural source of $\mathrm{P}$ is apatite, a group of primary phosphate minerals, $\left(\mathrm{Ca}_{5}\left(\mathrm{PO}_{4}\right)_{3}(\mathrm{~F}, \mathrm{Cl}, \mathrm{OH})\right)$, from which $\mathrm{P}$ can be released through physical and chemical weathering processes. Other natural sources of $P$ include riparian vegetation (Meyer \& Likens, 1979), migratory fish that return to their spawning grounds (Nislow et al., 2004), and erosion of river banks (Walling et al., 2008). Nevertheless, very small amounts of $P\left(<0.1 \mathrm{~kg} \mathrm{Pha}^{-1} \mathrm{yr}^{-1}\right)$, predominantly in particulate form, are released to surface waters from these sources (Withers \& Jarvie, 2008).

Agriculture has been recognized as the primary anthropogenic non-point source of $P$ in freshwater systems and presents significant environmental concerns across the world (Domagalski \& Johnson, 2011; McDowell et al., 2015). Other than the direct field application of P-containing fertilizers and manures, further sources of agricultural-derived $\mathrm{P}$ include intensive livestock operations and intensive horticultural activities (Robinson, 2015). Livestock operations, such as concentrated animal feeding operations, produce substantial amounts of manure which can be stored and applied incorrectly thus potentially contributing to elevated $P$ concentrations within the surface and subsurface (Robinson, 2015). Furthermore, significant horticultural activities can also impact $P$ due to high fertilizer and/or manure use in conjunction with extensive irrigation systems (Robinson, 2015).

Aside from agriculture, there are a vast number of non-agricultural point and non-point sources of $\mathrm{P}$. These include atmospheric deposition, septic systems, leaky underground sewer systems, industrial activities, landfill leachate, as well as small-scale fertilizer use (Robinson, 2015). Point sources exclusively comprise less than $10 \%$ of $P$ released into the environment (Puckett, 1995) and are comparatively easy to measure and manage (Holman et al., 2008). 


\subsection{Water quality guidelines}

Total phosphorus concentrations are most commonly used to measure $\mathrm{P}$ in surface water. Total P concentrations in natural freshwaters range from $<1 \mu \mathrm{g} / \mathrm{L}$ to $>200 \mu \mathrm{g} / \mathrm{L}$, though most typically contain between 10 and $50 \mu \mathrm{g} / \mathrm{L}$ of TP (Canadian Council of Ministers of the Environment, 2004). Excessive loading of TP beyond this range can pose a significant threat to the water quality of surface water bodies, thus certain guidelines and objectives exist at national and provincial levels.

The Provincial Water Quality Objectives (PWQOs) provide criteria to represent satisfactory levels of contaminants in Ontario for surface water and groundwater where it discharges to the surface (Ministry of the Environment and Energy, 1994). The levels are established to protect aquatic life and recreational uses of the water bodies. Currently, there is no firm objective for TP due to insufficient scientific evidence (Ministry of the Environment and Energy, 1994). However, general guidelines are available that are to be complemented by site-specific studies. To prevent nuisance concentrations of algae in lakes, the TP concentration should not surpass $20 \mu \mathrm{g} / \mathrm{L}$ (Ministry of the Environment and Energy, 1994). A TP concentration of less than $10 \mu \mathrm{g} / \mathrm{L}$ will provide protection against aesthetic deterioration for lakes naturally below this level (Ministry of the Environment and Energy, 1994). In rivers and streams, TP concentrations below $30 \mu \mathrm{g} / \mathrm{L}$ should eliminate excessive plant growth (Ministry of the Environment and Energy, 1994).

Phosphorus is the principal growth-limiting nutrient in the Great Lakes, therefore under the Great Lakes Water Quality Agreement (the Great Lakes Water Quality Protocol of 2012), Lake Ecosystem Objectives were developed to manage $\mathrm{P}$ concentrations and loadings and their impacts to the Waters of the Great Lakes. To achieve these objectives, Substance Objectives for $\mathrm{P}$ concentrations for the open waters and nearshore areas of each Great Lake were established. The Interim Substance Objective for TP concentration in open water for Lake Huron is $5 \mu \mathrm{g} / \mathrm{L}$, which is to be followed on an interim basis until updated (Government of Canada and Government of the United States of America, 2012).

Presently, there are no national water quality guidelines for P. A guidance framework has been derived by the Canadian Council of Ministers of the Environment (CCME), rather than guidelines, due to the complex dynamics of $P$ within the environment (Canadian Council of 
Ministers of the Environment, 2004). The framework requires the trophic status of water bodies to be compared to predefined trigger ranges (Canadian Council of Ministers of the Environment, 2004). The trigger ranges are established based on a range of TP concentrations in water that characterize the reference status for a site (Canadian Council of Ministers of the Environment, 2004).

The trigger ranges represent desired concentration ranges for TP (Table 2-1). If concentrations exceed the upper limit of a range further investigations related to environmental factors are required to assess potential environmental problems (Canadian Council of Ministers of the Environment, 2004). If the trigger range is not exceeded, the risk of environmental problems is low (Canadian Council of Ministers of the Environment, 2004). In the latter circumstance, the degree of increase of TP from the baseline is assessed (Canadian Council of Ministers of the Environment, 2004). An increase $\leq 50 \%$ in concentration above the baseline is considered acceptable (Canadian Council of Ministers of the Environment, 2004).

Table 2-1: Total phosphorus trigger ranges based on CCME (2004).

\begin{tabular}{lc}
\hline Trophic Status & $\begin{array}{c}\text { Trigger Ranges } \\
\text { Total phosphorus }(\mu \mathbf{g} / \mathbf{L})\end{array}$ \\
\hline Ultra-oligotrophic & $<4$ \\
Oligotrophic & $4-10$ \\
Mesotrophic & $10-20$ \\
Meso-eutrophic & $20-35$ \\
Eutrophic & $35-100$ \\
Hyper-eutrophic & $>100$ \\
\hline
\end{tabular}

No drinking water standards for phosphates exist under the Ontario Drinking Water Quality Standards as phosphates are not toxic to humans or animals except when present in extremely high levels (Nieder et al., 2018). Adverse health effects relating to very high levels of $\mathrm{P}$ include digestive problems (Nieder et al., 2018). 


\subsection{Phosphorus forms}

Phosphorus can be viewed as existing in three pools in the environment which are characterized according to reactivity: soluble, reactive, and stable $P$ (Figure 2-1). Of the forms present in soil, soluble $\mathrm{P}$ has the highest reactivity and is the most available to plants. This form is principally comprised of inorganic $\mathrm{P}$ as orthophosphate anions, such as $\mathrm{H}_{2} \mathrm{PO}^{4-}$ and $\mathrm{HPO}_{4}{ }^{2-}$. In typical soils, soluble $\mathrm{P}$ commonly comprises a minor amount of total soil $\mathrm{P}$, which is on average less than 1\% (Hansen et al., 2002). Reactive $P$ exists in both organic and inorganic forms and is typically dominated by inorganic forms that are in equilibrium with $\mathrm{P}$ in solution (Hansen et al., 2002). Organic forms originate from organic material that is easily decomposed or mineralized, while inorganic forms occur on soil exchange sites in minerals that are moderately soluble. As plants take up inorganic $P, P$ from the reactive pool is released to replenish $\mathrm{P}$ content in the solution. Stable $\mathrm{P}$ constitutes the greatest portion of $\mathrm{P}$ present in the soil and is fixed. This form consists of organic and inorganic compounds that are occluded, insoluble, or strongly sorbed, thereby rendering them not available biologically. Stable P occurs in equilibrium with the other pools; however, reactions involving this form are considerably prolonged. Phosphorus in this pool can persist in soils for years without becoming available to plants. 


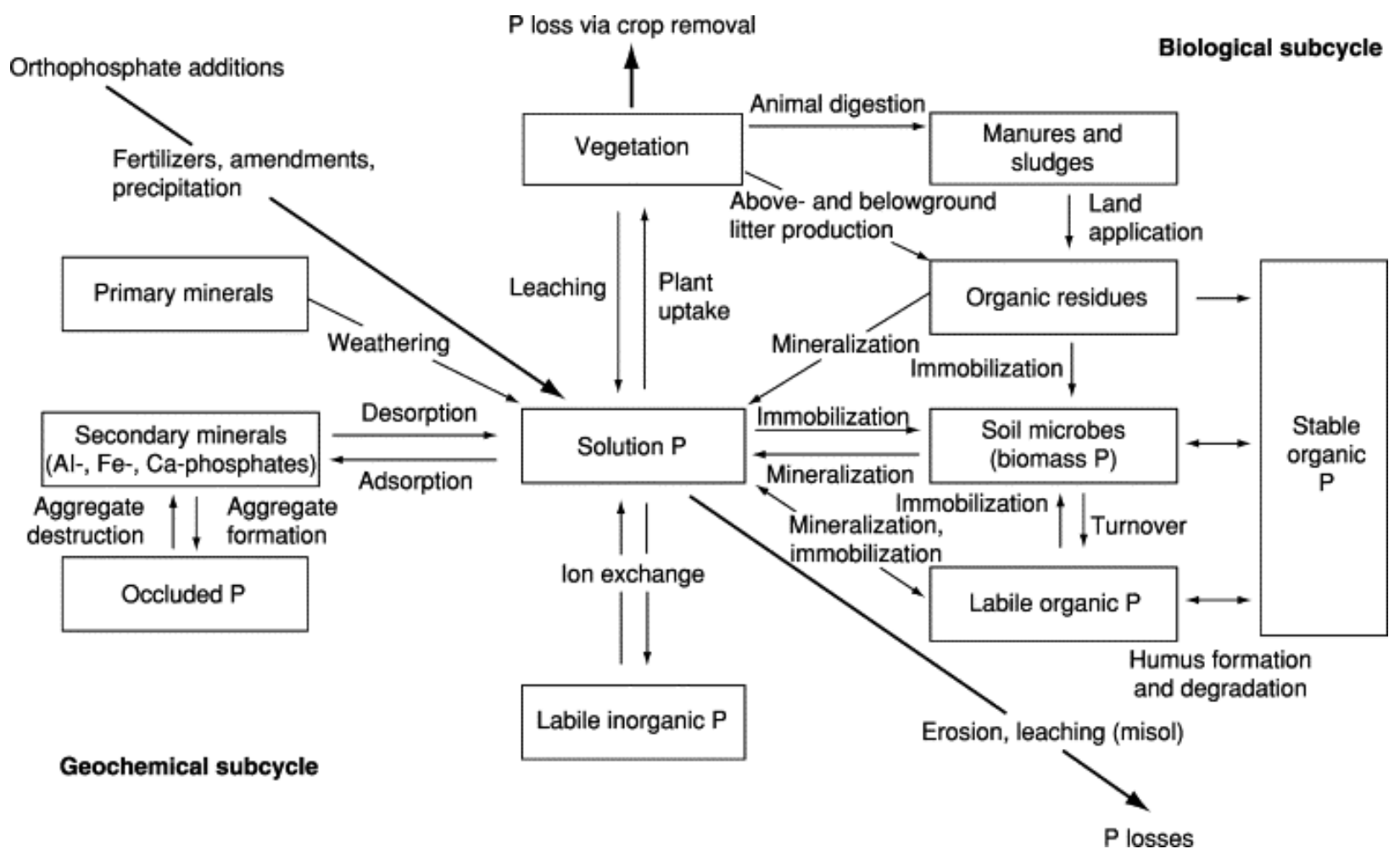

Figure 2-1: The terrestrial phosphorus cycle showing inputs, losses, and transformations (Mullen, 2005).

\subsubsection{Phosphorus forms in water}

In natural waters, P species are typically divided into three groups: SRP, soluble unreactive P (SUP), and PP (Rigler, 1973). The SRP pool is primarily constituted of orthophosphate, while SUP is comprised of colloidal, polymeric, or organic $P$.

Total $\mathrm{P}$ is a measure of all $\mathrm{P}$ components, dissolved and particulate, organic and inorganic, that are directly or indirectly available in a water sample. Studies have demonstrated that other forms of $\mathrm{P}$ can be converted to orthophosphate in natural waters, therefore the TP concentration can provide an indication of the long-term potential for eutrophication of a surface water body (Pote et al., 2009a). The TP represents the sum of TDP and PP and is expressed as follows (Eq. 1):

$$
T P=T D P+P P(1)
$$

Total dissolved $P$ represents the $P$ form present in water that has been filtered through a $0.45-$ $\mu \mathrm{m}$-pore-diameter membrane filter then subject to digestion (Pote at al., 2009). This includes dissolved inorganic and organic $\mathrm{P}$ and in certain circumstances colloidal $\mathrm{P}$. 
Soluble reactive $\mathrm{P}$ (also referred to as dissolved reactive phosphorus (DRP)) is a measure of the fraction of $P$ that passes through a $0.45-\mu \mathrm{m}$-pore-diameter membrane filter and without prior digestion or hydrolysis of the water sample, reacts to the molybdate colorimetric test (Pote \& Daniel, 2009). This fraction principally consists of dissolved orthophosphate, the form most readily available to algae, and thus represents an indicator of the amount of $P$ directly available for aquatic plant growth (Pote \& Daniel, 2009).

Particulate $P$ refers to the $P$ fraction that is retained on a $0.45-\mu \mathrm{m}$-pore-diameter membrane filter. This fraction contains both inorganic and organic and particulate and colloidal material that is captured on the filter. Particulate $P$ is typically characterized by $\mathrm{Ca}, \mathrm{Fe}$, and $\mathrm{Al}$ phosphate minerals (e.g. variscite, strengite, hydroxyapatite), $\mathrm{P}$ sorbed to clay minerals and $\mathrm{Fe}$ and $\mathrm{Al}$ oxides, $\mathrm{P}$ assimilated into $\mathrm{Fe}$ and $\mathrm{Al}$ oxides, and $\mathrm{P}$ in soil organisms and organic matter (Jarvie et al., 2002; Ketterings et al., 2003). Particulate P is not immediately available for biotic uptake; however, it can transform from one fraction to another under fluctuating physical and biogeochemical conditions (Reynolds \& Davies, 2001). Therefore, PP is also considered as a contributor to eutrophication of a surface water body over the long-term (Sharpley \& Beegle, 2001). Particulate $P$ is chiefly determined by the difference between TP and TDP (Eq. 2):

$$
\mathrm{PP}=\mathrm{TP}-\mathrm{TDP}(2)
$$

\subsection{Phosphorus fate in terrestrial systems}

As $\mathrm{P}$ enters the subsurface soil environment it is subject to distinct transformation processes. As $\mathrm{P}$ is added to the system, a considerable portion remains available on a short-term basis to plants (Hansen et al., 2002). As time progresses, the soluble $P$ is taken up by plants and converted into organic $\mathrm{P}$, adsorbed on mineral surfaces, or incorporated into insoluble or sparingly soluble minerals via reactions with ions in soil (Hansen et al., 2002). These transformations influence the movement of $P$ thus making it essential to understand these processes to address the subsurface transport of $P$ within a specific environment.

\subsubsection{Adsorption}

Sorption of $\mathrm{P}$ within soil involves the reactions that transform soluble and bioavailable forms of $P$ into less soluble or biologically available forms (Hansen et al., 2002). These reactions 
include metal complex formation and adsorption of $\mathrm{P}$ on mineral or organic surfaces (Hansen et al., 2002). Studies have demonstrated that these processes are the most significant methods for long-term P attenuation (Reddy et al., 1998). The sorption capacity of a soil is fixed and is dependent on the content and type of clay minerals, the content of organic matter, the quantity of aluminum ( $\mathrm{Al})$, iron ( $\mathrm{Fe})$, and calcium ( $\mathrm{Ca}$ ) that can be exchanged, as well as the $\mathrm{pH}$ of the soil (Hansen et al., 2002). The sorption capacity and degree of $\mathrm{P}$ saturation directly impact the quantity of $P$ transported to surface waters via runoff or leachate by influencing the dynamics of the $P$ within the unsaturated and saturated zones (Hansen et al., 2002).

High sorption capacities are associated with soils rich in Al, Fe, or Ca (Hansen et al., 2002). Furthermore, the quantity of clay, metal oxide, and calcium carbonate minerals in soils corresponds positively with P sorption capacities (Hoffmann et al., 2009; Domagalski \& Johnson, 2012). Phosphorus is predominantly absorbed to iron and aluminum oxides in acidic soils and to calcium carbonates in neutral or alkaline soils (Hoffmann et al., 2009). The total surface area of the oxides or clays present in the soil controls the amount of $P$ that can be absorbed (Domagalski \& Johnson, 2012). Phosphorus will remain in dissolved form if ions have filled the sorption sites on the mineral surfaces (Domagalski \& Johnson, 2012).

\subsubsection{Precipitation}

Phosphorus is also removed from solution via precipitation reactions wherein $\mathrm{P}$ reacts with another compound to create a mineral (Holtan et al., 1988). These reactions occur between $\mathrm{P}$ and $\mathrm{Al}, \mathrm{Fe}$, or $\mathrm{Ca}$ within the subsurface and produce insoluble or sparingly soluble phosphate minerals, such as variscite $\left(\mathrm{AlPO}_{4} \cdot 2\left(\mathrm{H}_{2} \mathrm{O}\right)\right)$, strengite $\left(\mathrm{FePO}_{4} \cdot\left(\mathrm{H}_{2} \mathrm{O}\right)\right)$, or apatite $\left(\mathrm{Ca}_{5}\left(\mathrm{PO}_{4}\right)_{3}(\mathrm{~F}, \mathrm{Cl}, \mathrm{OH})\right)$ (Bussey \& Walter, 1996; Denver et al., 2010).

It can be difficult to distinguish between adsorption and precipitation reactions in the soil environment, especially the longer the $P$ is adsorbed on the soil particle. However, both processes aide to reduce dissolved $\mathrm{P}$ concentrations in an aquifer system and therefore impede the mobility of $\mathrm{P}$ (Hansen et al., 2002).

\subsubsection{Biological processes}

The mobility of $P$, including attenuation and release, within the subsurface is also influenced by biological processes. Phosphorus attenuation can occur via microbial and plant uptake, 
which is considered as a temporary transient P pool (Richardson \& Marshall, 1986; Schechter et al., 2013). Considering that $P$ is an essential nutrient for living organisms; dissolved inorganic $P$ is assimilated into the biomass of bacteria, fungi, algae, and plants within the soil (Schechter et al., 2013). However, P demand and the efficacy of uptake differs between organisms. In contrast, decomposition of organic matter results in the release of both organic particulate and dissolved forms of $P$ to the surface and subsurface soil. The organic compounds are decomposed by organisms and the $\mathrm{P}$ compounds are released or retained as refractory complexes in the soil (Smeck, 1985). The rates of decomposition and release of $\mathrm{P}$ are contingent on $\mathrm{pH}$, the quality of litter, concentration of $\mathrm{Ca}$, redox potential, moisture of the soil, and temperature, as well as the life cycles of $P$ immobilizing/mineralizing organisms (Hoffmann et al., 2009). Accordingly, the complex factors influencing the biological processes render their evaluation difficult, especially on a large scale.

\subsection{Phosphorus fate in aqueous systems}

The transport and bioavailability of $P$ in water bodies is affected by the physical and biogeochemical environment in the water column and the sediment/water interface (Figure 2-2). Retention of $P$ in water bodies is temporary and highly variable in space and time; however, it allows for the removal and/or transformation of $\mathrm{P}$ for biotic and abiotic assimilation (Withers \& Jarvie, 2008). Phosphorus can be slowly removed from the water column through similar processes occurring in the terrestrial $\mathrm{P}$ cycle, including sorption reactions, mineral precipitation, biological assimilation and/or uptake. Correspondingly, $\mathrm{P}$ is released to the water column from streambed sediments via desorption and dissolution of $\mathrm{P}$ fixed in precipitates and inorganic materials, microbial mineralization of organic matter, and the diffusion of dissolved $P$ from the sediment pore water (Hou et al., 2013). The factors controlling the rate of dissolved $\mathrm{P}$ release include redox conditions, $\mathrm{pH}$, dissolved oxygen concentration, temperature, particle size, mixing conditions (turbulence), competitor ions, and sediment concentration (Withers \& Jarvie, 2008; Hou et al., 2013). In settings devoid of notable external $P$ loading, this internal cycling of $P$ has been demonstrated to sustain elevated concentrations of $P$ in the water column, thus suggesting that internal loading of $P$ from sediments can be a significant source of $P$ (Canadian Council of Ministers of the Environment, 2004). 


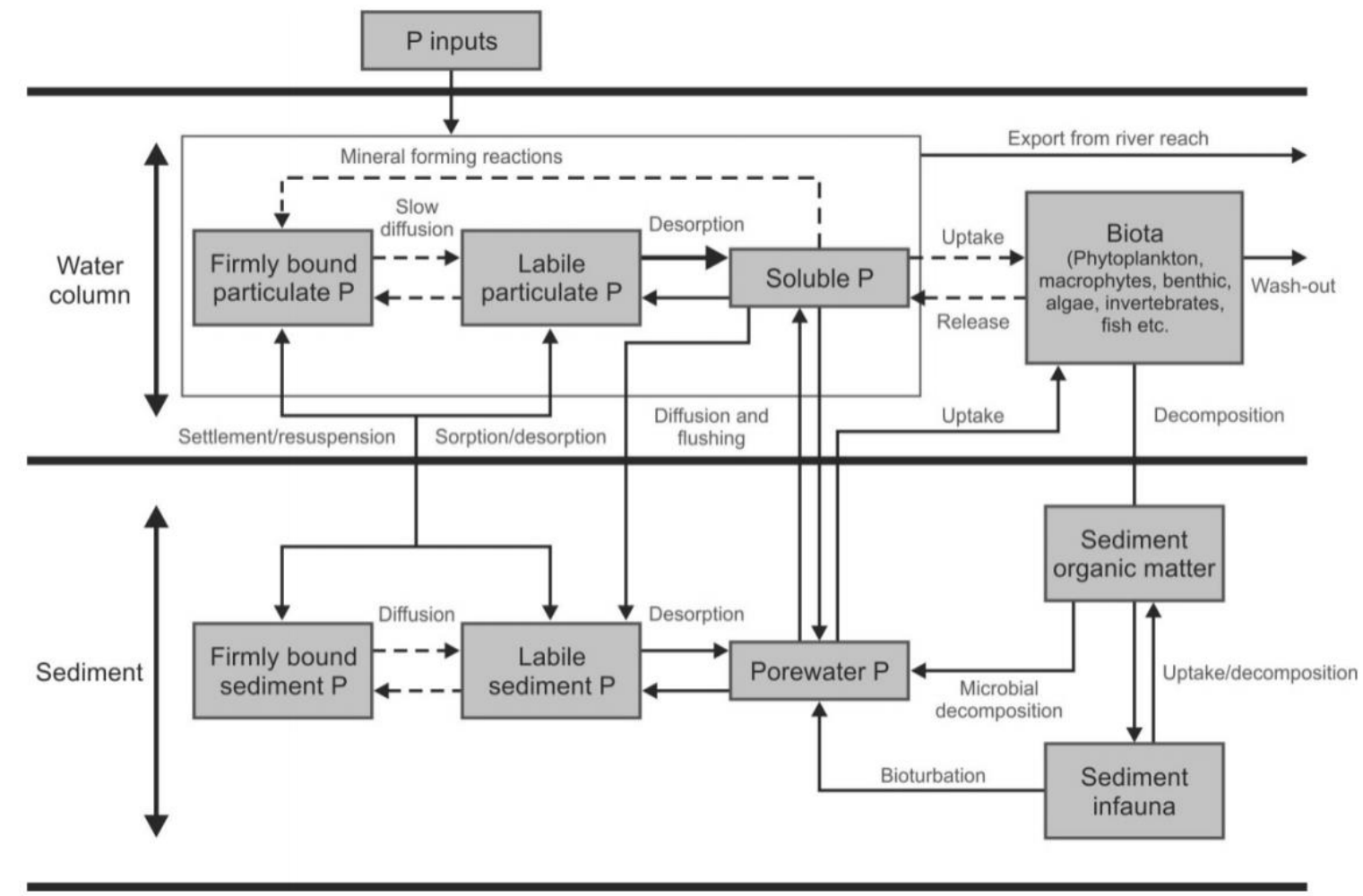

Figure 2-2: In-stream cycling of phosphorus near the sediment-water interface (adapted from Mainstone \& Parr, 2002; Environment Agency, 2015).

\subsection{Phosphorus mobility}

Phosphorous mobility in the saturated and unsaturated zone is generally inhibited primarily due to metal-complex formation and adsorption, as mentioned in Section 1.4, and therefore contributions of $\mathrm{P}$ to receiving surface water bodies are typically assumed to be negligible (Bussey \& Walter, 1996; Holman et al., 2008). However, recent studies indicate that in distinct environments inorganic $P$ is soluble and mobile and therefore exists as a threat to groundwater and surface water quality (Holman et al., 2008; Domagalski \& Johnson, 2011). Nonetheless, geochemical conditions along the groundwater-surface water pathway may vary, thus resulting in spatial fluctuations in $\mathrm{P}$ concentrations and mobility within the saturated zone (Domagalski \& Johnson, 2011).

Low $\mathrm{P}$ sorption capacities of soils, which promote $\mathrm{P}$ mobility, are associated with low dissolved oxygen (DO) concentrations and metal oxide content combined with high $\mathrm{pH}$ and organic content (Carlyle \& Hill, 2001; Domagalski \& Johnson, 2011). Continual P inputs can lead to an increase of $P$ exchange site saturation causing $P$ to be held less strongly and 
released more readily and therefore could contribute to leaching of $\mathrm{P}$ to groundwater (Hansen et al., 2002).

The redox state in an environment has been demonstrated to influence dissolved $P$ concentrations within the saturated zone. Greater concentrations of dissolved P present under reducing conditions are correlated to $\mathrm{P}$ desorbing from compounds (McCobb et al., 2003; Banaszuck et al., 2005). Phosphorus bound to $\mathrm{Fe}^{3+}$ in compounds is mobilized following the reduction of $\mathrm{Fe}^{3+}$ to $\mathrm{Fe}^{2+}$ (Carlyle \& Hill, 2001; Holman et al., 2010). Conversely, as redox potential increases, immobilization of $P$ may occur (Holman et al., 2010). Furthermore, microbial processes change with fluctuating redox states within an environment, thus resulting in inconsistencies in $\mathrm{P}$ attenuation and release via biological processes (Carlyle \& Hill, 2001).

Dissolved oxygen and $\mathrm{pH}$ also play a significant role in $\mathrm{P}$ retention and release by iron oxides. Generally, the $\mathrm{P}$ exchange site saturation increases more rapidly in environments that are alkaline or have low DO, in comparison to oxic or acidic conditions (Domagalski \& Johnson, 2012). Accordingly, increased dissolved $P$ concentrations have been associated with low dissolved oxygen concentrations and high pH (>7) (Domagalski \& Johnson, 2012). Nevertheless, the dissolution of iron oxides and the release of adsorbed $\mathrm{P}$ under these conditions is not guaranteed as this process requires specific microorganisms (Domagalski \& Johnson, 2012).

\subsection{Transport pathways}

Phosphorus is transported to surface water bodies via surface and subsurface pathways from adjacent agricultural fields. Surface runoff and soil erosion from fields are generally regarded as the principal sources of $\mathrm{P}$ loading to surface water, as $\mathrm{P}$ tends to adsorb and react with soil and geological media thus reducing its mobility (Holman et al., 2008; Meinikmann et al., 2015; Robinson, 2015). However, recent studies indicate that in certain environments $P$ can be transported through the soil profile to groundwater systems and ultimately into surface water under discharge settings (Hansen et al., 2002; Domagalski \& Johnson, 2011; Robinson, 2015). 


\subsubsection{Surface flow}

Erosion and runoff are the predominant $\mathrm{P}$ transportation pathways when $\mathrm{P}$-rich fertilizers and manures are applied on a field surface or if a soil is inherently enriched in $\mathrm{P}$. If the application immediately precedes a rainfall, irrigation, or wind event, the transport of $P$ through these pathways may be intensified (Potter et al., 2006). Rainfall has been demonstrated to have a dominant effect on diffuse $P$ transfer from agricultural land, specifically in temperate climates where rainfall monopolizes runoff compared to snowmelt events (Ockenden et al., 2017; Kieta et al., 2018). In two agriculturally-intensive catchments in the United Kingdom, Ockenden et al. (2017) found that annual rainfall accounts for $61-82 \%$ of annual P load.

\subsubsection{Erosion}

Erosion involves the movement of soil from one location to another by water, wind, or tillage. Water erosion dominates this transport pathway for soil moving outside of field boundaries in southern Ontario, as wind erosion is considered to be significant only in the sand and sandy loam deposits in the area (Dickinson et al., 1987; Snell and Cecile Environmental Research, 1995) and tillage erosion is primarily a within field phenomenom. Phosphorus adsorbed on soil particles can be conveyed from a field surface during and immediately following storm events via sheet and rill erosion (The N.C. PLAT Committee, 2005). Fine particles are preferentially carried away in water erosion, therefore exported sediments are typically enriched with clay- and silt-sized particles (Shi \& Schulin, 2018). Phosphorus attaches strongly to fine-grained particles due to their high sorption capacity, therefore erosion of these particles can also transport sorbed $\mathrm{P}$ from agricultural land to nearby surface water bodies (Potter et al., 2006; Shi \& Schulin, 2018). Phosphorus adsorbed to clay and organic matter in soil that erodes has shown to represent 60 to $90 \%$ of runoff $P$ from agricultural land (Sharpley et al., 1992).

\subsubsection{Surface runoff}

In contrast to erosion, runoff transports dissolved $\mathrm{P}$ to surface water exclusively via the movement of water over agricultural land with scarce relocation of soil (Dickinson et al., 1987; Daniel et al., 1998). The dissolution or desorption of $P$ from the soil, plant material, suspended sediments, fertilizer, and/or manure provides the source of dissolved $\mathrm{P}$ in the runoff (Sharpley et al., 2001). Several studies have demonstrated that an increase in the length of time 
between manure and/or fertilizer application and surface runoff corresponds to a reduction in P loss (Sharpley, 1997; Djodjic et al., 2000; Sharpley, 2015). The thin (1 $-5 \mathrm{~cm}$ ) layer of surface soil and surface plant material interacts with the rainfall or irrigation producing the runoff (Sharpley, 1985; Sharpley et al., 2001), thus P and geochemical conditions within this layer will directly influence the dissolved $\mathrm{P}$ content in the exported water.

\subsubsection{Subsurface flow}

Phosphorus transport in the subsurface occurs via the movement of water through the soil matrix or by preferential flow pathways. Soil matrix flow encompasses the slow and uniform movement of water and solutes through the soil profile. Preferential flow involves large amounts of water moving through a minute fraction of the soil volume (Simard et al., 2000). Rather than flowing through the bulk soil, water preferentially moves through cracks, biopores, or macropores in the soil profile (Zhang et al., 2015). Fine-textured soils with high clay content are more likely to develop these preferential flow pathways than coarse-textured soil, due to their greater tendency to crack (Simard et al., 2000). Water moving through these pathways experiences reduced interaction with the soil matrix thereby limiting the opportunity for $\mathrm{P}$ adsorption (Simard et al., 2000). Accordingly, even if a soil has a high sorption capacity, these pathways can promote the transport of $P$ in the subsurface (Heathwaite \& Dils, 2000; Simard et al., 2000). In consequence, increased $P$ may enter subsurface drainage or saturated zones hydraulically connected to these cracks or pores (Hansen et al., 2002; Zhang et al., 2015).

\subsubsection{Tile drains}

In Ontario, it is estimated that over $43 \%$ of agricultural land has been tile drained (Fraser \& Fleming, 2001) and experience a significant change in hydrology in the land where they are installed (Reid, 2011). Tile drains can reduce the quantity of surface runoff from a field, instead redirecting this flow into the subsurface (Reid, 2011). Haygarth et al. (1998) reported a decrease in total $\mathrm{P}$ export of approximately $30 \%$ in surface runoff in areas with tile drain systems present. A study conducted in the midwestern US by Smith et al. (2014) revealed a TP and soluble P loss of $48 \%$ and $49 \%$, respectively, via tile drains in agricultural land. Further, drains expand the extent of the contributing area directly connected to the drainage system (Heathwaite \& Dils, 2000). Given that drains lack a buffer to mitigate their effects 
(Heathwaite \& Dils, 2000), they therefore offer no opportunity to moderate $P$, and in consequence serve as a direct channel for $P$ loading to surface water (Reid, 2011). The subsurface preferential flow pathways provide a conduit for both dissolved and particulate $\mathrm{P}$ to enter the tile drainage system, and ultimately into connecting surface water bodies.

\subsubsection{Leaching}

Concentrations of $\mathrm{P}$ are typically greater in surface runoff and tile drain effluent (Sharpley \& Syers, 1979); however, sufficiently high concentrations of TDP in groundwater have been observed to support eutrophic conditions in surface water bodies (Burkart et al., 2004; Holman et al., 2008; Holman et al., 2010). Furthermore, many studies have highlighted the significant contribution of dissolved $\mathrm{P}$ via discharge of groundwater as baseflow to streams and river (Tesoriero et al., 2009; Mellander et al., 2016). Dubrovsky et al. (2010) observed elevated dissolved $P$ concentrations in groundwater across the United States, with $21 \%$ of median concentrations exceeding the background concentration $(0.03 \mathrm{mg} / \mathrm{L})$ in major aquifer and agricultural and urban land-use studies. Mellander et al. (2016) reported that $50-59 \%$ of the total reactive $\mathrm{P}$ export was via groundwater in two watersheds in Ireland.

The movement of $\mathrm{P}$ through the unsaturated zone to the saturated zone is influenced not only by geochemical and biological processes as discussed previously, but also site-specific conditions. The key factors affecting the potential for $\mathrm{P}$ leaching into groundwater at a site are as follows: climate, soil texture, type of crop, rooting depth of the crop, fertilizer and/or manure approach (e.g. placement, quantity, schedule), irrigation system(s), and hydrological and hydrogeological conditions present at the site (Almasri, 2007; Balderacchi et al., 2013; Robinson, 2015). Additional components affecting subsurface $P$ transport include soil characteristics (e.g. preferential flow, geochemical conditions), presence and design of drainage systems (e.g. tile spacing and depth), existing concentrations of $P$ in the soil, and tillage practices (King et al., 2015). An aquifer is significantly vulnerable to $P$ leachate when the soil is being used for intensive agricultural activities and the water table is shallow (Hansen et al., 2002; McDowell et al., 2015). Moreover, P is more likely to leach to groundwater where the overburden material is medium- or coarse-grained or in soils prone to preferential flow (Carlyle \& Hill, 2001; Hansen et al., 2002). Nevertheless, due to the diverse nature of the influencing factors, $\mathrm{P}$ loading to groundwater can vary significantly within a setting with corresponding land and fertilizer use (Dubrovsky et al., 2010). 


\subsection{Groundwater-surface water interactions}

Groundwater $\mathrm{P}$ contributions to surface water are exceedingly important in environments controlled by baseflow (Tesoriero et al., 2009). Phosphorus can be transported to surface waters via groundwater if it is not sequestered along its migration pathway (Holman et al., 2010). As dissolved $P$ is transported through the aquifer it is subject to the same transformation processes occurring in the unsaturated zone. Furthermore, prior to groundwater discharging to surface water it travels through the riparian and hyporheic zones, which attenuate and/or release P based on the environmental setting (Carlyle \& Hill, 2001; Robinson, 2015). These attenuation and retention processes transpiring in the riparian zone remove $P$ from groundwater before discharge; however, it is only stored for a short-term within this zone and is then released (Carlyle \& Hill, 2001; Hoffmann et al., 2009; Roy \& Bickerton, 2014; Robinson, 2015).

\subsubsection{Hyporheic zone}

Groundwater and surface water quality are connected by the hyporheic zone; a subsurface region represented by the exchange between surface stream water and groundwater (Triska et al., 1989). Lapworth et al. (2011) describe the hyporheic zone as "characterized by chemical and temperature gradients that are important in regulating chemicals and organisms at the mixing interface between river water and groundwater and at depth within the aquifer". Accordingly, this zone has been recognized to play a critical role in the processing and transformation of nutrients in a variety of environmental settings (Dahm et al., 1998; Lapworth et al., 2011). The significance of the hyporheic zone on stream chemistry is a function of the amount of surface water flowing through this zone, in addition to the water residence time and the rates at which the biogeochemical processes occur (Findlay, 1995; Valett et al., 1996; Hill, 1997).

The sharp transition of biogeochemical properties between the streambed interface and the hyporheic zone subjects constituents transported via stream and groundwater to distinct chemical and physical environments (Boano et al., 2014). The constituents are exposed to interactions with streambed sediments, pore water chemical reactions, and uptake by microbes linked to the sediments (Boano et al., 2014). Transformation and retention processes therefore include sorption to sediment on the streambed, oxidation and reduction 
reactions, precipitation and dissolution, in addition to an array of biochemical reactions facilitated by microbial metabolism (Boano et al., 2014). Similarly, the deposition of suspended matter is stimulated through the exchange of water in the hyporheic zone, thus resulting in the retention of particle-associated constituents, such as $P$ (Boano et al., 2014). Moreover, contact time between the biogeochemically active streambed is augmented as surface water enters the hyporheic zone, in comparison to the stream channel, thus enhancing nutrient attenuation and retention mechanisms and influencing the export of nutrients in agricultural watersheds (Boano et al., 2014).

Currently, most of the research regarding nutrient cycling in the hyporheic zone is focussed on $\mathrm{N}$, while there are few studies concerning $\mathrm{P}$ dynamics in this zone, especially with relation to other surface and subsurface pathways (e.g. Valett et al., 1990; Carlyle and Hill, 2001; Vervier et al, 2009; Lapworth et al., 2011; Boano et al., 2014). Furthermore, there are scarce investigations on the relationship between hyporheic $\mathrm{P}$ concentrations and hydraulic exchange or connection between the groundwater and surface water, particularly within a fine-grained setting. The current research aims to fill these gaps. Some studies have observed higher SRP concentrations in the hyporheic zone than in surface water (Valett et al., 1990; Hendricks \& White, 1995). Carlyle and Hill (2001) observed a similar trend in increasing SRP in the hyporheic zone in surface water bodies located in agricultural areas. In contrast, a study examining the hyporheic zone in three river gravel bars found that bioavailable $\mathrm{P}$ represented a small fraction of TP, while PP comprised the majority (Vervier et al., 2009). Results from Vervier et al. (2009) reveal a significant correlation between the magnitude of exchange in the hyporheic zone and TP concentration in interstitial water in a gravel-bed river. Assessing the relationship between groundwater-surface water interactions and nutrient transport is complex due to the diverse temporal and spatial nature of processes occurring along the mixing pathway; however, is essential to understand $\mathrm{P}$ cycling and transformation in surface water bodies. 


\section{GROUNDWATER - SURFACE WATER INTERACTIONS AND AGRICULTURAL NUTRIENT TRANSPORT IN A GREAT LAKES CLAY PLAIN SYSTEM}

\subsection{Abstract}

Nutrient export from agricultural land to surface waters currently presents a significant environmental concern within the Great Lakes Basin (GLB). A field-based watershed-scale study was completed to investigate spatial and temporal variations of phosphorus and nitrate to assess dominant nutrient transport pathways and groundwater-surface water interactions in an agriculturally dominated ( $76 \%$ of land use) clay plain system within the GLB. This research was conducted in the $127 \mathrm{~km}^{2}$ Upper Parkhill Watershed, southwestern Ontario, Canada, wherein data collection occurred from June 2018 to May 2019 via continuous sensor deployment and discrete sampling of stream water, groundwater, hyporheic zone, and tile drainage water. Samples were analyzed for various nutrient species (total, total dissolved, soluble reactive, and particulate phosphorus, and nitrate- $\mathrm{N}$ ) to examine the hydrological dynamics of principal transport pathways of agriculturally-derived nutrients in the system. Phosphorus and nitrate concentrations in all water sources repeatedly exceeded environmental guidelines during the study period. Dominant transport pathways in the watershed were surface runoff and tile drainage with varying influence throughout the study period, whereas groundwater is presently considered to have a negligible role in overall nutrient export. No distinct relationship was observed between nutrient concentrations in the hyporheic zone and the vertical hydraulic gradient within this zone in the studied stream reach. Water quality observations were found to correspond to land management practices in the watershed. Given the elevated nutrient concentrations in surface water bodies in the watershed, these results are consequential for the continual improvement of strategies and programs devised to conserve water resources within the GLB. 


\subsection{Introduction}

Presently, two of the most critical contaminants in the Great Lakes Basin (GLB) are phosphorus $(\mathrm{P})$ and nitrogen $(\mathrm{N})$, largely due to the vast extent of non-point sources, in particular agriculture (Grannemann \& Van Stempvoort, 2016). Twenty per cent of the world's surface fresh water and virtually all of the agricultural industry in Ontario is located within GLB (OMAFRA, 2016). While plants require $P$ and $N$ to thrive, excessive concentrations of these nutrients in water bodies can lead to eutrophication, loss of habitats, reduced species diversity, and impair drinking water systems (Sharpley et al., 1994; Carpenter et al., 1998). Phosphorus is typically the principal growth-limiting nutrient in temperate freshwater systems, thus eutrophication in the Great Lakes has been markedly linked to excessive P loading in the basin (Heathwaite et al., 2005; Grannemann \& Van Stempvoort, 2016).

Degradation of the water quality in the Great Lakes emerged as a critical concern in the 1960s, primarily as a result of excessive inputs of P. Collective actions between Canada and the United States set forth by the 1972 Great Lakes Water Quality Agreement (GLWQA) to reduce non-point $P$ inputs facilitated immense improvements over the following two decades (Environment Canada, 2017). However, eutrophication re-emerged as a significant issue in the mid-1990s and continues to be a critical environmental concern to this day (Grannemann \& Van Stempvoort, 2016; Environment Canada, 2017). Excessive P loading, combined with the increase in dissolved P (SRP) loss in certain areas, persists as the principal contributors leading to the exaggerated growth of algae within the GLB (Environment Canada, 2017).

Surface runoff and erosion have been typically regarded as the predominant pathways through which $P$ is exported from agricultural land, while subsurface $P$ transport is often deemed negligible due to sorption and precipitation reactions reducing its mobility in the subsurface (Sims et al.,1998; Holman et al., 2008). However, it is now recognized that subsurface losses of $P$ via tile drainage and/or leaching can be an important source of $P$ to surface water in favourable geochemical or hydrogeological settings, such as those with abundant preferential flow pathways or in soils with low P-sorption capacities (Beauchemin et al., 1998; Stamm et al., 1998; Carlyle \& Hill, 2001; Hansen et al., 2002; Macrae et al., 2007; Domagalski \& Johnson, 2011; King et al., 2015; Robinson, 2015). Significant subsurface transport of both TDP and PP has been reported (Holman et al., 2008; Domagalski \& Johnson, 2011; Domagalski \& Johnson, 2012) and in certain cases, the P concentrations in 
these hydrological pathways have exceeded ecologically relevant thresholds (Holman et al., 2008). Nevertheless, the role of groundwater specifically as a non-point nutrient source remains inadequately understood (Meinikmann et al., 2015; Robinson, 2015; Grannemann \& Van Stempvoort, 2016). Furthermore, there are few studies combining surface and subsurface pathways and their associated nutrient dynamics, particularly in certain geological settings such as the clay plain systems within the GLB. This research aims to address this gap.

The quality of groundwater within the GLB is typically good with respect to ecological and/or drinking water standards or objectives; however, elevated concentrations of nutrients, especially nitrate, are often observed in agricultural and urban areas (Dubrovsky et al., 2010; International Joint Commission, 2010; Grannemann \& Van Stempvoort, 2016). An estimated $5-25 \%$ of the total water inflow to the Great Lakes occurs via indirect discharge of groundwater to the lakes and their accompanying tributaries (Robinson, 2015). The dynamics of nutrient-enriched groundwater and its effects on receiving surface waters remain uncertain, despite the recent increase in studies suggesting that groundwater is a key contributing factor for the overall quality and state of the Great Lakes and their tributaries (Grannemann \& Van Stempvoort, 2016). Given such, this research aims to contribute to the understanding of groundwater as a source of nutrients to surface water bodies in agricultural areas within the GLB, particularly in a typical clay plain setting.

Groundwater-surface water interactions play a critical role in nutrient fluxes in watersheds; however, these interactions are difficult to evaluate due to their extremely high temporal and spatial variability and are therefore often neglected in watershed-scale studies (Robinson, 2015). Intense biogeochemical and/or hydrological activity that occurs in localized zones ("hot spots") or periods of time ("hot moments") within the hydrological system often exert the greatest control on the regulation of surface water and groundwater quality (Robinson, 2015; Grannemann \& Van Stempvoort, 2016). The hyporheic zone, a subsurface region represented by the exchange between surface stream water and groundwater, has been demonstrated to have a significant effect in the processing and transformation of nutrients across the sediment-water interface due to concentrated biogeochemical activity (Dahm et al., 1998; Lapworth et al., 2011; Grannemann \& Van Stempvoort, 2016). The understanding of how these interactions regulate the dynamics of groundwater nutrients into receiving 
waters, specifically through the hyporheic zone, is essential to elucidate nutrient contamination hotspots. The identification of these hotspots will further the evolution and adaption of environmentally sustainable nutrient and land management strategies.

This objective of this research is to contribute to the understanding of spatial and temporal variations of $P$ and nitrate, the variability in nutrient dynamics and hydrologic connection in the hyporheic zone, and the relationships between water quality observations and land management practices in an agriculturally dominated clay plain system within the GLB. A year-long field-based study of principal nutrient transport pathways and hydrologic systems within the agriculturally-dominant $127 \mathrm{~km}^{2}$ Upper Parkhill watershed in southern Ontario, Canada was executed to identify nutrient contamination hotspots, in both time and space. Additional data includes climate information from an Integrated Water and Climate Monitoring Station and watershed-specific land management practices. The methodology and results from this research can be applied in hydrologically-similar clay plain systems. Identifying where and when nutrient-related water-quality issues are most likely to occur is fundamental for developing pertinent watershed and land management plans. Establishing the dynamics and transport of nutrients in groundwater and surface water is therefore crucial for refining and executing strategies and programs devised to conserve water resources within the GLB.

\subsection{Study site}

\subsubsection{Site description}

The research was conducted in the Upper Parkhill watershed, which is a climate-sensitive (MacRitchie, 2011), agriculturally intensive watershed located in southwestern Ontario (Figure 3-1). The Upper Parkhill watershed is $127 \mathrm{~km}^{2}$ in area and forms a long, slender Lshaped drainage basin. Parkhill Creek, a tributary of Lake Huron, is the main surface water feature in the watershed. The watershed includes portions of the municipalities of North Middlesex, South Huron, and Bluewater and is within the jurisdiction of Ausable Bayfield Conservation Authority (ABCA). 
A

B

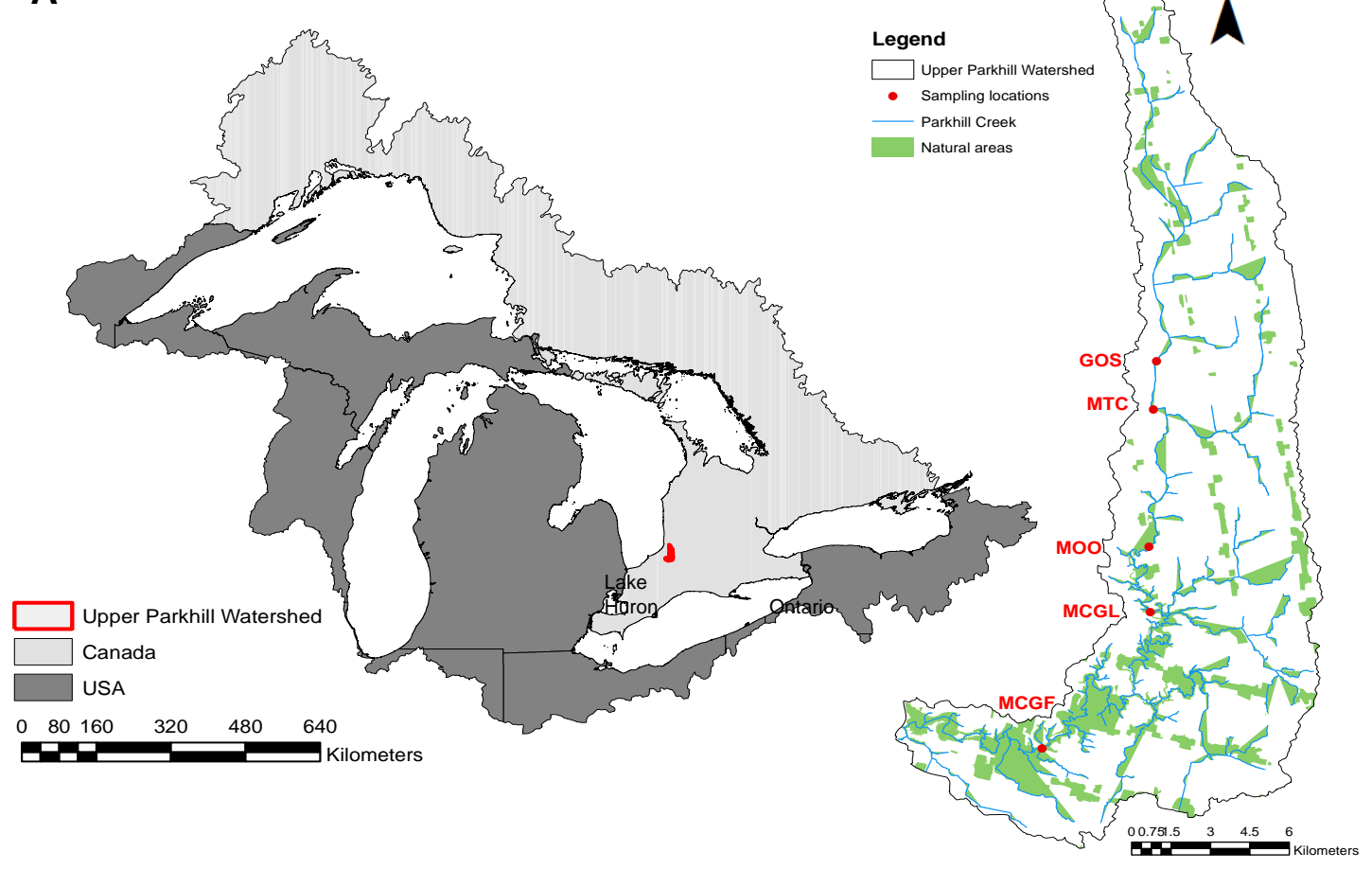

C

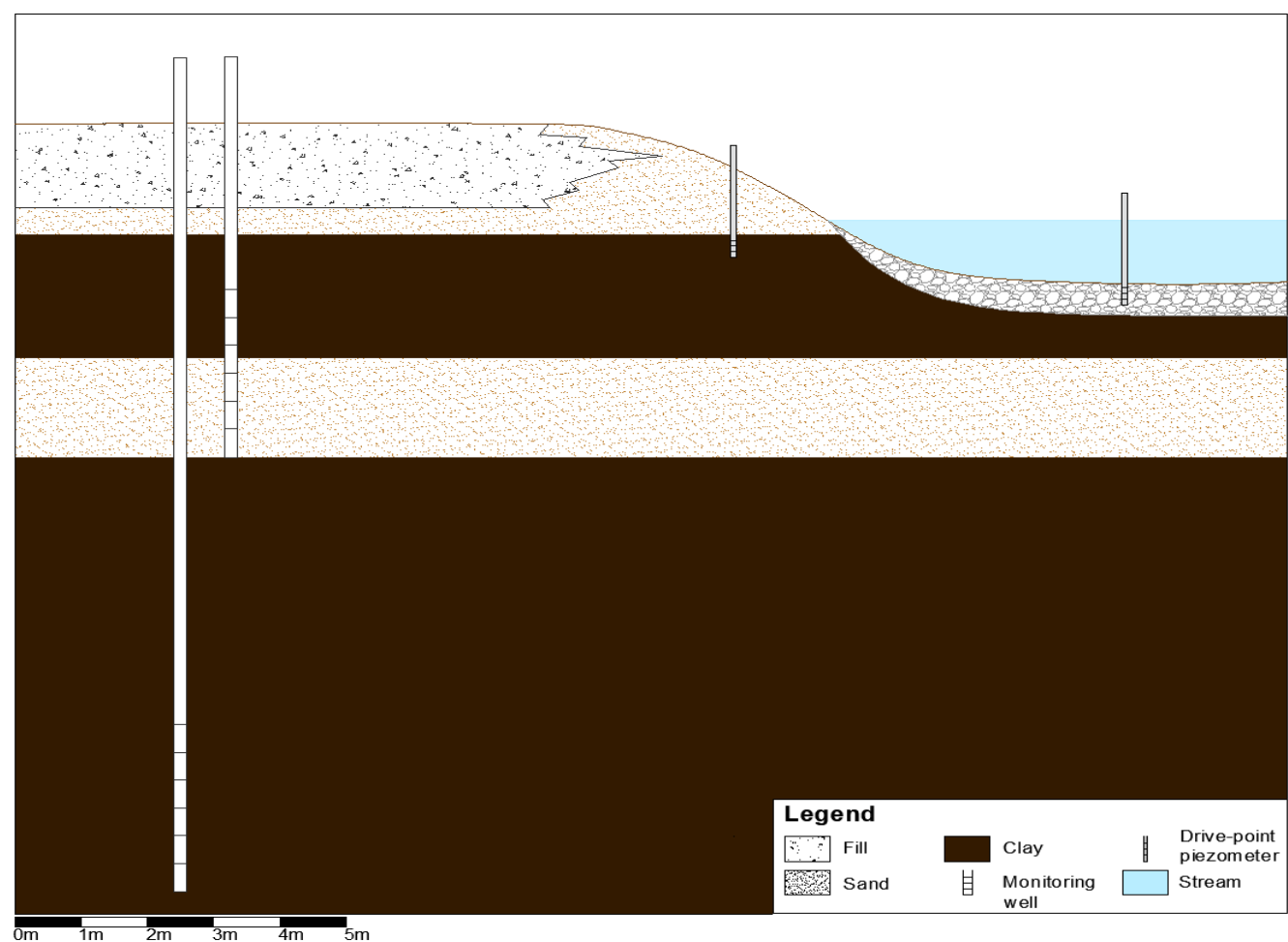

Figure 3-1: A) Upper Parkhill Watershed in relation to the Canadian and American boundaries of the Great Lakes Basin. B) Upper Parkhill Watershed with sampling locations (red) and natural areas (green). C) Conceptual model of site instrumentation at the Mooresville location, including groundwater wells and drivepoint piezometers. 
Surface water concentrations of $\mathrm{P}$ in the watershed have declined significantly over the past three decades; however, median TP concentrations remain substantially higher than the PWQO of $0.03 \mathrm{mg} / \mathrm{L}$ (Steele \& Veliz, 2007; Government of Ontario, 2019). A recent study has highlighted the elevated $\mathrm{P}$ concentrations in Parkhill Creek, with an observed $75^{\text {th }}$ percentile TP concentration of $0.105 \mathrm{mg} / \mathrm{L}$ (Ausable Bayfield Conservation Authority, 2018). An increasing trend in nitrate concentrations in Parkhill Creek has been observed since 1985, with median concentrations greater than the concentration set for the protection of aquatic ecosystems (2.95 $\mathrm{mg} \mathrm{NO}_{3}-\mathrm{N}$ (nitrate-N)/L) (Steele \& Veliz, 2007). Limited information is available regarding the quality of overburden groundwater quality within the watershed, aside from one Provincial Groundwater Monitoring Network (PGMN) well. Concentrations of TP at this groundwater monitoring location have fluctuated since sampling began in 2003, but have continuously exceeded $0.03 \mathrm{mg} / \mathrm{L}$ (Government of Ontario, 2019). Groundwater concentrations of nitrate, conversely, have been considered insignificant with respect to the aquatic protection limit and drinking water standards (Steele \& Veliz, 2007; Government of Ontario, 2019).

\subsubsection{Land use}

Land use in the watershed comprises $76 \%$ agriculture, 23\% natural, 1\% urban (Ausable Bayfield Conservation Authority, 2018). Forest covers approximately $14 \%$ of the watershed, with wooded areas concentrated in the southern extents of the watershed where ABCA land predominates (Ausable Bayfield Conservation Authority, 2018). Streamside forest cover, the amount of forest cover that is within a $30 \mathrm{~m}$ zone on both sides of an open watercourse, is approximately $40 \%$ for the Upper Parkhill watershed (Ausable Bayfield Conservation Authority, 2018). Minimal natural vegetation exists within the watershed, particularly in the northern section, thus giving rise to scarce natural riparian zones bordering surface water bodies (Figure 3-1B).

Corn, soybeans, and winter wheat are the main crops in the watershed, with approximately $92 \%$ of the agricultural land under a variation of corn-soybean-wheat rotation (Agriculture and Agri-Food Canada, 2019). In 2018, 29\% of the total watershed area was soybean crop, $27 \%$ corn, and 16\% winter wheat (Figure 3-2A) (Agriculture and Agri-Food Canada, 2019). This is similar to 2017 , where corn represented $33 \%$ of the total area, soybean $25 \%$, and winter wheat 19\% (Figure 3-2B) (Agriculture and Agri-Food Canada, 2019). The remainder of 
agricultural land is typically comprised of fallow, assorted vegetables and beans, and pasture/forages. According to recent aerial photography, overwinter vegetative cover on agricultural lands in the area varies between 9 to 19\% (Ausable Bayfield Conservation Authority, 2018).

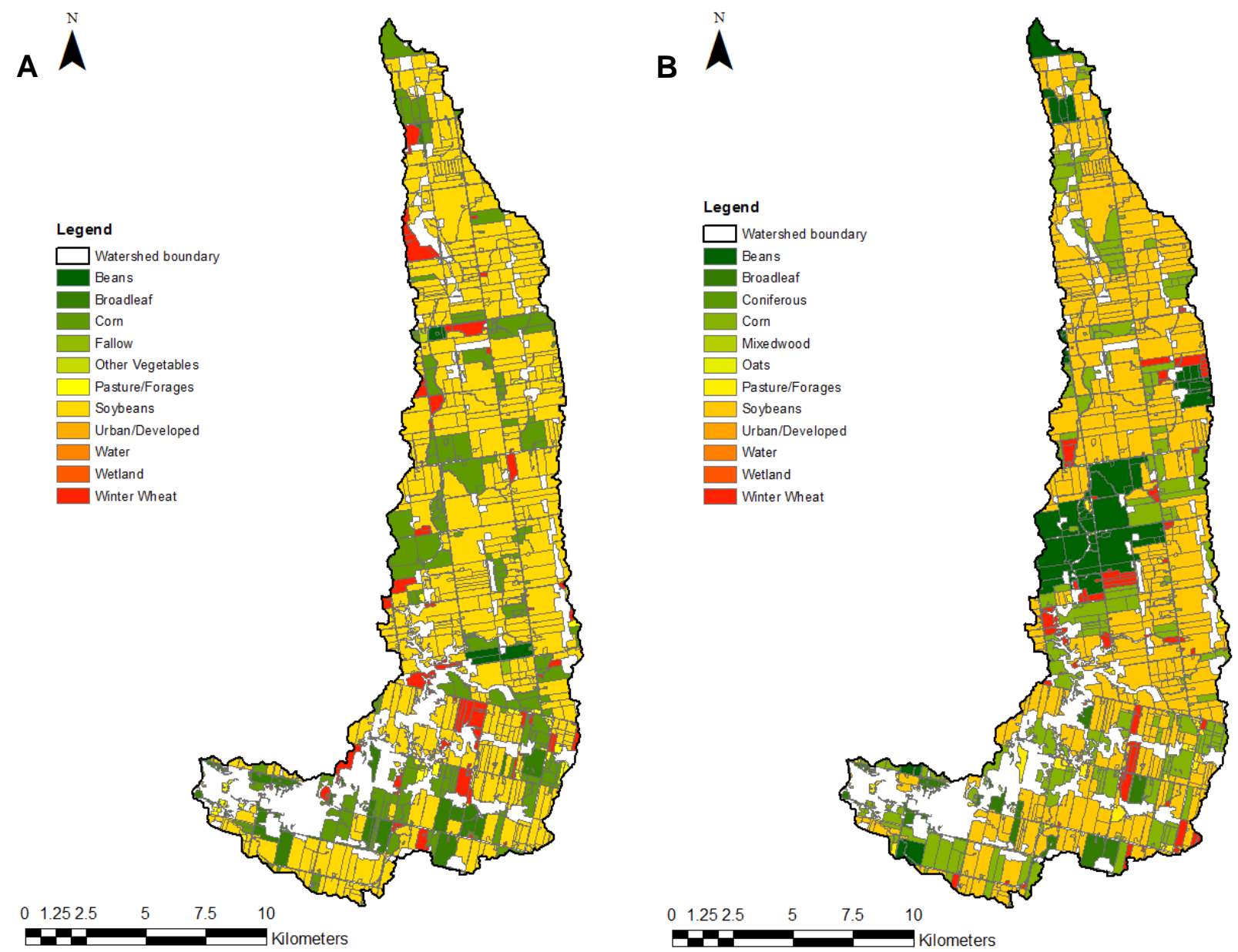

Figure 3-2: A) Land use distribution in the Upper Parkhill Watershed in 2017 and B) 2018 (Agriculture and AgriFood Canada, 2019).

Corn is typically planted from late April to late May in the watershed and is harvested starting mid-October to mid-November. Soybean planting generally occurs in early May to early June and is harvested from mid-September to mid-November. Winter wheat is commonly planted during the period from mid-September to mid-October and harvesting starts mid-July.

\subsubsection{Geology}

The Upper Parkhill watershed is generally flat to mildly undulating and is comprised primarily of till moraines $(82 \%)$, with minor bevelled till plains $(12 \%)$, sand plains $(1 \%)$, and beaches and shorecliffs (1\%) (Ausable Bayfield Conservation Authority, 2007). The moraines were 
produced by the glacial processes of the Huron Lobe, and are typically characterized as large, continuous features that mirror the form of the shoreline of Lake Huron (Cooper, 1979; Dillon Consulting Limited, 2004). The overburden consists of Quaternary deposits of fine-grained unconsolidated sediments (Dillon Consulting Limited, 2004). The Port Huron Stadial, a stade of the Late Wisconsinan quaternary deposits, can be found near Parkhill and comprises primarily of the St. Joseph Till (Figure 3-3A) (Cooper, 1979; Dillon Consulting Limited, 2004). This deposit is generally grey to yellowish brown in colour with a silt to silty clay matrix with varying clay content and little carbonate (Cooper, 1979; Dillon Consulting Limited, 2004). Lenses and inclusions of lacustrine silt and clay have been observed within this unit (Cooper, 1979). The overburden has a thickness ranging from 40$65 \mathrm{~m}$ (Cooper, 1979).

The bedrock within the watershed is from the Dundee Formation and is not exposed at any location (Dillon Consulting Limited, 2004; Singer et al., 2003). This unit consists predominantly of brown limestone with fossils and has an average thickness of $35-45 \mathrm{~m}$ (Dillon Consulting Limited, 2004). Surface elevations range from approximately 250-170 meters above sea level (masl) (Cooper, 1979). 


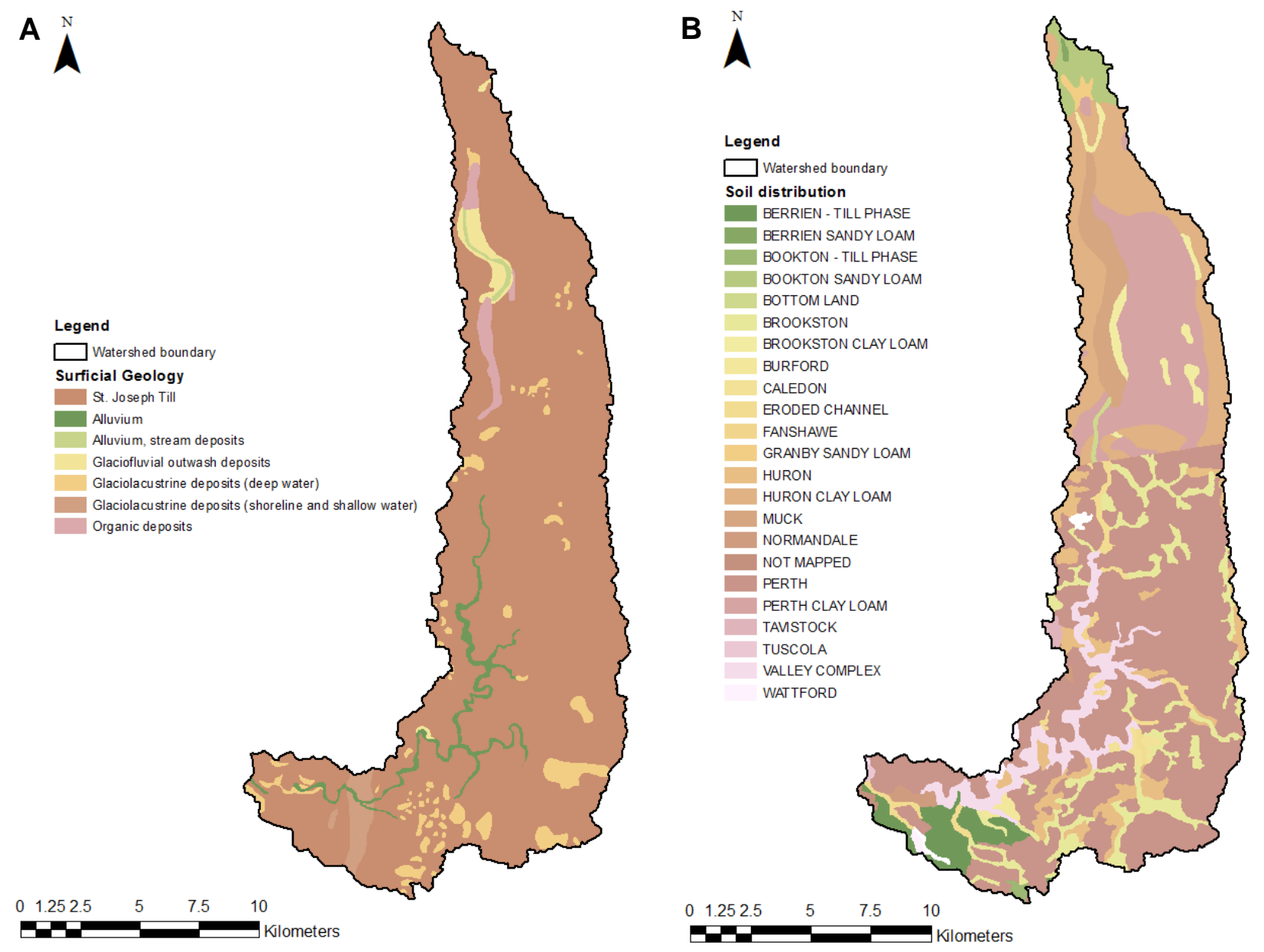

Figure 3-3: A) Surficial geology in the Upper Parkhill Watershed (Canadian Soil Information Service, 2013). B) Soil distribution in the Upper Parkhill Watershed (Canadian Soil Information Service, 2013).

The soils in this area predominantly consist of silty loam and clay loam, with lesser loam, sandy loam and silty loam and are of the Huron, Brookston and Perth series (Figure 3-3B) (Ausable Bayfield Conservation Authority, 2007; Dillon Consulting Limited, 2004). Soils in the watershed are considered to have little to no limitations for crop use and are therefore capable of effective sustained use for cultivated field crops (Agriculture Canada, 1975). However, due to the low permeability of these soils, a significant portion $(71.3 \%$, Land Information Ontario, 2015) of the Upper Parkhill watershed is tile drained (Figure 3-4). The use of surface and subsurface artificial drainage features in poorly drained soils mitigates flooding of agricultural fields, thus is widely adopted in this agriculturally intensive area. 


\subsubsection{Drainage characteristics \& general hydrology}

Parkhill Creek is the main surface water feature in the watershed and outlets directly to Lake Huron at Grand Bend through a channel constructed in 1892. A reservoir and dam were constructed at the outlet of the watershed in 1969 to regulate the flow of water in Parkhill Creek. Parkhill Creek is approximately $76 \mathrm{~km}$ long with an average gradient of $1.03 \mathrm{~m} / \mathrm{km}$ (Luinstra et al., 2008). The creek is separated from the bedrock aquifer with a substantial succession of the St. Joseph Till deposit (Ausable Bayfield Conservation Authority, 2007).

The limestone bedrock aquifer represents the only significant source of groundwater in the watershed (Ausable Bayfield Conservation Authority, 2007). Groundwater from this aquifer supplies most of the drinking water in this region; however, there are some less extensive shallow aquifers that can also be exploited as a source for dug or bored wells in the area (Ausable Bayfield Conservation Authority, 2007). 


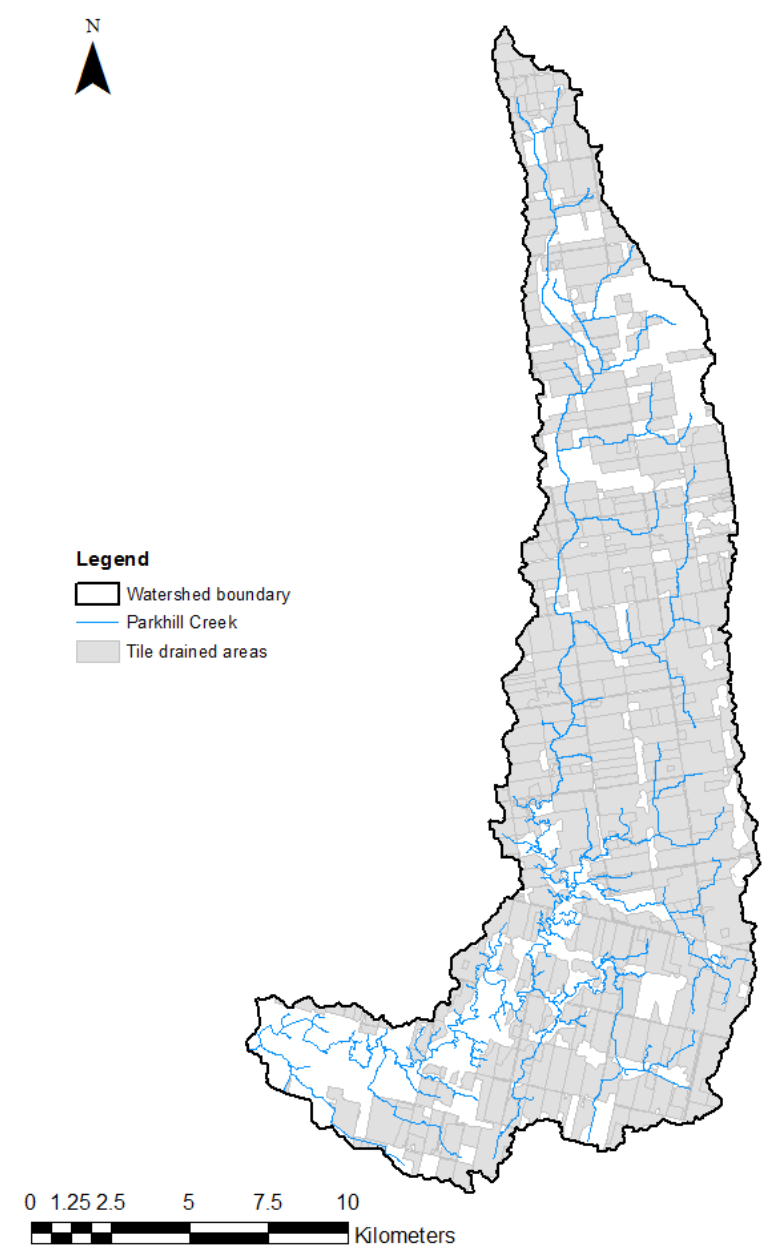

Figure 3-4: Tile drained areas and main surface water feature, Parkhill Creek, in the watershed (Land Information Ontario, 2015).

\subsection{Methods}

\subsubsection{Research design}

Five study sites (Figure 3-1B) were selected to monitor the quality of surface and subsurface water across the watershed. Samples were collected generally on a monthly basis over a one-year study period (June 2018 to May 2019) to observe nutrient concentrations and speciation with respect to the interaction of agriculture with hydrological systems.

\subsubsection{Study sites}

The principal research site, McGuffin (MCGF), is located at an Integrated Water and Climate Monitoring station established in collaboration with the Ontario Ministry of the Environment, 
Conservation and Parks (MECP) and the Ausable Bayfield Conservation Authority in 2012. This station serves to provide long-term continuous monitoring of water and climate data, which is used to evaluate the impacts of climate change on a climate sensitive watershed. The site was host to an existing Water Survey of Canada stream flow station, wherein an additional 28 instruments were installed in 2012 to continuously monitor surface water, groundwater, soil, and climate conditions. Two wells, a shallow (6.7 m deep) and a deep (15.85 m deep), were also installed at the station in late 2011. These wells are used for discrete (monthly) and continuous sampling, as well as the continuous monitoring of various parameters. Three drive-points (approximately $2 \mathrm{~m}$ deep) located in the floodplain adjacent to Parkhill creek are also continuously monitored regarding water levels and sampled monthly when there are sufficient water yields.

Two of the sites used solely for surface water sampling, McGillivray (MCGL) and Mount Carmel (MTC), were chosen in a previous study completed in the watershed (Rixon, 2018). The sites were selected to represent variable riparian zones along Parkhill Creek. McGillivray is situated approximately $5 \mathrm{~km}$ upstream from MCGF and has some surrounding natural vegetation with agricultural land nearby. Mount Carmel is located approximately $12 \mathrm{~km}$ upstream from MCGF and has a very little natural riparian zone, while dominantly surrounded by agricultural land.

The additional sites, Mooresville (MOO) and Goshen (GOS), were selected as supplementary water quality sampling locations in June 2018. These locations were chosen based on the predominance of surrounding agricultural land, the minimal extent of natural riparian zones, as well as their capacity for the installation of monitoring wells adjacent to Parkhill Creek. Two wells, a shallow (6 metres below ground surface (mbgs)) and a deep (13.7-16.8 mbgs), were installed at both sites (four total) in October 2018 (Figure 3-1C) to allow for a more comprehensive analysis of nutrient transport and groundwater-surface water interactions throughout the watershed. The wells were installed by Profile Drilling Inc. using rotosonic drilling. Sampling of the surface water at these two locations began in June 2018, while the groundwater sampling commenced following the installation of the wells in October 2018. Two drive-point piezometers were installed in the streambed at MOO in September 2018, upon which sampling and estimation of hydraulic gradients began. 


\subsubsection{Subsurface characterization}

There are six groundwater monitoring wells located within the watershed that were used for water quality sampling and subsurface characterization. Two wells were previously installed at the MCGF site, with total depths of $6.7 \mathrm{~m}$ (shallow well) and $15.85 \mathrm{~m}$ (deep well). The wells are screened from 2.15 to $6.70 \mathrm{mbgs}$ and 14.3 to $15.85 \mathrm{mbgs}$ for the shallow and deep well, respectively. Both wells are equipped with a $0.10 \mathrm{~m}$ diameter PVC screen (\#10), with the remainder of the hole finished with $0.10 \mathrm{~m}$ PVC casing. The screen and casing for the two wells were packed with sand $(00 \mathrm{~N})$ extending from $2.15 \mathrm{mbgs}$ to the bottom of each hole to enhance the recovery of the well during water quality sampling (Huron Geosciences, 2011). The subsurface material encountered at this location consists of brown, very fine-grained silty clay (St. Joseph's Till). The average hydraulic conductivity $(K)$ for the shallow and deep well is $1.15 \mathrm{E}-7 \mathrm{~m} / \mathrm{s}$ and $6.33 \mathrm{E}-8 \mathrm{~m} / \mathrm{s}$, respectively (Rixon, 2018). Borehole logs of the two wells can be found Appendix B-2.

Four additional wells, one shallow and one deep at each location, were installed at GOS and $\mathrm{MOO}$ in October 2018 via rotosonic drilling. The shallow well at GOS was completed to a total depth of $6 \mathrm{~m}$, with a screen extending from 3 to $6 \mathrm{mbgs}$. The length of the screen ( $3 \mathrm{~m}$ total) was packed with sand $(00 \mathrm{~N})$. The deep well at GOS was completed to a total depth of 16.8 $\mathrm{m}$, with a screen extending from 13.8 to $16.8 \mathrm{mbgs}$. The screen and approximately $1.5 \mathrm{~m}$ of the casing above the screen were packed with sand for the deep well, thus extending from the bottom of the hole to $12.2 \mathrm{mbgs}$. The subsurface material encountered during the completion of these wells was brown clay ( 0.6 to $4.9 \mathrm{mbgs}$ ), and grey clay (4.9 to $7.62 \mathrm{mbgs}$ ), followed by grey clay till (7.62 mbgs to bottom of borehole). Both wells are equipped with a $0.05 \mathrm{~m}$ diameter PVC screen (\#10), with the remainder of the hole furnished with 0.05 PVC casing. Borehole logs of the two wells can be found Appendix B-2.

At the MOO site, the two wells were installed to total depths of $6.7 \mathrm{~m}$ (shallow well) and 13.7 $\mathrm{m}$ (deep well). The wells are screened from 3 to $6 \mathrm{mbgs}$ and 9.1 to $13.7 \mathrm{mbgs}$ for the shallow and deep well, respectively. Both wells are equipped with a $0.05 \mathrm{~m}$ diameter PVC screen (\#10), with the remainder of the hole furnished with $0.05 \mathrm{~m}$ PVC casing. The total length of the screen was packed with sand $(00 \mathrm{~N})$ for the shallow well, and the deep well was packed from the bottom of the screen to approximately $0.5 \mathrm{~m}$ above the screen. The subsurface material encountered during the completion of these wells was fill ( 0 to $2.5 \mathrm{mbgs}$ ), coarse 
brown sand ( 2.5 to $2.8 \mathrm{mbgs}$ ), brown clay till (2.8 to $4.2 \mathrm{mbgs}$ ), coarse brown sand (4.2 to 5.9 mbgs), followed by brown clay till (5.9 to $13.7 \mathrm{mbgs}$ ). Borehole logs of the two wells can be found Appendix B-2.

Slug tests, both rising and falling head, were conducted on the pair of shallow and deep wells at the GOS and MOO sites in which a known volume of water was added or removed to/from the wells. The response of each well was analyzed using the Hvorslev Slug-Test Method (Hvorslev, 1951) in AquiferTest (Waterloo Hydrogeologic, 2016) to estimate the hydraulic conductivity of subsurface material at the research sites. The aquifer was assumed to be a homogeneous, isotropic and infinite medium for the purpose of this analysis. Results of these tests can be found in Section 3.8.7.

The vertical travel time of a water "particle" to the water table and horizontal travel time within the aquifer were also calculated using various analytical methods. These travel times elucidate the approximate travel time of phosphorus or nitrate, assuming a conservative behaviour of these nutrients, from agricultural land to adjacent surface water bodies (the receptor) via the subsurface and are found in Section 3.8.7. A recharge value of $206 \mathrm{~mm} / \mathrm{year}$ (Ausable Bayfield Maitland Valley, 2008) was chosen for these calculations from a water budget study of watersheds within the ABCA jurisdiction.

The travel time of water through the unsaturated zone from ground surface to the water table was calculated using two methods: "no-flow" van Genuchten and Surface to Aquifer Advection Time (SAAT) (Province of Ontario, 2006; Sousa et al., 2013). No-flow conditions were assumed in the unsaturated zone for the van Genuchten equation to allow for an approximation of the saturation profile, which was then used to calculate the unsaturated zone travel time. Values for residual saturation $\left(\mathrm{S}_{\mathrm{r}}\right)$, A (an empirical coefficient related to poresize distribution), and effective porosity ( $\left.n_{e}\right)$ were based on data from Sousa et el. (2013). The second method, SAAT (Province of Ontario, 2006), also directly estimates the travel time from ground surface to the water table using a simple calculation using preestablished values for the mobile moisture content. The mobile moisture content is outlined in Province of Ontario (2006) and is correlated to soil textures.

The saturated zone travel time from the source and the receptor, in this case a surface water body, was estimated using a straight-line approximation (Sousa et al., 2013). This method 
approximates a straight-line travel path for the water particle, with a few major assumptions: (1) the steady-state flow occurs in a homogeneous unconfined aquifer, (2) the hydraulic gradient is constant along the travel path, and (3) a horizontal straight-line is a suitable approximation of the travel path from the source to the receptor (Sousa et al., 2013). A distance of $25 \mathrm{~m}$ was assumed for the length between the water table underneath an agricultural field and an adjacent surface water body.

\subsubsection{Water chemistry \& quality}

Sampling of the water phase from groundwater, surface water, hyporheic zone, and tile flow locations was completed from June 2018 to May 2019.

Monthly surface water samples were collected manually via grab sampling at each of the five locations along Parkhill Creek (Figure 3-1B). Field parameters, including water temperature, specific electrical conductivity (EC), dissolved oxygen (DO), $\mathrm{pH}$, and oxygen reduction potential (ORP), were measured using the YSI Multi-Parameter-Probe Model 556 ${ }^{\mathrm{TM}}$. All samples were collected in new $500 \mathrm{~mL}$ high density polyethylene (HDPE) plastic bottles, which were rinsed three times with surface water at the location prior to collecting the final sample. Samples and field parameters were obtained from approximately the center of the stream, when possible; however, in high flow events and frozen environments they were collected from near the streambank as a safety precaution.

Groundwater samples were collected using a Grundfos (Grundfos Redi-Flo2) submersible pump. The static water level was measured in each well prior to sampling. Given the nature of the screened units at each of the study sites (very low transmissivity), each monitoring well was purged to a volume equivalent to the standing water present in the well casing and discarded. Groundwater was then subsequently pumped into a clean bucket and field parameters (water temperature, specific electrical conductivity, $\mathrm{DO}, \mathrm{pH}$, and $\mathrm{ORP}$ ) were obtained using the YSI Multi-Parameter-Probe Model $556^{\mathrm{TM}}$. Once stabilized (specifically DO and EC), the field parameters were recorded, and groundwater samples were collected in new, triple-rinsed bottles.

Shallow groundwater samples were also obtained from four drive-point piezometers located at two of the study sites (MCGF and MOO). Due to the low transmissivity of the overburden and the length of which the drive-points are screened, the drive-points typically yielded 
substantially less water than the monitoring wells. Accordingly, extensive purging of these drive-points was unfeasible. Samples were collected in new, triple-rinsed bottles using a Geotech (Geotech Geopump ${ }^{\mathrm{TM}}$ Peristaltic Pump) peristaltic pump and stabilized field parameters were recorded.

Sampling of the water in the hyporheic zone was conducted via two drive-point piezometers installed in the streambed at the MOO location (Figure 3-1C). These piezometers were installed approximately $0.50 \mathrm{~m}$ into the streambed in September 2018. Similarly, these drivepoints did not yield sufficient water to allow for extensive purging prior to sampling. Samples were collected in new, triple-rinsed bottles using HDPE tubing and a new, sterile syringe. Stabilized field parameters were recorded upon retrieval of the sample. The static water level in the drive-point and of the adjacent stream was measured preceding sampling to determine the vertical hydraulic gradient at each point at the time of collection.

Sampling of discharge from a tile outlet occurred manually, when flowing, approximately once a month from August 2018 to May 2019. This tile drain is located approximately $400 \mathrm{~m}$ southeast of the MTC location and serves as the primary outlet for the Lewis Drain in the watershed. Manual samples were taken into new, triple-rinsed bottles and analyzed for both $\mathrm{P}$ and $\mathrm{N}$ parameters. Tile sampling dates with respect to total daily precipitation in the watershed is found in Figure 3-5. 


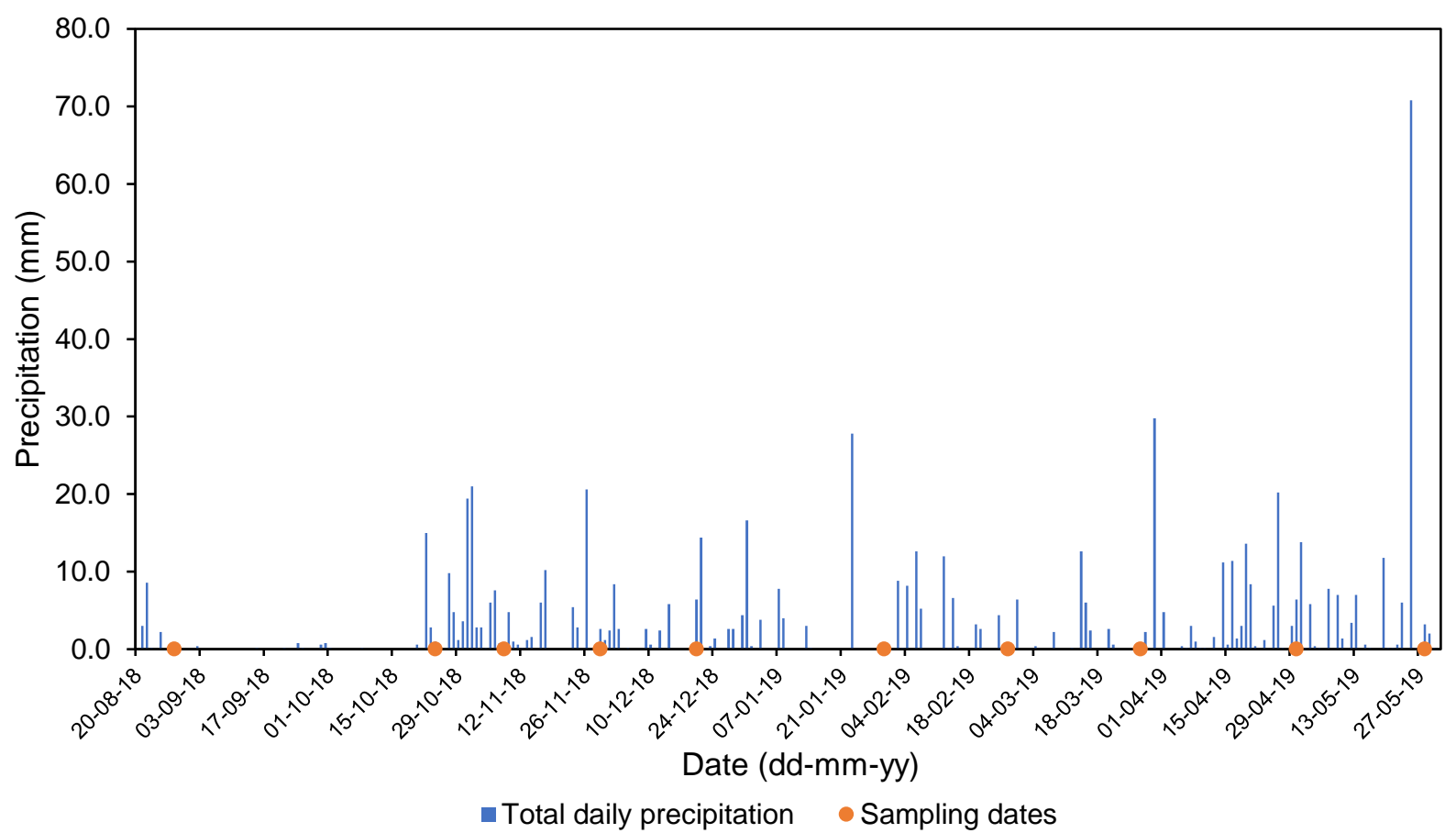

Figure 3-5: Total daily precipitation in the watershed with corresponding sampling dates for the tile outlet water.

Immediately following the collection of each sample, the sample bottle was placed into a cooler on ice. Upon return from the field after each sampling event, the samples were left in the cooler and placed in a refrigeration unit $\left(4^{\circ} \mathrm{C}\right)$ until submission to the analytical lab. Water samples were analyzed for total phosphorus, total dissolved phosphorus, soluble reactive phosphorus, and major anions $\left(\mathrm{NO}_{3}{ }^{-}, \mathrm{Cl}^{-}\right.$, and $\left.\mathrm{SO}_{4}{ }^{2-}\right)$. Total $\mathrm{P}, \mathrm{TDP}$, and SRP samples were sent to SGS Canada Inc., Lakefield, Ontario for analysis. Particulate $P$ was estimated as the difference between TP and TDP. Major anions were analyzed using ion chromatography in a School of Engineering Laboratory at the University of Guelph. A summary of sampling protocol and analysis methods for these parameters can be found in Table 3-1. Replicate samples for surface and groundwater were analyzed in May 2019. All samples were within an acceptable limit, $\leq 20 \%$ for water (Maxxam, 2015), for respective relative percent differences (RPD). The RPDs were calculated using Eq. 3, where $X_{1}$ and $X_{2}$ are concentrations of replicate samples.

$$
R P D=\frac{\left|X_{1}-X_{2}\right|}{\left(\frac{X_{1}+X_{2}}{2}\right)} \times 100(3)
$$


Table 3-1: Methods of analysis for various phosphorus species and anions in water samples.

\begin{tabular}{|c|c|c|c|}
\hline Parameter & Collection procedure & Analysis & $\begin{array}{c}\text { Detection } \\
\text { limit }\end{array}$ \\
\hline $\begin{array}{l}\text { Total } \\
\text { phosphorus } \\
\text { (TP) }\end{array}$ & $\begin{array}{l}\text { Collected with minimal headspace into a } \\
\text { new, triple rinsed HDPE plastic bottle. Bottle } \\
\text { is stored in the dark at approximately } 4^{\circ} \mathrm{C} \\
\text { until submission to the lab. }\end{array}$ & $\begin{array}{l}\text { TP aqueous samples are initially acidified to } \mathrm{pH}<2 \text { using } \\
\text { concentrated sulfuric acid. TP concentrations are } \\
\text { determined using a Skalar segmented flow autoanalyzer. A } \\
\text { digestion agent is added to the water sample to digest any } \\
\text { organically bound phosphorus to be released as phosphate. } \\
\text { A molybdate reagent reacts in an acidic medium with the } \\
\text { dilute solutions of phosphate to form a phosphomolybdate } \\
\text { complex. This complex is reduced to an intense blue colour } \\
\text { complex with ascorbic acid and is measured } \\
\text { colourimetrically at } 880 \mathrm{~nm} \text {. (SGS, 2018a). }\end{array}$ & $0.003 \mathrm{mg} / \mathrm{L}$ \\
\hline $\begin{array}{l}\text { Total } \\
\text { dissolved } \\
\text { phosphorus } \\
\text { (TDP) }\end{array}$ & $\begin{array}{l}\text { Collected with minimal headspace into a } \\
\text { new, triple rinsed HDPE plastic bottle. Bottle } \\
\text { is stored in the dark at approximately } 4^{\circ} \mathrm{C} \\
\text { until submission to the lab. }\end{array}$ & $\begin{array}{l}\text { TDP concentrations were determined in the same manner } \\
\text { as TP; however, the samples are first filtered through .45 } \mu \mathrm{m} \\
\text { filter and then preserved to a } \mathrm{pH}<2 \text {. (SGS, 2018a). }\end{array}$ & $0.003 \mathrm{mg} / \mathrm{L}$ \\
\hline $\begin{array}{l}\text { Soluble } \\
\text { reactive } \\
\text { phosphorus } \\
(\mathrm{SRP})\end{array}$ & $\begin{array}{l}\text { Collected into a new, triple rinsed } 60 \mathrm{~mL} \\
\text { HDPE plastic bottle following the field } \\
\text { filtering }(0.45 \mu \mathrm{m} \text { filter) from a clean plastic } \\
\text { bottle. Sample is collected with minimal } \\
\text { head space and stored in the dark at } \\
\text { approximately } 4^{\circ} \mathrm{C} \text { until submission to the } \\
\text { lab. }\end{array}$ & $\begin{array}{l}\text { Samples were field filtered through a } 0.45 \mu \mathrm{m} \text { filter prior to } \\
\text { analysis. SRP in aqueous samples was determined directly } \\
\text { by Skalar segmented flow autoanalyzer. Ammonium } \\
\text { molybdate and potassium tartrate react in an acidic medium } \\
\text { with diluted solutions of phosphate to form an antimony- } \\
\text { phospho-molybdate complex. This complex is reduced to an } \\
\text { intensely blue-coloured complex by ascorbic acid and is } \\
\text { measured colourimetrically at } 880 \mathrm{~nm} \text {. (SGS, 2018b). }\end{array}$ & $0.03 \mathrm{mg} / \mathrm{L}$ \\
\hline $\begin{array}{l}\text { Major ions: } \\
\text { nitrate, } \\
\text { chloride, } \\
\text { sulphate }\end{array}$ & $\begin{array}{l}\text { Collected into a } 60 \mathrm{~mL} \text { plastic bottle, leaving } \\
\text { minimal head space, and stored in the dark } \\
\text { at approximately } 4^{\circ} \mathrm{C} \text { until analysis. }\end{array}$ & $\begin{array}{l}\text { Analysis completed at the University of Guelph using Dionex } \\
\text { ICS } 2000 \text { ion chromatography system. Separation of the } \\
\text { anions was achieved using an lonPac AS18-RFIC (4x250 } \\
\mathrm{mm}) \text { column and an lonPac AG18-RFIC ( } 4 \times 50 \mathrm{~mm}) \text { guard } \\
\text { column. The columns were heated at } 30^{\circ} \mathrm{C} \text { with } 30 \mathrm{mM} \mathrm{KOH} \\
\text { eluent at } 1 \mathrm{~mL} / \mathrm{min} \text {. }\end{array}$ & $\begin{array}{l}\text { Min. }<0.5 \\
\mathrm{mg} / \mathrm{L} \text { on all } \\
\text { anions }\end{array}$ \\
\hline
\end{tabular}




\subsubsection{Continuous monitoring}

Present at two of the surface water sampling locations (MTC and MCGL), as well as the two wells located at MCGF, are VanEssen four electrode CTD-Divers (four total) which continuously measure specific electrical conductivity, temperature, and water levels every 15 minutes. Calibration of these divers was completed bi-monthly in the field.

Continuous monitoring stations were constructed at the MCGF site to collect data every 15 minutes from a Satlantic SUNA V2 and a YSI EXO multiparameter sonde located both in the stream and in the shallow groundwater well. The instream sensors were secured inside of a perforated PVC pipe affixed to a cinder block, which was then placed on the streambed in approximately the center of the creek.

The SUNA is a chemical-free UV sensor that measures in-situ nitrate concentrations with a detection limit of $0.004 \mathrm{mg} \mathrm{NO}_{3}-\mathrm{N} / \mathrm{L}$ in freshwater (Sea Bird Scientific, 2017). The SUNA experiences minimal drift $\left(<0.004 \mathrm{mg} / \mathrm{L} \mathrm{NO}_{3}-\mathrm{N} / \mathrm{L}\right.$ per hour of lamp time), and in consequence was only calibrated prior to deployment and was not calibrated in the field. However, the SUNA was retrieved monthly to clean the optical window using deionized water and a lint free cloth. The SUNA was deployed in the steam at MCGF from May to November 2018.

The YSI EXO multiparameter sondes collect continuous data in the creek and the shallow well for five parameters: temperature, $\mathrm{pH}$, specific conductivity, dissolved oxygen, and turbidity. The EXO in the shallow well was deployed in July of 2017 and has not been removed, excluding for calibration, since. The EXO was deployed in the creek from May to November 2018. The sensors for these sondes were calibrated bimonthly.

\subsection{Hydrometrics \& climate}

\subsubsection{Precipitation \& temperature}

The climatic conditions of the study area are influenced by its mid-content location and proximate and leeward direction to Lake Huron. The southern latitude of the watershed, in relation to Canada as a whole, promotes long growing seasons (May - October) (Luinstra et al., 2008). Continental hot summers and cold winters are moderated by the lake (Luinstra et al., 2008). The outcome is a mean daily temperature of $8.5^{\circ} \mathrm{C}$ in the region (Environment and Climate Change Canada, 2018). 
The location of the watershed favours precipitation levels among the highest in the Great Lakes basin (Luinstra et al., 2008). The area receives an average of $159.9 \mathrm{~cm}$ of snow annually, and $803.4 \mathrm{~mm}$ of rainfall spread throughout the year (Environment and Climate Change Canada, 2018). Significant flooding in the region can occur following sudden spring melts heightened by rain on frozen ground (Luinstra et al., 2008).

Precipitation and air temperature were measured continuously in 15-minute intervals at the Integrated Water and Climate Monitoring station at the MCGF site (Figure 3-6). The total precipitation for the duration of the study (June 1, 2018 to May 31, 2019) was $790.4 \mathrm{~mm}$. Rainfall was significantly greater in the spring 2019 in comparison to fall 2018, with September being extremely dry $(3.2 \mathrm{~mm})$ and May being inordinately wet $(143.4 \mathrm{~mm})$ (Ontario Ministry of Natural Resources and Forestry, 2019). The average daily temperature during this time was $8.3^{\circ} \mathrm{C}$, with a daily average maximum and minimum temperature of $27.2^{\circ} \mathrm{C}$ and $19.8^{\circ} \mathrm{C}$, respectively.

Daily snow on the ground for the area was obtained from the Strathroy-Mullifarry station (Environment and Climate Change Canada, 2019), located approximately $20 \mathrm{~km}$ away from the MCGF site. While this climate station is not situated within the Upper Parkhill watershed, the data is assumed to be representative of general snow patterns in the area. Snow was sporadically accumulated on the ground from mid-November to late March, with a maximum snow depth of $24 \mathrm{~cm}$ on January 9, 2019. 


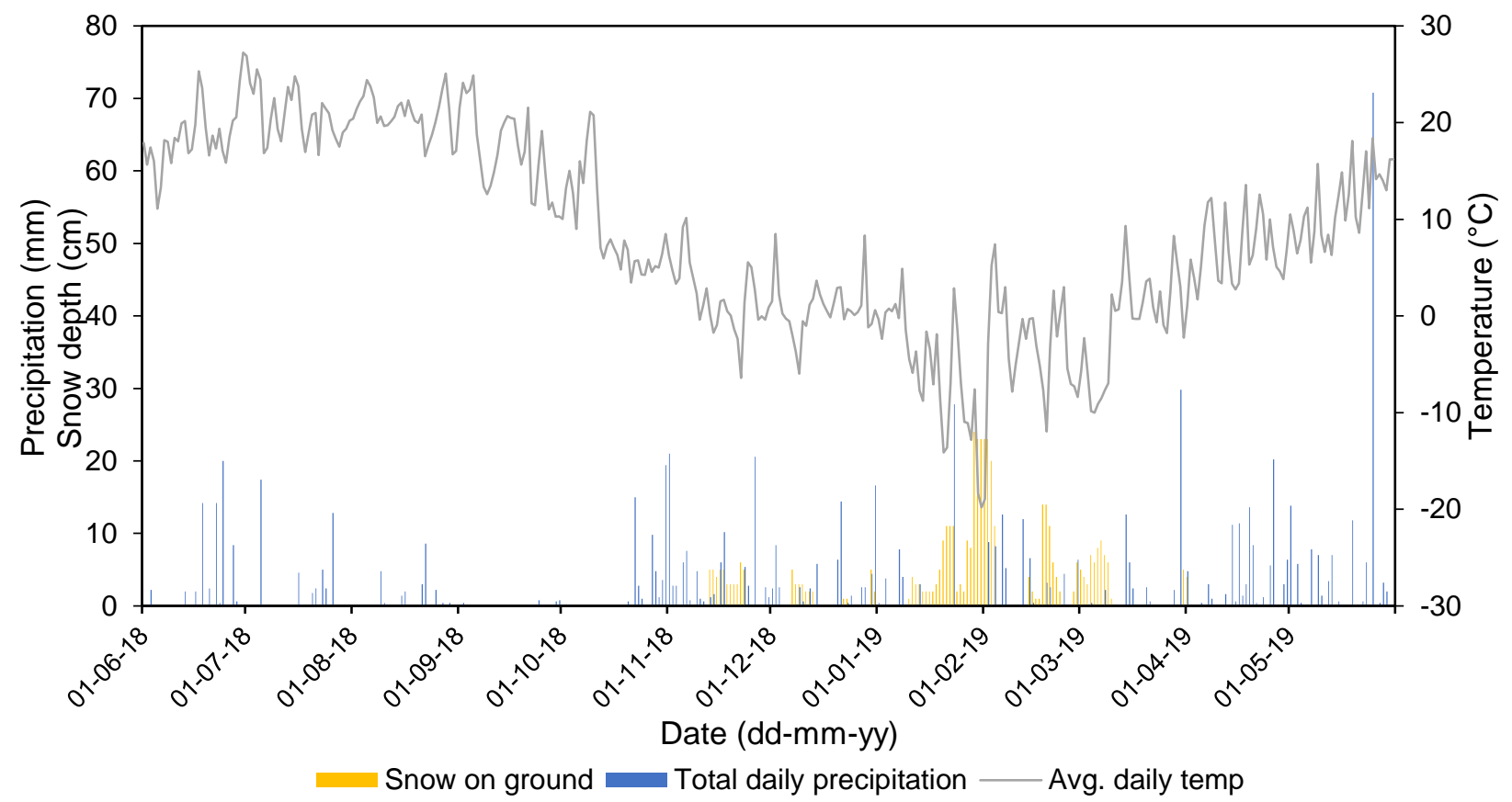

Figure 3-6: Total daily precipitation, total daily snow accumulation, and average daily temperature from June 1, 2018 to May 31, 2019 (Ontario Ministry of Natural Resources and Forestry, 2019; Environment and Climate Change Canada, 2019).

\subsubsection{Groundwater}

Groundwater elevations are recorded every 15 minutes for all six wells in the study area. Continuous measurements via CTD-Divers at the MCGF site have transpired since May 2017. Measurements at the four wells at GOS and MOO commenced in November 2018, following the installation of the Divers. These CTD-Divers record centimeters of water column that is compensated with barometric data, which is also recorded every 15 minutes the MCGF research site. This data was then adjusted to masl using the elevation of the Divers within each well.

The recorded water level elevations demonstrate that the monitoring wells responded to normal seasonal climatic fluctuations with higher elevations observed in the late fall through to the spring and lower levels in the summer and early fall. Furthermore, there is a similar trend in groundwater and surface water levels at MCGF suggesting that there may be connectivity between the two hydrological systems (Figure 3-7). 


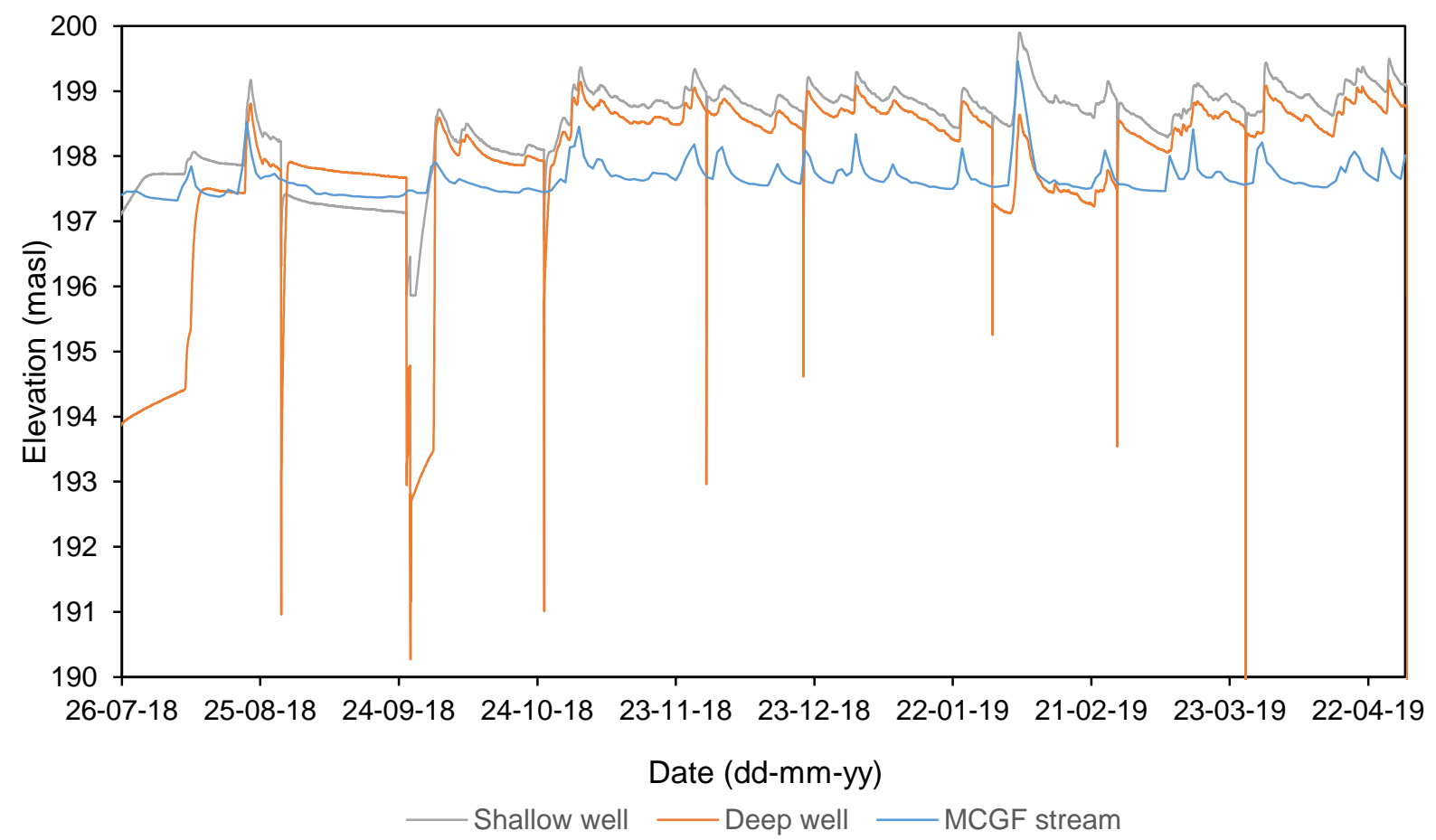

Figure 3-7: Daily average water levels of the two monitoring wells (shallow and deep) and surface water at the McGuffin (MCGF) research site.

\subsubsection{Surface water}

Stream discharge and primary water level are measured continuously every 15 minutes at a Water Survey of Canada stream gauge station in Parkhill Creek at the MCGF site (Figure 38). Flow within the stream fluctuates significantly from late fall through to the spring, corresponding to snow melt and heavy rains in these months. A maximum streamflow of 44.8 $\mathrm{m}^{3} / \mathrm{s}$ was observed on February 5, 2019 coinciding with an extensive melt event in the watershed. High evapotranspiration in the area typically lowers flows in the summer (Luinstra et al., 2008), with flow ceasing in certain reaches of Parkhill Creek from June-September. However, intense storms can produce large amounts of rain in the summer, thus causing peaks in streamflow during these low flow periods. 


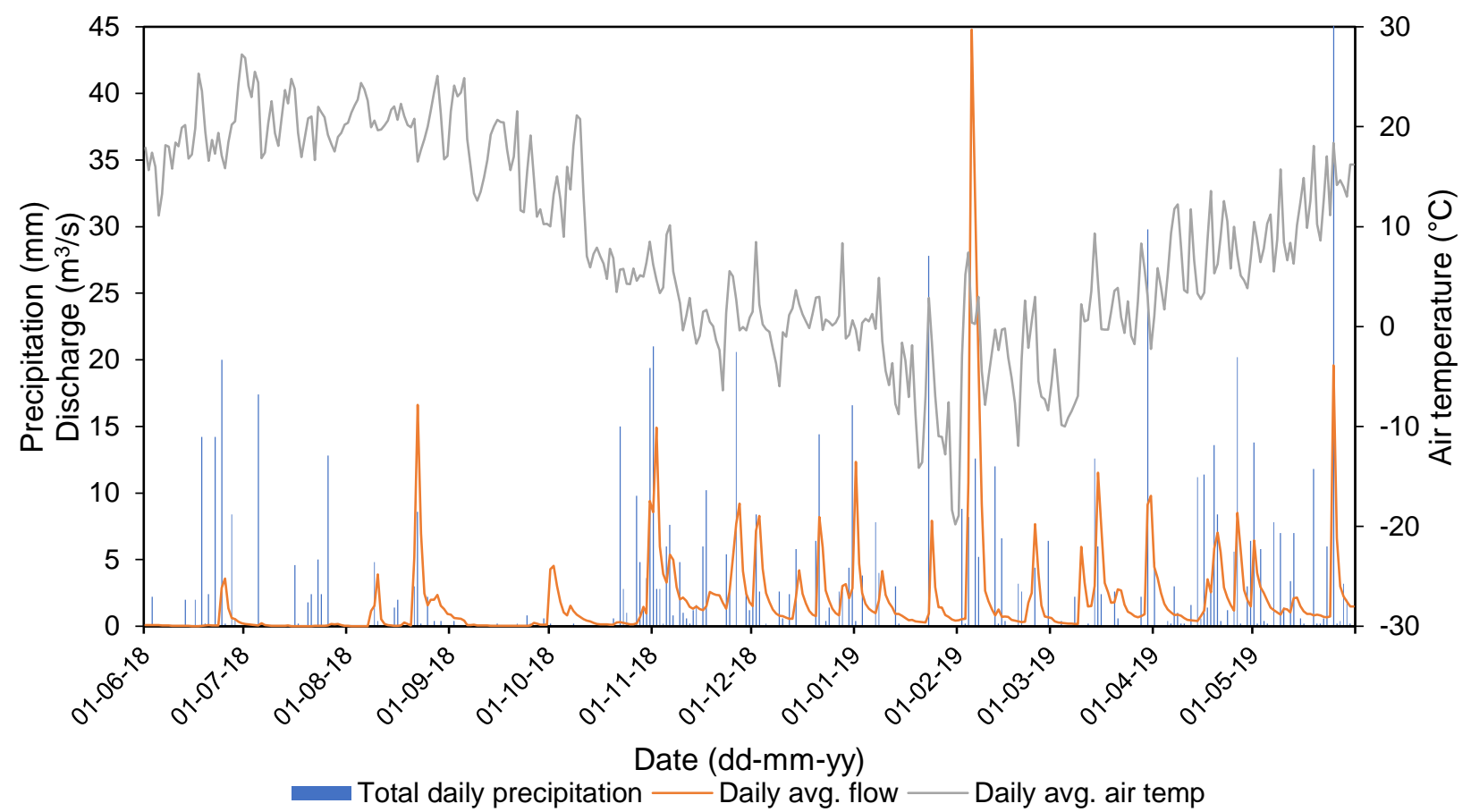

Figure 3-8: Total daily precipitation, daily average flow, and daily average air temperature from June 1, 2018 to May 31, 2019 (Ontario Ministry of Natural Resources and Forestry, 2019).

Although tile drainage systems are widespread in the watershed, the explicit influence of these systems on streamflow in Parkhill Creek is unknown and was not explored further in this study. In a study completed by Macrae et al. (2007) in a clay-till rich watershed in southern Ontario, it was estimated that $42 \%$ of streamflow is attributable to tile drain systems, with substantial flow generally occurring between November and May. Furthermore, in an Ohio watershed consisting predominantly of silt and clay soils, King et al. (2015) approximated that tile drainage systems contribute $56 \%$ of the total annual watershed discharge. Consequently, it is to be assumed that tile flow is a major contributor to streamflow in Parkhill Creek during this period of time. In contrast, tile flow is expected to have an inconsequential contribution to streamflow during periods of low flow.

Sephydro, a web-based hydrograph separation tool, was used to calculate baseflow in Parkhill Creek (Canadian Rivers Institute, 2019). Daily average stream flows and total daily precipitation recorded at the Integrated Water and Climate Station were used as inputs for the separation. The Eckhardt method was employed with parameters applicable for a perennial stream in a low permeability setting, including a maximum baseflow index (BFI) of 0.3 and a groundwater recession constant, $\alpha$, of 0.93 (Eckhardt, 2005). Since there exist 
considerable numerical methods for hydrograph separation, each producing different values for baseflow, the baseflow separation in this study should be considered as a relative estimate of baseflow, rather than an absolute measure (Eckhardt, 2008). The average baseflow from June 1, 2018 to May 31, 2019 was $0.495 \mathrm{~m}^{3} / \mathrm{s}$, in contrast to an average daily streamflow of $2.14 \mathrm{~m} / \mathrm{s}$. Baseflow fluctuated throughout the duration of the study, with maximum values of $2.94 \mathrm{~m}^{3} / \mathrm{s}$ during a melt event in February, whereas June through to August exhibited almost nonexistent baseflow within the stream, aside from following summer storms (Figure 3-9).

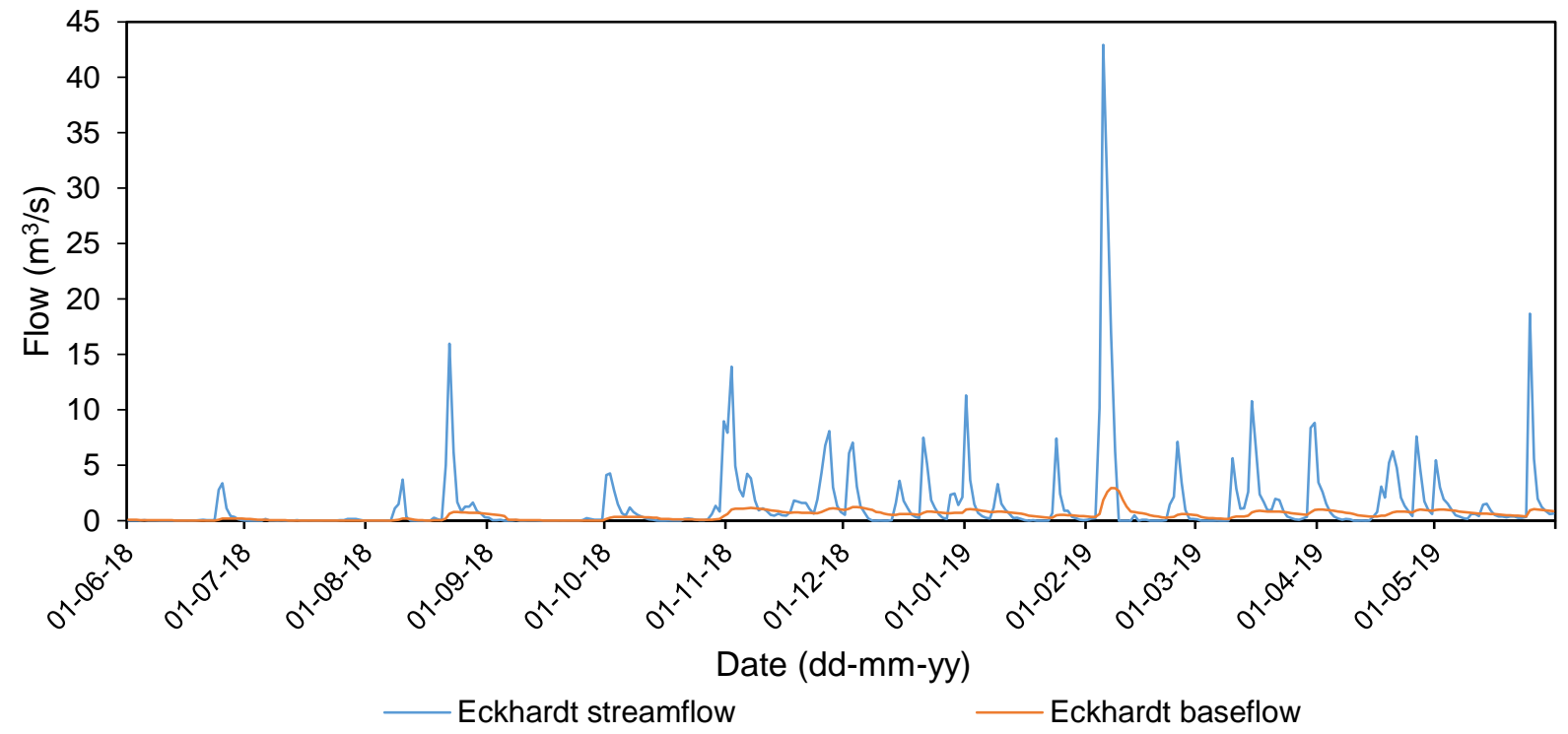

Figure 3-9: Eckhardt baseflow analysis of daily average streamflow data at the Integrated Water and Climate Monitoring Station (Canadian Rivers Institute, 2019; Ontario Ministry of Natural Resources and Forestry, 2019).

\subsection{Statistical data analysis}

All statistical analyses were performed using the data analysis function in Excel 2016. Normality of the data was evaluated using the Shapiro-Wilk test. Statistical tests, including ttests and ANOVA, were performed to assess the differences in the means of various groups. Statistical significance was affirmed at a $p$-value of $\leq 0.05$.

\subsection{Land management survey}

While crop types in the watershed are open-sourced (Agriculture and Agri-Food Canada, 2019), details regarding fertilizer type and usage and land management practices are not publicly available. A land owner survey, therefore, was conducted in the winter of both 2018 and 2019 in the watershed. The survey was conducted following ethics approval process and 
protocols at University of Guelph. The survey was carried out via door-to-door canvassing and mail outs. The intention of this survey was to better understand specific land management and fertilizer practices, such as tillage practices and fertilizer types, quantities, and application methods, which occur in the area. The results of the farmer survey provide a reasonable illustration of fertilization and land management techniques occurring in the watershed.

\subsection{Results \& discussion}

Results from the June 2018 to May 2019 water quality sampling of the five surface water locations, and six monitoring wells in the study area can be found in Appendix C-1. A summary of the results from the drive-points and the tile drain can be found in Appendix C-2. Potential sources of errors and/or uncertainties related to the water quality results presented in this study are discussed in Appendix E.

Samples were analyzed primarily for fundamental nutrient species, including TP, TDP, SRP, $\mathrm{PP}$, and nitrate $\left(\mathrm{NO}_{3}{ }^{-} \mathrm{N}\right)$. Total $\mathrm{P}$ represents the concentration of all $\mathrm{P}$ present in the sample, regardless of the form. In natural waters, $P$ has been demonstrated to cycle between forms in response to varying environmental conditions (Pote et al., 2009). Total P concentrations, in consequence, are critical for evaluating the long-term potential for eutrophication of a surface water body (Pote et al., 2009). Accordingly, the Canadian Council of Ministers of the Environment (2004) recommend TP as the most useful measurement of $P$ in water. Water quality guidelines and objectives for $\mathrm{P}$ at the provincial and national level are therefore presented in terms of TP concentrations. Furthermore, in systems with short residence times, such as rivers, quantifying $P$ concentrations rather than loads is considered to be more meaningful in evaluating the response of an ecosystem (Holman et al., 2008).

Nevertheless, measuring various forms of $\mathrm{P}$ allows for the assessment of relationships between hydrogeological settings, climatic and environmental conditions, and species concentrations. Soluble reactive $P$ is the form of $P$ that is most readily available for uptake by aquatic organisms, and therefore is regarded as the most influential form with respect to accelerated eutrophication of surface water bodies (Pote \& Daniel, 2009). Heathwaite and Dils (2000) found that water percolating through the soil matrix into the subsurface was dominated by the dissolved phase, while PP was the predominate $\mathrm{P}$ form in water transported in preferential flow pathways (e.g. macropores). This study therefore highlights the need, 
especially in a clay-dominant setting, to assess diverse forms of $P$ to elucidate hydrogeological controls on $\mathrm{P}$ transport dynamics. Moreover, few studies report all three forms of $P$ (dissolved, particulate, and total), especially studies related to subsurface water, thereby demonstrating a lack of comprehensive understanding of $P$ dynamics in the wide range of flow systems (Moore, 2016).

Field parameters, including temperature, electrical conductivity, dissolved oxygen, $\mathrm{pH}$, and oxidation reduction potential, can be found in Appendix C-3 for each sampling location and date.

\subsubsection{Phosphorus in tile drainage}

For all discrete sampling events of the tile drainage water, the median TP concentration was $0.038 \mathrm{mg} / \mathrm{L}$, ranging from 0.006 to $0.066 \mathrm{mg} / \mathrm{L}$ (Figure 3-10). Total dissolved $\mathrm{P}$ comprised on average $83 \%$ of the TP, with a median concentration of $0.029 \mathrm{mg} / \mathrm{L}$. Particulate $P$ concentrations within the tile flow were therefore minimal, with a median concentration of $0.007 \mathrm{mg} / \mathrm{L}$. These results are consistent with Zhang et al. (2015) and King et al. (2015) who reported that dissolved $\mathrm{P}$ was the major fraction of TP in drainage water, accounting for $72 \%$ and $78 \%$ of TP, respectively. Drainage water samples were collected via manual grab sampling when the tile was flowing and were therefore generally representative of baseflow conditions rather than stormflow. Total dissolved $\mathrm{P}$ is typically the dominant $\mathrm{P}$ fraction during baseflow since tile drains are mainly fed by water infiltrating through the soil matrix, while PP dominates during stormflow as large quantities of $\mathrm{P}$ are conveyed through preferential flow pathways (Ellison \& Brett, 2006; Heathwaite \& Dils, 2000). While discrete sampling is valuable to assess seasonal trends, Ellison \& Brett (2006) suggest that storms may have the most significant impact on nutrient transport via tile drainage in agricultural areas. Therefore, incorporating event-based sampling would elucidate the dynamics of subsurface nutrient transport under varying climatic conditions. 


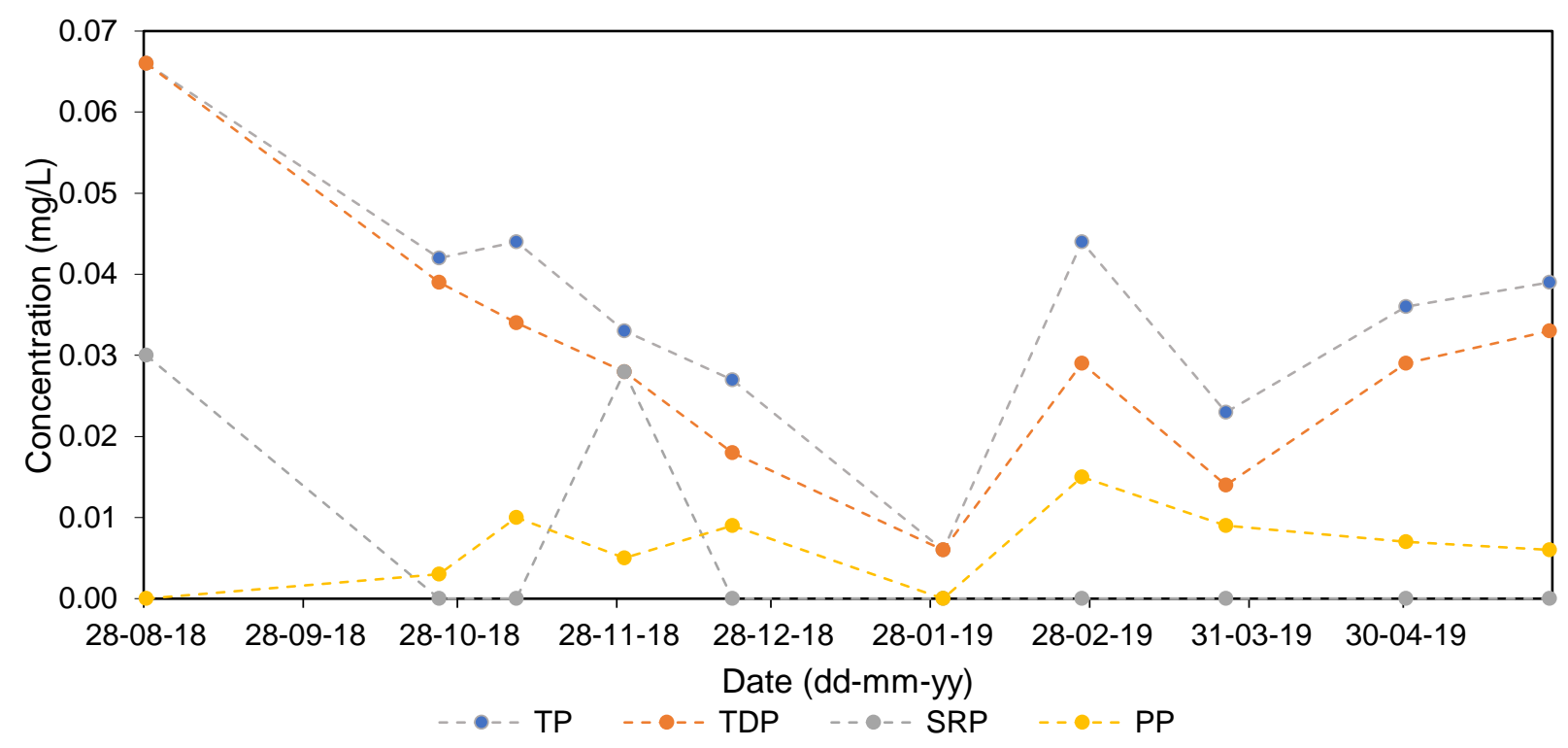

Figure 3-10: Phosphorus concentrations in the tile outlet water for each discrete sampling event.

Concentrations of TP were highest in late summer when sampling began and decreased steadily throughout the fall and winter, following which a general increasing trend is observed throughout the spring (Figure 3-10); a pattern similar to the annual variability observed by Ellison \& Brett (2006) and King et al. (2015). However, a peak in P concentrations (0.044 $\mathrm{mg} / \mathrm{L} \mathrm{TP}$ ) in the tile flow was observed in February 2019 (Figure 3-10). This increase in P was likely the result of a melt event in the days prior to the sampling event, wherein temperatures fluctuated between -12 to $3^{\circ} \mathrm{C}$ (average daily temperatures). While TP concentrations are generally smallest in winter, melt events can result in substantial quantities of $\mathrm{P}$ export via tile drainage long after fertilizer has been applied, potentially attributable to aggregate breakdown or flushing of material in the tile line with the increase in water flow (Macrae et al., 2007). Macrae et al. (2007) observed a similar peak in TP concentrations corresponding to snowmelt (mid-late February) and winter thaw. Consequently, substantial transport of $P$ through tile drains can follow large melt events long after application of nutrients to fields (Macrae et al., 2007; McDowell et al., 2001).

Concentrations observed in the tile water in comparison with the closest surface water sampling location, MTC (400 m upstream), illustrate greater TP concentrations in the stream in late summer to late fall and comparable concentrations through the winter and spring (Figure 3-11). No statistically significant difference between the stream and tile water $P$ concentrations were observed ( $p>0.05)$. Total dissolved $P$ concentrations followed a similar 
pattern, while SRP concentrations were congruous for the study, but remained at or below the detection limit. Particulate $\mathrm{P}$ concentrations in surface water were invariably greater than tile water observations. The difference between tile and stream concentrations from August to December 2018 suggest an additional pathway, or mechanism, for $P$ transport from agricultural land to Parkhill Creek. The supplementary $P$ is likely sourced from overland flow but could also be a result of the internal release of $P$ from streambed or bank sediments via geochemical cycling (Mainstone \& Parr, 2002). Conversely, the uniformity between the tile and stream TP concentrations from December through spring indicates that the drainage systems are the predominant pathway of $\mathrm{P}$ at this location during this period of time.

The exact contribution of tile drainage to streamflow in Parkhill Creek is unknown. In a watershed in Southern Ontario, Macrae et al. (2007) estimated that $42 \%$ of streamflow is attributable to tile drain systems, with substantial flow generally occurring between November and May. Consequently, it is to be assumed that tile flow is a major contributor to streamflow in Parkhill Creek during this period of time. Concentrations of TP in tile water exceeded the PWQO $(0.03 \mathrm{mg} / \mathrm{L})$ on seven out of ten sampling events. Soluble reactive $\mathrm{P}$ concentrations were typically below or just at the detection limit of $0.03 \mathrm{mg} / \mathrm{L}$ (Figure 3-10). While the tile drain therefore does not contribute significant SRP, the TP concentrations in the tile water are still a concern for water quality within the receiving body. The elevated TP concentrations $(>0.03 \mathrm{mg} / \mathrm{L}$ ), typically observed within the late summer and early fall, are potentially capable of promoting eutrophic conditions within Parkhill Creek, as the timing of this increased $\mathrm{P}$ transport corresponds to periods of maximum biological productivity. With approximately $71 \%$ of the total area tile drained, these subsurface systems represent a significant pathway for nutrient transport within the watershed and therefore influence the quality of water within the stream. 


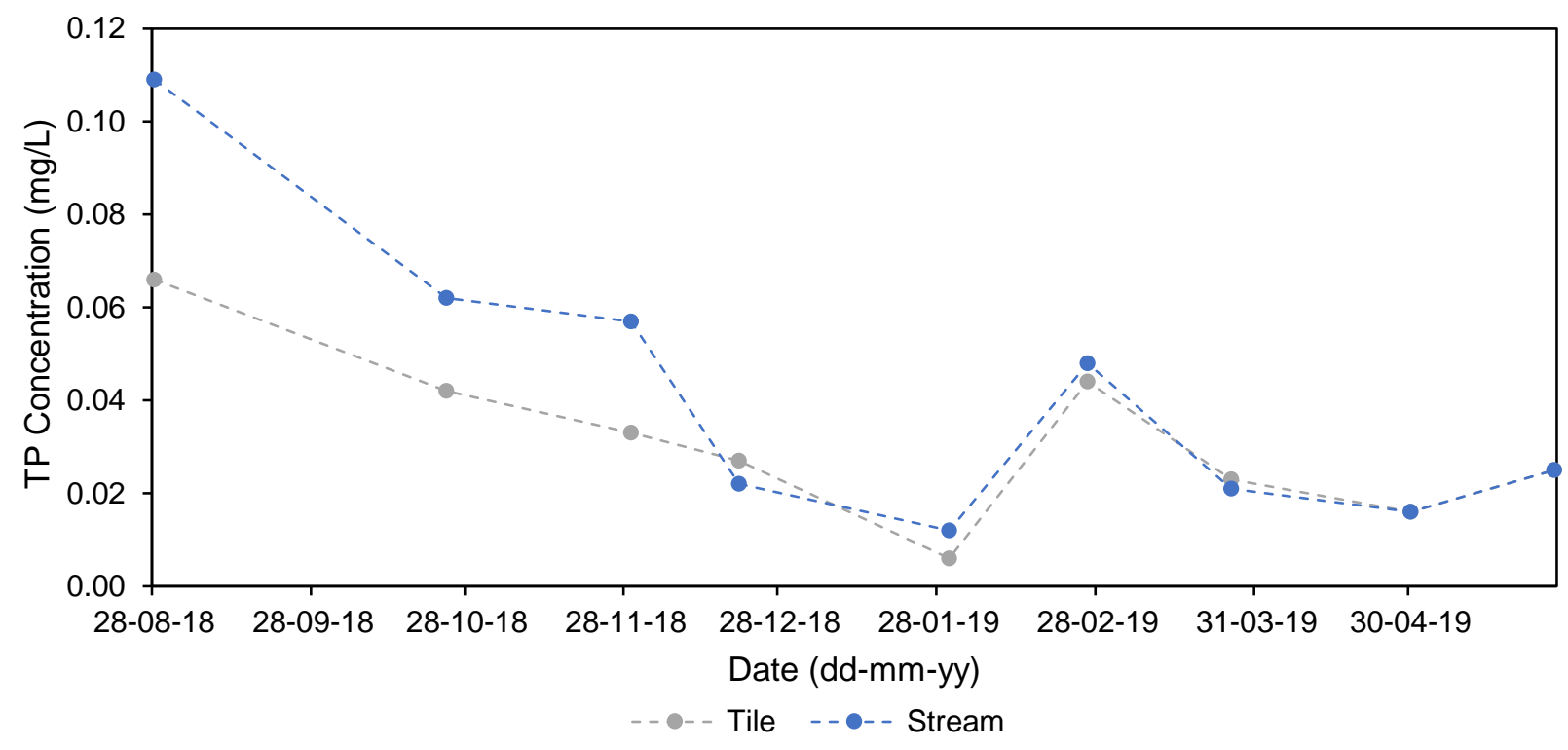

Figure 3-11: Total phosphorus concentrations in the tile outlet water and closest sampled stream reach.

\subsubsection{Phosphorus in groundwater}

While analysis for TP was completed for all groundwater samples, the results of these analyses are omitted since the concentrations were found to be attributable to formation sediments from monitoring wells completed in the clay till, similar to that observed in Burkart et al. (2004). TP values for groundwater in this study ranged from 2.33 to $<0.003 \mathrm{mg} / \mathrm{L}$. Dissolved P, both TDP and SRP, are therefore the forms presented in this study and are considered most representative of $\mathrm{P}$ transported into and through the saturated zone (Burkart et al., 2004). Elevated dissolved P, specifically SRP, can be used as an intrinsic indicator to assess if the groundwater system is expected to pose a risk to receiving surface water bodies in regards to eutrophication (Mellander et al., 2016).

The median concentration of TDP in groundwater was $0.011 \mathrm{mg} / \mathrm{L}$, with concentrations ranging from $<0.003$ to $0.085 \mathrm{mg} / \mathrm{L}$ (Figure $3-12$ ). Concentrations of SRP were consistently below the detection limit $(0.03 \mathrm{mg} / \mathrm{L})$, aside from one sample of $0.06 \mathrm{mg} / \mathrm{L}$ from the shallow MCGF well in November 2018. Anomalously high values (0.150 to $120 \mathrm{mg} / \mathrm{L})$ for TDP and SRP were observed at the GOS and MOO wells. These values were not considered further in the analysis because of sampling error (disturbance of sediments at bottom of screen) associated with these results. Total dissolved P and SRP in shallow groundwater exhibited similar ranges, with TDP varying from $<0.003$ to $0.064 \mathrm{mg} / \mathrm{L}$ and SRP persistently below 0.03 
$\mathrm{mg} / \mathrm{L}$ (Figure 3-12). No significant differences were observed between groundwater $\mathrm{P}$ concentrations at the three monitoring well and drive-point locations, suggesting that similar controls, such as soil, crop, fertilizer management and hydrological conditions, are present at each site, or that their variances result in the same outcome. Further, while samples were collected from piezometers and wells with varying depths of installation, there were no statistical significance between $\mathrm{P}$ concentrations and depth. The absence of a consistent relationship between P concentration and depth was also observed by Burkart et al. (2004) and Meinikmann et al. (2015).

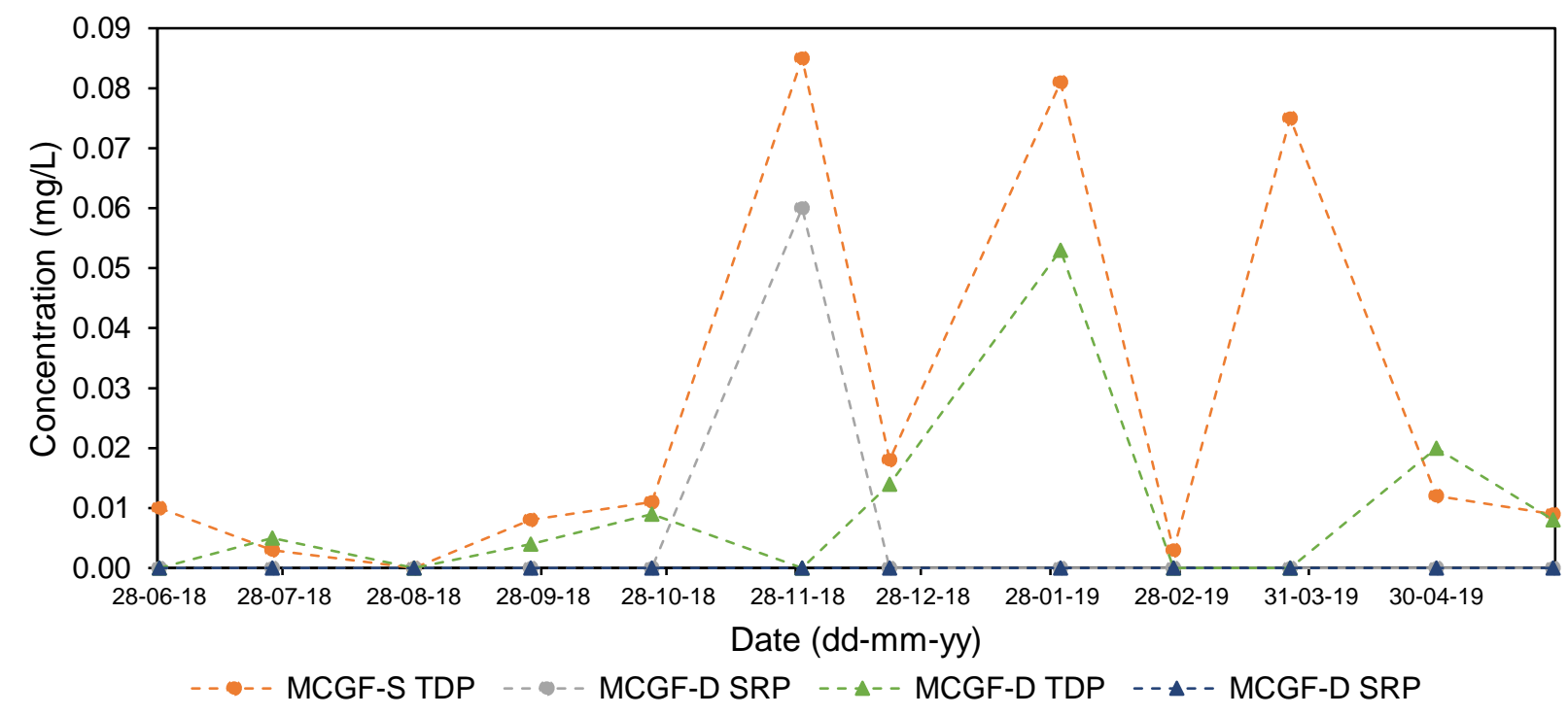

Figure 3-12: Dissolved phosphorus (TDP and SRP) concentrations for the shallow (MCGF-S, 6.7 mbgs) and deep (MCGF-D, $15.8 \mathrm{mbgs}$ ) monitoring wells at the McGuffin research site for each discrete sampling event.

Total dissolved $\mathrm{P}$ concentrations in this study fall on the lower end of the range reported by Burkart et al. (2004), who monitored over a hundred wells in unconsolidated geologic material in agricultural watersheds in lowa. Observed groundwater concentrations in this study in the Upper Parkhill watershed ranged from mean values of 0.07 to $0.21 \mathrm{mg} / \mathrm{L}$, with maximum concentrations of $1.0 \mathrm{mg} / \mathrm{L}$ (Burkart et al., 2004). The low concentrations of dissolved $P$ observed in the groundwater in the watershed are likely a function of the surficial geology and the prevalence of subsurface drainage in the area combined with $\mathrm{P}$ management practices in the area. The Upper Parkhill watershed is comprised predominantly of clay and silty clays, which amplifies the $\mathrm{P}$ sorption capacity of the soil since clays are one of a few minerals primarily responsible for orthophosphate adsorption in soil (Hansen et al., 2002; Domagalski \& Johnson, 2012). Leaching of $P$ is more likely to occur in soils low in clay, such as sandy 
soils, combined with low Fe and Al oxides and carbonates (Hansen et al., 2002). In addition, tile drains lower the water table thereby increasing $P$ contact with soil and thus decreasing $P$ concentrations in shallow groundwater prior to reaching the saturated zone, unless transported through prefential flow pathways. Furthermore, shallow groundwater is intercepted by the tile drains following precipitation events, therefore also decreasing overall $P$ transfer into the groundwater system.

Concentrations of dissolved P (TDP and SRP) in both the shallow and deep wells were lowest in the summer and early fall and fluctuated throughout the late fall and into spring (Figure 312). During low streamflow periods, such as in the late spring and summer, water quality within streams are particularly impacted by groundwater inputs as the flow is dominated by groundwater discharge (Robinson, 2015). Groundwater P concentrations become more significant during these low flow periods as they often coincide with periods of maximum primary productivity as biological demand for $\mathrm{P}$ is at its greatest resulting in conditions favourable for eutrophication (Holman et al., 2008). Groundwater SRP and TDP concentrations from June to October in this study are all below 0.03 and $0.01 \mathrm{mg} / \mathrm{L}$, respectively, suggesting that groundwater input during this time will have minimal impact on the stream's health regarding eutrophication risk. However, elevated dissolved P concentrations have been observed in the winter and spring. While these concentrations may not be immediately detrimental to the stream during this time, $\mathrm{P}$ can accumulate in the stream sediments and subsequently be released following fluctuations in the biogeochemical environment or hydrological events (McDowell et al., 2001; Orihel et al., 2017). Consequently, groundwater P could pose a eutrophication risk to Parkhill Creek, assuming adsorption of discharged $\mathrm{P}$ and ensuing release of reactive $\mathrm{P}$ in warmer, low flow periods. Furthermore, while groundwater $\mathrm{P}$ may not impact or contribute to immediate impairment of stream water quality, annual loading of $P$ downstream to Lake Huron may present an environmental concern for the state of the lake. Nonetheless, the groundwater $\mathrm{P}$ concentrations are significantly less than surface water $\mathrm{P}$ concentrations in the watershed thus indicating that groundwater is a minor source of $\mathrm{P}$, supporting that overland flow and tile drainage dominate the transport pathways. 


\subsubsection{Phosphorus in surface water}

Concentrations of TP were recurrently greater than or at the PWQO of $0.03 \mathrm{mg} / \mathrm{L}$, with 46 out of 60 (or $77 \%$ ) surface water samples exceeding this objective. The TP concentrations across the locations ranged from 0.007 to $0.324 \mathrm{mg} / \mathrm{L}$ (Figure 3-13). The annual median concentration of TP at all locations from June 2018 to May 2019 was $0.051 \mathrm{mg} / \mathrm{L}$. Mooresville had the highest median TP concentration $(0.061 \pm 0.084 \mathrm{mg} / \mathrm{L})$ out of the five sites, followed by MCGL $(0.058 \pm 0.050 \mathrm{mg} / \mathrm{L})$, GOS $(0.053 \pm 0.105 \mathrm{mg} / \mathrm{L})$, MTC $(0.047 \pm 0.073 \mathrm{mg} / \mathrm{L})$, and MCGF (0.041 $\pm 0.071 \mathrm{mg} / \mathrm{L})$ (Figure 3-14). A simple statistical test, Analysis of Variance (ANOVA), was used to analyze the differences in $\mathrm{P}$ concentrations between each of the five surface water sampling locations. This test indicated that there was no statistically significant difference between locations for any of the P species concentrations (TP, TDP, SRP, and PP). This suggests that while there may be some slight spatial variability in $\mathrm{P}$ concentrations in Parkhill Creek, the overarching watershed land management practices, rather than sitespecific activities, have greater influence on the overall water quality of the stream.

Total dissolved $\mathrm{P}$ concentrations consistently follow the same trends as TP, as TDP comprised the majority of $\mathrm{P}$ in Parkhill Creek. The annual median TDP concentration of the five surface water locations was $0.038 \mathrm{mg} / \mathrm{L}$, with a range from 0.003 to $0.226 \mathrm{mg} / \mathrm{L}$. Dissolved $\mathrm{P}$, on average, comprised approximately $75 \%$ of TP. The predominance of dissolved $\mathrm{P}$ in comparison to the particulate form is likely a result of the widespread use of no-till practices in the watershed. While no-till practices have shown to be beneficial to reduce particulate $P$ loss, increased dissolved $P$ in runoff has been attributed to conservation tillage (no-to-minimum till) in comparison to conventional tillage (McDowell \& McGregor, 1980; Kleinman et al., 2009; Daryanto et al., 2017). The observed relationship between this best management practice and water quality observations is discussed in Section 3.7.10.

Particulate $\mathrm{P}$ concentrations in Parkhill Creek were typically low with respect to TP concentrations, with a median concentration of $0.020 \mathrm{mg} / \mathrm{L}$ and ranging from 0 to $0.234 \mathrm{mg} / \mathrm{L}$. The maximum PP concentration observed throughout the study was obtained from the GOS site in February 2019 (Figure 3-14). Sample collection from this location was executed immediately adjacent to the streambank due to inaccessibility issues resulting from a partially frozen stream. Consequently, the aggravation of sediment when the sample was obtained likely resulted in the anomalous PP peak at this location. 
Concentrations of TP were greatest in the summer and early fall and decreased, but remained comparatively consistent, through the late fall and winter, aside from the peak observed in February 2019 (Figure 3-13). A similar seasonal pattern was reported by Dubrovsky et al. (2010) and Houser \& Richardson (2010), who observed higher P concentrations in the summer and fall when streamflow was low and lower concentrations in winter and spring under high streamflow. Total dissolved P and SRP concentrations follow the same trend as TP, aligning with baseflow conditions and maximum biological productivity, thus increasing the risk of eutrophication within the stream (Holman et al., 2008). While flow during these conditions is typically sustained by groundwater discharge, groundwater P concentrations observed in this time period are significantly less than surface water concentrations suggesting an additional source of $\mathrm{P}$ was present. Tile flow drainage can contribute to baseflows and may be dominant in agriculturally-intensive areas with low permeability soils; conditions analogous to the watershed. However, only one tile water sample was collected in this period at the end of August 2018 (TP concentration of $0.066 \mathrm{mg} / \mathrm{L}$ ) and thus the transfer of $P$ through tile drains during baseflow conditions cannot be sufficiently assessed. The internal release of $P$ from streambank or bed sediments due to changes in environmental conditions could also explain the observed elevated concentrations. While the exact contribution of internal cycling of $P$ within Parkhill Creek is unknown, the internal release of $P$ from sediment is likely a significant source of $\mathrm{P}$ to the stream during summer low flow periods (Mainstone \& Parr, 2002). Stream conditions during this period of time, including warmer temperatures and lower dissolved oxygen concentrations, can decrease the P sorption affinity and capacity of sediments, thus leading to the release of formerly bound $\mathrm{P}$ (Orihel et al., 2017). Future work in the watershed should aim to assess the dynamics and quantify the contribution of internal P loading in Parkhill Creek. 


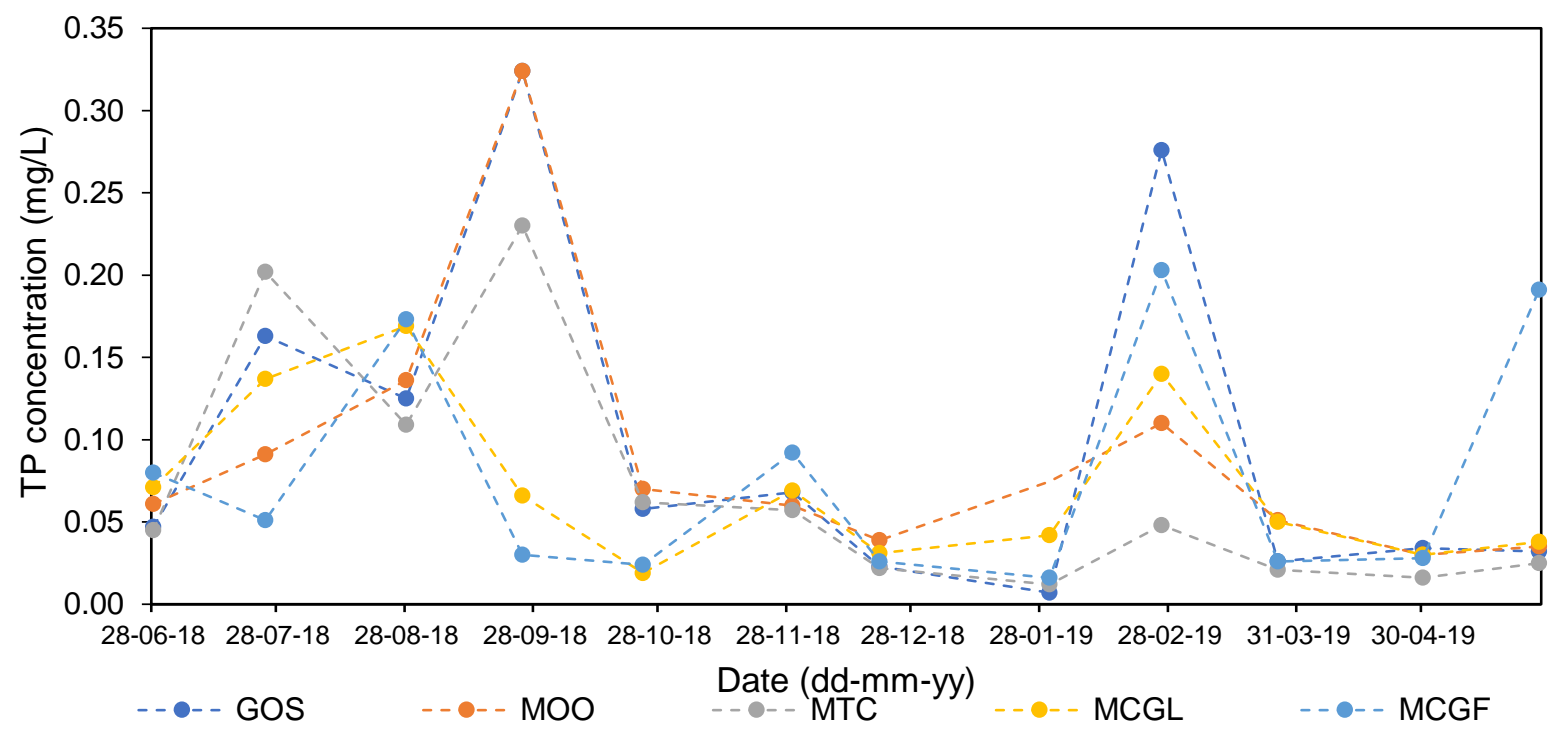

Figure 3-13: Temporal variability in TP concentrations for each surface water sampling location.

A substantial increase in P (TP, TDP, and SRP) occurred in September 2018 for GOS, MOO, and to a lesser extent MTC. The timing of the peak in concentrations corresponds with the fertilizer application period for winter wheat crops, which were planted in the land surrounding these sites. Winter wheat was not planted in fall 2018 around MCGF and MCGL, thus explaining the absence of a peak in concentrations for these locations. While September was very dry, a precipitation event occurred the day prior to sample collection which likely lead to $P$ loss via surface runoff (infiltration excess overland flow) or tile drainage systems, from the recently applied fertilizer.

Elevated $\mathrm{P}$ concentrations in surface water bodies have been associated with hydrological events, such as precipitation or snow melt events ("hot moments"), and consequently also correspond with peak stream flows (Robinson, 2015; Kiely et al., 2007; Ockenden et al., 2017). No consistent correlation was observed in this study between precipitation amount and $\mathrm{P}$ concentrations, with some locations exhibiting a strong negative relationship (GOS, MOO, MTC), while others were almost zero (MCGF) to slightly positive (MCGF). Similarly, there was no uniform relationship observed with streamflow. The absence of distinct correlations between hydrological events or streamflow and P concentrations is likely due to the collection of monthly discrete-based sampling, rather than event-based sampling. Contrarily, a study completed by Rixon (2018) in the watershed noted an association between peak $\mathrm{P}$ concentrations and melt events. The discrete sampling event for January 2018 in this 
study captured a significant melt event during a freeze thaw cycle which produced the highest streamflow in recorded history at the MCGF site (Rixon, 2018; Ontario Ministry of Natural Resources and Forestry, 2019). In comparison, January 2019 concentrations in the current study were amongst the lowest observed over the 12 months of sampling. This therefore highlights the need to complete event-based sampling to assess the influence of "hot moments" on $\mathrm{P}$ transport dynamics within the watershed. 

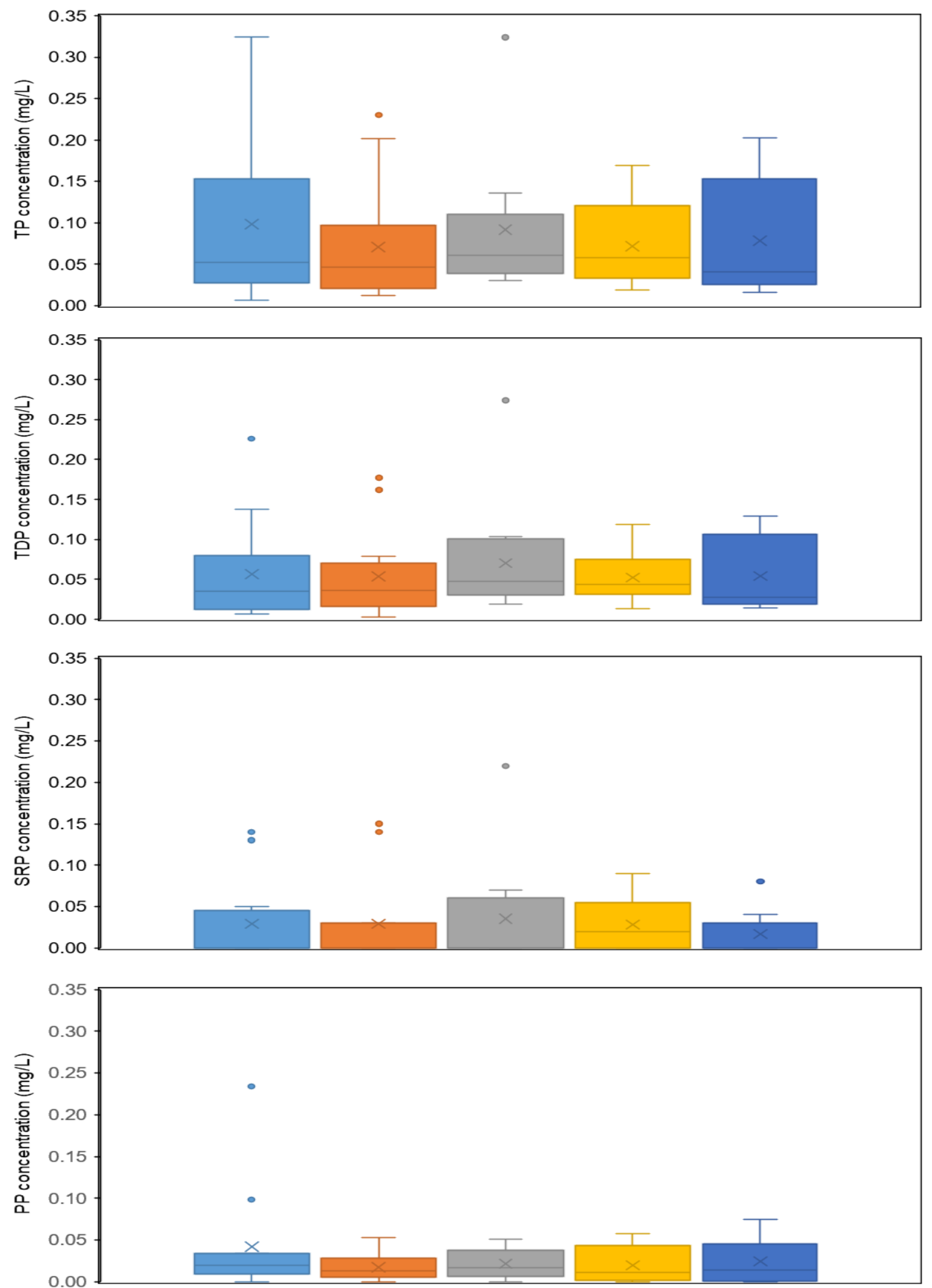

Figure 3-14: Boxplot representation of TP, TDP, PP and SRP concentrations for each surface water sampling location from north to south in the watershed. The median (center line), the average (the $\mathrm{x}$ ), the first quartile (bottom of box), and third quartile. Minimum and maximums are represented by bars extending from the boxes. 


\subsubsection{Nitrate in tile drainage}

The median concentration of nitrate in the tile water was $4.68 \mathrm{mg} \mathrm{NO}_{3}-\mathrm{N} / \mathrm{L}$ and ranged from 3.44 to $20.52 \mathrm{mg} \mathrm{NO}_{3}-\mathrm{N} / \mathrm{L}$ (Figure 3-15 and Appendix C-4). From a study completed in Indiana, nitrate concentrations in tile drainage water between 5-10 $\mathrm{mg} \mathrm{NO}_{3}{ }^{-} \mathrm{N} / \mathrm{L}$ indicate row crop production without fertilizer, or fertilizer applied below the economically optimum rate, or with effective winter crops that trap N (Brouder et al., 2005). Concentrations between 10-20 mg $\mathrm{NO}_{3}{ }^{-} \mathrm{N} / \mathrm{L}$ suggest $\mathrm{N}$ is applied at an optimum rate under row crop production, while concentrations $>20 \mathrm{mg} \mathrm{NO}_{3}{ }^{-} \mathrm{N} / \mathrm{L}$ indicate $\mathrm{N}$ applied exceeds or is not synchronized with crop needs (Brouder et al., 2005). Consequently, as the majority of nitrate concentrations are within the $5-10 \mathrm{mg} \mathrm{NO}_{3}-\mathrm{N} / \mathrm{L}$ range, it is likely that nitrate in the watershed is applied below the optimum rate and/or used in conjunction with a cover crop, or winter wheat, successfully capturing excess $\mathrm{N}$ and reducing the loss of $\mathrm{N}$. Increased potential for denitrification in the soil could also yield nitrate concentrations within this range.

Concentrations observed in the tile water in comparison with MTC, the closest stream sampling location, illustrate greater nitrate concentrations in the stream in late fall to spring, while tile concentrations were considerably higher in the tile water through late summer and early fall (Figure 3-15). The difference between tile and stream concentrations in the winter suggest that nitrate is also being transported via an additional pathway from agricultural land to Parkhill Creek or $\mathrm{N}$ mineralization of crop and plant residues in the absence of growing plants is occurring during this period of time. However, elevated concentrations of nitrate in the tile water relative to the stream suggest that tile drainage systems in the watershed are overall a significant pathway of nitrate to Parkhill Creek with varying influence over the seasons. This difference in stream and tile concentrations in August and October further suggests that there may be instream cycling of nitrate occurring at this time, leading to the sequestration of nitrate as it enters the surface water from the adjacent tile drain. 


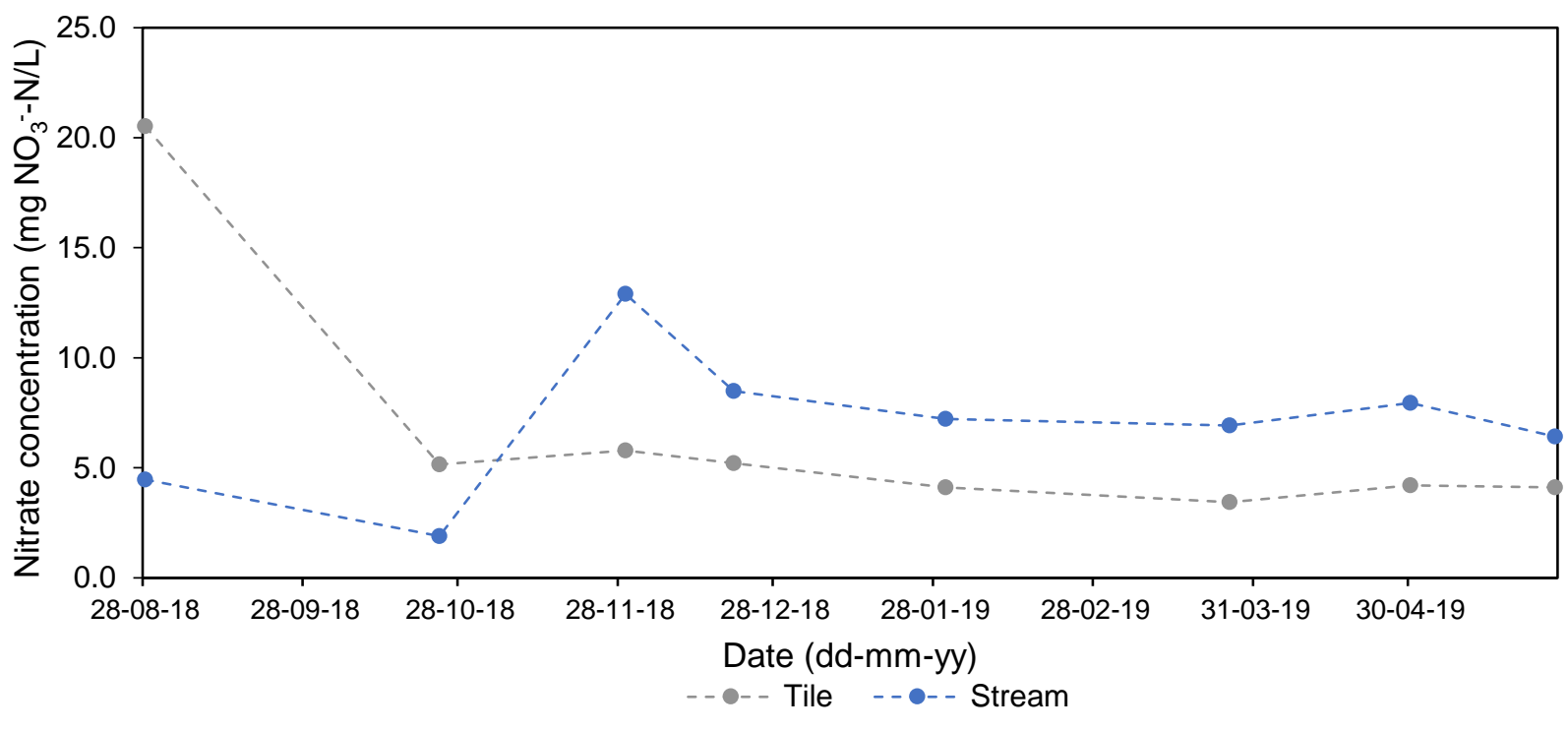

Figure 3-15: Nitrate concentrations in the tile outlet water and closest sampled stream reach.

\subsubsection{Nitrate in groundwater}

Nitrate concentrations in groundwater ranged from $<0.05$ to $1.59 \mathrm{mg} \mathrm{NO}_{3}^{-}-\mathrm{N} / \mathrm{L}$, with a median concentration of $0.48 \mathrm{mg} \mathrm{NO}_{3}-\mathrm{N} / \mathrm{L}$ (Appendix C-4). A PGMN well located approximately $2 \mathrm{~km}$ southwest of MCGF exhibits similar nitrate concentrations $\left(0.05 \mathrm{mg} \mathrm{NO}{ }^{-}-\mathrm{N} / \mathrm{L}\right.$ median) from 2003-2015. Concentrations were typically higher in the shallow wells in comparison to the deeper wells; however, there was no statistically significant difference between the two. Observed concentrations in this study are within the range of reported background concentrations of nitrate in groundwater, which varies from 0.9 to $2 \mathrm{mg} \mathrm{NO}_{3}{ }^{-} \mathrm{N} / \mathrm{L}$ (Burkart \& Stoner, 2002; Dubrovsky, et al., 2010). Consequently, these results suggest that anthropogenic activities, including agricultural activities, have a negligible influence on groundwater nitrate concentrations in this watershed. Likewise, ORP measurements for the shallow and deep wells indicate that the deep wells were predominantly in the sulphate reducing range $(-50$ to $250 \mathrm{mV})$, whereas the shallow wells had ORP measurements spanning across the ranges for denitrification $(-50 \mathrm{mV}$ to $+50 \mathrm{mV})$ and nitrification (+100 to $+350 \mathrm{mV}$ ) (Gerardi, 2008). Concentrations of nitrate in the shallow wells under the nitrification conditions were within the typical background concentrations, thus corroborating the absence of significant impact of agricultural activities on groundwater in the watershed. Furthermore, concentrations of nitrate in groundwater were considerably lower than the drinking water standard in Canada of $10 \mathrm{mg} \mathrm{NO}_{3}{ }^{-} \mathrm{N} / \mathrm{L}$ (Health Canada, 2013). Groundwater is therefore not 
considered to be a significant source of nitrate to Parkhill Creek, corresponding to Rixon (2018) who found no correlation between nitrate and 222-radon, a tracer used delineate groundwater discharge in surface waters bodies.

\subsubsection{Nitrate in surface water}

Concentrations of nitrate at all five surface water sampling locations ranged from 0.32 to $13.13 \mathrm{mg} \mathrm{NO}_{3}{ }^{-} \mathrm{N} / \mathrm{L}$, with a median of $7.17 \mathrm{mg} \mathrm{NO}_{3}{ }^{-} \mathrm{N} / \mathrm{L}$ (Figure 3-16 and Appendix C-4). These concentrations are within the range of reported values from long-term monitoring of Parkhill Creek at a PQWMN station downstream of the MCGF site. While the median nitrate concentration at this station from $2003-2017$ is $3.48 \mathrm{mg} \mathrm{NO}_{3}{ }^{-} \mathrm{N} / \mathrm{L}$, the concentrations ranged from 0.009 to $17.5 \mathrm{mg} \mathrm{NO}_{3}-\mathrm{N} / \mathrm{L}$. The median concentration reported by Rixon (2018) for samples collected in Parkhill Creek from May 2017 to May 2018 was 5.6 mg NO${ }^{-}{ }^{-} \mathrm{N} / \mathrm{L}$. Consequently, concentrations in this study, while similar to previous monitoring, are moderately elevated and routinely exceeded (47 out of 59 samples or $80 \%$ ) the Canadian Guideline for the Protection of Aquatic Life (CGPAL) of $2.95 \mathrm{mg} \mathrm{NO}_{3}{ }^{-}-\mathrm{N} / \mathrm{L}$.

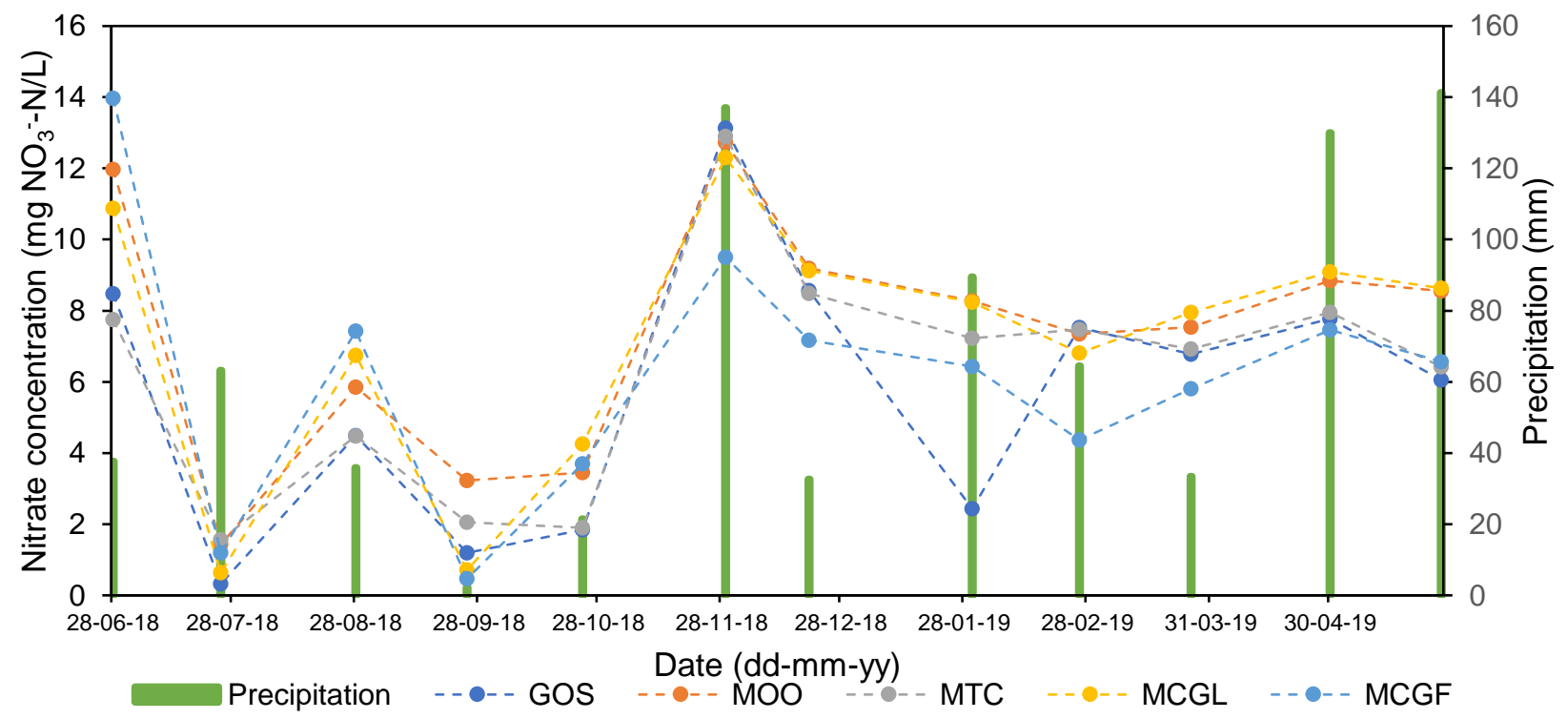

Figure 3-16: Monthly surface water nitrate concentrations and precipitation to date of sampling event.

Nitrate concentrations in the stream exhibited almost an inverse relationship to TP concentrations, with greatest overall concentrations observed in the late fall and winter (Figure 3-16). Houser \& Richardson (2010) observed a similar parallel between P and N concentrations, with maximum $\mathrm{P}$ concentrations coinciding with minimum $\mathrm{N}$ concentrations 
in the Upper Mississippi River. Wet periods, with increased precipitation or snowmelt events, generally correspond with higher nitrate concentrations in comparison to drier periods and is considered a typical annual nitrate pattern in agricultural streams (Martin et al., 2004). Nitrate readily dissolves in water and therefore transport of this nutrient from agricultural land is expected to increase with runoff events during the late spring and through late fall and winter (Miller et al., 2015). However, no distinct correlation was observed between monthly precipitation (from one sampling event to the next) and surface water nitrate concentrations during the study period. This is in contrast to Rixon (2018) who observed an $R^{2}$ of 0.68 between the previous month's precipitation and nitrate concentrations in Parkhill Creek.

While continuous water quality measurements at the MCGF site were collected from May 2018 to November 2018, continuous nitrate data was intermittently available from June 5 , 2018 to July 14,2018 . Nitrate concentrations during this time period ranged from 0.09 to 17 $\mathrm{mg} \mathrm{NO} 3^{-}-\mathrm{N} / \mathrm{L}$. A large increase in nitrate concentrations (approximately $16 \mathrm{mg} / \mathrm{L}$ ) was observed between June 24 to June 28,2018 , following $30 \mathrm{~mm}$ of rainfall during these four days. The quick response in stream concentrations likely suggests rapid conveyance of nitrate via overland flow and/or tile drainage systems in the watershed, corresponding to monthly discrete sampling results.

\subsubsection{Hydrologic site characterization}

Hydraulic conductivities for the four wells total at GOS and MOO were estimated using the Hvorslev method, as discussed in Section 3.4.3. The average $K$ for the shallow and deep GOS wells is $2.71 \mathrm{E}-09 \mathrm{~m} / \mathrm{s}$ and $1.42 \mathrm{E}-09 \mathrm{~m} / \mathrm{s}$, respectively. The average $\mathrm{K}$ for the MOO shallow and deep wells is $6.90 \mathrm{E}-06 \mathrm{~m} / \mathrm{s}$ and $1.03 \mathrm{E}-07 \mathrm{~m} / \mathrm{s}$, respectively.

The time of travel for water through the unsaturated zone from ground surface to the water table was calculated using two methods: "no-flow" van Genuchten and SAAT (Province of Ontario, 2006; Sousa et al., 2013). Using the van Genuchten approach, the unsaturated zone travel times ranged from 2.5 to 12 years, with a median of 3.5 years (Figure 3-17). Unsaturated zone travel times calculated using the SAAT method were slightly larger, ranging from 3.6 to 16.8 years, with a median of 5.0 years (Figure 3-17). The median water level over the year period for the six wells was $2.55 \mathrm{mbgs}$. However, the MCGF wells have the highest annual average water levels (1.83 and $1.975 \mathrm{mbgs}$, respectively for the shallow and deep well), thus have the shortest travel times for a water particle to travel from the ground surface 
(or agricultural land) to the water table. Contrarily, the deep well at GOS has a significantly lower annual average water level $(8.5 \mathrm{mbgs})$, therefore resulting in the longest travel times and producing a wide spread in the range of these times.

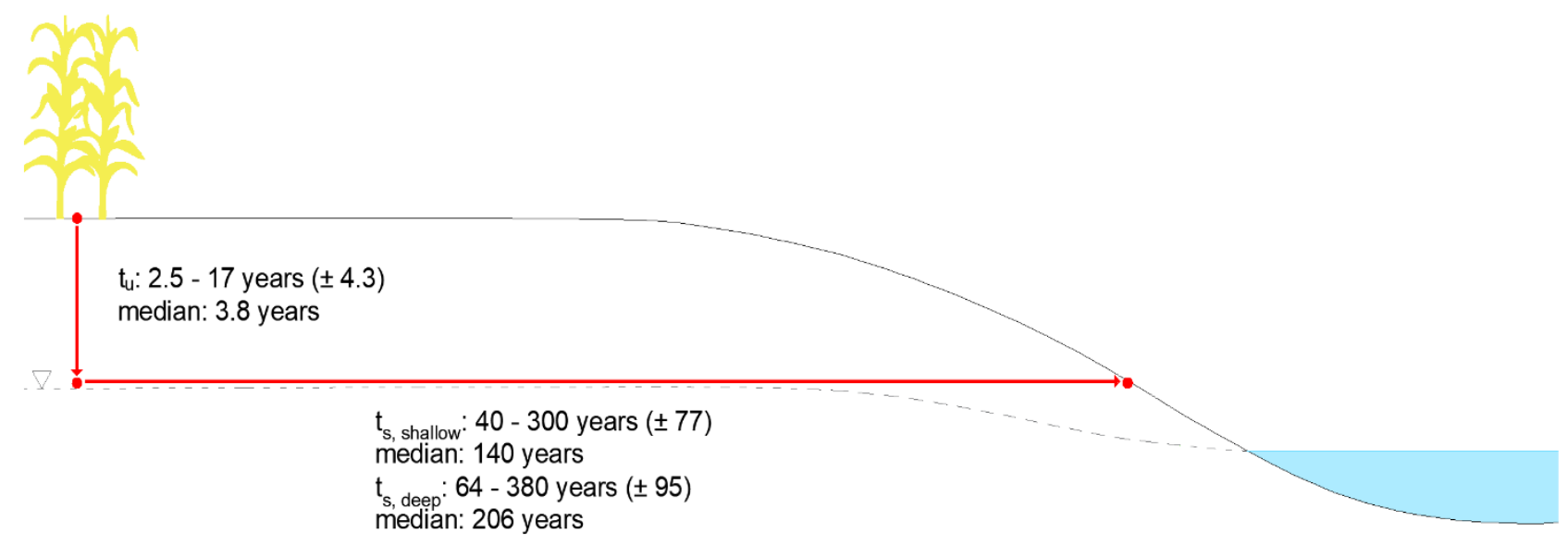

Figure 3-17: Schematic diagram of unsaturated zone travel times ( $\left.t_{u}\right)$ and saturated zone travel times (ts) for a conservative contaminant or water particle.

The unsaturated zone travel times indicate that a water particle, or a conservative contaminant, could travel from agricultural land to the water table in the span of a several years. This therefore suggests that the groundwater is young, aligning with groundwater ages from Rixon (2018), and the quality of the groundwater is representative of modern practices/conditions. However, $\mathrm{P}$ is not considered to be conservative and is readily subject to transformation processes in the subsurface soil environment, such as adsorption, thus substantially inhibiting the quantity and rate of $P$ that transported in or with the water in this zone, as well as in the saturated zone.

The saturated zone travel time was estimated using a straight-line approximation (Sousa et al., 2013). This method approximates the travel time of a water particle from the initial contact of the water particle on the water table surface to the receptor, an adjacent surface water body. The estimated saturated zone travel time ranged from 40 to 380 years, depending on the measured depth to groundwater and the adjacent surface water level (Figure 3-17). Given the low concentrations observed in the groundwater and the prolonged travel time through the saturated zone, it is unlikely that, at this time, groundwater would be a significant source of $\mathrm{P}$ or $\mathrm{N}$ to a water body receiving groundwater discharge in the watershed. 
Fine-textured soils with high clay content, such as those within the Upper Parkhill watershed, are susceptible to developing preferential flow pathways due to their tendency to crack (Simard et al., 2000). The presence of preferential flow pathways can significantly increase the hydraulic conductivity in clay-rich deposits. For example, McKay (1995) and Jørgensen et al. (2002) found that fractured clay had hydraulic conductivities two and one to three orders of magnitude larger than unfractured clay, respectively. This increase in magnitude would have a considerable effect on groundwater velocity within the clay material in the watershed and would reduce the travel time to surface water proportional to the magnitude of increase in hydraulic conductivity. However, a pedological survey was completed at the MCGF research site in August 2017 which did not confirm the presence of fractures and/or preferential flow pathways in the soil at this location (E. Persaud, personal communication, 2019). Nevertheless, an estimation of groundwater travel times in fractured clay with a hydraulic conductivity 2 orders of magnitude greater than the actual $\mathrm{K}$ was completed to assess variability in these times under different subsurface conditions. Saturated zone travel times under the varied $\mathrm{K}$ ranged from 0.38 to 2.83 years, significantly less than under the normal site conditions. While there is no immediate evidence of fractures at the MCGF site, it is possible that they are present in the surficial material elsewhere in the watershed. Given the short travel time and the bypass of the soil matrix associated with these conditions, there is potential for groundwater to be a greater concern, presently, for nutrient transport to receiving surface water bodies. Future work should assess the prospective presence of these preferential flow pathways at other locations throughout the watershed and their impact on $\mathrm{P}$ transport.

\subsubsection{Hyporheic zone variability \& hydraulic connection}

The median concentration of TP in the hyporheic water $(\mathrm{HW})$ for all discrete sampling events was $0.204 \mathrm{mg} / \mathrm{L}$, with concentrations ranging from 0.057 to $0.227 \mathrm{mg} / \mathrm{L}$ (Figure 3-18). The predominant form of $\mathrm{P}$ in this water was particulate $\mathrm{P}$. On two occasions, there were anomalous concentrations of TP and PP, likely resulting from disturbance of sediments at the bottom of the drive-point, and therefore were excluded from further analysis or discussion. Concentrations of PP ranged from 0.040 to $0.218 \mathrm{mg} / \mathrm{L}$, comprising $0-98 \%$, respectively, of the TP in this hyporheic water. Consequently, concentrations of the dissolved phases, TDP and SRP, were typically low; 0.009 to $0.064 \mathrm{mg} / \mathrm{L}$ for TDP and $<0.03 \mathrm{mg} / \mathrm{L}$ for SRP. Dissolved 
P concentrations were considerably less than values reported by Domagalski and Johnson (2011), who observed a median soluble $P$ concentration of $0.2 \mathrm{mg} / \mathrm{L}$ at the groundwater/stream interface. The predominance of particulate $\mathrm{P}$ in comparison to dissolved $\mathrm{P}$ may be a function of the composition of the streambed, as well as installation and characteristics of the drive-point piezometer.

Total P concentrations were consistently higher in the hyporheic water relative to the surface water in the stream reach (Figure 3-18). This pattern is also observed in the PP concentrations of the two water sources, likely suggesting that the high PP concentrations in the hyporheic water are a result of an influx of fine sediment, and therefore adsorbed $\mathrm{P}$, through the screen of the drive-point piezometer. Contrarily, concentrations of TDP are predominantly higher in the stream than in the hyporheic water (Figure 3-18). This is consistent with findings from Tesoriero et al. (2009) who observed lower soluble P concentrations in stream-bed pore water and in groundwater than in stream water. Correspondingly, these results suggest that overland flow and tile drainage systems, depending on total inflows of these sources, are the main transport pathways for $\mathrm{P}$ to Parkhill Creek, which aligns with to tile and surface water quality observations in this study.

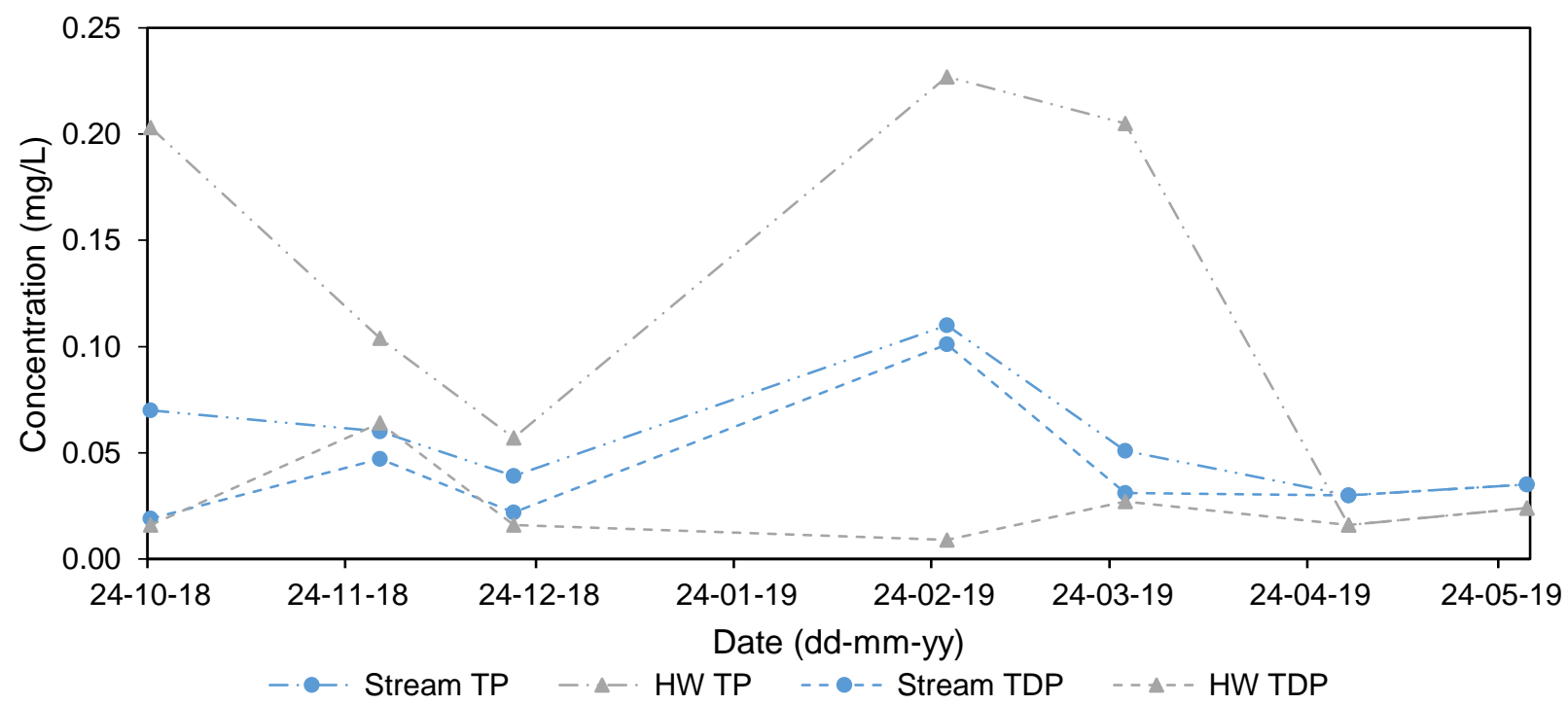

Figure 3-18: TP and TDP concentrations for the hyporheic zone water (HW) and surface water body (stream Mooresville sampling location).

Vertical hydraulic gradients (VHG) at the two piezometer locations were estimated and represent a unitless ratio of the difference in hydraulic head between the water inside and 
outside the piezometer relative to the depth of the piezometer screen below the sedimentwater interface (Lee \& Cherry, 1978; Vervier et al., 2009). The magnitude of hydraulic connection between surface water and the hyporheic zone, represented by the VHG, has been demonstrated to influence the concentration of $\mathrm{P}$ in hyporheic water (Vervier et al., 2009). The relationship between VHG and $P$ concentrations (TDP) is presented in Figure 319. A weak relationship ( $R^{2}$ of 0.267 ) was observed between $P$ concentrations in the $H W$ and the VHG in the present study, contrary to results from Vervier et al. (2009) which demonstrated a significant correlation between the VHG magnitude and TP concentration in HW in a gravel-bed river. Consequently, in the studied stream reach, the hydrodynamics of the system likely do not exclusively control the uptake of $P$ from HW to sediments via biotic and abiotic processes in the hyporheic zone.

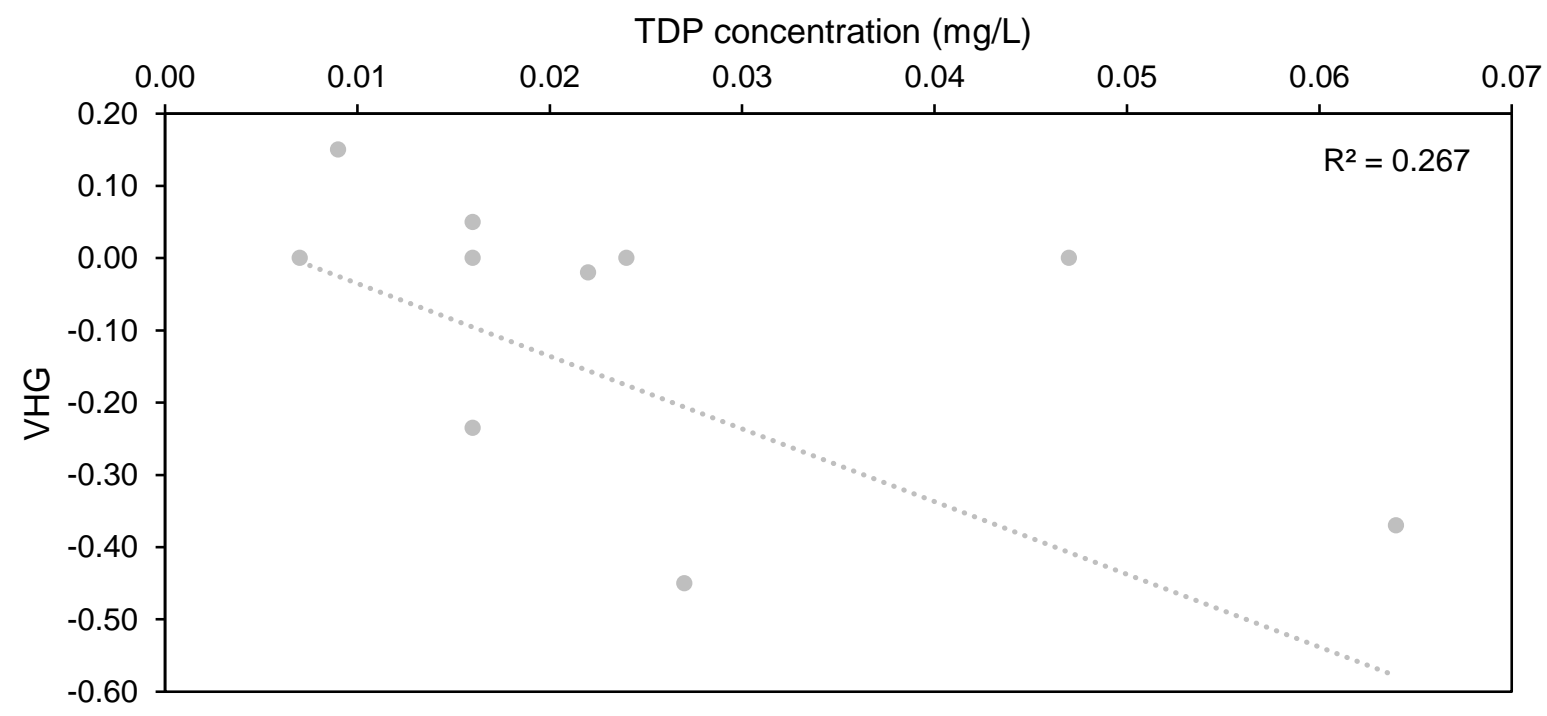

Figure 3-19: Relationship between the vertical hydraulic gradient (VHG) and TDP concentrations in the streambed piezometers at the Mooresville research location.

The VHG at the two piezometers was predominantly negative to neutral (zero) suggesting that the stream reach is downwelling, or losing, throughout most of the year. Water in downwelling zones generally mirror the quality of surface water in the reach (Figure 3-18) (Hendricks \& White, 2000). Statistical analyses (t-test, $p>0.05$ ) of the HW and surface water concentrations indicated that there is no statistically significant difference between the concentrations of the two water sources. The uniformity between the two sources may be a function of the downwelling environment in the reach and the strong negative VHG values. 
While there was no significant relationship established between hydraulic exchange and $P$ concentrations in this study, Vervier et al. (2009) found that strong negative VHG values reduce the residence time of water in the hyporheic zone thus limiting the potential for physical and chemical retention of $\mathrm{P}$. In consequence, the reduced contact time between HW and sediments, particularly in downwelling zones, results in analogous concentrations in the stream and hyporheic water in this study. Moreover, the predominantly losing nature of the studied stream further implies that groundwater is likely not a significant nutrient transport pathway to surface water in the watershed.

Monthly discrete sampling of 222-radon at MCGF, MCGL, MTC, and both wells (shallow and deep) at MCGF from Rixon (2018) also suggests that there is no significant flux of groundwater discharging to Parkhill Creek, thus further substantiating the negligible transport of nutrients to surface water via groundwater in the watershed. Groundwater typically has higher values of radon compared to surface water, therefore recent groundwater discharge would manifest as anomalously elevated radon concentrations in the stream (Gleeson et al., 2009). Radon concentrations in the surface water were approximately congruent during the sampling period of June 2017 to May 2018, with only one elevated radon concentration being observed at the MTC research site in December 2017. The uniformity in concentrations thus likely suggests that no substantial groundwater discharge to the stream was observed during this period of time.

\subsubsection{Land management practices \& water quality observations}

The understanding of nutrient concentrations, specifically $\mathrm{P}$, as they relate to land management and fertilization practices is essential to develop and improve agricultural best management practices within the Great Lakes Basin. Agricultural practices, such as fertilizer application methods and tillage systems, have been demonstrated to influence the concentration of nutrients in groundwater and surface water (Kleinman et al., 2009; King et al., 2015; Robinson, 2015). A land owner survey (Appendix D) was conducted in the winter of 2018 and 2019 to document specific fertilization and land management practices employed within the watershed. The response rate of this survey was limited, thus continual effort to engage land owners in the watershed in the research survey would help fill knowledge gaps regarding the use certain practices and/or techniques. 


\subsubsection{Landowner survey results}

Corn, soybeans, and winter wheat are the main types of crops in the watershed, with approximately $92 \%$ of cultivated land under corn-soybeans-wheat rotation (Agricultural and Agri-Food Canada). Corn and soybeans typically occupy approximately the same total cropped area of the watershed (25-30\%), whereas winter wheat accounts for about $15-20 \%$ (Agricultural and Agri-Food Canada). Based on landowner surveys, typical planting and harvesting periods for these three crops are summarized in Table 3-3.

Table 3-2: A summary of typical planting and harvesting periods for corn, soybean, and winter wheat crops (Anonymous land owners, personal communication, 2018, 2019).

\begin{tabular}{lll}
\hline Crop Type & \multicolumn{1}{c}{ Typical Planting Period } & \multicolumn{1}{c}{ Typical Harvesting Period } \\
\hline \hline Corn & Late April to late May & Mid-October to mid-November \\
Soybean & Beginning of May to beginning of June & Mid-September to mid-November \\
Winter wheat & Mid-September to mid-October & Mid-July \\
\hline
\end{tabular}

Results from the landowner survey regarding fertilization practices in the watershed are summarized in Table 3-4. Fertilizer type, application period, and method were generally consistent for each of the crops. An individual landowner commented on the usage of foliar application of liquid fertilizers, if needed as the crop is growing; however, foliar applications are predominantly used to supply micronutrients (e.g. zinc, boron, and manganese) and not macronutrients such as $\mathrm{P}$ and N (Mahanna \& Thomas, 2012). Manure can be used in place for urea, or any commercial $\mathrm{N}$ fertilizer, and is often applied by farmers in the area who have livestock, predominantly hogs, on their properties. 
Table 3-3: A summary of typical fertilizer type, application period, and application type for corn, soybean, and winter wheat crops in the watershed (Anonymous land owners, personal communication, 2018, 2019).

\begin{tabular}{|c|c|c|c|}
\hline $\begin{array}{l}\text { Crop } \\
\text { type }\end{array}$ & Fertilizer type & $\begin{array}{c}\text { Fertilizer } \\
\text { application period }\end{array}$ & $\begin{array}{c}\text { Fertilizer application } \\
\text { type }\end{array}$ \\
\hline \multirow[t]{3}{*}{ Corn } & $\begin{array}{l}\text { Blend of MAPa, potash, } \\
\text { ammonium thiosulfate, zinc }\end{array}$ & $\begin{array}{l}\text { Planting (late April - } \\
\text { late May) }\end{array}$ & $\begin{array}{l}\text { Placement application } \\
\text {-banded or in-furrow }\end{array}$ \\
\hline & $\begin{array}{l}\text { UAN }^{\mathrm{b}}, \quad \text { urea, } \\
\text { anhydrous ammonia }\end{array}$ & $\begin{array}{l}\text { Pre-plant, at plant, } \\
\text { and 3-6 weeks post } \\
\text { plant (June) }\end{array}$ & $\begin{array}{l}\text { Placement application } \\
\text {-banded or in-furrow }\end{array}$ \\
\hline & Manure (alternative to UAN) & Pre-plant & $\begin{array}{l}\text { Surface applied and } \\
\text { incorporated within } 48 \\
\text { hours }\end{array}$ \\
\hline Soybeans & $\begin{array}{l}\text { Blend of potash, urea, slow- } \\
\text { release N, MAP }\end{array}$ & Planting (May-June) & $\begin{array}{l}\text { Placement application } \\
\text { - banded or in-furrow }\end{array}$ \\
\hline \multirow[t]{3}{*}{$\begin{array}{l}\text { Winter } \\
\text { wheat }\end{array}$} & $\begin{array}{l}\text { Blend of MAP, urea, UAN, } \\
\text { ammonium thiosulfate, } \\
\text { potash }\end{array}$ & $\begin{array}{l}\text { Planting (mid- } \\
\text { September - mid } \\
\text { October) }\end{array}$ & $\begin{array}{l}\text { Placement application } \\
\text { - in-furrow }\end{array}$ \\
\hline & $\begin{array}{l}\text { Urea (or manure) and } \\
\text { ammonium nitrate }\end{array}$ & Early spring & $\begin{array}{l}\text { Surface applied - } \\
\text { broadcast }\end{array}$ \\
\hline & $\begin{array}{l}\text { Urea (or manure) and } \\
\text { ammonium nitrate, with } \\
\text { ammonium thiosulphate }\end{array}$ & Mid spring & $\begin{array}{l}\text { Surface applied - } \\
\text { broadcast }\end{array}$ \\
\hline
\end{tabular}


Out of the landowners surveyed, $75 \%$ indicated that they use conservation tillage practices on their cultivated land. No-till is the predominant soil tillage practice in the watershed, followed by minimum till methods such as strip till which disturbs only the fraction of soil that is to contain the seeds, both of which are conservation tillage practices. Conventional tillage practices in the watershed, comprising the other $25 \%$, include chisel and one way-disk plow amongst others.

\subsubsection{Phosphorus and land management practices}

The main method of $\mathrm{P}$ transfer from agricultural lands to water bodies has traditionally been associated with the erosion of soil particles rich in $\mathrm{P}$ (Daniel et al., 1998). In consequence, best management practices that reduce soil erosion and sediment-bound $\mathrm{P}$ losses are typically implemented to mitigate this transfer pathway. The Ausable Bayfield Conservation Authority has developed a conservation strategy for the area which promotes the reduction of tillage to decrease the exposure of particles to wind or water erosion, which is particularly important in a clay plain setting, resulting in widespread implementation of conservation tillage practices (Ausable Bayfield Conservation Authority, n.d.).

No-till practices have been shown to decrease both erosion and sediment-bound P losses in comparison to conventional tillage (McDowell \& McGregor, 1980; Kleinman et al., 2009; Daryanto et al., 2017). However, increased dissolved $P$ losses in runoff have been attributed to no-till and minimum till practices relative to conventional tillage (McDowell \& McGregor, 1980; Kleinman et al., 2009; Daryanto et al., 2017). No-till soils promote the stratification of $P$ with depth, the development of macropores, and minimal incorporation of fertilizer, all which encourage dissolved P loss from agricultural land (Kleinman et al., 2009).

The ratio of TDP to PP obtained from the results of the monthly surface water sampling indicates that dissolved P comprises the majority $(>70 \%)$ of TP in Parkhill Creek. This is consistent with Mueller et al. (1984) and Kleinman et al. (2009) who found that observed losses of TP from no-till soils were primarily in the dissolved form. Therefore, this likely suggests that the no and minimum till practices in the area are successfully limiting the loss of sediment-bound $\mathrm{P}$ and instead promoting the transfer of dissolved $\mathrm{P}$ to surface water bodies. Considering that nearly $80 \%$ of surface water samples exceed the PWQO $(0.03 \mathrm{mg} / \mathrm{L})$ for TP, it is recommended that conservation tillage be used in combination with other land 
management techniques to reduce dissolved P loss and therefore overall TP concentrations in the watershed (Daryanto et al., 2017).

Loss of $\mathrm{P}$ to surface water bodies is also affected by the timing of fertilizer applications, specifically with respect to the amount and time of rainfall after application (Shigaki et al., 2006). If the application immediately precedes a rainfall event, the transport of $P$ through these pathways may be intensified (Potter et al., 2006). A substantial increase in P (TP, TDP, and SRP) occurred in September 2018 for GOS, MOO, and to a lesser extent MTC. Maximum TP concentrations $(0.230-0.324 \mathrm{mg} / \mathrm{L})$ for these three locations over the year-long study were observed during this sampling event (Figure 3-13). This peak in concentrations coincides with the planting of winter wheat and therefore the application of P-rich fertilizer (MAP) for these crops. MAP is a highly concentrated source of $P(11$ units $N, 24.5$ units $P)$ and is used widely across the watershed on corn, soybean, and winter wheat crops. Survey respondents indicated the use of subsurface placement of P-rich fertilizer for winter wheat in the watershed; however, considering the P concentrations observed in this event, it is likely that this fertilizer was also applied via surface broadcast by certain landowners in the area. A precipitation event occurred the day prior to the sampling event which likely mobilized the dissolved $\mathrm{P}$ in the recently surface-applied fertilizer and transported it via infiltration excess overland flow or the subsurface tile drainage systems to Parkhill Creek. No tile outlet water was sampled on this date, therefore it is uncertain which pathway prevailed for this event. Winter wheat was not planted nearby the MCGL and MCGF locations in 2018 and therefore a peak in $\mathrm{P}$ concentrations was not observed at these sites. Best management practices (BMPs) in the watershed should thus integrate the 4R nutrient stewardship approach (right source, right rate, right time, and right place) (The Fertilizer Institute, n.d.) and highlight the importance of applying fertilizer at the right time to reduce $\mathrm{P}$ loss from fields.

Long-term monitoring of Parkhill Creek at the Provincial (Stream) Water Quality Monitoring Network (PWQMN) station just outside of the southwest border of the watershed (Appendix A-1) indicates that TP concentrations have been on a declining trend since sampling began in 2003 (Figure 3-20). The median concentration of TP from 2003-2016 at this station is 0.101 $\mathrm{mg} / \mathrm{L}$, in comparison to $0.051 \mathrm{mg} / \mathrm{L}$ in this study. However, while TP has been decreasing slowly over the last decade and a half, SRP concentrations at the monitoring station exhibit an upward trend over this time period (Figure 3-21). The median concentration of SRP from 
$2003-2016$ is $0.032 \mathrm{mg} / \mathrm{L}$, in contrast with a median SRP concentration of $0.06 \mathrm{mg} / \mathrm{L}$ (excluding non-detects) during this study. The downward trend in TP in this area is likely attributable to improved land use practices, such as the widespread adoption of conservation tillage as a best management practice. Nonetheless, as previously noted, while conservation tillage has been shown to decrease particulate $\mathrm{P}$ concentrations and therefore overall TP concentrations, this management technique may result in increased dissolved $\mathrm{P}$ losses, including SRP (McDowell \& McGregor, 1980; Kleinman et al., 2009; Daryanto et al., 2017). Consequently, the decrease in TP and increase in SRP is conceivably due to the pervasive no-to-minimum till practices in the watershed.

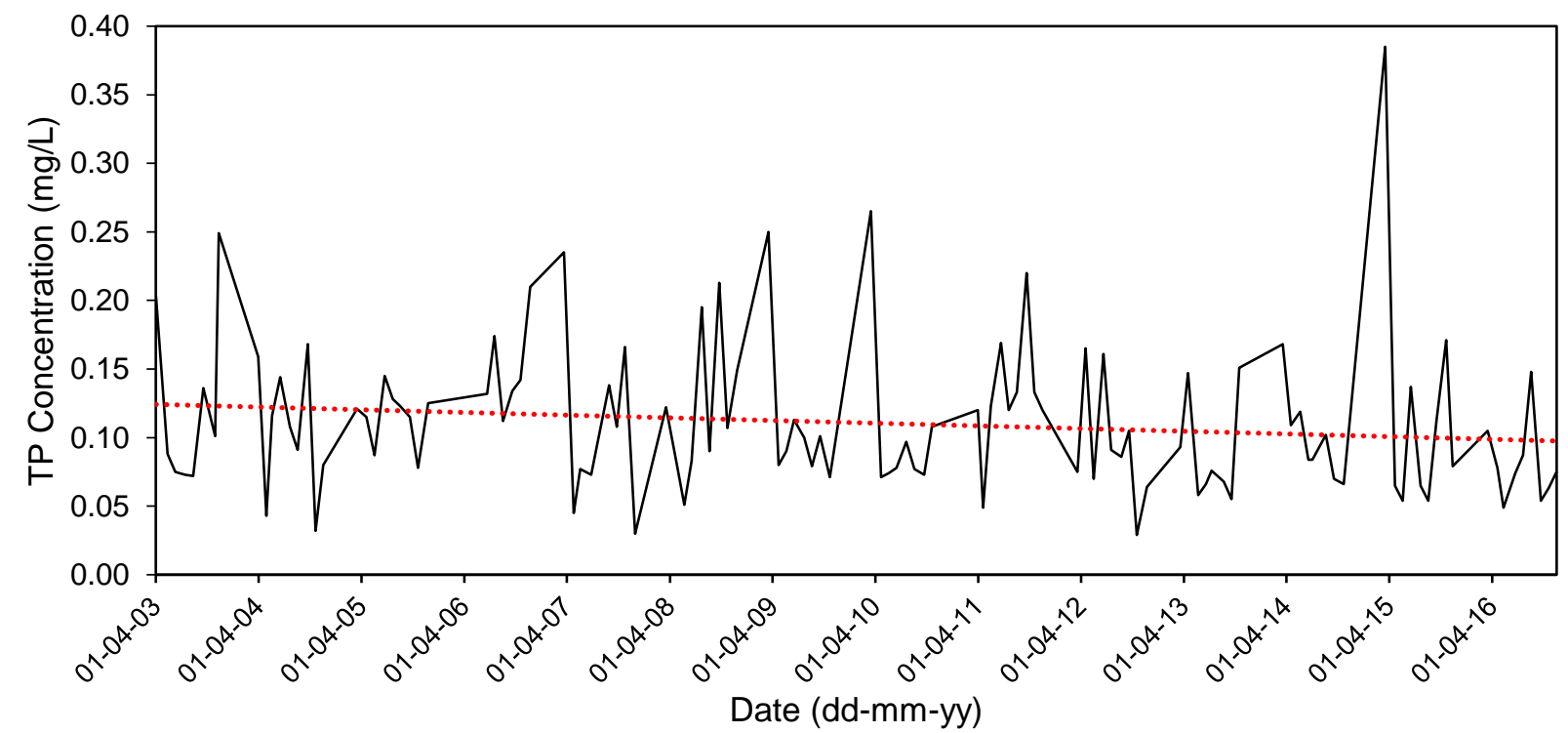

Figure 3-20: Total phosphorus concentrations from discrete sampling events at PWQMN station 0302 from 2003-2016 (Government of Ontario, 2019). 


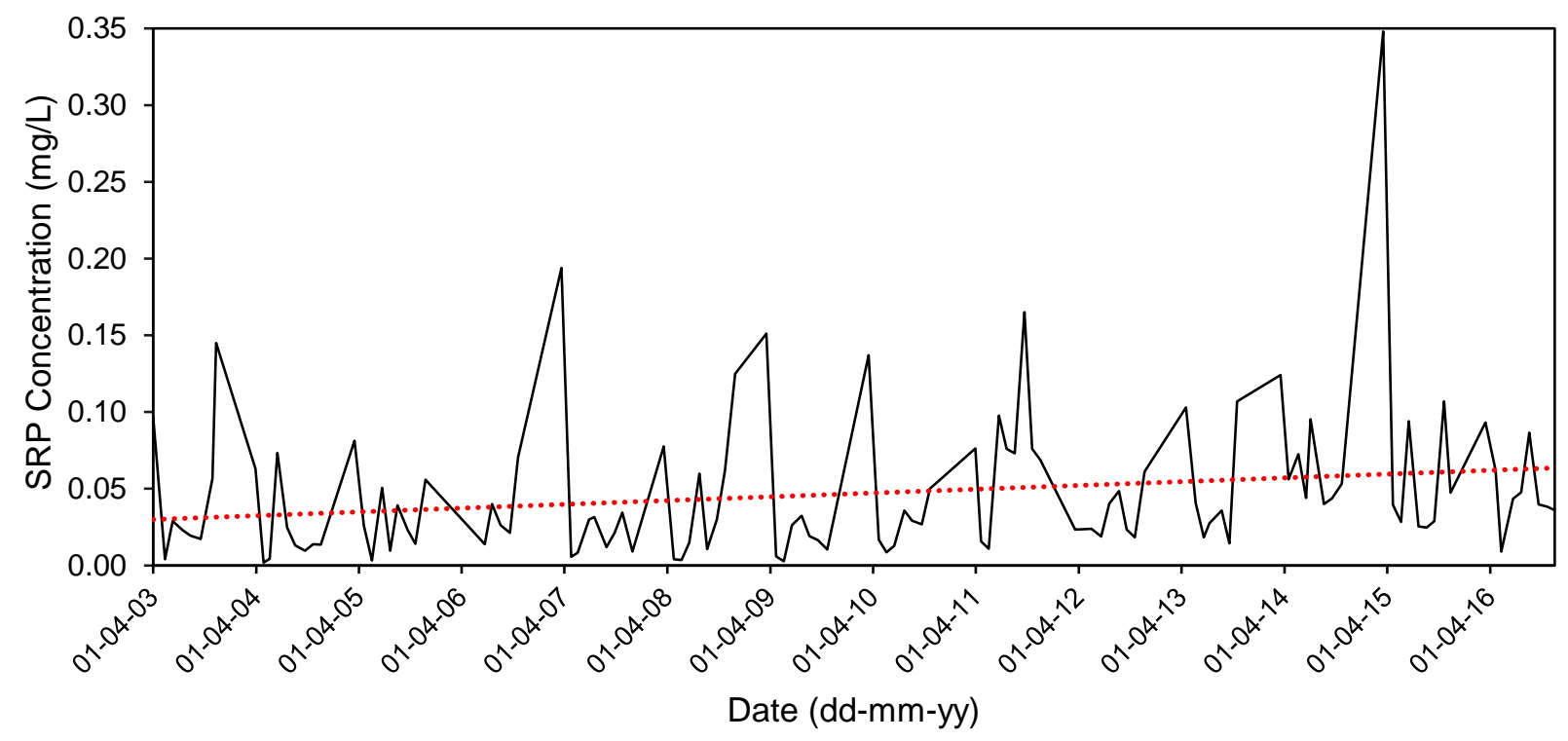

Figure 3-21: Soluble reactive phosphorus from discrete sampling events at PWQMN station 0302 from 20032016 (Government of Ontario, 2019).

The bioavailability of SRP and PP is approximately $100 \%$ and $20-30 \%$, respectively (Baker, 2010 ), and therefore SRP is the $P$ form most readily available to algae. Best management practices in the Upper Parkhill watershed should therefore be refined to incorporate techniques to reduce dissolved $P$ losses. While no single practice will solve the inordinate transport of $\mathrm{P}$ to surface water bodies in the area, a combination of customized practices or measures can be effective in reducing this concern. Additionally, the contribution of "legacy" $\mathrm{P}$, residual $\mathrm{P}$ that has accrued in watersheds over time, needs to be accounted for to effectively develop water quality and best management guidelines for the watershed (Kusmer et al., 2019). The effect of conservation measures on surface water quality is slow and in certain instances, legacy $P$ may conceal the impacts of current best management practices (Sharpley et al., 2013). Consquently, in addition to suggested BMPs to reduce $P$ loss, remedial strategies should also take into consideration the required time for the watershed to re-equilibrate with respect to sources and sinks of P (Sharpley et al., 2013).

Techniques and management practices to consider must start first with nutrient management planning and promote the $4 \mathrm{R}$ nutrient stewardship approach. Based on the average effectiveness of nutrient management plans, this BMP has the potential to reduce dissolved P by $26 \%$ (Gitau et al., 2005). When asked about the amount of fertilizer applied in the survey, only one landowner indicated that the quantity of fertilizer used on their crops was based on 
recommendations from the routine soil samples. Consequently, practices that incorporate managing specifically the application rate of fertilizer, but also the timing and method of application, should be encouraged within the watershed. Reduced fertilizer application implies less opportunity for the generation of dissolved P from the applied product (Cumrine, 2011). Furthermore, applying fertilizer closer to the time of crop utilization and avoiding application prior to rain storms or on frozen or snow-covered soils will positively impact the generation and movement of dissolved $P$ (Cumrine, 2011).

To avoid $\mathrm{P}$ loss through preferential flow pathways to tile drains under no-till systems, nutrient application should be avoided when tiles are actively flowing (Lawrence et al., 2011). Subsurface placement of nutrients, such as via injection or in bands, is encouraged for no-till systems (Johnston \& Bruulsema, 2014) and is often utilized as a management practice to reduce TDP losses. The potential for generation and transport of TDP is significantly reduced when fertilizers are placed in a location that decreases contact between rainfall and runoff and instead increases interactions within the soil or crop (Cumrine, 2011). Recent work by King et al. (2018) showed a 66\% reduction in SRP concentrations in leachate with subsurface placement of $\mathrm{P}$, compared to surface broadcast applications. As placement depth increases, the potential reduction in dissolved $\mathrm{P}$ concentrations also increases (Cumrine, 2011). Partial shallow incorporation of nutrients, using an aerator for example, can also break up preferential flow pathways and reduce P loss to subsurface drainage (Lawrence et al., 2011). While the results of the survey suggest subsurface placement of nutrients is a prevalent management technique in the watershed, it is uncertain to what depth the banding of fertilizer is occurring or the manner in which it is placed. Deeper placement of fertilizer, with a focus on getting the nutrients off the surface of the field, may therefore be a potential practice to explore to improve water quality in the area.

Conservation buffers, such as permanent streamside buffers or in-field buffers, can create opportunities to decrease dissolved $\mathrm{P}$ concentrations in runoff. While buffer strips are generally more effective at reducing PP concentrations in runoff, efficiently designed and located buffers can have a positive effect on dissolved P concentrations as well (Gitau et al., 2005; Cumrine, 2011). Buffers that are not maintained over the long-term are capable of becoming sources of $\mathrm{P}$, therefore it is necessary for vegetation to be effectively managed (Kieta et al., 2018). The average effectiveness of dissolved $P$ removal via filter strips and 
streamside buffers is $26 \%$ and $62 \%$, respectively (Gitau et al., 2005). Permanent streamside buffers with diverse vegetation, including trees, shrubs, and grass, are the most effective, but in-field buffers containing trees or grass can also promote infiltration and slow runoff, thus reducing dissolved $P$ transport (Cumrine, 2011). Buffer width is extremely variable within the watershed, with stream reaches in the northern section of the watershed having almost no streamside buffer vegetation. Consequently, incorporating the use of conservation buffers as a BMP should be a priority for agricultural landowners in the Upper Parkhill watershed.

Since tile drainage is likely a significant pathway for $P$ transport (Figure 3-9), best management practices should also integrate drainage management. The formation of a twostage ditch or stream channel, wherein floodplain benches are added within the overall channel, is a novel BMP currently used in watersheds across the Midwestern US. In these two-stage settings, the tile drain outflows discharge water onto the floodplains, instead of straight into the stream, which can have a similar influence as lateral wetlands (Davis et al., 2015). Variable effectiveness of these channels on reducing dissolved $P$ transport into streams from tile drainage systems has been reported. Mahl et al. (2015) found that this BMP reduced SRP concentrations by $3-53 \%$ in short $(<600 \mathrm{~m})$ two-stage reaches, while Davis et al. (2015) reported that reductions in SRP concentrations occurred only in systems with significant floodplain water retention time. Nevertheless, this two-stage design could be effective at reducing dissolved $\mathrm{P}$ loss in the watershed, in particular if used in combination with other suggested BMPs.

\subsubsection{Conceptual model}

A simplified conceptual model was created to visually compile the dynamics of nutrient transport, specifically $P$, within a reference site in the watershed (Figure 3-22). The red arrows depicting $P$ transport pathways are proportioned based on their relative influence on surface water quality, determined via hydrological observations and overall concentration of nutrients. Biogeochemical transformation processes of $\mathrm{P}$ are indexed in the grey box, with dark grey arrows depicting the locations where these processes can occur. The grey silty clay illustrating the surficial geology in the model was chosen to be representative of typical overburden deposits in the area.

The dominant $\mathrm{P}$ transport pathways in the watershed are overland flow and tile drainage systems. While there was $\mathrm{P}$ observed in the groundwater in this study, it is unlikely that 
groundwater is a significant pathway for $\mathrm{P}$ delivery to Parkhill Creek. It is presumed that the widespread use of tile drains, combined with the clay-rich soils and $\mathrm{P}$ management practices, reduce the mobility of $\mathrm{P}$ in the subsurface and thus limit its migration to the water table and through the system. Significant flux of $\mathrm{P}$ within the hyporheic zone is likely occurring, with more being transported from surface water to groundwater in this zone due to the predominantly losing nature of the stream. Substantial $P$ is believed to be cycled by the streambed sediment, though the explicit contribution of this pathway is unknown.

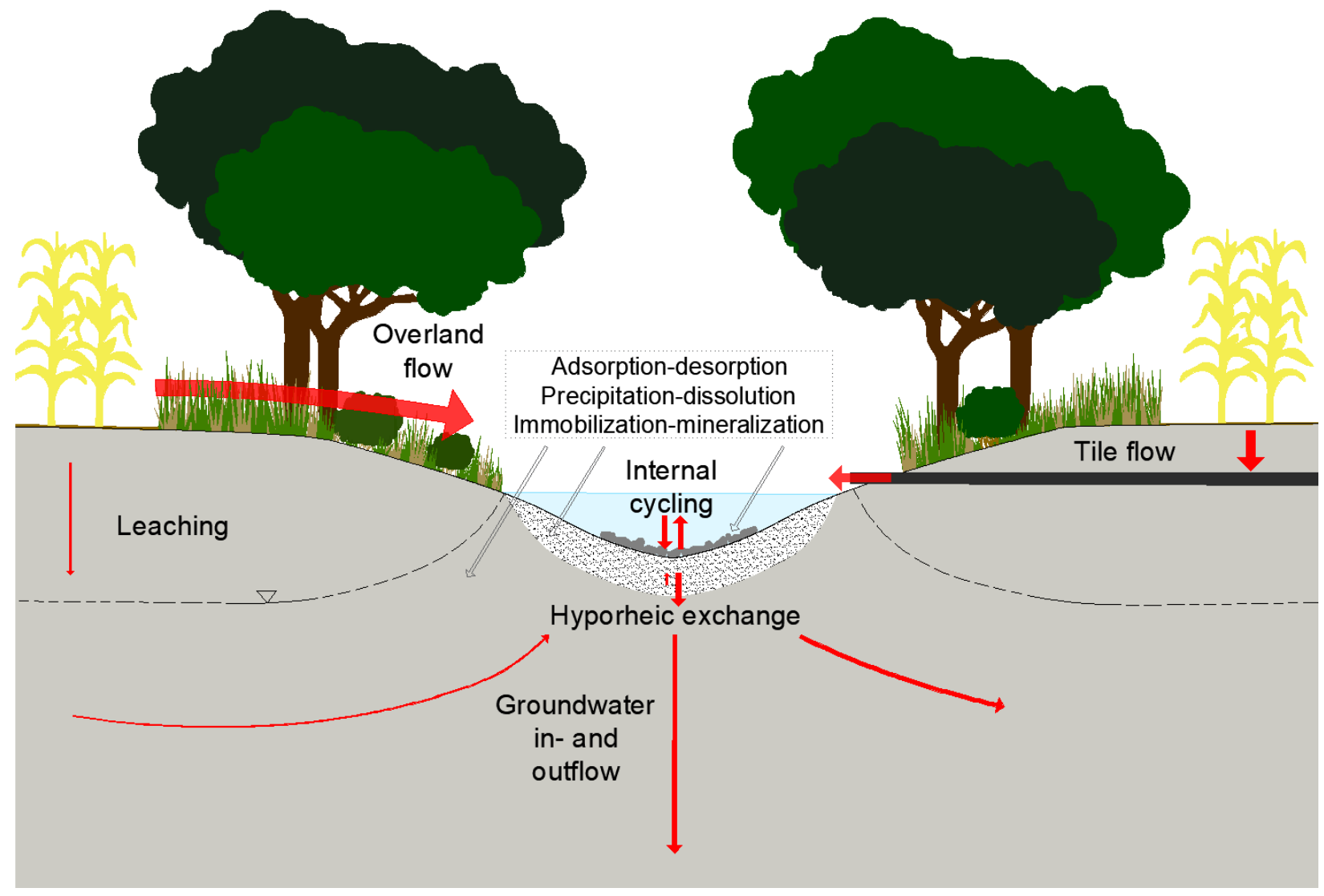

Figure 3-22: Conceptual model of phosphorus transport pathways in the Upper Parkhill watershed. Transport pathways are scaled to illuminate principal nutrient paths in the system.

\subsection{Conclusions \& recommendations}

This research demonstrated the value of field-based data collection to help to fill the knowledge gaps that currently exist concerning nutrient transport through surface water, hyporheic, and groundwater interfaces, and the hydrogeological processes influencing this transport in clay dominated settings. The variability of $\mathrm{P}$ and $\mathrm{N}$ transport and dynamics of nutrient movement in this system were elucidated via the assessment of major pathways and 
their hydraulic connection or relationship with land management practices within the watershed.

Spatial and temporal variations in nutrient concentrations and associated transport dynamics were observed across the study area. While there was no statistically significant difference in $P$ concentrations at the five surface water sampling locations, variations in median concentrations were observed with a highest median concentration at MOO and lowest at MCGF. This thus suggests that the overarching watershed land management practices, rather than site-specific activities, have greater influence on the overall water quality of the stream. The temporal patterns of $P$ and nitrate in this study are similar to previous research, with highest $\mathrm{P}$ concentrations observed throughout summer and fall, and lowest concentrations observed throughout the winter; the inverse of nitrate. Peaks in $P$ concentrations can be correlated to episodic events and/or specific land management activities, such as runoff events ensuing fertilizer application or freeze-thaw cycles within the watershed.

Minimal concentrations of $\mathrm{P}$ and nitrate were observed in the groundwater throughout the study period. Due to the characteristics of the watershed (clay soils, pervasive tile drains), overland flow and tile drainage systems represent the dominant transport pathways of nutrients to Parkhill Creek. Consequently, groundwater is not considered to be a significant source of nutrients, specifically $P$, to the surface water in the area at this time. However, internal cycling of $P$ from stream bed or bank sediments may serve as an important $P$ delivery mechanism due to the high $P$ concentrations found in the surface water during low-flow periods in summer 2018. The exact contribution of this internal loading of $P$ is unknown and should be explored in future research in the area, especially with relation to legacy $P$.

Phosphorus concentrations in the hyporheic zone were within reported ranges in previous studies (e.g. Domagalski \& Johnson, 2011). No statistically significant difference was observed between $\mathrm{P}$ concentrations in the hyporheic and surface water. A weak relationship was observed between the vertical hydraulic gradient and P concentrations in the hyporheic zone, suggesting that in this study, the hydrodynamics of the system do not exclusively control the uptake of $P$ from water to sediments via biotic and abiotic processes in the hyporheic zone. 
Surface water $\mathrm{P}$ concentrations observed in this study combined with historical water quality data for Parkhill Creek suggest that the majority of $P$ delivered to the stream is in the dissolved phase. This predominance of dissolved $P$ likely corresponds to the widespread use of conservation tillage practices in the area. To improve overall water quality in the watershed it is suggested that land owners incorporate best management practices such as modifying nutrient timing and placement (such as deep injection of nutrients rather than broadcast), infield or streamside buffers, and/or channel modification for "buffering" of tile outlet water.

Environmental guidelines (PWQO and CGPAL) were routinely exceeded in Parkhill Creek for both $\mathrm{P}$ and $\mathrm{N}$ throughout the study period. Continual monitoring and evaluation of the inordinate loading of nutrients, specifically $P$, to the stream is necessitated to further understand the dynamics of nutrient transport in the system and improve water quality in the watershed. This extended research effort will be significant for refining nutrient management strategies and agricultural best management practices in the basin.

Further research should incorporate higher-resolution monitoring, such as the inclusion of event-based sampling of both surface and tile drain water, to assess event-based $P$ transport dynamics and speciation in the system. The influence of internal loading of $P$ and significance of legacy $P$ within the watershed should be addressed to lead to effective and sustainable land management practices in the area. Continuous monitoring of the hyporheic zone should be executed throughout the watershed to increase the comprehension of groundwatersurface water interactions' influence on nutrient transport within an agriculturally intensive system. It is expected that the methodology and results from this research can be employed as a reference in the GLB for similar agriculturally intensive systems. 


\section{CONCLUSIONS}

\subsection{Summary of results}

Non-point source agricultural contamination ( $\mathrm{P}$ and $\mathrm{N}$ ) is a serious concern for surface and groundwater quality within the GLB. A year long field-based study in the Upper Parkhill watershed was used to evaluate hydrogeological processes affecting nutrient transport, specifically through groundwater-surface water, and nutrient contamination hot spots. This study revealed dominant transport pathways and hydrogeological processes influencing this transport in clay-dominated subsurface settings. The main conclusions of the study are presented herein.

1. Both spatial and temporal variability in nutrient concentrations were observed in surface and subsurface hydrological pathways throughout the study period. Phosphorus concentrations in surface water were greatest in the summer and following episodic events, while nitrate exhibited an opposite trend with greater concentrations in wetter periods throughout late fall to spring. While concentrations varied at each surface sample location, no statistically significant difference was discerned between the water quality observations.

Overland flow and tile drainage were the dominant nutrient transport pathways in the Upper Parkhill watershed. Low nutrient concentrations were observed in the groundwater and long saturated zone travel times (median of 140 - 206 years) were estimated, thus this subsurface pathway is not presently considered to a significant pathway for nutrient transport to surface water in the area. Internal cycling or loading of $P$ from stream sediments is postulated to be an important $P$ delivery mechanism throughout low flow periods in Parkhill Creek. Future work should focus on assessing the role of this cycling on overall water quality and the influence of legacy $P$ in the watershed.

2. Concentrations of $P$ in the hyporheic zone did not exhibit vast temporal variability throughout the study period. A weak relationship was exhibited between the vertical hydraulic gradient and $P$ concentrations in the hyporheic zone. This indeterminate relationship suggests that $P$ uptake and release is the function of numerous processes and not solely dependent on the hydrodynamics of the system. The predominantly losing nature of the studied stream $(\mathrm{VHG}<0)$ further implies that groundwater is not a significant nutrient transport pathway to surface water in the watershed. No statistically significant difference was observed 
between $\mathrm{P}$ concentrations in the hyporheic and surface water. Continued monitoring of this zone is essential to further the understanding of the role of groundwater-surface water interactions in agricultural nutrient transport.

3. The comprehensive water quality observations in this study, combined with historical data, revealed that much $(>70 \%)$ of the $\mathrm{P}$ in Parkhill Creek is in the dissolved phase. This likely corresponds to the pervasive use of conservation tillage practices in the watershed. It is therefore recommended that BMPs in the area are modified to reduce the loss of dissolved $\mathrm{P}$ and improve overall water quality. Suggested BMPs include adding or augmenting buffer zones (streamside or in-field), reworking channels and positioning of tile outlet onto floodplains, and concentrating on pertinent nutrient stewardship, such as altering the method or timing of nutrient application.

A thorough understanding of where and when nutrient-related water-quality issues are most likely to occur is essential for developing pertinent watershed and land management plans. Nutrient dynamics along principal hydrological pathways were examined in this study, with a focus on the interactions of these systems in a Great Lakes clay plain setting. It is expected that the methodology and results from this research can be employed as a reference in the GLB for similar agriculturally intensive systems and will be significant for refining nutrient management strategies and agricultural best management practices in the basin.

\subsection{Study limitations \& recommendations}

While this this study provided valuable insight on nutrient dynamics in various hydrological pathways, there were some shortcomings and/or limitations that could be addressed to thoroughly understand nutrient transport and groundwater-surface water interactions. Consequently, in accordance with observations from this study, the following recommendations or continued research are suggested.

Higher-resolution observation and monitoring could enhance the comprehensive understanding of nutrient dynamics in this hydrological system. The spatial resolution for monitoring in the watershed was improved via the addition of two additional surface water and groundwater sampling locations; however, increasing sampling frequency, at these locations, to capture a range of hydrologic events would aid to elucidate event-based $P$ dynamics and speciation in the system. These episodic events, such as intense rainfall or 
winter thaw events, are particularly important for the transport of soluble P (Macrae et al., 2007) and therefore are vital to capture the variability in $P$ speciation during base and event flow.

Similarly, while this study provides a broad year-long snapshot of water quality conditions and hydrological processes in the watershed, long-term monitoring of water quality, hydrological processes, and climatic conditions is necessary to evaluate the effects of current land management processes and best management practices. Legacy $\mathrm{P}$ may conceal or buffer the effects of conservation measures presently occurring within the watershed (Sharpley et al., 2013). In consequence, long-term monitoring would allow for an assessment of the time lag between practice implementation and improvements in water quality and therefore aid to mitigate future degradation of water quality. Furthermore, long-term monitoring is crucial for evaluating the control of climatic conditions on nutrient transport. Conditions in the watershed vary from year to year (e.g. more wet vs. dry years, warm vs. cool years), thus prolonged monitoring would be beneficial to assess the explicit influence of hydro-climatic conditions on nutrient transport, especially under the changing climate.

While quantifying $\mathrm{P}$ concentrations is valuable for evaluating the response of an ecosystem in systems with short residence times (Holman et al., 2008), such as rivers, estimating the loading of $\mathrm{P}$ to Parkhill Creek via the various hydrological pathways would aid to elucidate the principal source of $P$ in the watershed. Consequently, flow rates of the surface and subsurface transport pathways should be measured, along with the concentrations, to obtain an estimation of $\mathrm{P}$ loading through these pathways.

To assess the impacts of legacy $P$ on water quality within the watershed the sampling regime should extend to include sediments (suspended, bed, and core). Phosphorus is highly sorptive and thus often binds with sediments within a surface water body; however, can be internally cycled under fluctuating hydrological and biogeochemical conditions. Evaluating the dynamics of $P$ retention and release in the stream sediment would provide valuable insight on legacy $P$ in the watershed, and thus lead to effective and sustainable land management practices.

The five surface water sampling locations exhibit considerable differences in the extent of riparian zones surrounding the stream. Phosphorus sorbs to fine-grained particles, which are 
preferentially carried away during and following storm events. Riparian zones play an important role in trapping this sediment and thus mitigating the transport of nutrients from fields into surface water bodies (Haycock Associated Limited, 1997). It would be useful to assess the impact of riparian buffer zones on the observed water quality at each sampling location, given the abundance of clay-rich deposits combined with surface runoff dominated flow paths in the watershed. Furthermore, distinct groundwater-surface water interactions occur within the riparian zone, similar to that of the hyporheic zone, and therefore influence nutrient processing within the system. To provide a comprehensive evaluation of groundwater-surface water interactions in the watershed, the exchanges between shallow groundwater and stream water in the riparian zone should be incorporated into the current study.

Considering that the surficial geology in the watershed is dominated by clay and clay tills, soil analyses should be completed to evaluate the presence of macropores. Fine-textured soils with high clay content are more likely to develop these preferential flow pathways, which essential bypass the soil matrix and therefore may influence the amount and form of $P$ reaching the stream network (Simard et al., 2000). Consequently, it would be valuable to assess the potential existence of macropores and their impact on $\mathrm{P}$ transport and speciation within the watershed. 


\section{LITERATURE CITED}

Almasri, M. N. (2007). Nitrate contamination of groundwater: A conceptual management framework. Environmental Impact Assessment Review, 27(3), 220-242.

Agriculture and Agri-Food Canada. (2019). Annual Crop Inventory 2011-2018. Retrieved from https://open.canada.ca/data/en/dataset/ba2645d5-4458-414d-b196-6303ac06c1c9

Agriculture Canada. (1975). Ontario: South Part. Soil Capability for Agriculture. Canada Land Inventory.

Ausable Bayfield Conservation Authority. (n.d.). Soil Health Recent Initiatives. Retrieved from Ausable Bayfield Conservation Authority: https://www.abca.ca/monitoring/soil/

Ausable Bayfield Conservation Authority. (2007). Upper Parkhill Watershed Report Card. Retrieved from Ausable Bayfield Conservation: http://www.abca.on.ca/downloads/reportcard/Upper_Parkhill.pdf.

Ausable Bayfield Maitland Valley. (2008). Ausable Bayfield Maitland Valley Region Tier I Numeric Water Budget. Retrieved from: https://www.sourcewaterinfo.on.ca/uploads/8SD_Water_Budget_Report_Tier_1_ABMV_v_3 _d_3.pdf

Ausable Bayfield Conservation Authority. (2018). Upper Parkhill Watershed Report Card. Retrieved from Ausable Bayfield Conservation: http://www.abca.ca/downloads/WRC_2018_Upper_Parkhill_Web.pdf

Baker, D. B. (2010). Trends in bioavailable phosphorus loading to Lake Erie. Lake Erie Protection Fund, Ohio Lake Erie Commission.

Balderacchi, M., Benoit, P., Cambier, P., Eklo, O., Gargini, A., Gemitzi, A., ... Trevisan, M. (2013). Groundwater Pollution and Quality Monitoring Approaches at the European Level. Critical Reviews in Environmental Science and Technology, 43(4), 323-408.

Banaszuck, P., Wysocka-Czubaszek, A., \& Kondratiuk, P. (2005). Spatial and temporal patterns of groundwater chemistry in the river riparian zone. Agriculture, Ecosystems \& Environment, 107(2), 167-179.

Beauchemin, S., Simard, R., \& Cluis, D. (1998). Forms and concentrations of phosphorus in drainage water of twenty-seven tile-drained soils. Journal of Environmental Quality, 27(3), 721-728.

Boano, F., Harvey, J. W., Marion, A., Packman, A. I., Revelli, R., Ridolfi, L., \& Worman, A. (2014). Hyporheic flow and transport processes: Mechanisms, models, and biogeochemical implications. Reviews of Geophysics, 52(4), 603-679.

Boulton, A. J., Findlay, S., Marmonier, P., Stanley, E. H., \& Valett, H. M. (1998). The functional significance of the hyporheic zone in streams and rivers. Annual Review of Ecology and Systematics, 29(1), 59-81. 
Brouder, S., Hofmann, B., Kladivko, E., Turco, R., Bongen, A., \& Frankenberger, J. (2005). Interpreting Nitrate Concentration in Tile Drainage Water. Agronomy Guide, AY-318-W. Purdue University.

Burkart, M. R., \& Stoner, J. D. (2002). Nitrate in aquifers beneath agricultural systems. Water Science and Technology, 45(9), 19-29.

Burkart, M. R., Simpkins, W. W., Morrow, A. J., \& Gannon, J. M. (2004). Occurrence of total dissolved phosphorus in unconsolidated aquifers and aquitards in lowa. Journal of the American Water Resources Association, 40(3), 827-834.

Bussey, K. W., \& Walter, D. A. (1996). Spatial and Temporal Distribution of Specific Conductance, Boron, and Phosphorus in a Sewage-Contaminated Aquifer Near Ashumet Pond, Cape Cod, Massachusetts. U.S. Geological Survey; Branch of Information Services.

Canadian Council of Ministers of the Environment. (2004). Canadian water quality guidelines for the protection of aquatic life: Phosphorus: Canadian Guidance Framework for the Management of Freshwater Systems. Winnipeg: Canadian Council of Ministers of the Environment.

Canadian Rivers Institute. (2019). SepHydro - Hydrograph Separation Tool. Retrieved from http://canadianriversinstitute.com/tool/pageMain.php

Canadian Soil Information Service. (2013). Soils of Ontario. Government of Canada. Retrieved from http://sis.agr.gc.ca/cansis/soils/on/soils.html

Carlyle, G. C., \& Hill, A. R. (2001). Groundwater phosphate dynamics in a river riparian zone: effects of hydrologic flowpaths, lithology and redox chemistry. Journal of Hydrology, 247(3), 151-168.

Carpenter, S. R., Caraco, N. F., Correll, D. L., Howarth, R. W., Sharpley, A. N., \& Smith, V. H. (1998). Nonpoint pollution of surface waters with phosphorus and nitrogen. Ecological Applications, 8(3), 559-568.

Cooper, A. J. (1979). Quaternary Geology of the Grand Bend-Parkhill Area, Southern Ontario. Ontario Geological Survey Report 188.

Cumrine, J. P. (2011). A working document for the development of a BMP toolbox for reducing dissolved phosphorus runoff from cropland to Lake Erie. Heidelberg University, National Center for Water Quality Research.

Dahm, N. C., Grimm, N. B., Marmonier, P., Valett, H. M., \& Vervier, P. (1998). Nutrient dynamics at the interface between surface waters and groundwaters. Freshwater Biology, 40(3), 427-451.

Daniel, T. C., Sharpley, A. N., \& Lemunyon, J. L. (1998). Agricultural Phosphorus and Eutrophication: A Symposium Overview. Journal of Environmental Quality, 27(2), 251-257.

Daryanto, S., Wang, L., \& Jacinthe, P. (2017). Meta-Analysis of Phosphorus Loss from NoTill Soils. Journal of Environmental Quality, 26, 1028-1037. 
Davis, R. T., Tank, J. L., Mahl, U. H., Winikoff, S. G., \& Roley, S. S. (2015). The influence of two-stage ditches with constructed floodplains on water column nutrients and sediments in agricultural streams. Journal of the American Water Resources Association, 51, 941-955.

Denver, M. J., Cravotta, C. A., Ator, W. S., \& Lindsey, D. B. (2010). Contributions of Phosphorus from Groundwater to Streams in the Piedmont, Blue Ridge, and Valley and Ridge Physiographic Provinces, Eastern United States. Reston, VA: U.S. Geological Survey.

Dickinson, W. T., Kachanoski, R. G., Lobb, D. A., Smithers, J. A., Vyn, T. J., \& Miller, M. H. (1987). Soil Erosion and Phosphorus in Runoff from Agricultural Cropland in Southwestern Ontario. The Centre for Soil and Water Conservation - University of Guelph.

Dillon Consulting Limited. (2004). Middlesex Elgin Groundwater Study. Retrieved from http://thamesriver.on.ca/wp-content/uploads/Groundwater/Middlesex-Elgin/Final_Report.pdf

Djodjic, F., Ulen, B., \& Bergstrom, L. (2000). Temporal and spatial variations in phosphorus losses and drainage in a structured clay soil. Water Research, 34, 1687-1695.

Dolan, D. M., \& Chapra, S. C. (2012). Great Lakes total phosphorus revisited: 1. Loading analysis and update (1994-2008). Journal of Great Lakes Research, 38(4), 730-740.

Domagalski, J. L., \& Johnson, H. M. (2011). Subsurface transport of orthophosphate in five agricultural watersheds, USA. Journal of Hydrology, 409(1), 157-171.

Domagalski, J. L., \& Johnson, H. M. (2012). Phosphorus and Groundwater: Establishing Links Between Agricultural Use and Transport to Streams. U.S. Geological Survey Fact Sheet 2012-3004, 4.

Dubrovsky, N. M., Burow, K. R., Clark, G. M., Gronberg, J. M., Hamilton, P. A., Hitt, K. J., . . . Wilber, W. G. (2010). The Quality of Our Nation's Water - Nutrients in the Nation's Streams and Groundwater, 1992-2004. U.S. Geological Survey Circular 1350.

Eckhardt, K. (2005). How to construct recursive digital filters for baseflow separation. Hydrological Processes, 19, 507-515.

Eckhardt, K. (2008). A comparison of baseflow indices, which were calculated with seven different baseflow separation methods. Journal of Hydrology, 352(1-2), 168-173.

Ellison, E. M., \& Brett, M. T. (2006). Particulate phosphorus bioavailability as a function of stream flow and land cover. Water Research, 40(6), 1258-1268.

Environment Agency. (2015). Phosphorus cycling in rivers. Retrieved from https://assets.publishing.service.gov.uk/government/uploads/system/uploads/attachment_d ata/file/411994/Phosphorus_cycling_in_rivers_report.pdf

Environment and Climate Change Canada. (2018). 1981-2010 Climate Normals and Averages - $\quad$ Thedford Station. Retrieved from http://climate.weather.gc.ca/climate_normals/results_1981_2010_e.html

Environment and Climate Change Canada. (2019). Historical Climate Data - StrathroyMullifarry Climate Station. Retrieved from http://climate.weather.gc.ca/historical_data/search_historic_data_e.html 
Environment Canada. (2017). Phosphorus and Excess Algal Growth. Retrieved from http://www.ec.gc.ca/grandslacs-greatlakes/default.asp?lang=en\&n=6201fd24-1

Findlay, S. (1995). Importance of surface-subsurface exchange in stream ecosystems: The hyporheic zone. Limnology and Oceanography, 40(1), 159-164.

Fraser, H., \& Fleming, R. (2001). Environmental Benefits of Tile Drainage: Literature Review. University of Guelph.

Gerardi, M. H. (2008). ORP Management in Wastewater as an Indicator of Process Efficiency. Retrieved from www.neiwpcc.org/iwr/reductionpotential.asp

Gitau, M. W., Gburek, W. J., \& Jarrett, A. R. (2005). A tool for estimating best management practice effectiveness for phosphorus pollution control. Journal of Soil and Water Conservation, 60(1), 1-10.

Gleeson T, Novakowski K, Cook PG, Kyser TK. (2009). Constraining groundwater discharge in a large watershed: Integrated isotopic, hydraulic, and thermal data from the Canadian shield. Water Resources Research, 45(8).

Government of Canada and Government of the United States of America. (2012). Annex 4 Nutrients. Great Lakes Water Quality Agreement 2012.

Government of Canada and Government of the United States of America. (2012, September 7). Great Lakes Water Quality Protocol of 2012. Great Lakes Water Quality Agreement, 56.

Government of Ontario. (2016). Ontario's Great Lakes Strategy. Retrieved from https://www.ontario.ca/page/ontarios-great-lakes-strategy

Government of Ontario. (2019). Provincial (Stream) Water Quality Monitoring. Retrieved from https://www.ontario.ca/environment-and-energy/map-provincial-stream-water-qualitymonitoring-network

Grannemann, G., \& Van Stempvoort, D. (2016). Groundwater science relevant to the Great Lakes Water Quality Agreement: A status report. Environment and Climate Change Canada and U.S. Environmental Protection Agency.

Gregory, P. J., \& Nortcliff, S. (2013). Soil Conditions and Plant Growth. John Wiley \& Sons.

Hansen, N. C., Daniel, T. C., Sharpley, A. N., \& Lemunyon, J. L. (2002). The fate and transport of phosphorus in agricultural systems. Journal of Soil and Water Conservation, 57(6), 408416.

Haycock Associated Limited. (1997). Buffer Zones: Their Processes and Potential in Water Protection. Harpenden, Hertfordshire: Quest Environmental.

Haygarth, P. M., Hepworth, L., \& Jarvis, S. C. (1998). Forms of phosphorus transfer in hydrological pathways from soil under grazed grassland. European Journal of Soil Science, 49(1), 65-72. 
Haygarth, P. M., \& Edwards, A. C. (2009). Water Sample Collection, Handling, Preparation and Storage. Methods of Phosphorus Analysis for Soils, Sediments, Residuals, and Waters. Southern Cooperative Series Bulletin No. 408.

Health Canada. (2013). Guidelines for Canadian Drinking Water Quality: Guideline Technical Document - Nitrate and Nitrite. Ottawa, Ontario: Water and Air Quality Bureau, Healthy Environments and Consumer Safety Branch, Health Canada.

Heathwaite, A. L., \& Dils, R. M. (2000). Characterizing phosphorus loss in surface and subsurface hydrological pathways. Science of the Total Environment, 251-252(1-3), 523-538.

Heathwaite, A., Dils, R. M., Liu, S., Carvalho, L., Brazier, R. E., Pope, L., . . May, L. (2005). A tiered risk-based approach for predicting diffuse and point source phosphorus losses in agricultural areas. Science of the Total Environment, 344(1), 225-239.

Hendricks, G. S., Shukla, S., Obreza, T. A., \& Harris, W. G. (2014). Measurement and modeling of phosphorus transport in shallow groundwater environments. Journal of Contaminant Hydrology, 164, 125-137.

Hendricks, S. P., \& White, D. S. (1995). Seasonal biogeochemical patterns in surface water, subsurface hyporheic, and riparian groundwater in a temperate stream ecosystem. Archive fur Hydrobiologie, 134, 459-490.

Hendricks, S. P., \& White, D. S. (2000). Stream and Groundwater Influences on Phosphorus Biogeochemistry. In J. B. Jones, \& P. J. Mulholland, Streams and Ground Waters (pp. 221235). San Diego, California: Academic Press.

Hill, A. R. (1997). The potential role of in-stream and hyporheic environments as buffer zones. In B. T. Haycock N. E., Buffer zones: their processes and potential in water protection (pp. 115-127). Harpenden, Hertfordshire, England: Quest Environmental.

Hoffmann, C. C., Kjaergaard, C., Uusi-Kämppä, J., Bruun, H. C., \& Kronvang, B. (2009). Phosphorus Retention in Riparian Buffers: Review of Their Efficacy. Journal of Environmental Quality, 38(5), 1942-1955.

Holman, I. P., Howden, N. K., Bellamy, P., Whelan, M. J., \& Rivas-Casado, M. (2010). An assessment to the risk of surface water ecosystems of groundwater $P$ in the UK and Ireland. Science of the Total Environment, 408(8), 1847-1857.

Holman, I. P., Whelan, M. J., Howden, N. K., Bellamny, P. H., Willby, N. J., Rivas-Casado, M., \& McConvey, P. (2008). Phosphorus in groundwater - an overlooked contributor to eutrophication? Hydrological Processes, 22(26), 5121-5127.

Holtan, H., Kamp-Nielsen, L., \& Stuanes, O. (1988). Phosphorus in soil, water and sediment: an overview. Hydrobiologia, 170(1), 19-34.

Hou, D., He, J., Lu, C., Sun, Y., Zhang, F., \& Otgonbayar, K. (2013). Effects of Environmental Factors on Nutrients Release at Sediment-Water Interface and Assessment of Trophic Status for a Typical Shallow Lake, Northwest China. The Scientific World Journal, 2013(3), 16. 
Houser, J. N., \& Richardson, W. B. (2010). Nitrogen and phosphorus in the Upper Mississippi River: transport, processing, and effects on the river ecosystem. Hydrobiologia, 640, 71-88.

Huron Geosciences. (2011). Parkhill Creek Station Monitoring Well Installation.

Hvorslev, M. J. (1951). Time Lag and Soil Permeability in Ground-Water Observations. Bulletin 36, 50. Vicksburg, MS: US Army Engineer Waterways Experiment Station.

International Joint Commission. (2010). Groundwater in the Great Lakes Basin: a report of the Great Lakes Science Advisory Board to the International Joint Commission. Windsor $(\mathrm{ON})$.

Jarvie, H. P., Withers, J. A., \& Neal, C. (2002). Review of robust measurement of phosphorus in river water: sampling, storage, fractionation and sensitivity. Hydrology and Earth System Sciences, 6(1), 113-132.

Johnston, A. M., \& Bruulsema, T. W. (2014). 4R Nutrient Stewardship for Improved Nutrient Use Efficiency. Procedia Engineering, 83, 365-370.

Jørgensen, P. R., Hoffman, M., Kistrup, J. P., Bryde, C., Bossi, R., \& Villholth, K. G. (2002). Preferential flow and pesticide transport in a clay-rich till: Field, laboratory, and modeling analysis. Water Resources Research, 38(11), 1-15.

Ketterings, Q. M., Czymmek, K. K., \& Klausner, S. D. (2003). Phosphorus guidelines for Field Crops in New York. Second Release. Department of Crop and Soil Sciences Extension Series E03-15. Ithaca, NY: Cornell University.

Kiely, G., Morgan, G., Quishi, X., Moles, R., Paul, B., O'Regan, B., . . Manary, W. (2007). Eutrophication from agricultural sources - Soil and phosphorus: Catchment studies. Ireland: Environmental Protection Agency.

Kieta, K. A., Owens, P. N., Lobb, D. A., Vanrobaeys, J. A., \& Flaten, D. N. (2018). Phosphorus dynamics in vegetated buffer strips in cold climates: a review. Environmental Reviews, 26(3), 255-272.

King, K., Williams, M., LaBarge, G. A., Smith, D. R., Reutter, J., Duncan, E. W., \& Pease, L. (2018). Addressing agricultural phosphorus loss in artificially drained landscapes with 4R nutrient management practices. Journal of Soil and Water Conservation, 73, 35-47.

King, K. W., Williams, M. R., Macrae, M. L., Fausey, N. R., Frankenberger, J., \& Smith, R. L. (2015). Phosphorus Transport in Agricultural Subsurface Drainage: A Review. Journal of Environmental Quality, 44(2), 467-485.

Kleinman, P. J., Sharpley, A. N., Saporito, L. S., Buda, A. R., \& Bryant, R. B. (2009). Application of manure to no-till soils: phosphorus losses by sub-surface and surface pathways. Nutrient Cycling in Agroecosystems, 84(3), 215-227.

Kusmer, A. S., Goyette, J. -O., Macdonald, K., Bennett, E. M., Maranger, R., \& Withers, P. J. (2019). Watershed Buffering of Legacy Phosphorus at a Regional Scale: A Comparison Across Space and Time. Ecosystems, 22(1), 91-109. 
Land Information Ontario. (2015). Constructed Drain. Government of Ontario. Retrieved from https://www.javacoeapp.Irc.gov.on.ca/geonetwork/srv/en/main.home?uuid=cc499164-bfe54d66-9fd6-0a442fa7b741

Lapworth, D. J., Gooddy, D. C., \& Jarvie, P. H. (2011). Understanding Phosphorus Mobility and Bioavailability in the Hyporheic Zone of a Chalk Stream. Water, Air, \& Soil Pollution, 218(1), 213-226.

Lawrence, J., Kettering, Q., Czymmek, K., Mahoney, S., Young, E., \& Geohring, L. (2011). Subsurface (Tile) Drainage - Best Management Practices. Agronomy Fact Sheet Series, 58. Cornell University Cooperative Extension.

Lee, D. R., \& Cherry, J. A. (1978). A Field Exercise on Groundwater Flow Using Seepage Meters and Mini-piezometers. Journal of Geological Education, 27, 6-10.

Luinstra, B., Snell, L., Steele, R., Walker, M., \& Veliz, M. (2008). Ausable Bayfield \& Maitland Valley Source Protection Region - Watershed Characterization. Retrieved from http://www.sourcewaterinfo.on.ca/images/uploaded/uploadedDownloads/WC_Chap1.pdf

Macrae, M. L., English, M. C., Schiff, S. L., \& Stone, M. (2007). Intra-annual variability in the contribution of tile drains to basin discharge and phosphorus export in a first-order agricultural catchment. Agricultural Water Management, 92(3), 171-182.

MacRitchie, S. (2011). Assessment of Water Monitoring Networks for Climate Change.

Mahanna, B., \& Thomas, E. (2012). Foliar Feeding has its Limitations. Retrieved from Pioneer: https://www.pioneer.com/home/site/us/silage-zone/corn_silage_grow/foliarfeeding/

Mahl, U. H., Tank, J. L., Roley, S. S., \& Davis, R. T. (2015). Two-stage ditch floodplains enhance $\mathrm{N}$-removal capacity and reduce turbidity and dissolved $\mathrm{P}$ in agricultural streams. Journal of the American Water Resources Association, 51, 923-940.

Mainstone, C. P., \& Parr, W. (2002). Phosphorus in rivers - ecology and management. The Science of the Total Environment, 282, 25-47.

Martin, C., Aquilina, L., Gascuel-Odoux, C., Molenat, J., Faucheux, M., \& Ruiz, L. (2004). Seasonal and interannual variations of nitrate and chloride in stream waters related to spatial and temporal patterns of groundwater concentrations in agricultural catchments. Hydrological Processes, 18, 1237-1254.

Maxxam. (2015). Ontario QA/QC Interpretation Guide - Environmental Services. Retrieved from http://maxxam.ca/wp-content/uploads/2016/03/QAQC_Ontario\%20Guide_2015.pdf

McCobb, T. D., LeBlanc, D. R., Walter, D. A., Hess, K. M., Kent, D. B., \& Smith, R. L. (2003). Phosphorus in a Ground-Water Contaminant Plume Discharging to Ashumet Pond, Cape Cod, Massachusetts, 1999. U.S. Geological Survey Water Resources Investigations Report 02-4306.

McDowell, R. W., Cox, N., Daughney, C. J., Wheeler, D., \& Moreau, M. (2015). A National Assessment of the Potential Linkage between Soil, and Surface and Groundwater 
Concentrations of Phosphorus. Journal of the American Water Resources Association, 51(4), 992-1002.

McDowell, L. L., \& McGregor, K. C. (1980). Nitrogen and Phosphorus Losses in Runoff from No-Till Soybeans. Transactions of the ASAE, 23(3), 643-648.

McDowell, R. W., Sharpley, A. N., Condron, L. M., Haygarth, P. M., \& Brookes, P. C. (2001). Processes controlling soil phosphorus release to runoff and implications for agricultural management. Nutrient Cycling in Agroecosystems, 59(3), 269-284.

McKay, L. D. (1995). Distribution, origin, and hydraulic influence of fractures in a clay-rich glacial deposit. Canadian Geotechnical Journal, 32(6), 957-975.

Meinikmann, K., Hupfer, M., \& Lewandowski, J. (2015). Phosphorus in groundwater discharge - A potential source for lake eutrophication. Journal of Hydrology, 524(c), 214-226.

Mellander, P. E., Jordan, P., Shore, M., McDonald, N. T., Wall, D. P., Shortle, G., \& Daly, K. (2016). Identifying contrasting influences and surface water signals for specific groundwater phosphorus vulnerability. Science of the Total Environment, 541(15), 292-302.

Meyer, J. L., \& Likens, G. E. (1979). Transport and transformation of phosphorus in a forest stream ecosystem. Ecology, 60(6), 1255-1269.

Miller, M. P., Tesoriero, A. J., Capel, P. D., Pellerin, B., Hyer, K. E., \& Burns, D. (2016). Stream Fate of Nitrate Using High-Frequency Water Quality Data. Water Resources Bulletin, 52, 330-347.

Ministry of the Environment and Energy. (1994). Water Management: Policies, Guidelines, Provincial Water Quality Objectives. Ontario Ministry of the Environment and Energy.

Moore, J. (2016). Literature Review: Tile Drainage and Phosphorus Losses from Agricultural Land. Lake Champlain Basin Program.

Mueller, D. K., Wendt, R. C., \& Daniel, T. C. (1984). Phosphorus losses as affected by tillage and manure application. Soil Science Society of America Journal, 48, 901-905.

Mueller, D. K., \& Helsel, D. R. (1996). Nutrients in the Nation's Waters -- Too Much of a Good Thing? U.S. Geological Survey Circular 1136.

Mullen, M. D. (2005). Phosphorus in Soils | Biological Interaction. Encyclopedia of Soil in the Environment, 210-216.

Nieder, R., Benbi, D. K., \& Reichl, F.-X. (2018). Soil Components and Human Health. Springer Netherlands.

Nislow, K. H., Armstrong, J. D., \& McKelvey, S. (2004). Phosphorus flux due to Atlantic salmon (Salmo salar) in an oligotrophic upland stream: effects of management and demography. Canadian Journal of Fisheries and Aquatic Sciences, 61(12), 2401-2410.

Ockenden, M. C., Hollaway, M. J., Beven, K. J., Collins, A. L., Evans, R., Falloon, P. D., . . Haygarth, P. M. (2017). Major agricultural changes required to mitigate phosphorus losses under climate change. Nature Communications, 181, 1-9. 
OMAFRA. (2016). Agriculture in the Great Lakes Basin - Stewardship and Innovation. Retrieved from http://www.omafra.gov.on.ca/english/environment/facts/gl_basin.htm

OMAFRA. (2018). OMAFRA Consolidated Research Priorities. Retrieved from https://www.uoguelph.ca/alliance/sites/uoguelph.ca.omafra_partnership/files/201819\%20Consolidated\%20Research\%20Priorities.pdf

Ontario Ministry of Natural Resources and Forestry. (2019). Surface Water Monitoring Centre. Retrieved from https://www.swmc.mnr.gov.on.ca/kistersweb/main.php?sid=j4vif2nk4hric6jdip33mlce46

Orihel, D. M., Baulch, H. M., Casson, N. J., North, R. L., Parsons, C. T., Seckar, D. M., \& Venkiteswaran, J. J. (2017). Internal phosphorus loading in Canadian fresh waters: a critical review and data analysis. Canadian Journal of Fisheries and Aquatic Sciences, 74(12), 20052029.

Pote, D. H., \& Daniel, T. C. (2009). Dissolved Phosphorus in Water Samples. Methods of Phosphorus Analysis for Soils, Sediments, Residuals, and Waters. Southern Cooperative Series No. 408.

Pote, D. H., Daniel, T. C., \& DeLaune, P. B. (2009). Total Phosphorus and Total Dissolved Phosphorus in Water Samples. Methods of Phosphorus Analysis for Soils, Sediments, Residuals, and Waters, 113-117. (J. L. Kovar, \& G. M. Pierzynski, Eds.) Southern Cooperative Series Bulletin No. 408.

Potter, R. S., Andrews, S., Atwood, J. D., Kellogg, L. R., Lemunyon, J., Norfleet, L., \& Oman, D. (2006). Model Simulation of Soil Loss, Nutrient Loss, and Change in Soil Organic Carbon Associated with Crop Production. United States Department of Agriculture - Natural Resources Conservation Service.

Province of Ontario. (2006). Assessment report: draft guidance module 3, Groundwater vulnerability analysis. Ministry of the Environment. Toronto: Queen's Printer.

Puckett, L. (1995). Identifying the major sources of nutrient water pollution. Environmental Science \& Technology, 29(9), 408-414.

Reddy, K. R., Connor, G. O., \& Gale, P. M. (1998). Phosphorus sorption capacities of wetland soils and stream sediments impacted by dairy effluent. Journal of Environmental Quality, 27(2), 438.

Reid, D. K. (2011). A modified Ontario $P$ index as a tool for on-farm phosphorus management. Canadian Journal of Soil Science, 91(3), 455-466.

Reynolds, C. S., \& Davies, P. S. (2001). Sources and Bioavailability of Phosphorus Fractions in Freshwaters: A British Perspective. Biological Reviews, 76(1), 27-64.

Richardson, C. J., \& Marshall, P. E. (1986). Processes controlling movement, storage, and export of phosphorus in a fen peatland. Ecological Monographs (4), 279-302. 
Rigler, F. H. (1973). A dynamic view of the phosphorus cycle in lakes. In E. J. Griffith, A. Beeton, J. M. Spencer, \& D. T. Mitchell, Environmental Phosphorus Handbook (pp. 539-572). New York: John Wiley and Sons.

Rixon, S. J. (2018). Agricultural Nutrient Transport Through Various Water Pathways in a Great Lakes Clay Plain System. Retrieved from http://hdl.handle.net/10214/14151

Robinson, C. (2015). Review of groundwater as a source of nutrients to the Great Lakes and their tributaries. Journal of Great Lakes Research, 41(4), 941-950.

Rott, E., Duthie, H. C., \& Pipp, E. (1998). Monitoring organic pollution and eutrophication in the Grand River, Ontario, by means of diatoms. Canadian Journal of Fisheries and Aquatic Sciences, 55(6), 1443-1453.

Roy, J. W., \& Bickerton, G. (2014). Elevated dissolved phosphorus in riparian groundwater along gaining urban streams. Environmental Science \& Technology, 48(3), 1492-1498.

Schechter, S. P., Canfield, T. J., \& Mayer, P. M. (2013). Meta-Analysis of Phosphorus Attenuation in Best Management Practices (BMP) and Low Impact Development (LID) Practices in Urban and Agricultural Areas. United States Environmental Protection Agency.

Sea Bird Scientific. (2017). User manual Submersible Ultraviolet Nitrate Analyzer SUNA V2. Retrieved from http://www.seabird.com/sites/default/files/documents/SUNAe.pdf.

SGS. (2018a). Determination of Total and Dissolved Reactive Phosphorous in Aqueous Samples by Skalar Segmented Flow Autoanalyzer.

SGS. (2018b). Determination of Total and Total Dissolved Phosphorous in Aqueous Samples and Extractable Phosphorus in Soil Samples by Skalar Segmented Flow Autoanalyzer.

Sharpley, A. (2015). Managing agricultural phosphorus to minimize water quality impacts. Scientia Agricola, 73(1), 1-8.

Sharpley, A. N. (1985). Depth of Surface Soil-runoff Interaction as Affected by Rainfall, Soil Slope, and Management. Soil Science Society of America, 49(4), 1010-1015.

Sharpley, A. N. (1997). Rainfall frequency and nitrogen and phosphorus in runoff from soil amended with poultry litter. Journal of Environmental Quality, 26, 1127-1132.

Sharpley, A. N., \& Syers, J. K. (1979). Phosphorus inputs into a stream draining an agricultural watershed. Water, Air, and Soil Pollution, 11(4), 417-428.

Sharpley, A. N., Chapra, S. C., Wedepohl, R., Sims, J. T., Daniel, T. C., \& Reddy, K. R. (1994). Managing agricultural phosphorus for protection of surface waters: issues and options. Journal of Environmental Quality, 23(3), 437-451.

Sharpley, A. N., Daniel, T., Sims, T., Lemunyon, J., Stevens, R., \& Parry, R. (2003). Agricultural Phosphorus and Eutrophication, Second Edition. U.S. Department of Agriculture, Agricultural Research Service, ARS-149. 
Sharpley, A., Jarvie, H. P., Buda, A., May, L., Spears, B., \& Kleinman, P. (2013). Phosphorus Legacy: Overcoming the Effects of Past Management Practices to Mitigate Future Water Quality Impairment. Journal of Environmental Quality, 42, 1308-1326.

Sharpley, A. N., McDowell, R. W., \& Kleinman, P. J. (2001). Phosphorus loss from land to water: integrating agricultural and environmental management. Plant and Soil, 237(2), 287307.

Sharpley, A. N., Smith, S. J., Jones, O. R., Berg, W. A., \& Coleman, G. A. (1992). The transport of bioavailable phosphorus in agricultural runoff. Journal of Environmental Quality, 21(1), 30-35.

Sharpley, A., \& Beegle, D. (2001). Managing Phosphorus for Agriculture and the Environment. The Pennsylvania State University.

Shi, P., \& Schulin, R. (2018). Erosion-induced losses of carbon, nitrogen, phosphorus and heavy metals from agricultural soils of contrasting organic matter management. Science of the Total Environment, 618, 210-218.

Shigaki, F., Sharpley, A., \& Prochnow, L. I. (2006). Animal-based agriculture, phosphorus management and water quality in Brazil: options for the future. Scientia Agricola, 63(2), 194209.

Simard, R. R., Beauchemin, S., \& Haygarth, P. M. (2000). Potential for Preferential Pathways of Phosphorus Transport. Journal of Environmental Quality, 29(1), 97-105.

Sims, J. T., Simard, R. R., \& Joern, B. C. (1998). Phosphorus loss in agricultural drainage: historical perspective and current research. Journal of Environmental Quality, 27(2), 277-293.

Singer, S. N., Cheng, C. K., \& Scafe, M. G. (2003). The Hydrogeology of Southern Ontario Second Edition. Environmental Monitoring and Reporting Branch. Ministry of the Environment.

Smeck, N. (1985). Phosphorus dynamics in soils and landscapes. Geoderma, 36(3), 185199.

Smith, D. R., King, K. W., Johnson, L., Francesconi, W., Richards, P., Baker, D., \& Sharpley, A. N. (2014). Surface Runoff and Tile Drainage Transport of Phosphorus in the Midwestern United States. Journal of Environmental Quality, 44(2), 495-502.

Snell and Cecile Environmental Research. (1995). Ausable-Bayfield Conservation Authority: Watershed Management Strategy. Ausable-Bayfield Conservation Authority.

Sousa, M. R., Jones, P. J., Frind, E. O., \& Rudolph, D. L. (2013). A simple method to assess unsaturated zone time lag in the travel time from ground surface to receptor. Journal of Contaminant Hydrology, 144, 138-151.

Spivakov, B. Y., Maryutina, T. A., \& Muntau, H. (1999). Phosphorus speciation in water and sediments. Pure and Applied Chemistry, 71(11), 2161-2176. 
Stamm, C., Fluhler, H., Gachter, R., Leuenberger, J., \& Wunderli, H. (1998). Preferential transport of phosphorus in drained grassland soils. Journal of Environmental Quality, 27(3), 515-522.

Steele, R., \& Veliz, M. (2007). Water Quality in the Ausable Bayfield Maitland Valley Planning Region, Including the Nearshore of Lake Huron. Retrieved from http://www.sourcewaterinfo.on.ca/images/uploaded/uploadedDownloads/WC_Chap2_Mar_ 08.pdf

Tesoriero, A. J., Duff, J. H., Wolock, D. M., Spahr, N. E., \& Almendinger, J. E. (2009). Identifying pathways and processes affecting nitrate and orthophosphate inputs to streams in agricultural watersheds. Journal of Environmental Quality, 38(5), 1892-1900.

The Fertilizer Institute. (n.d.). Retrieved from Nutrient Stewardship: https://www.nutrientstewardship.com/4rs/

The N.C. PLAT Committee. (2005). North Carolina Phosphorus Loss Assessment: I. Model Description and II. Scientific Basis and Supporting Literature. North Carolina Agricultural and Research Service Technical Bulletin 323. Raleigh, N.C.: North Carolina State University.

Triska, F. J., Kennedy, V. C., Avanzino, R. J., Zellweger, G. W., \& Bencala, K. E. (1989). Retention and Transport of Nutrients in a Third-Order Stream: Hyporheic Processes. Ecology, 70(6), 1893-1905.

Valett, H. M., Fisher, S. G., \& Stanley, E. H. (1990). Physical and Chemical Characteristics of the Hyporheic Zone of a Sonoran Desert Stream. Journal of the North American Benthological Society, 9(3), 201-215.

Valett, H. M., Morrice, J. A., Dahm, C. N., \& Campana, M. E. (1996). Parent lithology, surfacegroundwater exchange, and nitrate retention in headwater streams. Limnology and Oceanography, 41(2), 333-345.

Vervier, P., Bonvallet-Garay, S., Sauvage, S., Valett, H. M., \& Sanchez-Perez, J.-M. (2009). Influence of the hyporheic zone on the phosphorus dynamics of a large gravel-bed river, Garonne River, France. Hydrological Processes, 23(12), 1801-1812.

Walling, D. E., Collins, A. L., \& Stroud, R. W. (2008). Tracing suspended sediments and particulate phosphorus sources in catchments. Journal of Hydrology, 350(3), 274-289.

Waterloo Hydrogeologic. (2016). AquiferTest Pro. Retrieved from http://trials.swstechnology.com/software/Aquifertest/2011/AQT_2011.1_Users_Manual.pdf

Withers, P. A., \& Haygarth, P. M. (2007). Agriculture, phosphorus and eutrophication: a European perspective. Soil Use and Management, 23, 1-4.

Withers, P., \& Jarvie, H. P. (2008). Delivery and cycling of phosphorus in rivers: A review. Science of The Total Environment, 400(1), 379-395.

Zhang, T. Q., Tan, C. S., Zheng, Z. M., \& Drury, C. F. (2015). Tile Drainage Phosphorus Loss with Long-Term Consistent Cropping Systems and Fertilization. Journal of Environmental Quality, 44(2), 503-511. 
Zhang, Z. (2007). Effect of Hydrological Regimes on Groundwater Phosphorus Transfer in a Riparian Wetland. UWSpace. 


\section{APPENDICES}

Appendix A - Historical water quality data

\section{A-1 Historical groundwater data}

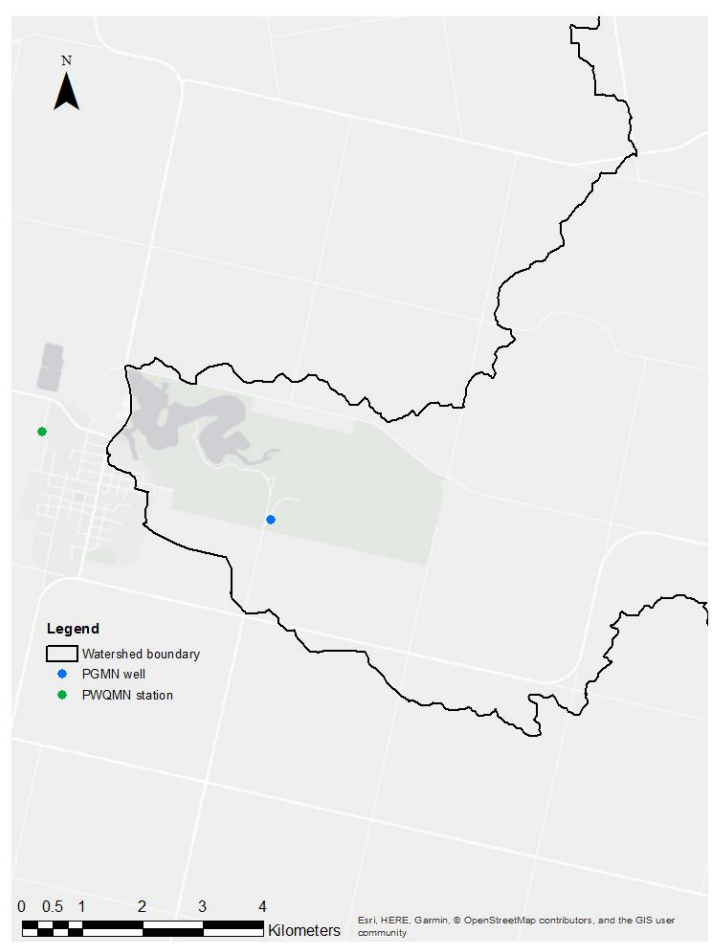

Figure 6-1: Location of PGMN well from which historical groundwater data was obtained.

Sampling date

Total phosphorus (mg/L)

Nitrate-N (mg/L)

\begin{tabular}{ccc}
\hline \hline $25 / 09 / 2003$ & 0.920 & 0.060 \\
\hline $06 / 10 / 2004$ & 0.900 & $<0.01$ \\
\hline $02 / 01 / 2006$ & - & $<0.01$ \\
\hline $11 / 15 / 2006$ & - & $<0.01$ \\
\hline $10 / 30 / 2007$ & - & $<0.01$ \\
\hline $15 / 09 / 2008$ & 10.50 & 0.050 \\
\hline $14 / 10 / 2009$ & 0.630 & 0.050 \\
\hline $28 / 09 / 2010$ & 0.470 & 0.050 \\
\hline $28 / 09 / 2011$ & 0.020 & 0.050 \\
\hline $01 / 10 / 2012$ & - & 0.070 \\
\hline $23 / 09 / 2013$ & 0.075 & 0.124 \\
\hline $04 / 11 / 2013$ & 0.055 & 0.050 \\
\hline $29 / 09 / 2014$ & 0.061 & 0.116 \\
\hline $21 / 09 / 2015$ & 0.300 & 0.020
\end{tabular}

Table 0-1: Historical groundwater data for total phosphorus and nitrate- $\mathrm{N}$ from discrete sampling dates between 2003 and 2015 (Government of Ontario, 2019). 


\section{Appendix B - Site characterization}

\section{B-1 Research site figures and photos}

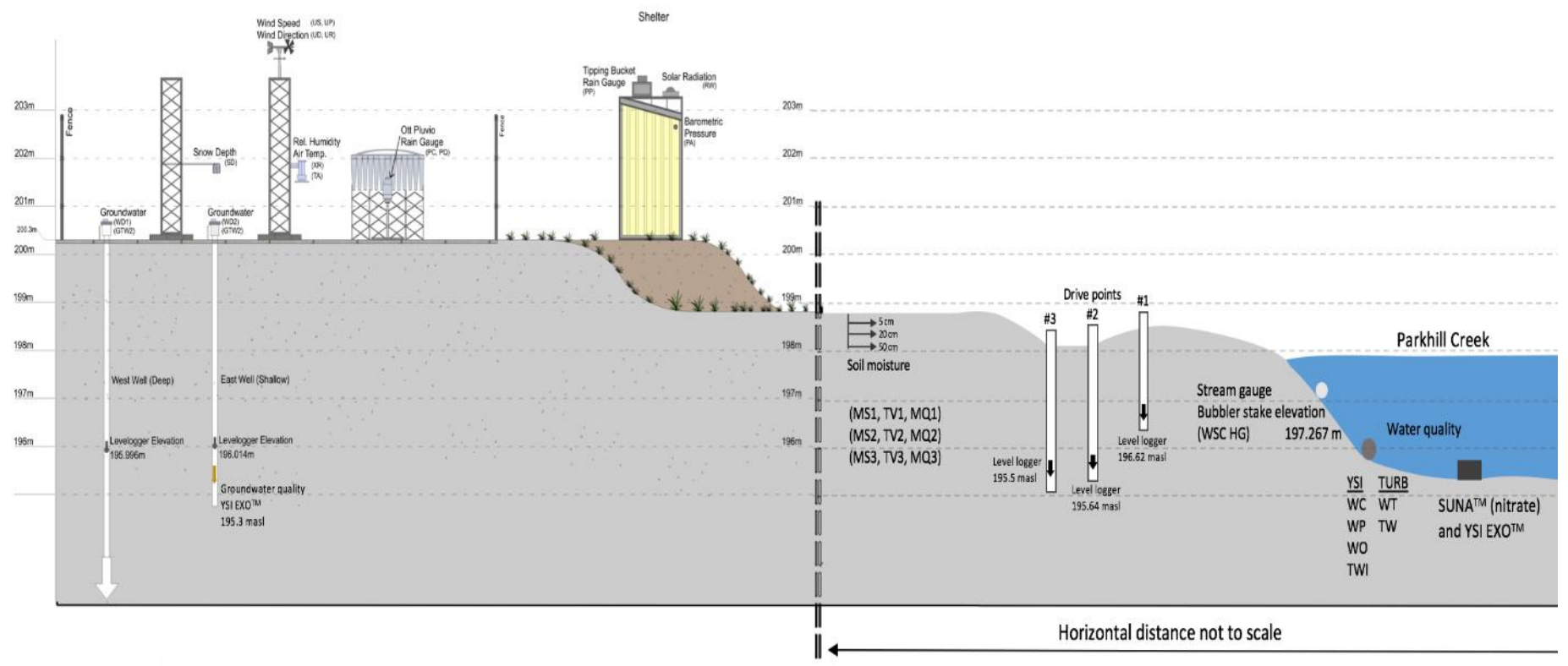

Figure 6-2: Layout of site instrumentation at the McGuffin study location (Integrated Water and Climate Monitoring Station). Adapted from ABCA and E. Persaud (2019).

A

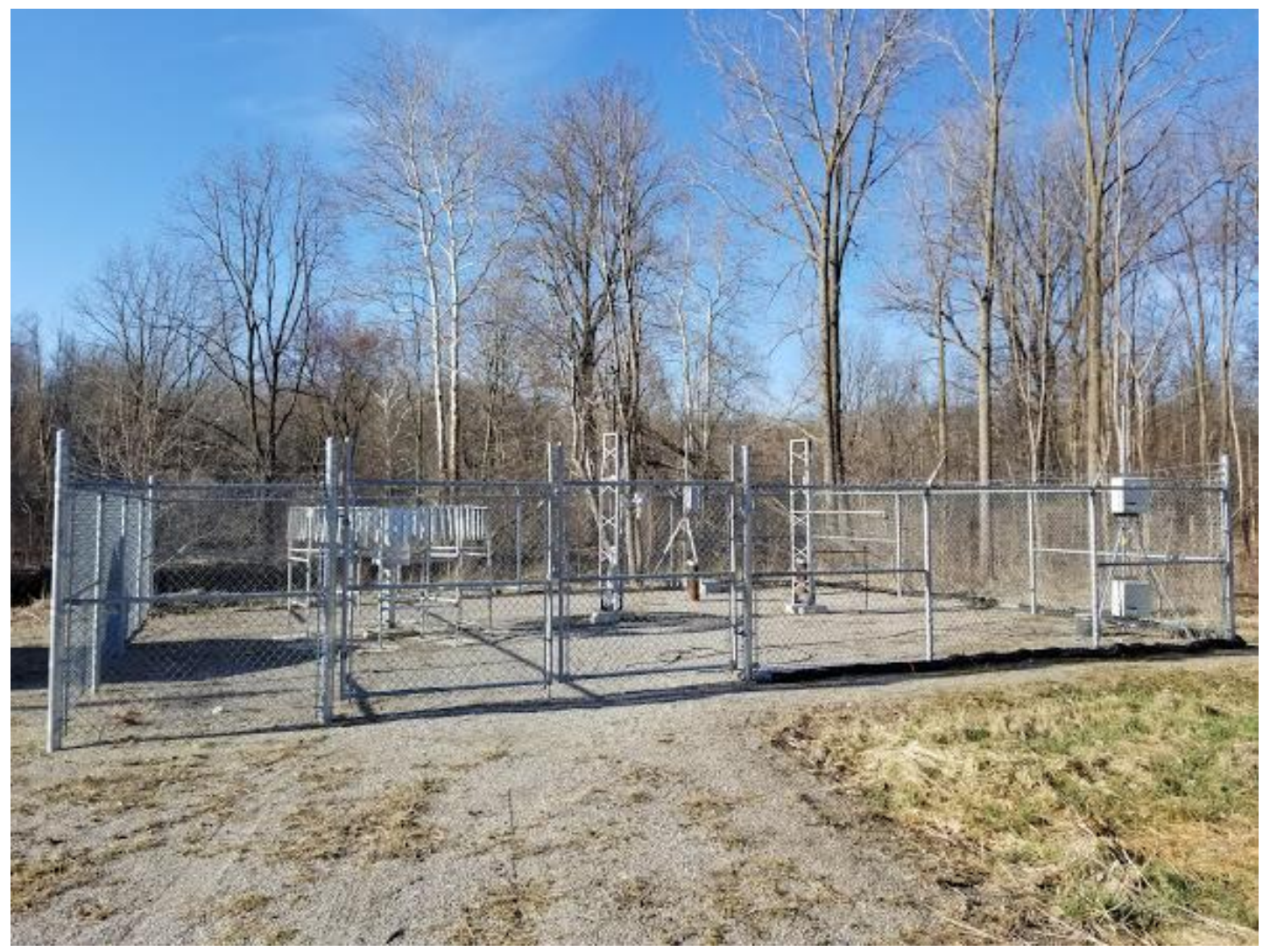




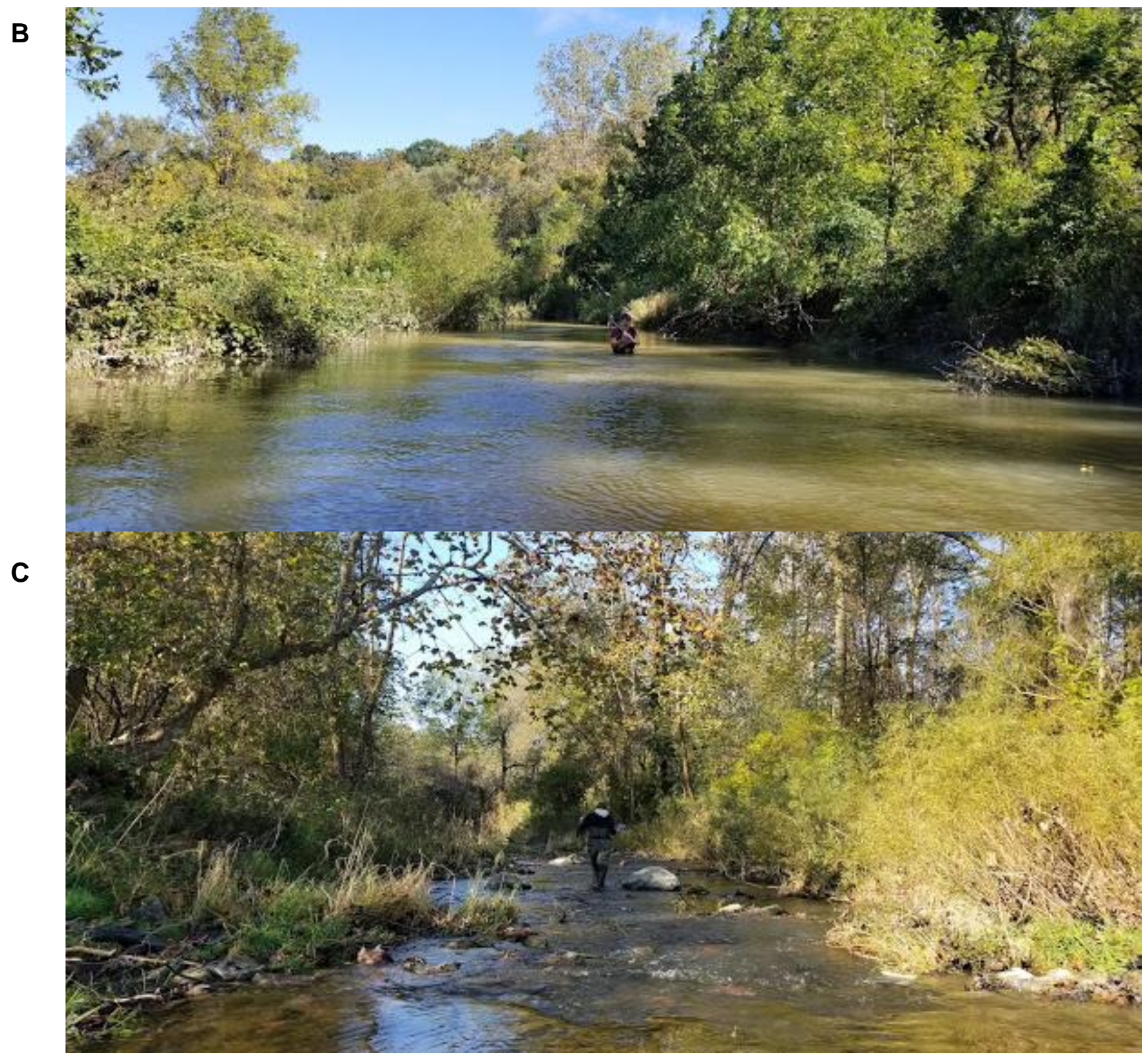

Figure 6-3: Photos of McGuffin research site. A) Site instrumentation. B) Upstream perspective of stream reach. C) Downstream perspective of stream reach. 


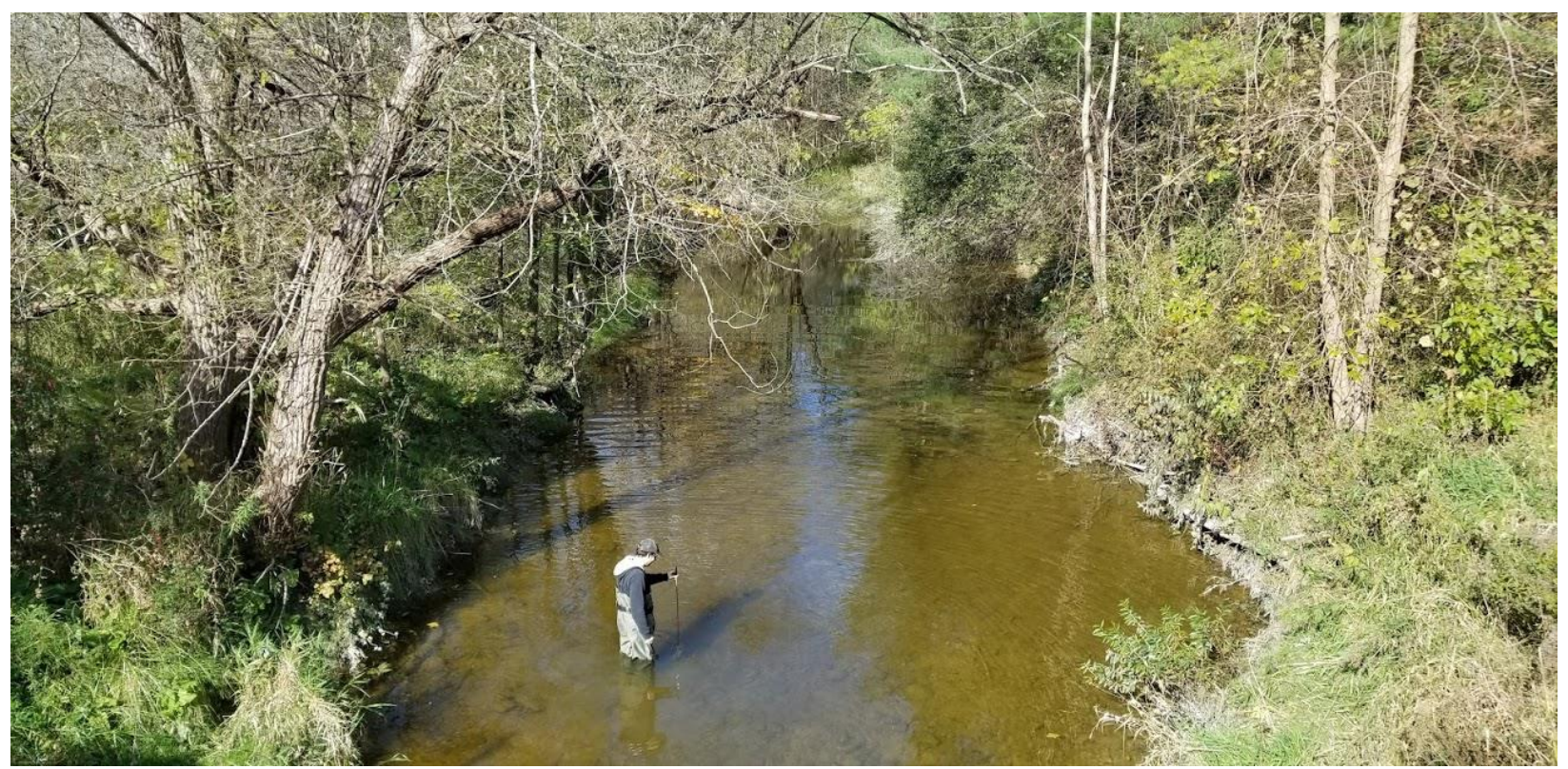

Figure 6-4: Photo of McGillivray research site.

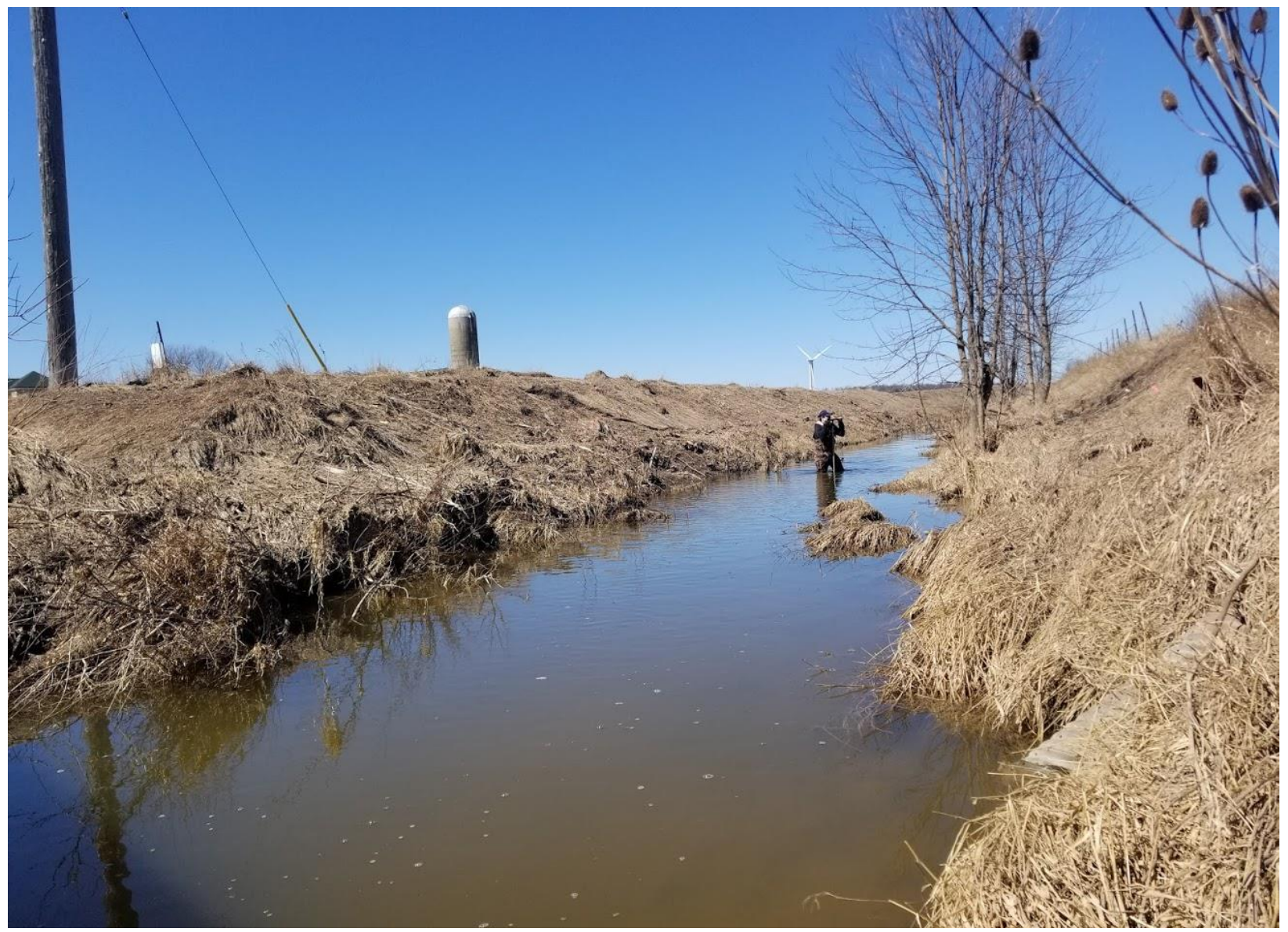

Figure 6-5: Photo of Mount Carmel research site. 
A

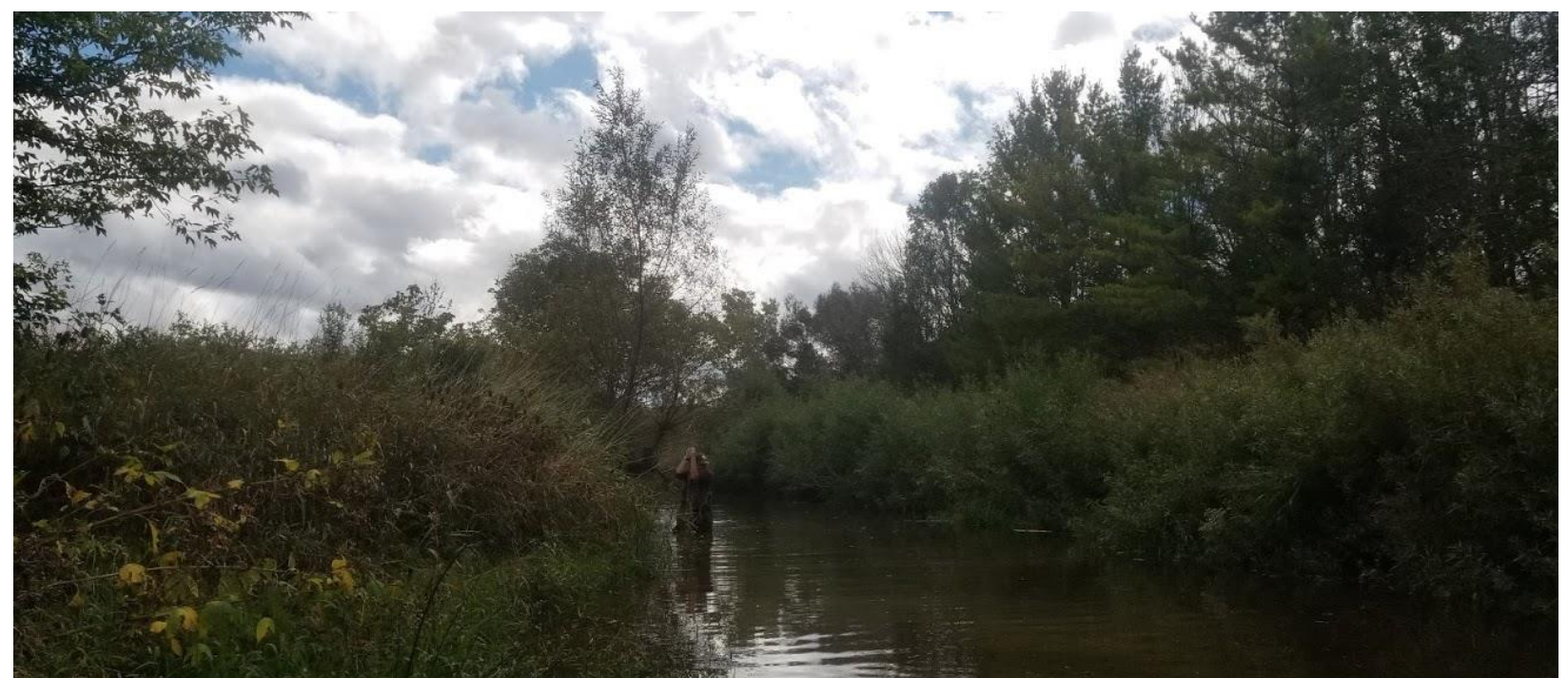

B

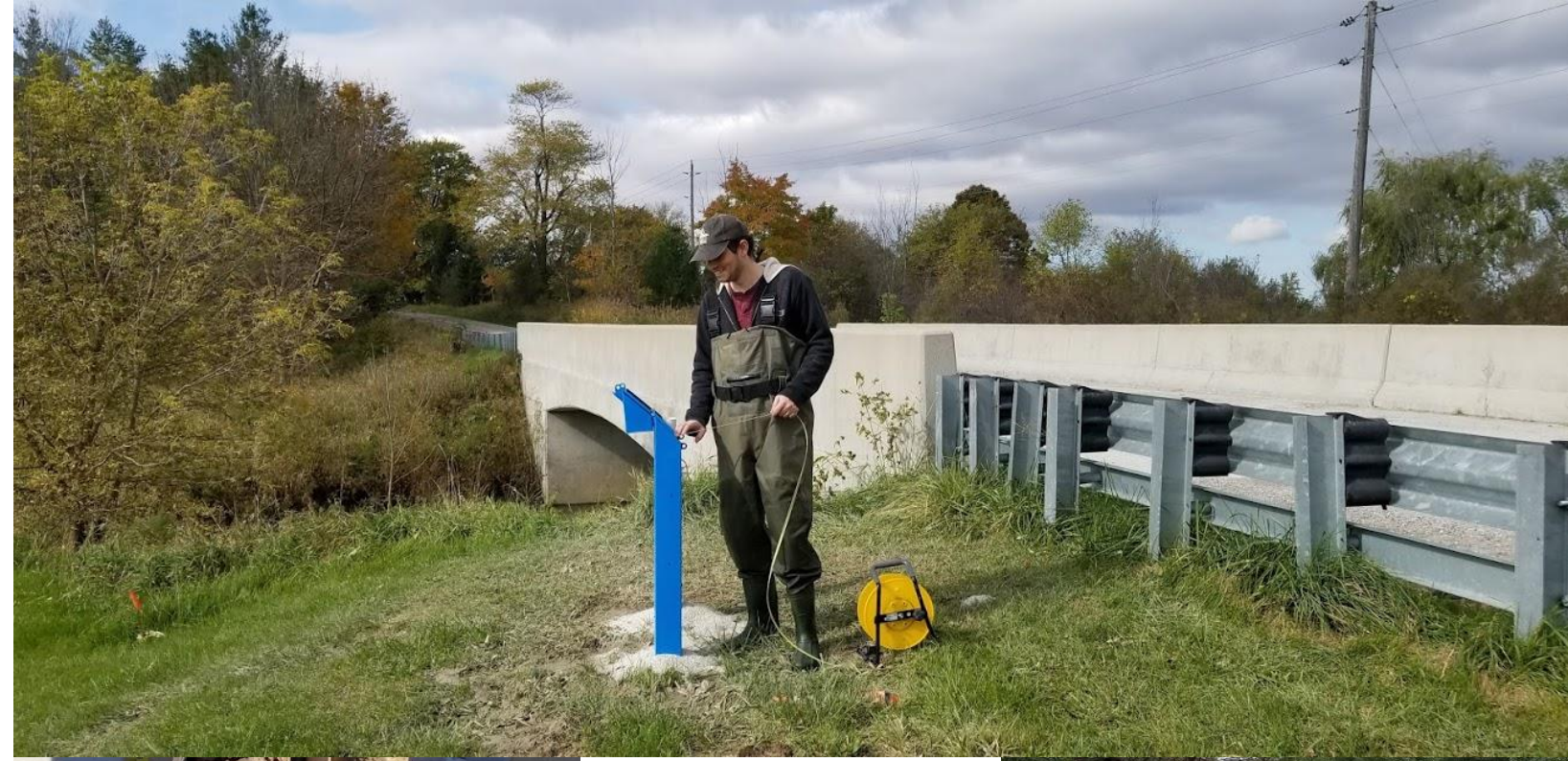

C

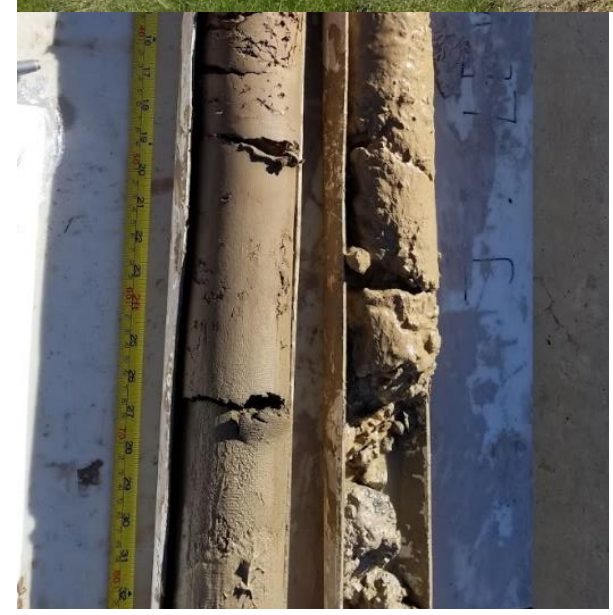

D

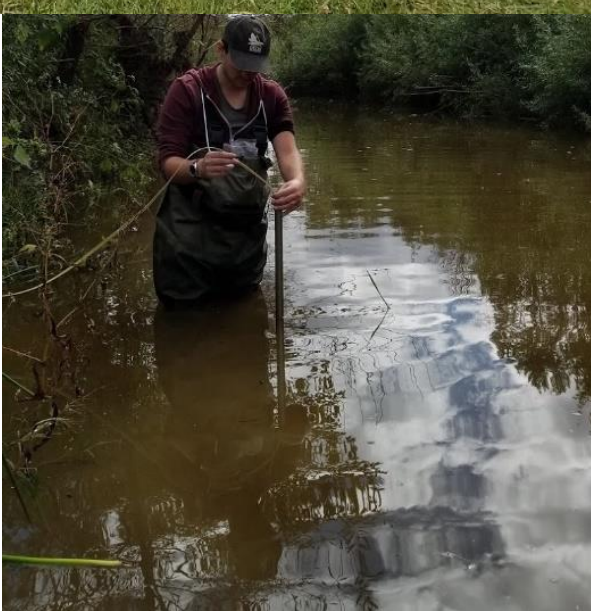

Figure 6-6: Photos of Mooresville research site. A) Stream reach. B) Monitoring well in floodplain adjacent to the stream. C) Close-up of core from drilling of wells at this location. D) Drive-point piezometer in streambed. 
A

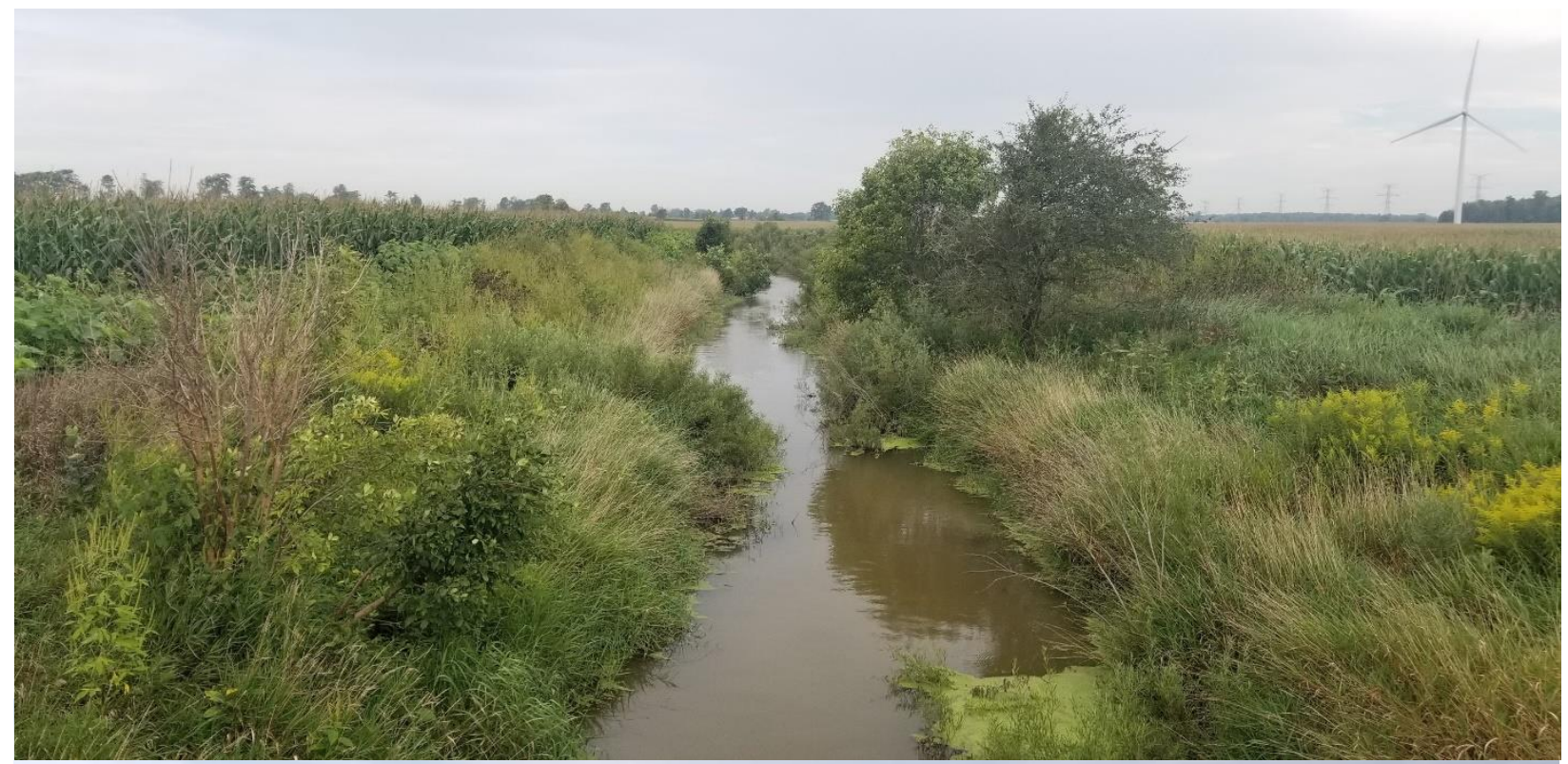

B

C

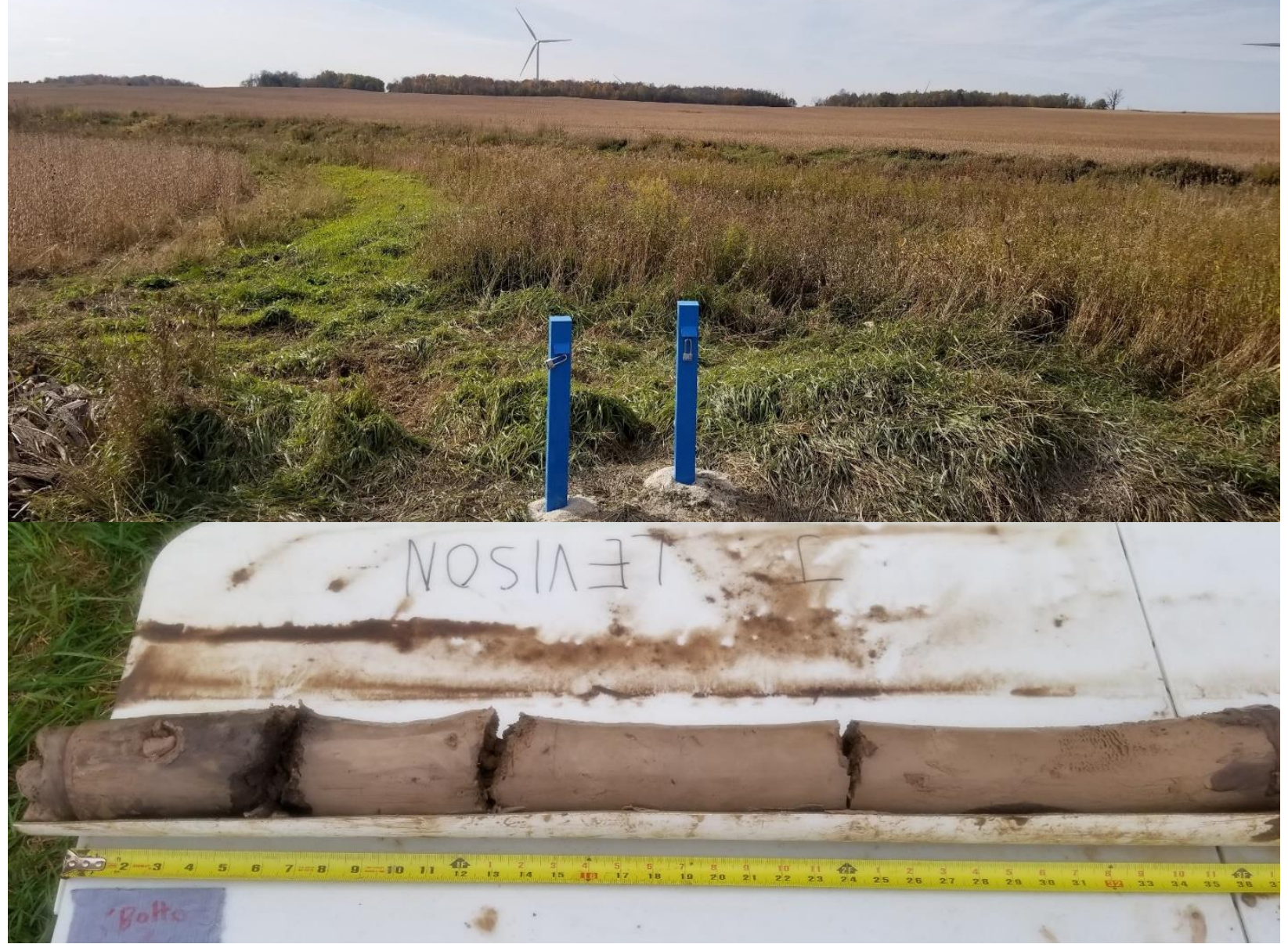

Figure 6-7: Photos of Goshen research site. A) Stream reach. B) Monitoring well locations in floodplain. C) Close-up of core during drilling of wells at this location. 
B-2 Borehole logs 
Client: Ausable Bayfield Conservation

Date Logged: 21/Nov/2011

Date Installed: $21 / \mathrm{Nov} / 2011$

Location: $50 \mathrm{~m}$ southwest of intersection of McGuffin Hills Dr. and Godkin Ln

UTM:17TNAD86 448597E 4779237N +/- 5m

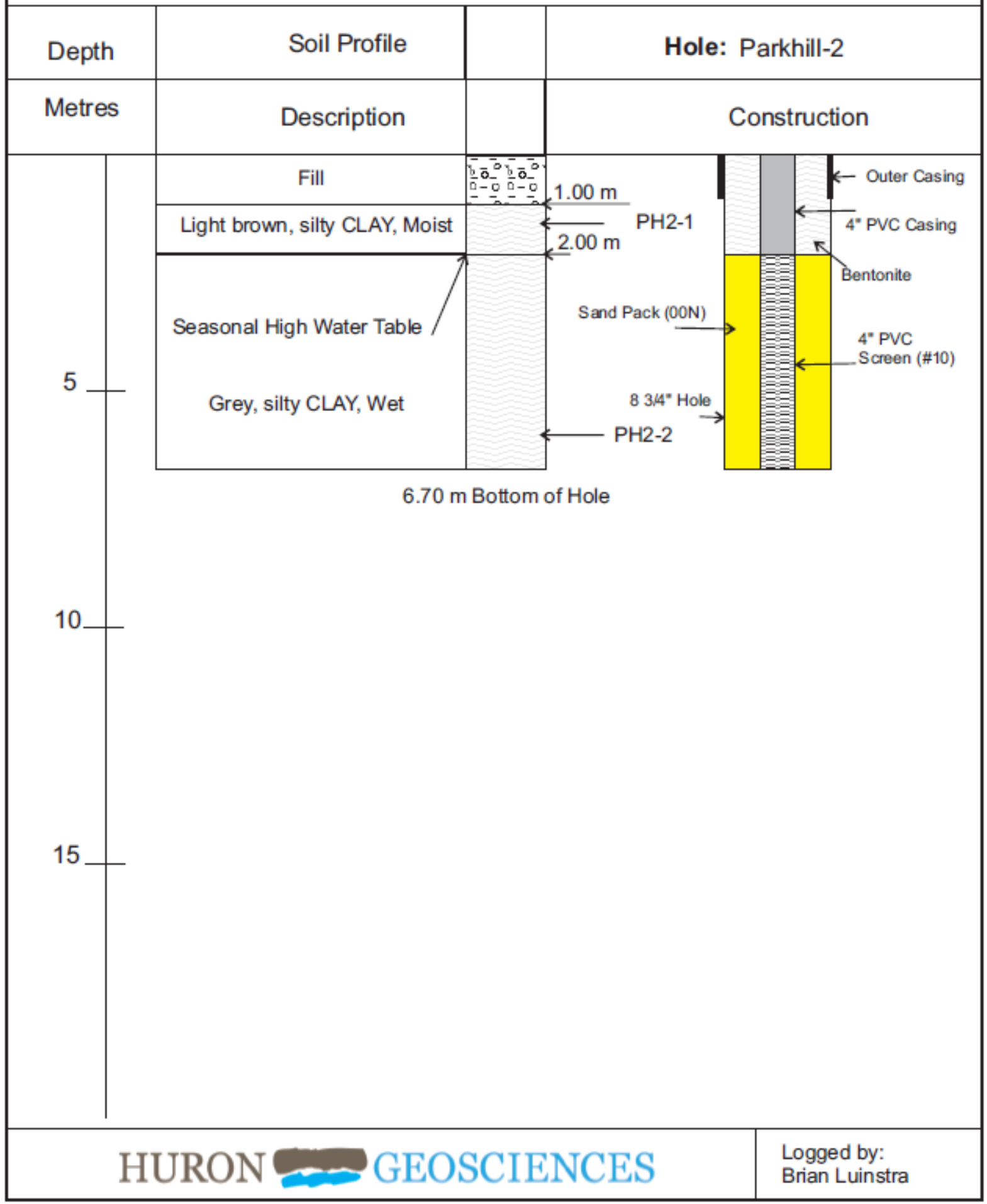

Figure 6-8: Borehole log for shallow McGuffin well (adapted from Huron Geosciences, 2011). 


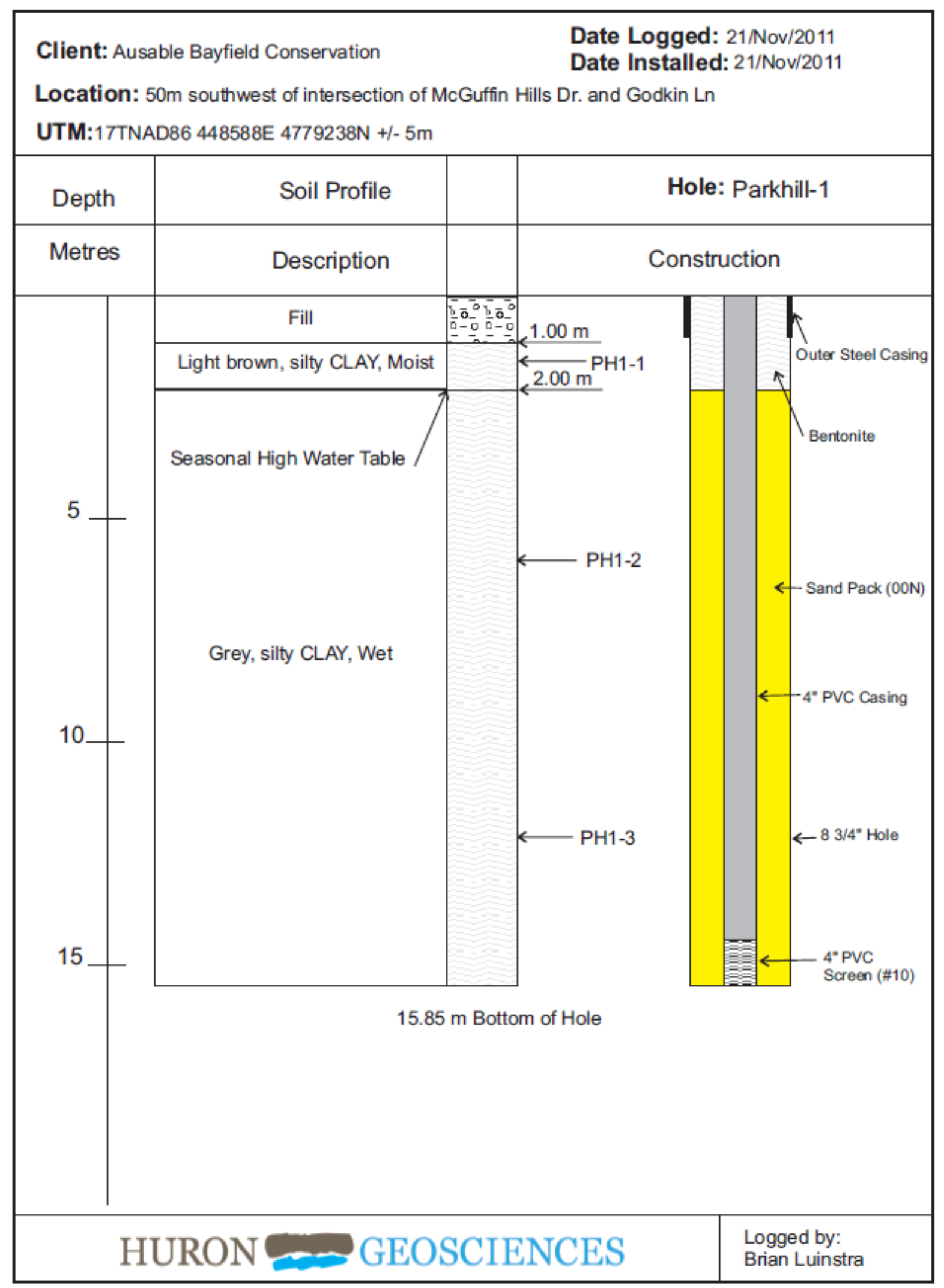

Figure 6-9: Borehole log for deep McGuffin well (adapted from Huron Geosciences, 2011). 


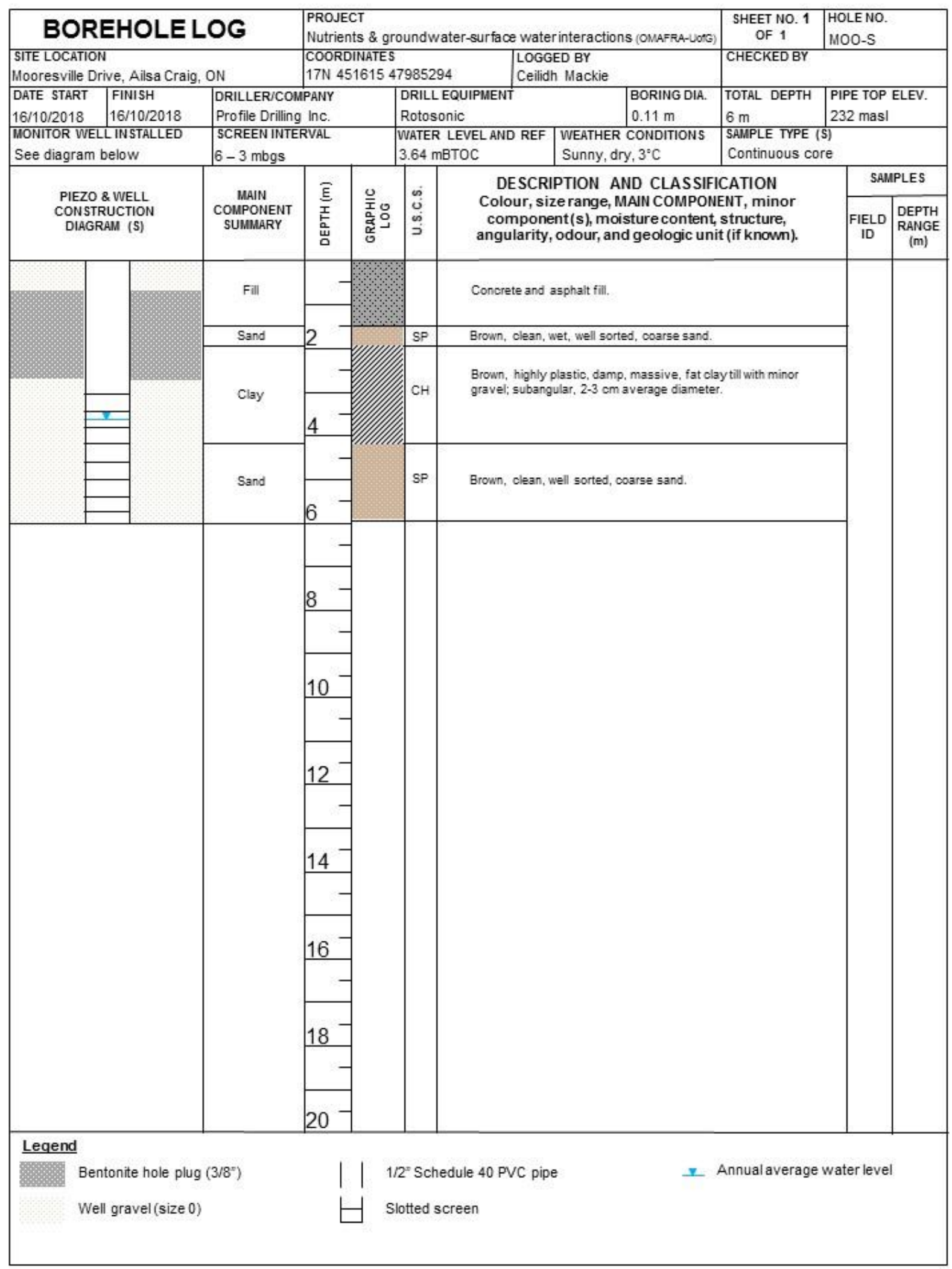

Figure 6-10: Borehole log for shallow Mooresville well. 


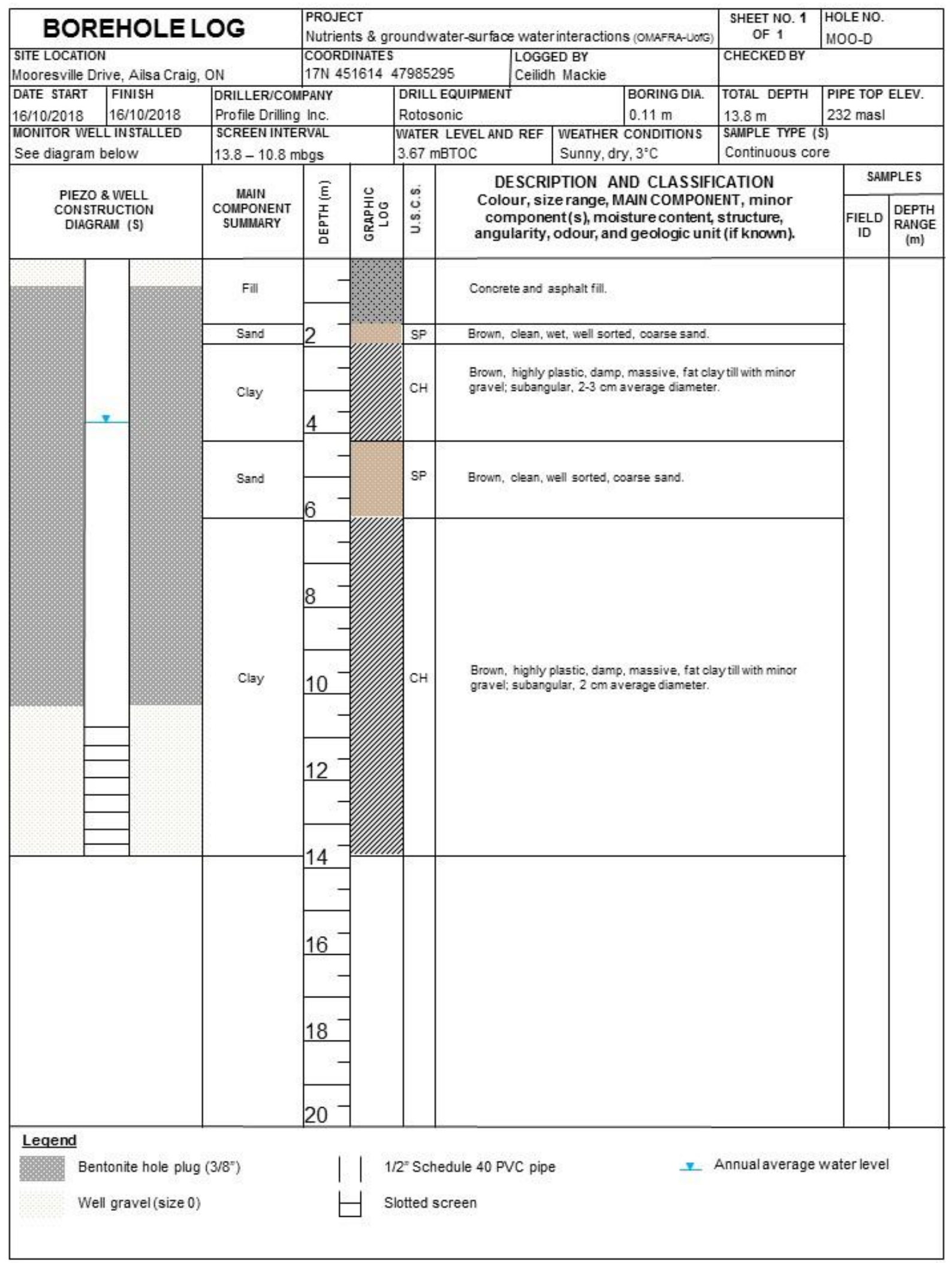

Figure 6-11: Borehole log for deep Mooresville well. 


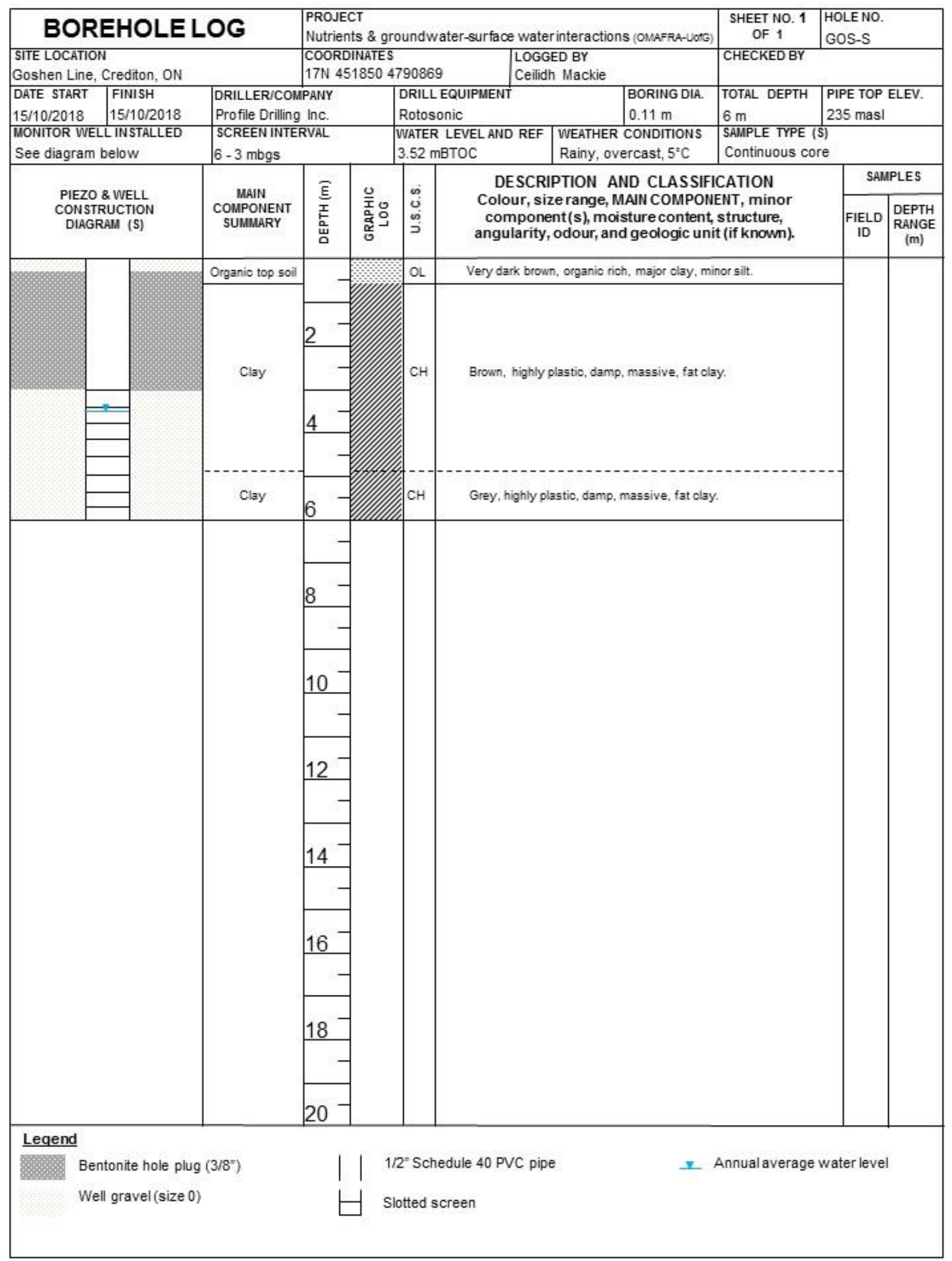

Figure 6-12: Borehole log for shallow Goshen well. 


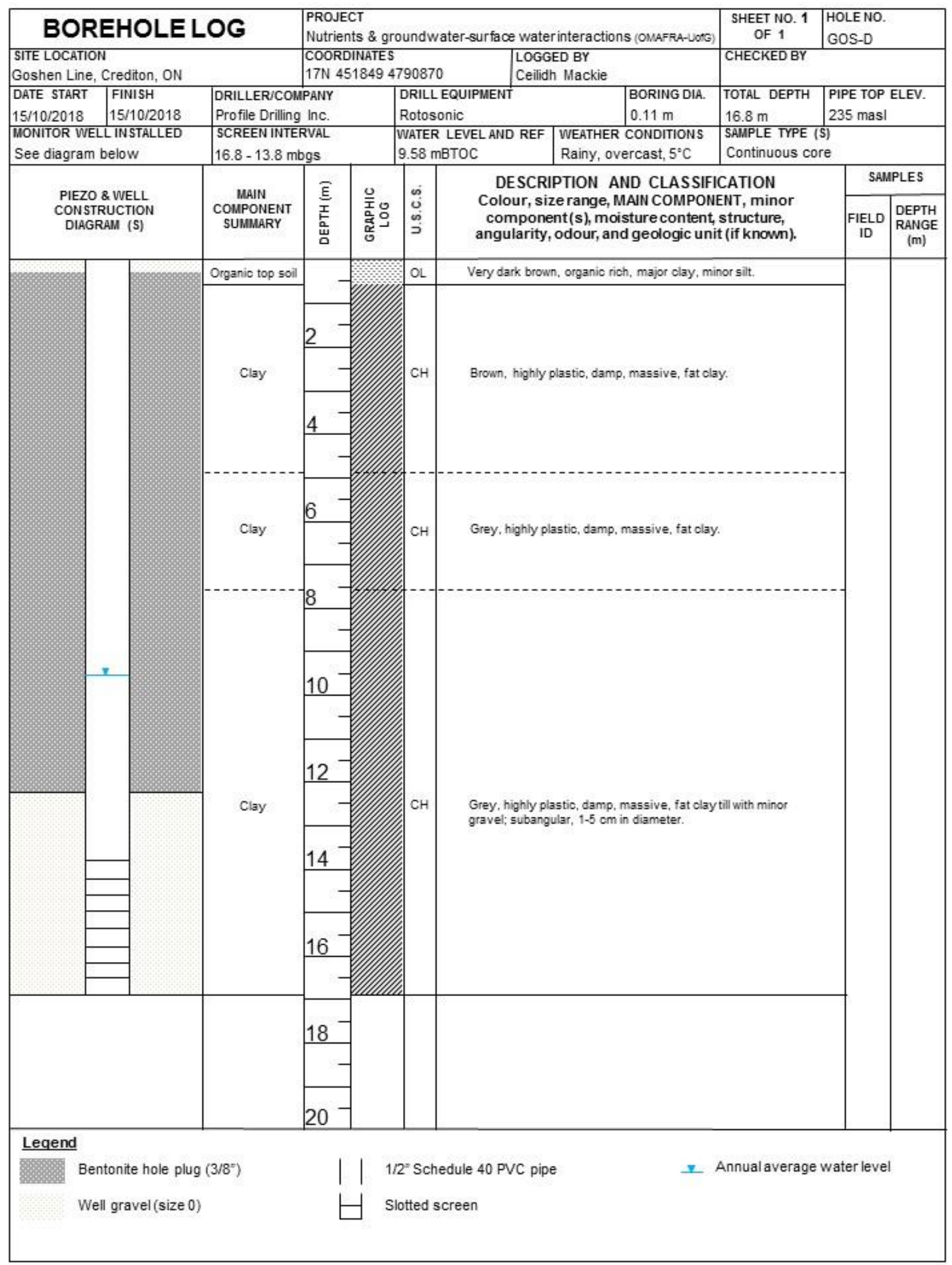

Figure 6-13: Borehole log for deep Goshen well. 
Appendix C - Additional sampling and analysis data

C-1 Phosphorus analytical results for all surface water and groundwater locations.

\begin{tabular}{|c|c|c|c|c|c|c|c|c|c|c|c|c|}
\hline \multicolumn{13}{|c|}{ Total Phosphorus (mg/L) } \\
\hline & $\begin{array}{c}23-06- \\
18\end{array}$ & $\begin{array}{c}25-07- \\
18\end{array}$ & $\begin{array}{c}28-08- \\
18\end{array}$ & $\begin{array}{c}26-09- \\
18\end{array}$ & $\begin{array}{c}25-10- \\
18\end{array}$ & $\begin{array}{c}29-11- \\
18\end{array}$ & $\begin{array}{c}20-12- \\
18\end{array}$ & $\begin{array}{c}30-01- \\
19\end{array}$ & $\begin{array}{c}26-02- \\
19\end{array}$ & $\begin{array}{c}26-03- \\
19\end{array}$ & $\begin{array}{c}30-04- \\
19\end{array}$ & $\begin{array}{c}28-05- \\
19\end{array}$ \\
\hline GOS & 0.047 & 0.163 & 0.125 & 0.324 & 0.058 & 0.068 & 0.023 & 0.007 & 0.276 & 0.026 & 0.034 & 0.032 \\
\hline MOO & 0.061 & 0.091 & 0.136 & 0.324 & 0.070 & 0.060 & 0.039 & - & 0.110 & 0.051 & 0.030 & 0.035 \\
\hline MTC & 0.045 & 0.202 & 0.109 & 0.230 & 0.062 & 0.057 & 0.022 & 0.012 & 0.048 & 0.021 & 0.016 & 0.025 \\
\hline MCGL & 0.071 & 0.137 & 0.169 & 0.066 & 0.019 & 0.069 & 0.031 & 0.042 & 0.140 & 0.050 & 0.030 & 0.038 \\
\hline
\end{tabular}

\begin{tabular}{|c|c|c|c|c|c|c|c|c|c|c|c|c|}
\hline \multicolumn{13}{|c|}{ Total Dissolved Phosphorus (mg/L) } \\
\hline & $\begin{array}{c}23-06- \\
18 \\
\end{array}$ & $\begin{array}{c}25-07- \\
18 \\
\end{array}$ & $\begin{array}{c}28-08- \\
18\end{array}$ & $\begin{array}{c}26-09- \\
18 \\
\end{array}$ & $\begin{array}{c}25-10- \\
18\end{array}$ & $\begin{array}{c}29-11- \\
18 \\
\end{array}$ & $\begin{array}{c}20-12- \\
18\end{array}$ & $\begin{array}{c}30-01- \\
19 \\
\end{array}$ & $\begin{array}{c}26-02- \\
19 \\
\end{array}$ & $\begin{array}{c}26-03- \\
19 \\
\end{array}$ & $\begin{array}{c}30-04- \\
19 \\
\end{array}$ & $\begin{array}{c}28-05- \\
19 \\
\end{array}$ \\
\hline GOS & 0.041 & 0.138 & 0.092 & 0.226 & 0.036 & 0.034 & 0.006 & 0.007 & 0.042 & 0.009 & 0.023 & 0.024 \\
\hline MOO & 0.055 & 0.053 & 0.103 & 0.274 & 0.019 & 0.047 & 0.022 & - & 0.101 & 0.031 & 0.03 & 0.035 \\
\hline MTC & 0.034 & 0.162 & 0.079 & 0.177 & 0.038 & 0.042 & 0.003 & 0.012 & 0.043 & 0.016 & 0.016 & 0.019 \\
\hline MCGL & 0.048 & 0.079 & 0.119 & 0.045 & 0.013 & 0.062 & 0.026 & 0.042 & 0.090 & 0.035 & 0.030 & 0.038 \\
\hline MCGF & 0.056 & 0.027 & 0.121 & 0.018 & 0.014 & 0.076 & 0.026 & 0.016 & 0.129 & 0.022 & 0.028 & 0.116 \\
\hline $\begin{array}{l}\text { MCGF- } \\
\mathrm{S}\end{array}$ & 0.01 & 0.003 & $<0.003$ & 0.008 & 0.011 & 0.085 & 0.018 & 0.081 & 0.003 & 0.075 & 0.012 & 0.009 \\
\hline $\begin{array}{l}\text { MCGF- } \\
\text { D }\end{array}$ & $<0.003$ & 0.005 & $<0.003$ & 0.004 & 0.009 & $<0.003$ & 0.014 & 0.053 & $<0.003$ & $<0.003$ & 0.020 & 0.008 \\
\hline GOS-S & - & - & - & - & - & - & - & - & $<0.003$ & 0.005 & 0.010 & 0.009 \\
\hline GOS-D & - & - & - & - & - & - & 0.150 & - & - & 0.020 & 0.013 & 0.018 \\
\hline $\begin{array}{l}\mathrm{MOO}- \\
\mathrm{S}\end{array}$ & - & - & - & - & - & - & 0.003 & $<0.003$ & $<0.003$ & 0.131 & 0.009 & 0.016 \\
\hline $\begin{array}{l}\mathrm{MOO}- \\
\mathrm{D}\end{array}$ & - & - & - & - & - & 0.005 & $<0.003$ & - & $<0.003$ & 0.007 & 0.033 & 0.024 \\
\hline
\end{tabular}


Soluble Reactive Phosphorus (mg/L)

\begin{tabular}{|c|c|c|c|c|c|c|c|c|c|c|c|c|}
\hline & $\begin{array}{c}23-06- \\
18\end{array}$ & $\begin{array}{c}25-07- \\
18 \\
\end{array}$ & $\begin{array}{c}28-08- \\
18 \\
\end{array}$ & $\begin{array}{c}26-09- \\
18 \\
\end{array}$ & $\begin{array}{c}25-10- \\
18\end{array}$ & $\begin{array}{c}29-11- \\
18\end{array}$ & $\begin{array}{c}20-12- \\
18 \\
\end{array}$ & $\begin{array}{c}30-01- \\
19 \\
\end{array}$ & $\begin{array}{c}26-02- \\
19 \\
\end{array}$ & $\begin{array}{c}26-03- \\
19 \\
\end{array}$ & $\begin{array}{c}30-04- \\
19\end{array}$ & $\begin{array}{c}28-05- \\
19 \\
\end{array}$ \\
\hline GOS & 0.030 & 0.130 & 0.050 & 0.140 & $<0.03$ & $<0.03$ & $<0.03$ & $<0.03$ & $<0.03$ & $<0.03$ & $<0.03$ & $<0.03$ \\
\hline $\mathrm{MOO}$ & 0.040 & $<0.03$ & 0.060 & 0.220 & $<0.03$ & $<0.03$ & $<0.03$ & - & 0.070 & $<0.03$ & $<0.03$ & $<0.03$ \\
\hline MTC & $<0.03$ & 0.140 & 0.030 & 0.150 & $<0.03$ & 0.030 & $<0.03$ & $<0.03$ & $<0.03$ & $<0.03$ & $<0.03$ & $<0.03$ \\
\hline MCGL & 0.040 & 0.060 & 0.090 & $<0.03$ & $<0.03$ & 0.040 & $<0.03$ & $<0.03$ & 0.070 & 0.040 & $<0.03$ & $<0.03$ \\
\hline MCGF & 0.040 & $<0.03$ & 0.080 & $<0.03$ & $<0.03$ & $<0.03$ & $<0.03$ & $<0.03$ & 0.080 & $<0.03$ & $<0.03$ & $<0.03$ \\
\hline $\begin{array}{l}\text { MCGF- } \\
\text { D }\end{array}$ & $<0.03$ & $<0.03$ & $<0.03$ & $<0.03$ & $<0.03$ & $<0.03$ & $<0.03$ & $<0.03$ & $<0.03$ & $<0.03$ & $<0.03$ & $<0.03$ \\
\hline GOS-S & - & - & - & - & - & - & - & - & $<0.03$ & $<0.03$ & $<0.03$ & $<0.03$ \\
\hline GOS-D & - & - & - & - & - & - & 0.120 & - & - & $<0.03$ & $<0.03$ & $<0.03$ \\
\hline $\begin{array}{l}\mathrm{MOO}- \\
\mathrm{S}\end{array}$ & - & - & - & - & - & - & $<0.03$ & $<0.03$ & $<0.03$ & $<0.03$ & $<0.03$ & $<0.03$ \\
\hline
\end{tabular}

\section{Particulate Phosphorus ( $\mathrm{mg} / \mathrm{L}$ )}

\begin{tabular}{|c|c|c|c|c|c|c|c|c|c|c|c|c|}
\hline & $\begin{array}{c}23-06- \\
18\end{array}$ & $\begin{array}{c}25-07- \\
18 \\
\end{array}$ & $\begin{array}{c}28-08- \\
18 \\
\end{array}$ & $\begin{array}{c}26-09- \\
18 \\
\end{array}$ & $\begin{array}{c}25-10- \\
18 \\
\end{array}$ & $\begin{array}{c}29-11- \\
18 \\
\end{array}$ & $\begin{array}{c}20-12- \\
18 \\
\end{array}$ & $\begin{array}{c}30-01- \\
19 \\
\end{array}$ & $\begin{array}{c}26-02- \\
19 \\
\end{array}$ & $\begin{array}{c}26-03- \\
19 \\
\end{array}$ & $\begin{array}{c}30-04- \\
19 \\
\end{array}$ & $\begin{array}{c}28-05- \\
19 \\
\end{array}$ \\
\hline GOS & 0.006 & 0.025 & 0.033 & 0.098 & 0.022 & 0.034 & 0.017 & 0.000 & 0.234 & 0.017 & 0.234 & 0.008 \\
\hline $\mathrm{MOO}$ & 0.006 & 0.038 & 0.033 & 0.050 & 0.051 & 0.013 & 0.017 & - & 0.009 & 0.020 & 0.009 & 0.000 \\
\hline MTC & 0.011 & 0.040 & 0.030 & 0.053 & 0.024 & 0.015 & 0.019 & 0.000 & 0.005 & 0.005 & 0.005 & 0.006 \\
\hline MCGL & 0.023 & 0.058 & 0.050 & 0.021 & 0.006 & 0.007 & 0.005 & 0.000 & 0.050 & 0.015 & 0.050 & 0.000 \\
\hline MCGF & 0.024 & 0.024 & 0.052 & 0.012 & 0.010 & 0.016 & 0.000 & 0.000 & 0.074 & 0.004 & 0.074 & 0.075 \\
\hline
\end{tabular}

Table 0-2: Phosphorus species (TP, TDP, SRP, and PP) concentrations for all surface water and groundwater sampling locations. 


\section{C-2 Tile drain and drive-point piezometer analytical results}

\section{Tile Drain $(\mathrm{mg} / \mathrm{L})$}

\begin{tabular}{|c|c|c|c|c|c|c|c|c|c|c|}
\hline & $\begin{array}{c}2018-08- \\
28 \\
\end{array}$ & $\begin{array}{c}2018-10- \\
25 \\
\end{array}$ & $\begin{array}{c}2018-11- \\
08 \\
\end{array}$ & $\begin{array}{c}2018-11- \\
29 \\
\end{array}$ & $2018-12-20$ & $2019-01-30$ & $\begin{array}{c}2019-02- \\
26 \\
\end{array}$ & $\begin{array}{l}2019- \\
03-26 \\
\end{array}$ & $\begin{array}{c}2019-04- \\
30 \\
\end{array}$ & $\begin{array}{c}2019-05 \\
28 \\
\end{array}$ \\
\hline Total Phosphorus & 0.066 & 0.042 & 0.044 & 0.033 & 0.027 & 0.006 & 0.044 & 0.023 & 0.036 & 0.039 \\
\hline Total Dissolved Phosphorus & 0.066 & 0.039 & 0.034 & 0.028 & 0.018 & 0.006 & 0.029 & 0.014 & 0.029 & 0.033 \\
\hline Soluble Reactive Phosphorus & 0.030 & $<0.03$ & $<0.03$ & 0.030 & $<0.03$ & $<0.03$ & $<0.03$ & $<0.03$ & $<0.03$ & $<0.03$ \\
\hline Particulate Phosphorus & 0.000 & 0.003 & 0.010 & 0.005 & 0.009 & 0.000 & 0.015 & 0.009 & 0.007 & 0.006 \\
\hline
\end{tabular}

\begin{tabular}{|c|c|c|c|c|c|c|c|}
\hline \multicolumn{8}{|c|}{ Streambed Drive-Point 1 (mg/L) } \\
\hline Total Dissolved Phosphorus & 0.016 & 0.064 & 0.016 & 0.009 & 0.027 & 0.063 & 0.035 \\
\hline Soluble Reactive Phosphorus & $<0.03$ & $<0.03$ & $<0.03$ & $<0.03$ & $<0.03$ & $<0.03$ & $<0.03$ \\
\hline
\end{tabular}

\begin{tabular}{|c|c|c|c|c|c|c|c|}
\hline \multicolumn{8}{|c|}{ Floodplain Drive-Point (mg/L) } \\
\hline & $\begin{array}{c}2018-08- \\
28\end{array}$ & $\begin{array}{c}2018-10- \\
25\end{array}$ & $\begin{array}{c}2018-11- \\
29 \\
\end{array}$ & $\begin{array}{c}2018-12- \\
20\end{array}$ & 2018-04-13 & 2018-04-30 & $\begin{array}{c}2018-05- \\
28 \\
\end{array}$ \\
\hline Total Dissolved Phosphorus & $<0.003$ & 0.009 & 0.006 & $<0.003$ & $<0.003$ & 0.022 & 0.019 \\
\hline Soluble Reactive Phosphorus & $<0.03$ & $<0.03$ & $<0.03$ & $<0.03$ & $<0.03$ & $<0.03$ & $<0.03$ \\
\hline
\end{tabular}

Table 0-3: Tile drain, streambed piezometer (at Mooresville location), and average floodplain drive-point phosphorus concentrations. 


\section{C-3 Field parameters}

\begin{tabular}{|c|c|c|c|c|c|c|c|c|c|c|c|c|}
\hline \multicolumn{13}{|c|}{ Temperature $\left({ }^{\circ} \mathrm{C}\right)$} \\
\hline & $\begin{array}{c}23-06- \\
18\end{array}$ & $\begin{array}{c}25-07- \\
18\end{array}$ & $\begin{array}{c}28-08- \\
18\end{array}$ & $\begin{array}{c}26-09- \\
18\end{array}$ & $\begin{array}{c}25-10- \\
18\end{array}$ & $\begin{array}{c}29-11- \\
18\end{array}$ & $\begin{array}{c}20-12- \\
18\end{array}$ & $\begin{array}{c}30-01- \\
19\end{array}$ & $\begin{array}{c}26-02- \\
19\end{array}$ & $\begin{array}{c}26-03- \\
19\end{array}$ & $\begin{array}{c}30-04- \\
19\end{array}$ & $\begin{array}{c}28-05 \\
19 \\
\end{array}$ \\
\hline GOS & 18.97 & 22.17 & 20.92 & 18.14 & 6.39 & 4.18 & 2.50 & 0.30 & 0.10 & 4.80 & 7.70 & 13.80 \\
\hline MOO & 18.57 & 22.41 & 21.32 & 18.38 & 6.81 & 3.95 & 2.90 & - & -0.10 & 3.60 & 6.80 & 14.10 \\
\hline MTC & 18.99 & 21.39 & 21.00 & 18.26 & 7.34 & 4.19 & 2.60 & 1.90 & -0.10 & 4.50 & 7.40 & 13.80 \\
\hline MCGL & 19.21 & 21.73 & 21.46 & 17.52 & 6.44 & 3.65 & 2.60 & 0.10 & -0.10 & 3.00 & 6.40 & 15.00 \\
\hline MCGF & 19.36 & 22.42 & 22.54 & 17.67 & 6.05 & 2.89 & 2.10 & 0.10 & 0.00 & 2.10 & 6.60 & 15.10 \\
\hline $\begin{array}{l}\text { MCGF- } \\
\mathrm{S}\end{array}$ & 13.28 & 15.60 & 15.72 & 15.25 & 14.47 & 10.27 & 10.50 & 9.20 & 6.10 & 7.70 & 7.70 & 12.40 \\
\hline $\begin{array}{l}\text { MCGF- } \\
\text { D }\end{array}$ & 13.07 & 12.23 & 11.95 & 11.10 & 12.40 & 9.32 & 9.70 & 9.54 & 8.70 & 9.00 & 9.90 & 10.40 \\
\hline GOS-S & - & - & - & - & - & - & - & - & 3.00 & 7.30 & 10.10 & 9.90 \\
\hline GOS-D & - & - & - & - & - & - & - & - & - & 9.60 & 9.90 & 11.20 \\
\hline MOO-S & - & - & - & - & - & - & 11.60 & 9.20 & 5.70 & 7.80 & 9.70 & 9.50 \\
\hline MOO-D & - & - & - & - & - & 9.86 & 11.10 & - & 6.60 & 10.10 & 9.70 & 10.60 \\
\hline
\end{tabular}

\begin{tabular}{|c|c|c|c|c|c|c|c|c|c|c|c|c|}
\hline \multicolumn{13}{|c|}{ Electrical conductivity ( $\mu \mathrm{S} / \mathrm{cm})$} \\
\hline & $\begin{array}{c}23-06- \\
18 \\
\end{array}$ & $\begin{array}{c}25-07- \\
18\end{array}$ & $\begin{array}{c}28-08- \\
18 \\
\end{array}$ & $\begin{array}{c}26-09- \\
18\end{array}$ & $\begin{array}{c}25-10- \\
18\end{array}$ & $\begin{array}{c}29-11- \\
18 \\
\end{array}$ & $\begin{array}{c}20-12- \\
18 \\
\end{array}$ & $\begin{array}{c}30-01- \\
19 \\
\end{array}$ & $\begin{array}{c}26-02- \\
19\end{array}$ & $\begin{array}{c}26-03- \\
19 \\
\end{array}$ & $\begin{array}{c}30-04- \\
19 \\
\end{array}$ & $\begin{array}{c}28-05- \\
19 \\
\end{array}$ \\
\hline GOS & 0.722 & 0.614 & 0.628 & 0.720 & 0.751 & 0.737 & 0.435 & 0.491 & 0.297 & 0.409 & 0.427 & 0.530 \\
\hline MOO & 0.749 & 0.565 & 0.693 & 0.720 & 0.718 & 0.750 & 0.446 & - & 0.293 & 0.400 & 0.429 & 0.550 \\
\hline MTC & 0.732 & 0.640 & 0.639 & 0.742 & 0.742 & 0.746 & 0.433 & 0.454 & 0.206 & 0.400 & 0.424 & 0.530 \\
\hline MCGL & 0.732 & 0.456 & 0.709 & 0.632 & 0.724 & 0.737 & 0.440 & 0.412 & 0.282 & 0.390 & 0.422 & 0.550 \\
\hline MCGF & 0.717 & 0.480 & 0.714 & 0.618 & 0.705 & 0.690 & 0.422 & 0.401 & 0.217 & 0.376 & 0.419 & 0.495 \\
\hline $\begin{array}{l}\text { MCGF- } \\
\mathrm{S}\end{array}$ & 0.805 & 0.754 & 0.826 & 0.912 & 0.944 & 1.002 & 0.640 & 0.459 & 0.520 & 0.520 & 0.496 & 0.560 \\
\hline $\begin{array}{l}\text { MCGF- } \\
\text { D }\end{array}$ & 0.834 & 0.793 & 0.819 & 0.779 & 0.814 & 0.850 & 0.600 & 0.520 & 0.590 & 0.590 & 0.600 & 0.600 \\
\hline
\end{tabular}




\begin{tabular}{lllllllllllll}
\hline GOS-S & - & - & - & - & - & - & - & - & 1.570 & 1.850 & 1.370 & 1.880 \\
\hline GOS-D & - & - & - & - & - & - & - & - & 0.560 & 0.800 & 0.610 \\
\hline MOO-S & - & - & - & - & - & & 0.112 & 0.105 & 0.900 & 0.820 & 1.010 & 1.000 \\
\hline MOO-D & - & - & - & - & - & 1.178 & 0.930 & - & 0.830 & 0.890 & 1.010 & 0.900 \\
\hline
\end{tabular}

\begin{tabular}{|c|c|c|c|c|c|c|c|c|c|c|c|c|}
\hline \multicolumn{13}{|c|}{ Dissolved Oxygen (mg/L) } \\
\hline & $\begin{array}{c}23-06- \\
18\end{array}$ & $\begin{array}{c}25-07- \\
18\end{array}$ & $\begin{array}{c}28-08- \\
18\end{array}$ & $\begin{array}{c}26-09- \\
18\end{array}$ & $\begin{array}{c}25-10- \\
18\end{array}$ & $\begin{array}{c}29-11- \\
18\end{array}$ & $\begin{array}{c}20-12- \\
18\end{array}$ & $\begin{array}{c}30-01- \\
19\end{array}$ & $\begin{array}{c}26-02- \\
19\end{array}$ & $\begin{array}{c}26-03- \\
19 \\
\end{array}$ & $\begin{array}{c}30-04- \\
19\end{array}$ & $\begin{array}{c}28-05- \\
19\end{array}$ \\
\hline GOS & 1.75 & 0.56 & 3.07 & 2.89 & 8.88 & 10.40 & 10.70 & 12.40 & 11.47 & 12.50 & 12.62 & 8.73 \\
\hline MOO & 7.95 & 5.37 & 7.20 & 3.13 & 12.98 & 12.31 & 12.14 & - & 13.49 & 13.98 & 13.01 & 9.07 \\
\hline MTC & 6.06 & 5.18 & 4.25 & 2.93 & 13.01 & 10.57 & 11.33 & 11.10 & 12.19 & 12.22 & 13.16 & 8.71 \\
\hline MCGL & 7.92 & 5.99 & 7.76 & 6.72 & 10.98 & 12.74 & 13.81 & 14.88 & 14.26 & 12.66 & 12.15 & 8.28 \\
\hline MCGF & 7.97 & 6.93 & 7.83 & 6.32 & 11.08 & 13.06 & 14.41 & 12.35 & 14.62 & 13.28 & 12.37 & 8.76 \\
\hline $\begin{array}{l}\text { MCGF- } \\
\mathrm{S}\end{array}$ & 0.48 & 6.14 & 4.68 & 3.13 & 2.82 & 1.32 & 0.83 & 0.96 & 1.21 & 0.80 & 0.87 & 1.98 \\
\hline $\begin{array}{l}\text { MCGF- } \\
\text { D }\end{array}$ & 0.74 & 0.40 & 0.61 & 0.53 & 0.85 & 0.83 & 0.43 & 0.52 & 0.33 & 1.48 & 0.42 & 0.36 \\
\hline GOS-S & - & - & - & - & - & - & - & - & 3.92 & 2.37 & 4.24 & 2.50 \\
\hline GOS-D & - & - & - & - & - & - & - & - & - & 2.61 & 3.03 & 2.95 \\
\hline MOO-S & - & - & - & - & - & & 4.09 & 4.37 & 4.59 & 0.64 & 1.90 & 2.81 \\
\hline MOO-D & - & - & - & - & - & 2.24 & 1.50 & - & 2.59 & 1.80 & 4.90 & 2.66 \\
\hline
\end{tabular}

\begin{tabular}{|c|c|c|c|c|c|c|c|c|c|c|c|c|}
\hline \multicolumn{13}{|c|}{$\mathrm{pH}$} \\
\hline & $\begin{array}{c}23-06- \\
18 \\
\end{array}$ & $\begin{array}{c}25-07- \\
18 \\
\end{array}$ & $\begin{array}{c}28-08- \\
18 \\
\end{array}$ & $\begin{array}{c}26-09- \\
18\end{array}$ & $\begin{array}{c}25-10- \\
18\end{array}$ & $\begin{array}{c}29-11- \\
18\end{array}$ & $\begin{array}{c}20-12- \\
18\end{array}$ & $\begin{array}{c}30-01- \\
19\end{array}$ & $\begin{array}{c}26-02- \\
19\end{array}$ & $\begin{array}{c}26-03- \\
19 \\
\end{array}$ & $\begin{array}{c}30-04- \\
19 \\
\end{array}$ & $\begin{array}{c}28-05- \\
19 \\
\end{array}$ \\
\hline GOS & 7.09 & 7.34 & 7.45 & 7.67 & 8.05 & 7.87 & 7.87 & 7.53 & 8.27 & 8.16 & 8.11 & 8.17 \\
\hline $\mathrm{MOO}$ & 7.85 & 7.92 & 7.70 & 7.18 & 8.13 & 7.81 & 8.38 & - & 7.13 & 8.50 & 8.44 & 8.38 \\
\hline MTC & 7.47 & 7.70 & 7.49 & 7.66 & 8.17 & 7.62 & 8.07 & 8.18 & 8.04 & 8.22 & 8.22 & 8.21 \\
\hline MCGL & 8.03 & 8.04 & 7.99 & 7.95 & 7.98 & 7.93 & 8.47 & 8.31 & 8.39 & 8.58 & 8.55 & 8.42 \\
\hline
\end{tabular}




\begin{tabular}{lcccccccccccc} 
MCGF & 8.12 & 8.11 & 8.16 & 8.03 & 7.77 & 8.04 & 8.48 & 7.59 & 8.50 & 7.98 & 8.52 & 8.45 \\
\hline $\begin{array}{l}\text { MCGF- } \\
\text { S }\end{array}$ & 7.02 & 6.96 & 7.26 & 7.13 & 7.08 & 7.32 & 7.13 & 7.38 & 7.75 & 7.46 & 7.58 & 7.41 \\
\hline $\begin{array}{l}\text { MCGF- } \\
\text { D }\end{array}$ & 7.19 & 7.22 & 7.35 & 7.14 & 7.27 & 7.73 & 7.38 & 7.28 & 7.61 & 7.85 & 7.76 & 7.69 \\
\hline GOS-S & - & - & - & - & - & - & - & - & 6.63 & 7.35 & 7.39 & 7.45 \\
\hline GOS-D & - & - & - & - & - & - & - & - & - \\
\hline MOO-S & - & - & - & - & - & & 6.97 & 7.35 & 7.27 & 7.21 & 7.21 & 7.17 \\
\hline MOO-D & - & - & - & - & - & 7.44 & 7.26 & - & 7.48 & 7.45 & 7.23 & 7.42 \\
\hline
\end{tabular}

\begin{tabular}{|c|c|c|c|c|c|c|c|c|c|c|c|c|}
\hline \multicolumn{13}{|c|}{ Oxidation Reduction Potential (mV) } \\
\hline & $\begin{array}{c}23-06- \\
18\end{array}$ & $\begin{array}{c}25-07- \\
18\end{array}$ & $\begin{array}{c}28-08- \\
18\end{array}$ & $\begin{array}{c}26-09- \\
18\end{array}$ & $\begin{array}{c}25-10- \\
18\end{array}$ & $\begin{array}{c}29-11- \\
18\end{array}$ & $\begin{array}{c}20-12- \\
18\end{array}$ & $\begin{array}{c}30-01- \\
19\end{array}$ & $\begin{array}{c}26-02- \\
19\end{array}$ & $\begin{array}{c}26-03- \\
19\end{array}$ & $\begin{array}{c}30-04- \\
19\end{array}$ & $\begin{array}{c}28-05- \\
19\end{array}$ \\
\hline GOS & 146.5 & 112.5 & 49.4 & 47.5 & 56.6 & 94.1 & 162.6 & 187.2 & 168.6 & 133.7 & 85.1 & 82.0 \\
\hline $\mathrm{MOO}$ & 128.5 & 128.6 & 12.0 & -8.0 & 45.1 & 95.3 & 208.2 & - & 170.5 & 118.0 & 92.4 & 98.7 \\
\hline MTC & 106.5 & 108.5 & 46.3 & 39.0 & 28.6 & 104.6 & 195.4 & 203.1 & 175.4 & 83.5 & 70.5 & 67.8 \\
\hline MCGL & 135.0 & 110.1 & 49.1 & 5.2 & 29.8 & 56.7 & 141.6 & 205.5 & 54.5 & 94.5 & 83.2 & 90.6 \\
\hline MCGF & 124.6 & 111.1 & 27.3 & 43.0 & 83.3 & 82.3 & 178.1 & 183.3 & 108.1 & 253.4 & 189.7 & 135.1 \\
\hline $\begin{array}{l}\text { MCGF- } \\
\mathrm{S}\end{array}$ & 125.1 & 175.8 & 106.2 & 140.1 & 96.8 & 144.0 & 82.2 & 147.3 & 18.5 & 48.7 & 27.0 & 69.5 \\
\hline $\begin{array}{l}\text { MCGF- } \\
\text { D }\end{array}$ & -71.6 & -44.4 & -98.3 & -130.7 & -124.8 & -180.8 & -73.6 & -133.1 & -96.0 & -14.3 & -65.6 & -63.9 \\
\hline GOS-S & - & - & - & - & - & - & - & - & 210.7 & 137.2 & 83.1 & 97.3 \\
\hline GOS-D & - & - & - & - & - & - & - & - & - & 145.2 & 69.1 & 75.0 \\
\hline MOO-S & - & - & - & - & - & - & 28.7 & 10.6 & -6.4 & -4.2 & -18.4 & -30.2 \\
\hline MOO-D & - & - & - & - & - & 8.3 & 79.8 & - & 167.0 & 25.3 & -9.6 & -24.2 \\
\hline
\end{tabular}

Table 0-4: Temperature, electrical conductivity, dissolved oxygen, $\mathrm{pH}$, and oxidation reduction potential at each sampling location (groundwater and surface water) for every sampling date. 


\section{C-4 Ion chromatography results}

\section{Nitrate $\left(\mathrm{mg} \mathrm{NO}_{3}{ }^{-}-\mathrm{N} / \mathrm{L}\right)$}

\begin{tabular}{|c|c|c|c|c|c|c|c|c|c|c|c|c|}
\hline & $23-06-18$ & $25-07-18$ & $28-08-18$ & $26-09-18$ & $25-10-18$ & $29-11-18$ & $20-12-18$ & $30-01-19$ & $26-02-19$ & 26-03-19 & 30-04-19 & $28-05-19$ \\
\hline GOS & 8.48 & 0.32 & 4.49 & 1.19 & 1.84 & 13.13 & 8.57 & 2.44 & 7.52 & 6.78 & 7.77 & 6.06 \\
\hline MOO & 11.96 & 1.43 & 5.85 & 3.23 & 3.45 & 12.73 & 9.19 & - & 7.35 & 7.54 & 8.84 & 8.56 \\
\hline MTC & 7.75 & 1.56 & 4.47 & 2.05 & 1.90 & 12.90 & 8.49 & 7.22 & 7.47 & 6.92 & 7.95 & 6.42 \\
\hline MCGL & 10.88 & 0.63 & 6.74 & 0.72 & 4.25 & 12.30 & 9.13 & 8.24 & 6.81 & - & 9.09 & 8.64 \\
\hline MCGF & 13.97 & 1.20 & 7.43 & 0.46 & 3.70 & 9.51 & 7.17 & 6.43 & 4.37 & 5.81 & 7.46 & 6.57 \\
\hline MCGF-S & 0.14 & 0.30 & 0.27 & 0.21 & 0.48 & 1.59 & 0.52 & 0.90 & 1.18 & 0.56 & $<0.05$ & $<0.05$ \\
\hline MCGF-D & 0.28 & 0.84 & 0.74 & 0.11 & 0.10 & 0.05 & 0.40 & $<0.05$ & 0.06 & $<0.05$ & $<0.05$ & $<0.05$ \\
\hline GOS-S & - & - & - & - & - & - & - & - & 4.04 & 0.97 & $<0.05$ & $<0.05$ \\
\hline GOS-D & - & - & - & - & - & - & 0.21 & - & - & $<0.05$ & $<0.05$ & $<0.05$ \\
\hline MOO-S & - & - & - & - & - & - & 0.24 & - & 0.34 & 0.09 & $<0.05$ & $<0.05$ \\
\hline MOO-D & - & - & - & - & - & 1.85 & 1.32 & - & 0.80 & 0.51 & $<0.05$ & $<0.05$ \\
\hline JTILE & - & - & 20.52 & - & 5.15 & 5.78 & 5.20 & 4.11 & - & 3.44 & 4.21 & 4.11 \\
\hline
\end{tabular}

Sulphate (mg/L)

\begin{tabular}{|c|c|c|c|c|c|c|c|c|c|c|c|c|}
\hline & $23-06-18$ & $25-07-18$ & $28-08-18$ & $26-09-18$ & $25-10-18$ & $29-11-18$ & $20-12-18$ & $30-01-19$ & $26-02-19$ & 26-03-19 & $30-04-19$ & $28-05-19$ \\
\hline GOS & 22.20 & 4.29 & 14.78 & 17.49 & 29.34 & 35.60 & 36.70 & 9.80 & 26.53 & 28.73 & 21.20 & 18.30 \\
\hline MOO & 22.70 & 19.44 & 26.31 & 21.13 & 28.18 & 32.70 & 34.60 & - & 24.70 & 28.14 & 21.40 & 20.00 \\
\hline MTC & 18.26 & 6.03 & 14.76 & 14.90 & 28.81 & 34.70 & 35.70 & 36.40 & 26.20 & 28.97 & 21.10 & 18.20 \\
\hline MCGL & 10.88 & 19.12 & 18.49 & 19.54 & 27.57 & 34.90 & 30.10 & 33.40 & 20.70 & - & 21.50 & 19.00 \\
\hline MCGF & 13.97 & 17.92 & 22.47 & 18.58 & 27.28 & 25.40 & 30.20 & 29.80 & 12.90 & 37.30 & 19.00 & 14.90 \\
\hline MCGF-S & 37.39 & 19.04 & 45.29 & 52.85 & 28.36 & 27.60 & 28.90 & 16.00 & 22.00 & 27.49 & 19.27 & 13.30 \\
\hline MCGF-D & 28.92 & 52.05 & 22.53 & 32.49 & 26.08 & 20.10 & 18.80 & 18.40 & 11.20 & 17.40 & 14.53 & 12.90 \\
\hline GOS-S & - & - & - & - & - & - & - & - & 23.89 & 32.49 & 39.74 & 28.32 \\
\hline GOS-D & - & - & - & - & - & - & 30.88 & - & - & 30.8 & 23.93 & 17.89 \\
\hline MOO-S & - & - & - & - & - & - & 23.20 & - & 24.60 & 22.54 & 34.51 & 20.34 \\
\hline MOO-D & - & - & - & - & - & 33.48 & 34.90 & - & 28.00 & 22.16 & 30.12 & 24.80 \\
\hline
\end{tabular}




\begin{tabular}{|c|c|c|c|c|c|c|c|c|c|c|c|c|}
\hline \multicolumn{13}{|c|}{ Chloride (mg/L) } \\
\hline & $23-06-18$ & $25-07-18$ & $28-08-18$ & $26-09-18$ & $25-10-18$ & $29-11-18$ & $20-12-18$ & $30-01-19$ & $26-02-19$ & $26-03-19$ & $30-04-19$ & $28-05-19$ \\
\hline GOS & 26.59 & 29.58 & 28.09 & 45.11 & 40.42 & 34.09 & 31.00 & 55.83 & 20.88 & 23.61 & 23.18 & 23.22 \\
\hline $\mathrm{MOO}$ & 28.46 & 60.60 & 42.43 & 56.74 & 40.98 & 35.92 & 34.68 & - & 20.90 & 28.15 & 24.49 & 25.18 \\
\hline MTC & 19.29 & 29.89 & 28.54 & 50.71 & 41.23 & 34.71 & 31.31 & 29.07 & 20.46 & 24.09 & 23.38 & 24.83 \\
\hline MCGL & 20.69 & 28.60 & 33.24 & 46.24 & 40.49 & 34.34 & 31.79 & 31.34 & 19.17 & - & 25.13 & 24.32 \\
\hline MCGF & 23.58 & 30.64 & 35.49 & 40.00 & 39.56 & 34.23 & 32.02 & 32.24 & 17.86 & 27.18 & 25.71 & 21.15 \\
\hline MCGF-S & 35.20 & 33.54 & 39.78 & 40.26 & 46.30 & 70.76 & 60.78 & 31.19 & 44.37 & 37.20 & 32.48 & 38.90 \\
\hline MCGF-D & 39.68 & 42.29 & 44.25 & 33.54 & 35.43 & 35.96 & 34.95 & 34.35 & 30.00 & 30.40 & 29.51 & 34.75 \\
\hline GOS-S & - & - & - & - & - & - & - & - & 11.72 & 135.27 & 140.83 & 138.69 \\
\hline GOS-D & - & - & - & - & - & - & 16.29 & - & - & 11.59 & 13.57 & 14.39 \\
\hline MOO-S & - & - & - & - & - & - & 202.26 & - & 151.94 & 136.49 & 170.40 & 168.61 \\
\hline MOO-D & - & - & - & - & - & 106.92 & 133.12 & - & 126.48 & 121.29 & 173.50 & 130.67 \\
\hline JTILE & - & - & 52.82 & - & 353.34 & 186.66 & 204.07 & 211.75 & - & 199.58 & 184.24 & 162.07 \\
\hline
\end{tabular}

Table 0-5: IC results for surface water, groundwater, and tile water for nitrate-N, sulphate, and chloride. 
Appendix D - Landowner survey template

\section{GENERAL INFORMATION}

Survey Date and Time:

Survey Participant ID:

1. What is the total farm acreage?

2. What type of crops have you grown in the last 4 years?

\begin{tabular}{|l|l|l|l|l|}
\hline Crop Type & $\begin{array}{l}\text { How many } \\
\text { acres in the } \\
\text { coming year } \\
\text { (2019) }\end{array}$ & $\begin{array}{l}\text { How } \\
\text { many } \\
\text { acres in } \\
\text { 2018? }\end{array}$ & $\begin{array}{l}\text { How } \\
\text { many } \\
\text { acres in } \\
2017 ?\end{array}$ & $\begin{array}{l}\text { How } \\
\text { many } \\
\text { acres in } \\
\text { 2016? }\end{array}$ \\
\hline Corn & & & & \\
\hline Soybean & & & & \\
\hline $\begin{array}{l}\text { Wheat } \\
\text { (Spring/Winter) }\end{array}$ & & & & \\
\hline Oats & & & & \\
\hline Alfalfa (or hay \\
crop)
\end{tabular}




\begin{tabular}{|l|l|l|l|l|}
\hline $\begin{array}{l}\text { Please list } \\
\text { types: }\end{array}$ & & & & \\
& & & & \\
\hline $\begin{array}{l}\text { Market } \\
\text { Vegetables } \\
\text { Please list } \\
\text { types: }\end{array}$ & & & & \\
\hline Other: & & & & \\
& & & & \\
& & & & \\
\hline
\end{tabular}

3. What is the typical planting and harvesting period for different crops (month/week)?

\begin{tabular}{|l|l|l|}
\hline Crop type & $\begin{array}{l}\text { Typical planting } \\
\text { period } \\
\text { (please list } \\
\text { month/week) }\end{array}$ & $\begin{array}{l}\text { Typical harvesting } \\
\text { period } \\
\text { (please list } \\
\text { month/week) }\end{array}$ \\
\hline Corn & & \\
\hline Soybean & & \\
\hline $\begin{array}{l}\text { Wheat } \\
\text { (Spring/Winter) }\end{array}$ & & \\
\hline
\end{tabular}




\begin{tabular}{|l|l|l|}
\hline Oats & & \\
\hline Alfalfa (or hay crop) & & \\
\hline $\begin{array}{l}\text { Fruit } \\
\text { Please list types: }\end{array}$ & & \\
\hline $\begin{array}{l}\text { Market Vegetables } \\
\text { Please list types: }\end{array}$ & & \\
\hline Other: & & \\
\end{tabular}

4. What soil tillage practices were used in the fields?

\begin{tabular}{|l|l|l|}
\hline Crop type & $\begin{array}{l}\text { Tillage } \\
\text { Practice }\end{array}$ & $\begin{array}{l}\text { If applicable, when and how is cover } \\
\text { crop planted and are any fertilizers } \\
\text { or pesticides used? }\end{array}$ \\
\hline Corn & & \\
\hline Soybean & & \\
\hline $\begin{array}{l}\text { Wheat } \\
\text { (Spring/Winter) }\end{array}$ & & \\
\hline
\end{tabular}




\begin{tabular}{|l|l|l|}
\hline & & \\
\hline Oats & & \\
\hline $\begin{array}{l}\text { Alfalfa (or hay } \\
\text { crop) }\end{array}$ & & \\
\hline $\begin{array}{l}\text { Fruit } \\
\text { Please list types: }\end{array}$ & & \\
\hline $\begin{array}{l}\text { Market } \\
\text { Pegetables } \\
\text { Please list types: }\end{array}$ & & \\
\hline
\end{tabular}


5. What type of fertilizer or inputs do you apply? When and how many times are they applied? What is the quantity of fertilizer applied?

\begin{tabular}{|l|l|l|l|l|}
\hline Crop type & $\begin{array}{l}\text { What type of } \\
\text { fertilizer do you } \\
\text { apply, if any? } \\
\text { (e.g. DAP, Urea, } \\
\text { Dairy Manure) }\end{array}$ & $\begin{array}{l}\text { When and how } \\
\text { many times do you } \\
\text { apply fertilizer } \\
\text { during the } \\
\text { season? }\end{array}$ & $\begin{array}{l}\text { How much } \\
\text { fertilizer is } \\
\text { applied? }\end{array}$ & $\begin{array}{l}\text { How is it applied? } \\
\text { (e.g. topical, side } \\
\text { dressing) }\end{array}$ \\
\hline Corn & & & & \\
\hline
\end{tabular}




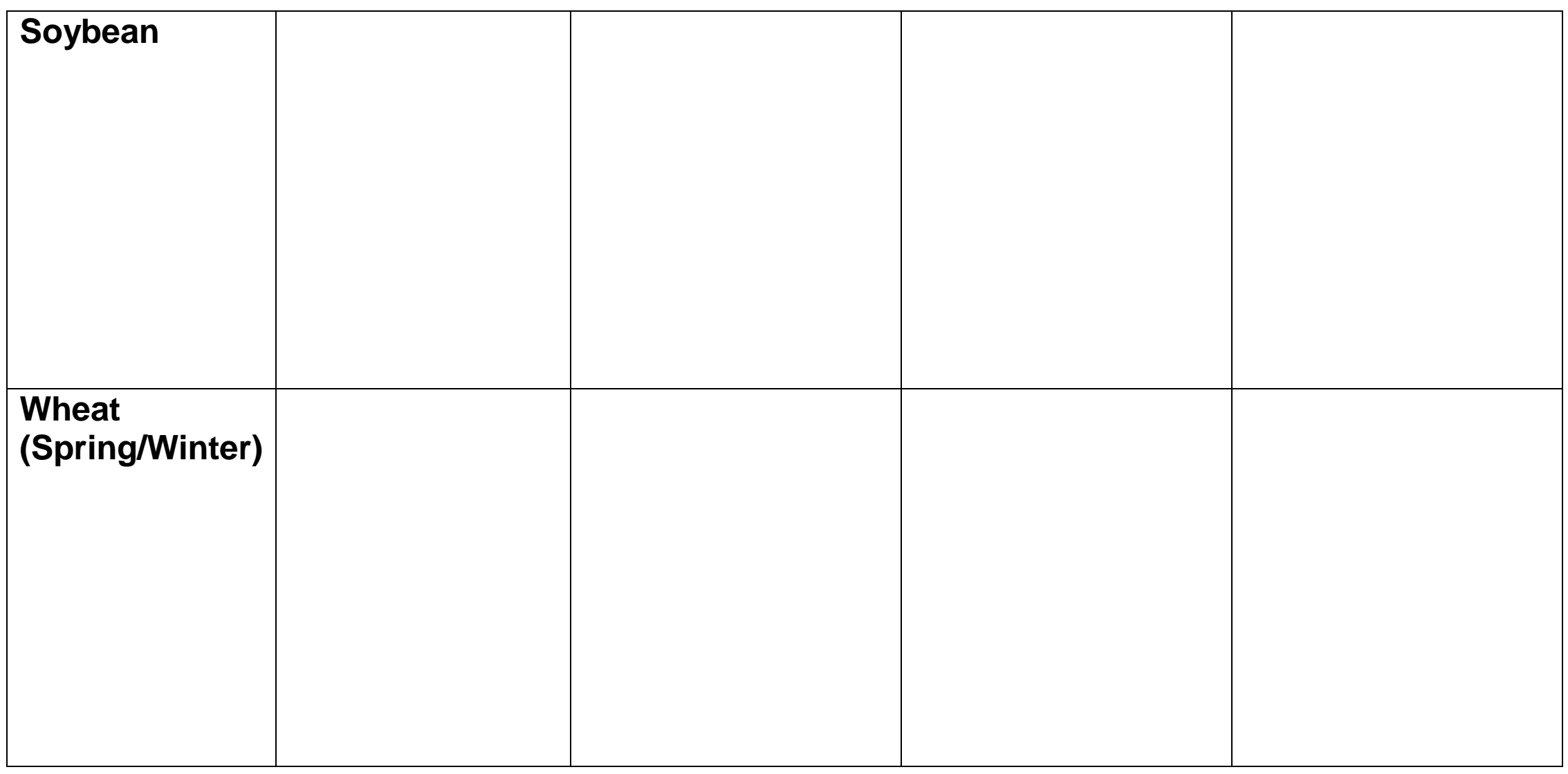

120 


\begin{tabular}{|l|l|l|l|l|}
\hline Oats & & & & \\
& & & & \\
\hline $\begin{array}{l}\text { Alfalfa (or hay } \\
\text { crop) }\end{array}$ & & & & \\
\hline $\begin{array}{l}\text { Fruit } \\
\text { Please list } \\
\text { types: }\end{array}$ & & & & \\
& & & & \\
\hline
\end{tabular}




\begin{tabular}{|l|l|l|l|l|}
\hline Market & & & & \\
Vegetables \\
Please list \\
types:
\end{tabular}


6. A) Do you have livestock on the property? For what purpose (e.g. dairy cows) and how many do you have?

B) Do you use all the manure from your livestock on your property?

C) Do you have pasture/grazing land? If so, how much? 
7. Do you have tile drainage on the property? If so, how many acres are drained and to your knowledge where is the outlet located?

\begin{tabular}{|l|l|l|l|l|}
\hline Crop type & $\begin{array}{l}\text { Tile } \\
\text { Drainage } \\
\text { Area }\end{array}$ & $\begin{array}{l}\text { Natural } \\
\text { Drainage } \\
\text { Area }\end{array}$ & $\begin{array}{l}\text { Location of } \\
\text { tile drain } \\
\text { outlet(s)? } \\
\text { (i.e. in } \\
\text { Parkhill } \\
\text { Creek) }\end{array}$ & $\begin{array}{l}\text { Other details } \\
\text { (i.e. depth of } \\
\text { installation, } \\
\text { density of } \\
\text { network) }\end{array}$ \\
\hline Corn & & & & \\
\hline Soybean & & & & \\
\hline $\begin{array}{l}\text { Wheat } \\
\text { (Spring/Winter) }\end{array}$ & & & & \\
\hline Oats & & & & \\
\hline $\begin{array}{l}\text { Alfalfa (or hay } \\
\text { crop) }\end{array}$ & & & & \\
\hline $\begin{array}{l}\text { Fruit } \\
\text { Please list } \\
\text { types: }\end{array}$ & & & & \\
\hline & & & & \\
\hline
\end{tabular}




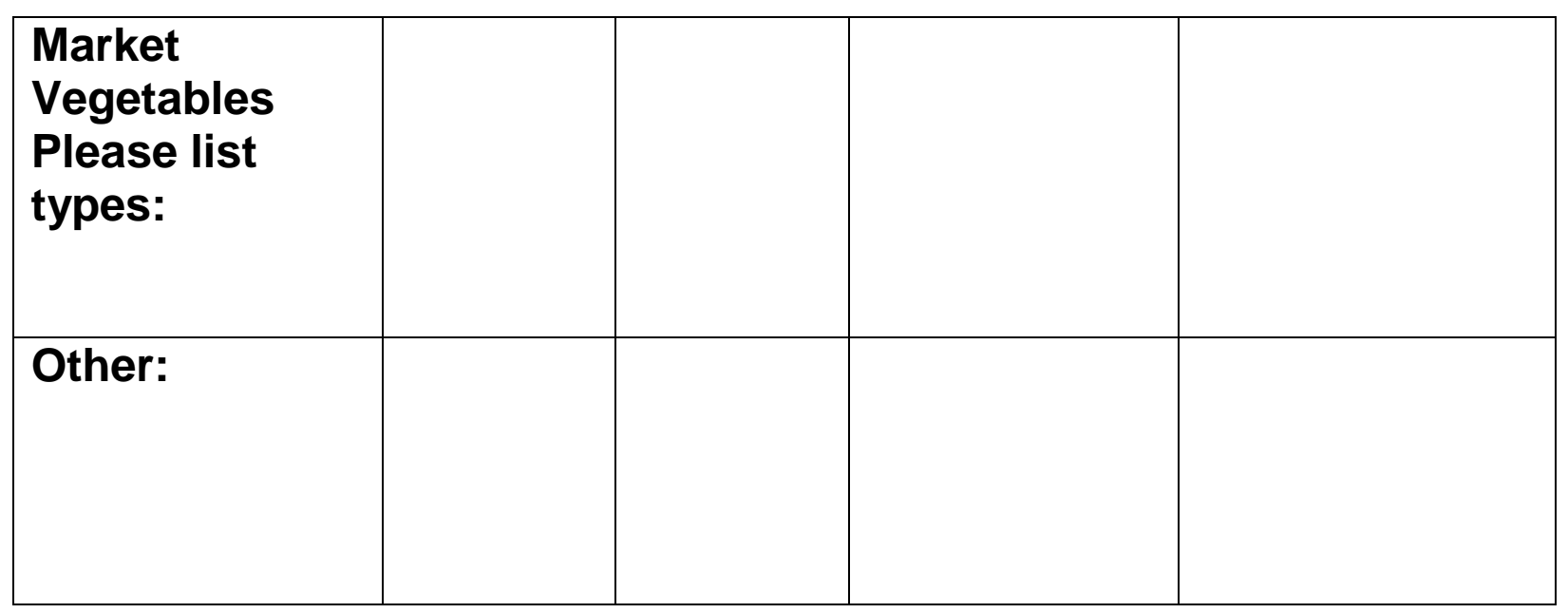

8. Is your land irrigated? If so, how much water are you using and are you using groundwater or surface water?

\begin{tabular}{|l|l|l|}
\hline Crop type & $\begin{array}{l}\text { Irrigated } \\
\text { Land Area }\end{array}$ & $\begin{array}{l}\text { Irrigation Method (please include } \\
\text { amount of water, source of water and } \\
\text { schedule of irrigation) }\end{array}$ \\
\hline Corn & & \\
\hline Soybean & & \\
\hline $\begin{array}{l}\text { Wheat } \\
\text { (Spring/Winter) }\end{array}$ & & \\
\hline Oats & & \\
\hline $\begin{array}{l}\text { Alfalfa (or hay } \\
\text { crop) }\end{array}$ & & \\
\hline
\end{tabular}




\begin{tabular}{|l|l|l|}
\hline & & \\
\hline $\begin{array}{l}\text { Fruit } \\
\text { Please list } \\
\text { types: }\end{array}$ & & \\
\hline $\begin{array}{l}\text { Market } \\
\text { Vegetables } \\
\text { Please list } \\
\text { types: }\end{array}$ & & \\
\hline Other: & & \\
\hline
\end{tabular}

9. A) Do you have a well and/or storage pond on the property? What do you use it for? How are they filled up (natural or water pumped into them, etc.)?

B) In the case of a storage pond, please illustrate the relationship to surface water features (i.e connected, dugout)?

C) What is the source of pond water (i.e. groundwater, surface water runoff, flowing watercourse)? 
10. Do you currently have a Permit to Take Water (PTTW)? Does your permit allow you to take groundwater, surface water or both?

11. What is the allowed amount of water provided by the permit? How often do you take water and for what purpose?

12. In which of the last 5 years do you recall having the best yields?

13. Do you recall any unusual weather conditions during the growing or harvesting period in the last 5 years (e.g. drought, heavy rains) that have impacted your crops? Please list the unusual conditions and which years they occurred. 
14. What is the optimal yield of each of the crops you plant? What is the average yield over the past 4 years?

\begin{tabular}{|c|c|c|c|c|c|}
\hline Crop type & $\begin{array}{l}\text { What is } \\
\text { the } \\
\text { optimal } \\
\text { yield of } \\
\text { each of } \\
\text { the crops } \\
\text { you } \\
\text { plant? }\end{array}$ & \begin{tabular}{|l} 
Average \\
yield in \\
2018
\end{tabular} & \begin{tabular}{|l} 
Average \\
yield in \\
2017
\end{tabular} & \begin{tabular}{|l|} 
Average \\
yield in \\
2016
\end{tabular} & $\begin{array}{l}\text { Average } \\
\text { yield in } \\
2015\end{array}$ \\
\hline \multicolumn{6}{|l|}{ Corn } \\
\hline \multicolumn{6}{|l|}{ Soybean } \\
\hline \multicolumn{6}{|l|}{$\begin{array}{l}\text { Wheat } \\
\text { (Spring/Winter) }\end{array}$} \\
\hline \multicolumn{6}{|l|}{ Oats } \\
\hline \multicolumn{6}{|l|}{$\begin{array}{l}\text { Alfalfa (or hay } \\
\text { crop) }\end{array}$} \\
\hline $\begin{array}{l}\text { Fruit } \\
\text { Please list } \\
\text { types: }\end{array}$ & & & & & \\
\hline
\end{tabular}




\begin{tabular}{|l|l|l|l|l|l|}
\hline Market & & & & & \\
Vegetables \\
Please list \\
types:
\end{tabular}




\section{Appendix E - Sampling uncertainty}

The collection of field data will invariably introduce possible sources of error or uncertainties into the research. While efforts were made to avoid or mitigate these, potential sources of errors and/or uncertainties related to the water quality results presented in this study include:

- Samples from surface water were collected from a consistent location, predominantly the middle of the stream, each month. When high flow or ice events prevented access to the mid-stream, samples were taken adjacent to the bank.

- Precaution was taken to face upstream and limit the amount of resuspension or agitation to the bottom sediments when collecting surface water samples. Resuspension of sediments can lead to bias in samples.

- Field parameters measured in situ using the YSI Multi-Parameter-Probe were taken from just below the surface in the surface water bodies. In certain instances (e.g. extreme cold), the field measurements were taken from a sub-sample of water. In this case, separate water samples were taken for field measurements and laboratory submission.

- Groundwater field parameters were measured from groundwater discharged into a clean bucket, acting as a flow-through cell. Minor changes in conditions (e.g. temperature) could occur prior to stabilization of these measurements. Sampling of groundwater occurred upon attaining stable field parameters.

- Phosphorus is susceptible to transformations during handling and storage; however, no single standardized methodology exists for sampling and storage of phosphorus (Jarvie et al., 2002; Haygarth \& Edwards, 2009). Best practices were therefore implemented for $\mathrm{P}$ sampling for the duration of this project. These include conditioning sample bottles, limited head space and sample disturbance, field-filtering for SRP, storage of samples in the dark at approximately $4^{\circ} \mathrm{C}$, and prompt transport to the laboratory for analysis.

- Samples for nitrate were also collected using best practice methodologies (triplerinsed bottles, minimal head space and disturbance, storage in the dark at $4^{\circ} \mathrm{C}$ ). Samples were analyzed as early as possible.

- Precipitation data obtained from the Integrated Water and Climate Monitoring Station at the MCGF site was used for analysis across the watershed. The actual amount of 
rainfall at specific locations within the watershed may vary, thus potentially skewing the results and/or analysis. 